WALDEMAR BONVENTI JR.

\title{
APRENDIZADO NEBULOSO HÍBRIDO E INCREMENTAL PARA CLASSIFICAR PIXELS POR CORES
}

Tese apresentada à Escola Politécnica da Universidade de São Paulo para obtenção do Título de Doutor em Engenharia Elétrica. 
WALDEMAR BONVENTI JR.

\section{APRENDIZADO NEBULOSO HÍBRIDO E INCREMENTAL PARA CLASSIFICAR PIXELS POR CORES}

Tese apresentada à Escola Politécnica da Universidade de São Paulo para obtenção do Título de Doutor em Engenharia Elétrica.

Área de concentração:

Sistemas Digitais

Orientador:

Prof ${ }^{\mathrm{a}}$. Livre-Docente

Anna Helena Reali Costa 
FICHA CATALOGRÁFICA

BONVENTI JR., WALDEMAR

APRENDIZADO NEBULOSO HÍBRIDO E INCREMENTAL PARA CLASSIFICAR PIXELS POR CORES. São Paulo, 2005.

$156 \mathrm{p}$.

Tese (Doutorado) - Escola Politécnica da Universidade de São Paulo. Departamento de Engenharia de Computação e Sistemas Digitais.

1. Processamento de imagens. 2. Fuzzy (Inteligência Artificial). 3. Aprendizado computacional. I. Universidade de São Paulo. Escola Politécnica. Departamento de Engenharia de Computação e Sistemas Digitais. II. t. 
"Feliz o homem que acha sabedoria, ... e adquire conhecimento; porque melhor é o lucro que ela dá do que o da prata, e melhor a sua renda do que o ouro mais fino." (Provérbios, cap.4, vv.13-14) 


\section{Agradecimentos}

À orientadora, prof ${ }^{a}$ Anna Helena Reali Costa, pela amizade, firmeza e paciência.

À minha esposa, Lucimara, e aos meus filhos, Jônatas e Rebeca, pelo apoio durante esta travessia, compreensão nas tempestades e sorrisos nos dias de sol.

À Faculdade de Tecnologia de Sorocaba, pelo incentivo e suporte nos anos finais desta jornada.

À Universidade de Sorocaba, pelo apoio e incentivo.

Aos colegas do Laboratório de Técnicas Inteligentes, pela amizade, apoio e auxílio inestimáveis.

Aos meus amigos, pela preocupação e atenção sinceramente demonstradas. 


\section{RESUMO}

Segmentação de uma imagem é um processo de extrema importância em processamento de imagens e consiste em subdividir a imagem em partes constituintes correspondentes a objetos de interesse no domínio de aplicação. Objetos de interesse podem apresentar cores que se caracterizam numa imagem por um conjunto de pixels, que por sua vez possuem um número muito grande de valores cromáticos. Estes conjuntos podem ser denominados por relativamente poucos rótulos lingüísticos atribuídos por seres humanos, caracterizando as cores, representadas por classes. Entretanto, a fronteira entre estas classes é vaga, pois os valores cromáticos que definem a transição de uma cor para outra dependem de diversos fatores do domínio. Esta tese visa contribuir no processo de segmentação de imagens através da proposta de um classificador de pixels exclusivamente por meio do atributo cor. Para lidar com o problema da vagueza entre as classes de cores, emprega-se a teoria dos conjuntos nebulosos. Assim, propõe-se um aprendizado híbrido e incremental de modelos nebulosos de classes de cores constituintes do classificador. O aprendizado híbrido combina os paradigmas de aprendizado supervisionado e não-supervisionado, transferindo a rotulação individual das instâncias (muito custosa) para a rotulação dos grupos de instâncias similares, pelo agente supervisor. Estes grupos são combinados por meio da aplicação de operadores de agregação adequados, que possibilitam uma forma de aprendizado incremental, onde os modelos das classes existentes podem ser revisados ou novas classes, obtidas com a continuidade do treinamento, podem ser incorporadas aos modelos. Propõe-se, ainda, um processo de generalização do modelo, visando sua completude. O classificador proposto foi testado na modelagem da cor da pele humana em imagens adquiridas em condições ambientais controladas e em condições variadas. Os resultados obtidos mostram a eficácia do classificador proposto, obtendo uma detecção robusta e acurada da cor da pele em imagens digitais coloridas. 


\section{ABSTRACT}

Image segmentation is a very important process, which aims at subdividing an image in parts that correspond to objects of interest in the application domain. Objects may depict few colors that are represented in an image by a set of pixels presenting a very large range of chromatic values. A relatively small number of human-defined linguistic labels can be assigned to these sets, and these labels characterize colors represented by classes. However, the borders among these classes are fuzzy, since the chromatic values that define the transition from a class to another depend on different domain factors. This thesis contributes in the image segmentation process by proposing a pixel classifier based exclusively on the color attribute. Fuzzy sets theory is used to deal with the problem of fuzziness among color classes. This thesis proposes a hybrid and incremental scheme for learning fuzzy models of color classes included in the classifier. The hybrid-learning scheme combines unsupervised and supervised learning paradigms, transferring the labeling by a supervisor from individual instances (a very computationally costly task) to groups of similar instances. These groups are combined by application of adequate aggregation operators, providing an incremental learning scheme to the classifier, so that models can be revised and new classes can be incorporated into the models. In order to provide completeness to the models, a generalization process is also proposed. The classifier was tested in the human skin color-modeling problem, by using digital color-images captured under controlled and uncontrolled conditions. Experimental results assess its effectiveness, providing a robust and accurate detection of skin color in digital color-images. 


\section{Sumário}

1 INTRODUÇÃO 1

1.1 Classificação de cores. . . . . . . . . . . . . . . . . . . . . . . . 2

1.2 Construção de classificadores. . . . . . . . . . . . . . . . . . . . . . . 7

1.3 Objetivos deste trabalho . . . . . . . . . . . . . . . . . . . . . 12

1.4 Proposta: construção de classificador nebuloso por aprendizado computacional. . . . . . . . . . . . . . . . . . . . . 13

1.5 Contribuições . . . . . . . . . . . . . . . . . . . . . . . . . . 14

1.6 Organização deste trabalho . . . . . . . . . . . . . . . . . . . . 15

I CONCEITOS FUNDAMENTAIS $\quad 17$

2 RECONHECIMENTO DE PADRÕES: CLASSIFICAÇÃO 18

2.1 Modelagem do processo de reconhecimento . . . . . . . . . . . . . . . . . 19

2.1.1 Descrição do processo. . . . . . . . . . . . . . . . . . . . . 21

2.1.2 Atributos e vetores de atributos. . . . . . . . . . . . . . . 21

2.1.3 Análise de agrupamentos. . . . . . . . . . . . . . . . . . . 24

2.1.4 Construção do classificador. . . . . . . . . . . . . . . . 25

2.2 Discriminação entre classes f . . . . . . . . . . . . . . . . . . . 28

2.3 Conclusão do capítulo . . . . . . . . . . . . . . . . . . . . 30

3 CLASSIFICAÇÃO INCERTA E TEORIA DOS CONJUNTOS NEBULOSOS

3.1 Conjuntos nebulosos _. . . . . . . . . . . . . . . . . . . 32 
3.1 .1 Relações e operações . . . . . . . . . . . . . . . . . . . . . . . . . 33

3.1.2 Modificadores de conjuntos nebulosos. . . . . . . . . . . . . . . 34

3.1.3 Operadores de agregação nebulosa . . . . . . . . . . . . . . 35

3.1.4 Determinação das funções de pertinência . . . . . . . . . . . . . . 39

3.2 Agrupamentos nebulosos . . . . . . . . . . . . . . . . . . . . . . . 40

3.2.1 Algoritmos de agrupamento nebuloso. . . . . . . . . . . . . . . . . . 41

3.2.2 "Fuzzy c-means" ........................ 43

3.2.3 Medidas de desempenho do processo de agrupamento. . . . . . . . . 47

3.2.4 Aplicações do agrupamento nebuloso em processamento de imagens 49

3.3 Conclusão do capítulo . . . . . . . . . . . . . . . . . . 52

4 APRENDIZADO COMPUTACIONAL 53

4.1 Estratégia de aprendizado indutivo. . . . . . . . . . . . . . . 55

4.2 Paradigmas de aprendizado f . . . . . . . . . . . . . . 58

4.2.1 Supervisionado . . . . . . . . . . . . . . . . . . . . 59

4.2 .2 Não-supervisionado . . . . . . . . . . . . . . . . . . . . . . 60

4.2 .3 Aprendizado por reforço . . . . . . . . . . . . . . . . . . 60

4.3 Aprendizado híbrido . . . . . . . . . . . . . . . . . . . . 61

4.4 Conclusão do capítulo . . . . . . . . . . . . . . . . . . . 63

\section{PROPOSTA E DETALHAMENTO DO CLASSIFICADOR POR CORES

5 CONCEPÇÃO DO CLASSIFICADOR 66

5.1 Uso da cor para a classificação . . . . . . . . . . . . . . . . . . 66

5.2 Proposta de construção do classificador . . . . . . . . . . . . . . . . . 67

5.2.1 Módulo 1. Agrupamentos nebulosos. . . . . . . . . . . . . . . . . . 71

5.2 .2 Módulo 2. Definição de classes. . . . . . . . . . . . . . . . . . . . . 72 
5.2.3 Módulo 3. Agregação dos grupos nebulosos . . . . . . . . . . . . . 73

5.2.4 Módulo 4. Generalização da base de conhecimento . . . . . . . . . . 75

5.3 Aspectos do aprendizado computacional . . . . . . . . . . . . . . . . . . . 79

5.4 Conclusão do capítulo . . . . . . . . . . . . . . . . . . . 81

6 ARQUITETURA DE CONSTRUÇÃO DO CLASSIFICADOR 84

6.1 Módulo 1: Agrupamentos nebulosos. . . . . . . . . . . . . . . . . . 84

6.2 Módulo 2. Definição das classes . . . . . . . . . . . . . . . . . . . . 87

6.3 Módulo 3. Agregação. . . . . . . . . . . . . . . . . . . . . . . . . . . 90

6.4 Módulo 4. Generalização. . . . . . . . . . . . . . . . . . . . . . . . . 94

6.5 Conclusão do capítulo . . . . . . . . . . . . . . . . . 96

7 ESTUDO DE CASOS EM MODELAGEM DA COR DA PELE 97

7.1 Propriedades ópticas da pele humana . . . . . . . . . . . . . . . . . . . 98

7.2 Pesquisa relacionada à detecção de pele em imagens coloridas. . . . . . . . . 99

7.2.1 Representação da classe "cor da pele" nos espaços de cores. . . . . . 102

7.3 Avaliação do classificador . . . . . . . . . . . . . . . . . . . . . . . . . 104

7.3.1 Geração dos gabaritos de pele humana para avaliação do classificador110

7.4 Caso 1: banco de imagens de faces. . . . . . . . . . . . . . . . . . . 112

7.4.1 Parâmetros experimentais . . . . . . . . . . . . . . . . 112

7.4.2 Resultados do módulo 1 . . . . . . . . . . . . . . . . . 114

7.4.3 Resultados do módulo 2 . . . . . . . . . . . . . . . 115

7.4.4 Resultados do módulo 3 . . . . . . . . . . . . . . . . 115

7.4.5 Resultados do módulo 4. . . . . . . . . . . . . . . . 115

7.4.6 Teste do modelo e detecção da cor da pele . . . . . . . . . . . . . . 117

7.5 Caso 2: imagens humanas em ambientes variados . . . . . . . . . . . 123

7.5.1 Parâmetros experimentais . . . . . . . . . . . . 123

7.5.2 Resultados do módulo 1 . . . . . . . . . . . . . . . . . 124 
7.5.3 Resultados do módulo 2 . . . . . . . . . . . . . . . . . . . 124

7.5.4 Resultados do módulo 3 . . . . . . . . . . . . . . . . . . 127

7.5.5 Resultados do módulo 4. . . . . . . . . . . . . . . . . . 127

7.5.6 Teste do modelo e detecção da cor da pele . . . . . . . . . . . . . . 128

7.6 Análise dos resultados e conclusão do capítulo. . . . . . . . . . . . . . . . 131

8 CONSIDERAÇÕES FINAIS E PROPOSTAS FUTURAS 136

8.1 Sumário das contribuições . . . . . . . . . . . . . . . . . . . . . 138

8.2 Propostas futuras . . . . . . . . . . . . . . . . . . . . 139

Anexos 


\section{Lista de Figuras}

1.1 Imagens digitalizadas (à esquerda) e respectivas distribuições de cores em projeções planas do espaço RGB (à direita). . . . . . . . . . . . . . . . . . 4

2.1 Gráfico representando atributos de objetos e uma curva de decisão. . . . . 28

4.1 Atualização das hipóteses. a) Consistente. b) Aparece um falso negativo.

c) Generalização. d) Aparece um falso positivo. e) Especialização. . . . . . 58

5.1 Diagrama de blocos da modelagem do classificador. . . . . . . . . . . . 70

6.1 Diagrama de blocos do módulo de agrupamentos nebulosos. . . . . . . . . . 85

6.2 Imagem original e subimagens obtidas para $c^{*}=4(a, b, c$ e $d) . \ldots 86$

6.3 Imagem original e subimagens obtidas $(a, b, c, d, e, f$ e $g) . \ldots . \ldots 6$

6.4 Imagem original e recortes definidos pelo supervisor, com a cor da pele sendo a classe de interesse. . . . . . . . . . . . . . . . . . . . . . 87

6.5 Diagrama de blocos do módulo de definição das classes. . . . . . . . . . . 90

6.6 Diagrama de blocos do módulo de agregação. . . . . . . . . . . . . . . . . 94

6.7 Diagrama de blocos do módulo de generalização. . . . . . . . . . . . . . 95

7.1 Curvas de nível da mistura de gaussianas que modelam a distribuição da cor da pele no espaço RGB. . . . . . . . . . . . . . . . . . . . 100

7.2 Distribuição de amostras de cor de pele nos espaços de cores. (a) RGB, YCbCr, L*a*b* e HSV; (b) espaços YCbCr e HSV; (c) projeções nos planos cromáticos de diferentes espaços de cores. . . . . . . . . . . . . 103

7.3 Conjuntos que definem a matriz de confusão nebulosa. . . . . . . . . . . 107

7.4 Curvas ROC típicas para classificadores paramétricos. . . . . . . . . 108

7.5 Formação da figura de referência: a) original, b) crescimento de regiões, c) FCM, d) conjunção das figs. b) e c) . . . . . . . . . . . . . . . . 111 
7.6 Superior: exemplo de imagem colorida utilizada no treinamento do classificador, e subimagens construídas por grupo de pixels. Inferior: distribuições das cores nas projeções laterais do cubo RGB, com marcas indicando os centros dos grupos.

7.7 Distribuição dos pontos cor da pele, após apresentação das imagens de treinamento. Em cima, duas visões da classe formada no espaço RGB. Embaixo, projeção no plano RG do espaço de cores (horizontal). No eixo vertical, os valores de pertinência após o treinamento. . . . . . . . . . . 116

7.8 Esquerda: imagem original, ao centro: cor da pele detectada antes do procedimento de generalização e à direita, após a generalização. . . . . . 117

7.9 Pixels da classe cor da pele no plano GB, secção $R=140$ do espaço RGB. À esquerda, antes da generalização e à direita, após a mesma. . . . . . . . 117

7.10 Algumas imagens de teste e detecção de pele resultantes.

7.11 Gráficos ROC: (a) nebuloso parametrizado por $N_{T}$; (b) clássico parametrizado por $u_{l i m}$; (c) e (d), sensibilidade no ROC clássico como função de $u_{l i m} \ldots \ldots \ldots \ldots \ldots \ldots$

7.12 Exemplo de imagens retiradas da Internet e de revistas, e resultados na detecção de pele. . . . . . . . . . . . . . . . . . . . . . . 122

7.13 Em cima e centro: (a) exemplo de imagem colorida utilizada no treinamento e (b-d) subimagens construídas por grupo de pixels. Embaixo: distribuições das cores nas projeções laterais do cubo RGB. . . . . . . . . . 126

7.14 Exemplo de seleções de subimagens com pixels cor da pele, construídas no módulo 1. . . . . . . . . . . . . . . . . . . . . . 127

7.15 Distribuição dos pontos cor da pele, após apresentação das imagens de treinamento. Em (a), antes do procedimento de generalização, em (b), após o mesmo, e em (c), a distribuição de pertinências projetando-se a classe no plano RG. . . . . . . . . . . . . . . . . . . . . . . . 128

7.16 Esquerda: imagem original, ao centro: cor da pele detectada antes do procedimento de generalização e à direita, após a generalização. . . . . . 128

7.17 Algumas imagens de teste do caso 2 e detecção de pele resultante. . . . . . 129 
7.18 Algumas imagens de teste do caso 2 com referência apenas para a pele, e detecção resultante. . . . . . . . . . . . . . . . . . . . . . . . . 130

1 Algumas imagens de treinamento do caso 1. . . . . . . . . . . . . . . 146

2 Algumas das imagens de treinamento do caso 2. . . . . . . . . . . . . 147 


\section{Lista de Tabelas}

2.1 Exemplo de pessoas e atributos. . . . . . . . . . . . . . . . . . 22

2.2 Uma possível classificação de pessoas, a partir da tabela $2.1 \quad \ldots$. . . . . . 23

7.1 Matriz de confusão para duas classes . . . . . . . . . . . . . . 106

7.2 Matriz de confusão para várias classes . . . . . . . . . . . . . 106

7.3 Exemplo de inicialização heurística dos centros de quatro grupos no espaço de cores RGB, onde cada componente $\{x \mid 0 \leqslant x \leqslant 255\}$. . . . . . . . 113

7.4 Número de grupos dados pelo algoritmo FCM-GK e respectiva função de validação $S$, aplicados à fig. 7.6. . . . . . . . . . . . . . . . . . . . 115

7.5 Avaliações nebulosa e clássica do desempenho nas 20 imagens da Internet e revistas, com valores médios de especificidade e sensibilidade e respectivos desvios padrões. . . . . . . . . . . . . . . . . . . . . . . . 123

7.6 Número de grupos dados pelo algoritmo FCM-GK e respectiva função de validação $S$, aplicados à fig. 7.13a. . . . . . . . . . . . . . . . . . . . . . . . 124

7.7 Avaliações nebulosa e clássica do desempenho nas 12 imagens de teste do caso 2, com valores médios de especificidade e sensibilidade e respectivos desvios padrões. . . . . . . . . . . . . . . . . . . . . . 131 


\section{LISTA DE ABREVIATURAS E SIGLAS}

CIE "Commission Internationale de l'Éclairage"

DCP distância ao classificador perfeito

FAM "fuzzy associative memory"

FCM algoritmo "fuzzy c-means"

FCM-GK "fuzzy c-means" modificado por Gustafson e Kessel (1979)

FCM-GG "fuzzy c-means" modificado por Gath e Geva (1989)

FkNN algoritmo "fuzzy k-nearest neighbors"

FLVQ "fuzzy learning vector quantization"

FN "false negatives"

FP "false positives"

HSI espaço de cores definido pelas primárias [hue, saturation, intensity]

HSV espaço de cores definido pelas primárias [hue, saturation, value]

HSx algum dos espaços de cores HSI ou HSV

I1I2I3 espaço de cores definido por Ohta

kNN algoritmo "k-nearest neighbors"

LUT "lookup table"

LVQ "learning vector quantization"

MLP rede neural "multilayer perceptron"

OCR "optical character recognition" 
PAC learning "probably approximately correct learning"

PCA "principal component analysis"

rg espaço de cores definido pelas projeções das componentes das cores $[R, G, B]$ em um plano perpendicular à diagonal principal do cubo $[R, G, B]$

RGB espaço de cores definido pelas primárias [red,green, blue]

ROC "receiver operating characteristic"

SOM rede neural "self-organizing maps"

TN "true negatives"

TP "true positives"

UCS "Uniform Chromaticity Scale"

UVW espaço de cores definido pelas primárias de intensidade $Y$, e componentes cromáticas $[U, V, W]$

XYZ espaço de cores definido pelas primárias CIE-1931

YCbCr espaço de cores definido pelas primárias de intensidade $Y$, e componentes cromáticas $\left[C_{b}, C_{r}\right]$

YES espaço de cores definido pelas primárias de intensidade $Y$, e componentes cromáticas $[E, S]$

YIQ espaço de cores definido pelas primárias de intensidade $Y$, e componentes cromáticas $[I, Q]$

YUV espaço de cores definido pelas primárias de intensidade $Y$, e componentes cromáticas $[U, V]$ 


\section{CONVENÇÕES E LISTA DE SÍMBOLOS}

Na notação das equações, as seguintes convenções foram utilizadas:

- letras minúsculas em itálico denotam variáveis e parâmetros: $u$;

- letras minúsculas em negrito denotam vetores de algum atributo: x;

- letras maiúsculas em negrito denotam conjuntos: $\mathbf{X}, \mathbf{U}$;

- letras maiúsculas caligráficas denotam conjuntos: $\mathcal{T}, \mathcal{R}$ e representam imagens como conjuntos de pixels;

- letras gregas, maiúsculas ou minúsculas representam entidades diferentes conforme o contexto onde estiverem;

- letras entre colchetes representam componentes de um vetor: $\left[x_{1} x_{2} x_{3}\right],[R G B]$;

- a transposta de uma matriz linha [.] $]^{T}$ representa um vetor (matriz coluna);

- subscritos diferenciam elementos de um conjunto: $\omega_{\text {pele }}, u_{i k}$, ou, em casos mais específicos, rotulam parâmetros específicos: $N_{T}$ (número de imagens de treinamento), $u_{\text {agreg }}$ pertinência após operação de agregação;

- um traço sobrescrito sobre uma variável a representa seu valor médio $\bar{a}$ em uma faixa especificada. 
Os seguintes símbolos são importantes neste trabalho:

\begin{tabular}{|c|c|}
\hline símbolo & descrição \\
\hline$a$ & número de instâncias atribuídas corretamente como negativas \\
\hline $\arg \max _{\mathbf{x}} f(\mathbf{x})$ & valor do argumento que maximiza a função \\
\hline $\arg \min _{\mathbf{x}} f(\mathbf{x})$ & valor do argumento que minimiza a função \\
\hline$B$ & componente da cor primária "blue" no espaço de cores RGB \\
\hline$b$ & componente normalizada da cor primária "blue" \\
\hline$b$ & número de instâncias atribuídas incorretamente como positivas \\
\hline$c$ & número de grupos em que o espaço de atributos é particionado \\
\hline$c$ & número de instâncias atribuídas incorretamente como negativas \\
\hline$c^{*}$ & melhor número de grupos para particionar o espaço de atributos \\
\hline$c^{*}(n)$ & melhor número de grupos da enésima imagem de treinamento \\
\hline $\mathrm{C}$ & matriz de covariância \\
\hline$d$ & distância entre dois elementos no espaço de atributos \\
\hline$d_{M a h}$ & $\begin{array}{l}\text { distância de Mahalanobis entre dois elementos no espaço de atri- } \\
\text { butos }\end{array}$ \\
\hline$d$ & número de instâncias atribuídas corretamente como positivas \\
\hline $\mathcal{D}$ & conjunto de pixels da imagem detectada pelo classificador \\
\hline espec & especificidade do classificador \\
\hline$\epsilon$ & limite de convergência do algoritmo FCM \\
\hline$G$ & componente da cor primária "green" no espaço de cores RGB \\
\hline$g$ & componente normalizada da cor primária "green" \\
\hline$G_{i}$ & i-ésimo grupo obtido pelo algoritmo FCM \\
\hline$\Gamma$ & conjunto de grupos obtidos \\
\hline$i$ & índice de um grupo \\
\hline$I T$ & número de iterações do algoritmo FCM \\
\hline$J(\cdot)$ & função objetivo a ser minimizada no algoritmo FCM \\
\hline$k$ & índice de um elemento no espaço de atributos \\
\hline$k$ & $\begin{array}{l}\text { número de vizinhos a serem considerados no módulo de genera- } \\
\text { lização ("fuzzy kNN") }\end{array}$ \\
\hline$m$ & fator de nebulosidade no particionamento nebuloso \\
\hline $\max (\cdot)$ & maior valor dos elementos do argumento \\
\hline $\min (\cdot)$ & menor valor dos elementos do argumento \\
\hline$n$ & enésima imagem \\
\hline
\end{tabular}




\begin{tabular}{|c|c|}
\hline símbolo & descrição \\
\hline$N$ & número de pixels de uma imagem \\
\hline$N_{T}$ & número de imagens de treinamento \\
\hline$N_{\text {Teste }}$ & número de imagens de teste \\
\hline$p(\cdot \mid \cdot)$ & probabilidade condicional \\
\hline$R$ & componente da cor primária "red" no espaço de cores RGB \\
\hline$r$ & componente normalizada da cor primária "red" \\
\hline $\mathcal{R}$ & conjunto de pixels da imagem de referência \\
\hline sens & sensibilidade do classificador \\
\hline$S$ & função de validação de Xie e Beni (1991) \\
\hline$\sum$ & somatório dos argumentos \\
\hline $\mathcal{T}$ & conjunto de pixels da imagem de teste \\
\hline$\Theta()$. & operador de agregação nebulosa \\
\hline$u_{\mathbf{A}}(\mathbf{x})$ & pertinência do atributo $\mathbf{x}$ ao conjunto $\mathbf{A}$ \\
\hline $\mathrm{U}$ & matriz de pertinências $\left\{u_{i k}\right\}$ \\
\hline $\mathbf{U}_{n}$ & matriz de pertinências $\left\{u_{i k}\right\}$ da enésima imagem \\
\hline $\mathbf{v}_{i}$ & posição do centro do i-ésimo grupo no espaço de atributos \\
\hline$w$ & peso associado à relevância do grupo $G$ na classe $\omega$ \\
\hline $\mathbf{x}_{k}$ & vetor de atributos do $k$-ésimo dado \\
\hline $\mathrm{X}$ & $\begin{array}{l}\text { conjunto de } N \text { elementos expressos pelos seus vetores de atribu- } \\
\text { tos } \mathbf{x}_{k}\end{array}$ \\
\hline$\omega$ & classe no espaço de atributos \\
\hline$\omega_{p}$ & classe de interesse \\
\hline$\Omega$ & conjunto das classes definidas pelo supervisor \\
\hline$\cap$ & intersecção entre dois conjuntos \\
\hline$\cup$ & união entre dois conjuntos \\
\hline$\bigcap$ & intersecção entre vários conjuntos \\
\hline$\bigcup$ & união entre vários conjuntos \\
\hline$\subset$ & subconjunto de \\
\hline$\in$ & elemento no conjunto \\
\hline$\forall$ & qualquer, para todo \\
\hline$\varnothing$ & conjunto vazio \\
\hline$\times$ & produto cartesiano entre dois conjuntos \\
\hline$\neg$ & negação \\
\hline
\end{tabular}





\section{INTRODUÇÃO}

Em reconhecimento de padrões, e também em visão de máquinas, várias técnicas têm sido desenvolvidas e testadas, sendo a classificação uma das principais tarefas que compõem tais técnicas. Teoria de decisão de Bayes (PRESS, 1989), classificadores lineares (perceptrons (HAYKIN, 1999) e mínimos quadrados (THEODORIDIS; KOUTROUMBAS, 1999)) e não-lineares (perceptrons multicamadas (HAYKIN, 1999), árvores de decisão (QUINLAN, 1993)), modelos de Markov (CHEN; KUNDU, 1995) e técnicas de agrupamento (JAIN; MURTY; FLYNN, 1999) são técnicas intensamente investigadas nos últimos anos para definir classes em reconhecimento de formas, faces, texturas, palavras, caracteres manuscritos, entre outros elementos. Classes definem padrões, e o reconhecimento de novos exemplos se dá por algum processo comparativo.

Cor é um atributo extremamente relevante em tarefas de reconhecimento e interpretação de imagens coloridas; assim, uma classificação de objetos pela cor torna-se um importante pré-requisito para o sucesso na realização de tais tarefas. Cores são usadas em diversas tarefas que envolvem imagens coloridas, como, por exemplo:

- indexação de objetos em imagens (DAS; MANMATHA; RISEMAN, 1998);

- segmentação por limiares de cor (LIM; LEE, 1990); (ITO, 1995); (BONVENTI JR.; COSTA, 2000b) e (TAO; HUANG, 2000);

- detecção de pessoas pela cor da pele (VEZHNEVETS; SAZONOV; ANDREEVA, 2003);

- redução e quantização de cores (PAPAMARKOS, 1999) e (WU; LIU; HUANG, 2000);

- inspeção e controle de qualidade (NOORDAM, 2000);

- rastreamento em vídeo (SCHUMEYER; BARNER, 1998);

- informações geográficas (ZHANG, 2000); 
- futebol de robôs (BRUCE; BALCH; VELOSO, 2000) e (BONVENTI JR.; COSTA, 2000a).

Para lidar com as incertezas advindas de informações imprecisas, mal definidas, vagas e até mesmo contraditórias sobre a percepção das cores, a teoria dos conjuntos nebulosos incorporada à classificação de cores possibilita enriquecimento e flexibilidade no tratamento da informação colorida (ZADEH, 1965) e (CHI; YAN; PHAM, 1996).

\subsection{Classificação de cores.}

Em uma imagem em cores, associar cada pixel ${ }^{1}$ a um objeto da cena é uma tarefa preliminar muito importante em visão computacional. Geralmente, cada objeto é caracterizado por poucas cores distintas e que apresentam variações, e, embora a identificação de um objeto e seus contornos seja natural no sistema de visão humano, a segmentação de imagens é uma tarefa complexa. A precisão da segmentação depende principalmente da detecção de uniformidades através de atributos dos pixels (como cor) e de suas vizinhanças (como a textura), e daí então isolar as regiões que englobem estas uniformidades. Para detectar tal uniformidade, é necessário classificar, previamente, os pixels de acordo com padrões de interesse em relação aos atributos. Segundo Gonzalez e Woods (1992),

\footnotetext{
"a segmentação subdivide uma imagem em suas partes ou objetos constituintes ... (e) deve parar quando os objetos de interesse na aplicação tiverem sido isolados".
}

Os algoritmos de segmentação são geralmente baseados em descontinuidades ou similaridades nos atributos dos pixels. O agrupamento por similaridades define as classes da imagem, possibilitando a segmentação.

Em uma cena natural, as cores dos objetos e a iluminação não são restritos nem controlados. Deformações nas texturas, sombras, oclusões, variações de luminosidade e outros problemas dificultam a segmentação da imagem. Esta dificuldade pode ser melhor compreendida ao representar as cores existentes da imagem em algum espaço de representação, RGB, HSI, YUV ou qualquer outro. Devido às características das cenas naturais, as cores são visualizadas nestes espaços formando "nuvens" de diversas configurações, algumas esparsas, outras mais densas, algumas apresentando uma grande variação nos valores da

\footnotetext{
1 "picture element" - unidade elementar de visualização em imagens digitais, caracterizada por uma posição discreta $(i, j)$ e sua cor.
} 
cor percebida. Em domínios nos quais os objetos apresentam cores mais distintas, e a iluminação é praticamente constante (HANEK, 2002), o trabalho de classificação fica um pouco mais facilitado, pois há maior separação das classes no espaço de atributos, o que nem sempre ocorre em cenas naturais, conforme se observa nos exemplos da fig. 1.1. Nesta figura, são mostradas algumas imagens e suas distribuições de cores representadas no espaço RGB por projeções nos planos RG, BG e BR.

Estas nuvens apresentam variações de densidade e revelam a formação de grupos. Ao se considerar que objetos coloridos em uma cena não apresentam cores constantes em sua imagem, espera-se que seus pixels tenham uma distribuição de densidade gradual no espaço de cores considerado. A análise destas nuvens revela que seus limites não são precisos, e também pode haver interseções entre elas. A detecção destas nuvens por análise de agrupamentos parece ser uma solução interessante para a classificação, pois a distribuição das nuvens é obtida de acordo com as propriedades intrínsecas dos dados.

Considerando-se ainda sua natureza física, a cor é produto de uma excitação luminosa na retina humana, e esta sensação varia sob três aspectos: a) a intensidade luminosa ou brilho, b) o comprimento de onda, que varia continuamente na faixa visível do espectro eletromagnético e c) a proporção de mistura entre cores, dado que a retina humana é composta de três tipos de sensores, com maior sensibilidade respectivamente à cor vermelha, verde e azul. A forma com que o sistema visual humano capta as cores é uma função não-linear dos três aspectos, por isto, afirma-se que a cor é um fenômeno psicofísico (WYSZECKI; STILES, 1982). O processo de comunicação humana a respeito destas sensações se dá através de descrições linguísticas, que produzem os nomes das cores. O nome, ou rótulo da cor, é aprendido e incorporado na linguagem diária e cheio de conotações culturais. Muitas vezes, um indivíduo descreve a cor de um objeto por um nome, e outro indivíduo por outro nome (ou alguma variante daquele); exemplos: verdemar, verde-folha, verde-esmeralda, verde azulado. A sensibilidade a pequenas mudanças de cores também varia de indivíduo para indivíduo (WYSZECKI; STILES, 1982). Assim, os nomes das cores são, por si, semanticamente vagos, e havendo um número finito deles para descrever as cores, ocorre que cada denominação de cor terá significado em uma certa faixa do espectro visível, e de acordo com alguma mistura de cores em uma dada proporção.

Reunindo-se as duas considerações mencionadas:

a) cenas naturais apresentam objetos cujas cores se distribuem na forma de nuvens em qualquer espaço de representação; 
b) a descrição da cor é intrinsecamente vaga, de escopo difuso em relação à combinação de freqüências luminosas percebidas;

pode-se inferir que o tratamento da informação colorida se torna bem adequado utilizandose a teoria de conjuntos nebulosos. Assim, a classificação de cores em uma imagem digital pode ser melhor executada por análise de agrupamentos nebulosos, e as nuvens de cores representadas por conjuntos nebulosos, correspondentes a cada grupo obtido.

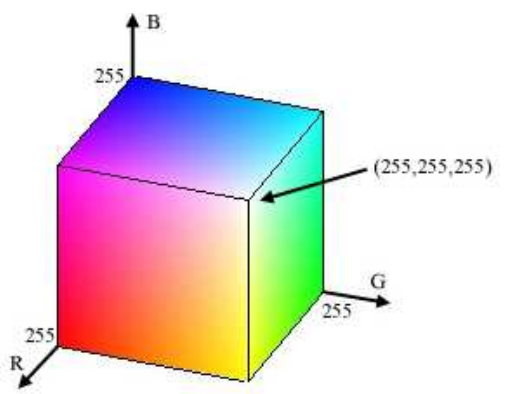

Espaço de cores RGB.
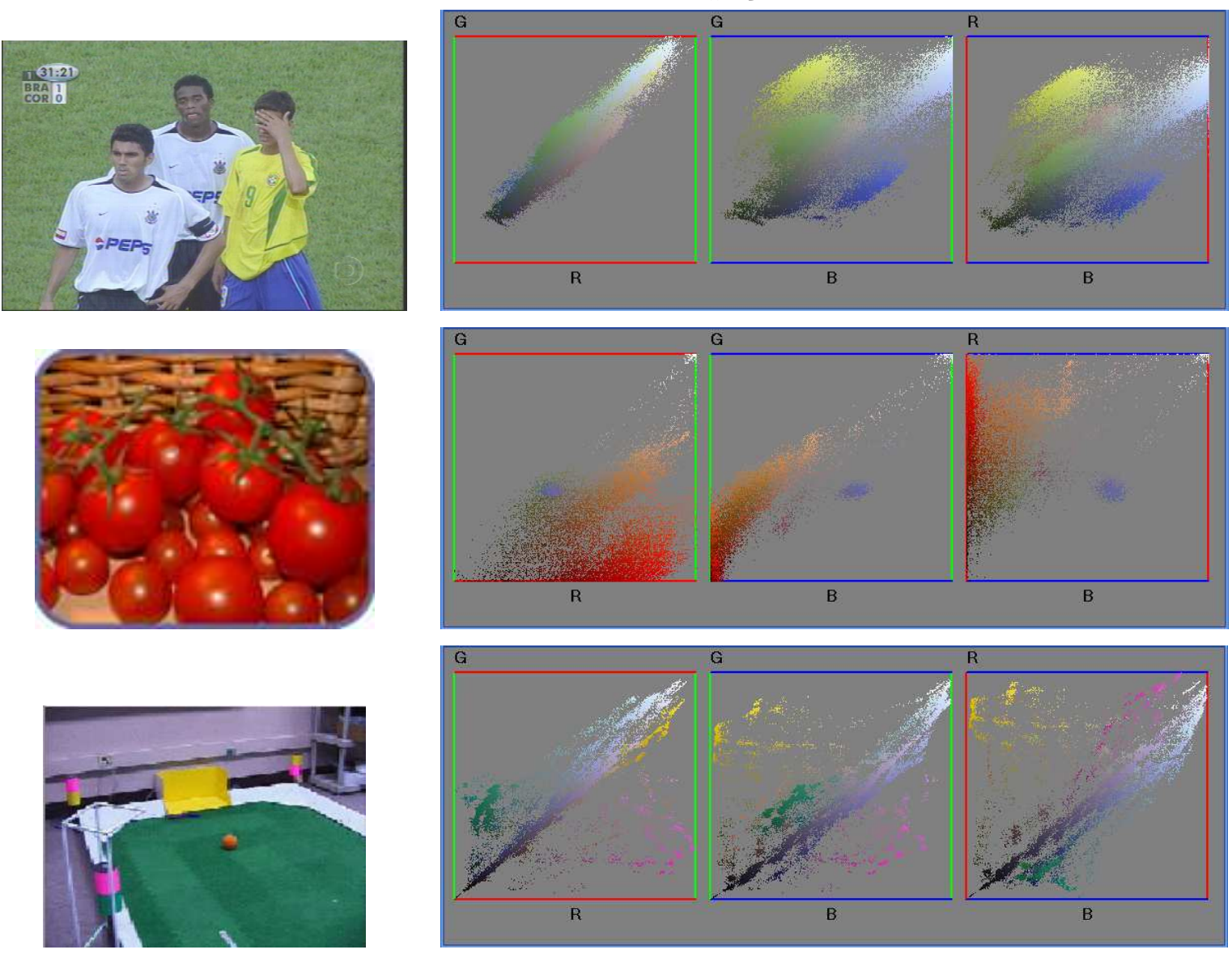

Figura 1.1: Imagens digitalizadas (à esquerda) e respectivas distribuições de cores em projeções planas do espaço RGB (à direita). 
Há ainda outro aspecto: quantos e quais são os rótulos lingüísticos dos conjuntos nebulosos de cores, identificados em uma imagem? Não é útil rotular os conjuntos nebulosos por nomes de cores, pois elas variam continuamente, e a cada ponto no espaço de cores pode ser associada uma cor. Por exemplo, os equipamentos de digitalização de imagens representam as cores em conjuntos de 24 ou 32 bits, resultando em $2^{24}$ ou $2^{32}$ "cores diferentes". Os conjuntos nebulosos são melhor rotulados de acordo com os objetos detectados (ou grupo de objetos), que são caracterizados por uma determinada cor.

Aos pontos da imagem devem estar associados basicamente duas informações: sua posição na imagem, cuja vizinhança compõe um determinado objeto, e sua cor. A segmentação de uma imagem pode levar em conta ambas as informações, como relações de vizinhança espacial e proximidade de cores no espaço de representação.

A segmentação de imagens tem sido desenvolvida com vários algoritmos e técnicas direcionadas para tons de cinza, quando associadas à lógica nebulosa (PAL; ROSENFELD, 1988); (TIZHOOSH; KRELL; MICHAELIS, 1997); (KIM; CIPARRONE; ANDRADE, 1997); (SALLES; LING, 1997) e (GULIATO, 1998). Contudo, as imagens coloridas revelam mais informações sobre os objetos da cena, tanto que a informação colorida desempenha um papel importante na comunicação visual. Ao longo do tempo, técnicas específicas para a segmentação de imagens em cores, baseadas em lógica nebulosa, têm surgido em menor escala. As técnicas desenvolvidas para imagens em tons de cinza muitas vezes não possuem similares para imagens coloridas. Entre as técnicas mais usadas no tratamento da imagem estão (GONZALEZ; WOODS, 1992): segmentação por regiões, detecção de contornos, cálculos de propriedades morfológicas e realce. Nesta tese, explora-se a segmentação por cores através da técnica de agrupamentos nebulosos.

Agrupamentos nebulosos. Agrupamento é uma técnica bastante utilizada em reconhecimento de padrões e objetos em uma cena. Como a segmentação busca separar partes da imagem, os pixels pertencentes a cada parte possuem alguma similaridade entre si, de acordo com os atributos relevantes para a aplicação. A similaridade é a relação entre dados que dirige o processo de agrupamento. Na segmentação de imagens, cada pixel é descrito por um vetor, que pode conter informações de cor, vizinhança, localização relativa ou algum outro atributo. Algoritmos de agrupamento determinam um conjunto de grupos o mais compactos e bem separados possível, e os grupos recebem um rótulo, associado a um objeto, cor, estrutura, ou outra descrição relevante na cena analisada. Esta descrição pode ser utilizada em tarefas posteriores de processamento de imagens.

Assim, a classificação nebulosa se torna adequada em tarefas de visão computacional 
envolvendo o atributo cor, pelas características observadas nas distribuições da fig. 1.1. Uma decisão tomada em uma fase do processamento apresentará conseqüências nas fases seguintes. A representação da vaguidade relativa às cores permite a manutenção de mais informações durante o processamento global. Com a definição das classes de forma nebulosa, os dados podem pertencer a mais de uma classe, com um grau de pertinência variando de 0 (certamente não pertence) a 1 (certamente pertence). Além disso, a classificação nebulosa de cores fica mais robusta a ruídos, pois os dados que não apresentam pertinência alta em relação a um grupo não é sumariamente descartado. Acrescenta-se uma flexibilidade e um enriquecimento suficientes para permitir a tomada de decisões mais embasadas, em etapas posteriores, preservando dados que seriam estritamente eliminados se não estivessem exclusivamente nos grupos de interesse.

Dentre os modelos provenientes da teoria de conjuntos nebulosos, aplicados em processamento de imagens, a classificação por agrupamento ( "fuzzy c-means" - FCM) é a mais utilizada (TIZHOOSH, 1998). Há poucos casos in natura onde a separação entre classes é bem definida, e os problemas de classificação em imagens têm sido efetivamente resolvidos com esta técnica.

As técnicas de agrupamento apresentam algumas vantagens adicionais sobre outras técnicas, justificando seu emprego observado em vários trabalhos:

- permitem a construção de vetores em espaços multidimensionais, agregando atributos numéricos diferentes (cor, relações com vizinhança e outras). Porém, o custo de execução de tais algoritmos cresce exponencialmente com o número de atributos considerados (JAIN; MURTY; FLYNN, 1999);

- resultam em uma efetiva separação em classes, particionando o espaço de atributos coerentemente. As classes podem ser visualizadas como nuvens de pontos no espaço multidimensional, e as partições ocorrem nas regiões de menor densidade (CHI; YAN; PHAM, 1996);

- em processamento de imagens, em especial as imagens em cores, produzem resultados muito bons. Quando o objetivo é quantizar cores, os centros dos grupos são os melhores representantes (PAPAMARKOS, 1999) e (WU; LIU; HUANG, 2000);

- em quase todos os casos, possibilitaram a completa identificação das características desejadas, e também funcionaram como filtros eficientes.

No entanto, estas técnicas são fortemente dependentes da métrica utilizada. Uma 
pequena alteração na norma (p.ex. distância quarteirão ${ }^{2}$ para euclidiana ${ }^{3}$ ) pode alterar facilmente o número de grupos obtido. Ainda, espaços não-isotrópicos (eixos dos atributos de medidas diferentes) requerem uma correção no cálculo da distância, em função das componentes do vetor de atributos.

\subsection{Construção de classificadores.}

A classificação é a tarefa onde se processa a identificação propriamente dita. Um determinado padrão, representado por alguns de seus atributos, é submetido ao classificador para que seja associado a uma das classes previamente definidas. Um bom classificador deve atingir altos índices de acerto, revelando classes coerentes entre si. Esta coerência está relacionada ao fato de que objetos mais similares (segundo os atributos em consideração) estejam alocados na mesma classe, ou em classes vizinhas, de acordo com o grau de refinamento. Então, uma preocupação anterior ao processo de reconhecimento é:

como construir o classificador, atendendo a requisitos de acurácia?

As questões principais da construção de classificadores são:

- qual o número de classes que deve existir, para representar o conjunto de padrões possíveis de uma coleção de entidades?

- como estabelecer as classes e representá-las, utilizando os atributos das entidades envolvidas?

Um classificador pode ser delineado basicamente de duas maneiras: manualmente ou automaticamente. Por construção manual, entende-se que algum agente especialista define os atributos relevantes, indica o número de classes, suas denominações e quais os limites de cada classe em função dos atributos dos objetos a serem classificados. Tal estratégia é, a princípio, isenta de erros, e, no caso de haver tal possibilidade, um conjunto de especialistas pode ser acionado, e eventuais divergências de classificação resolvidas por voto majoritário ou algum outro procedimento ponderado. Mas, a principal desvantagem é que esta estratégia funciona bem somente para definir classes cujos limites sejam bem claros. Quando a classificação depende de decisões mais complicadas, ou o número de atributos é muito grande, ou ainda as relações entre estes atributos forem complexas, um

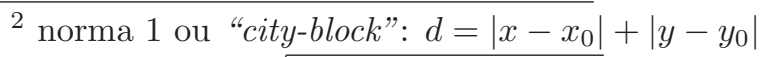

${ }^{3}$ norma $2: d=\sqrt{\left(x-x_{0}\right)^{2}+\left(y-y_{0}\right)^{2}}$
} 
alto poder de (re)processamento e memória são requeridos. Torna-se necessário recorrer a alguma forma automática de obtenção das classes.

A construção de classificadores pela cor requer muitas imagens contendo os objetos de interesse, para que sejam caracterizados por seus respectivos conjuntos de cores. O motivo é que tais objetos podem surgir em diversas imagens em condições distintas de iluminação, ou apresentarem uma grande variação na cor. Então, como as cores em imagens são utilizadas como um dos atributos para a segmentação, e normalmente estão envolvidos milhares ou milhões de pixels, o processo de classificação e agrupamento deve ser bastante eficiente, com altos requisitos de processamento e memória. Logo, é altamente desejável que a construção de classificadores seja automática. Para isto, são explorados os paradigmas de aprendizado computacional.

Aprendizado de classificadores. O aprendizado computacional é um conjunto de técnicas envolvendo diversas áreas do conhecimento. Este estuda como modelar um bom sistema de predição, baseado em observações prévias ("experiências passadas"). Segundo Mitchell (1997),

"um programa de computador aprende com a experiência $E$ em relação a alguma classe de tarefas $T$, se o seu desempenho $P$ nas tarefas de $T$ aumenta com a experiência $E "$.

Normalmente distinguem-se três paradigmas de aprendizado: supervisionado, não-supervisionado e por reforço. O paradigma de aprendizado totalmente supervisionado (ou "com professor") é baseado na obtenção de exemplos contendo os rótulos das classes. O classificador vai moldando sua resposta à medida que estes exemplos vão sendo apresentados (fase de treinamento). Em uma etapa seguinte, esta resposta é avaliada através de alguma função de erro, ao classificar novos exemplos e comparar com seus rótulos prévios (fase de testes). Ao final do processo, o classificador terá induzido uma função de mapeamento (dos exemplos para os rótulos), sendo esta modalidade denominada aprendizado indutivo (CARBONELL, 1989). A utilização conjunta de exemplos positivos e negativos possibilita uma avaliação da consistência do classificador, auxiliando também a prevenir a superespecialização. Nesta, o classificador responde corretamente à quase totalidade dos exemplos de treinamento, mas apresenta uma alta taxa de erros ao classificar exemplos ainda não apresentados. Apesar disto, este paradigma é uma solução bastante eficaz e precisa, desde que haja uma grande quantidade dos exemplos com os rótulos das classes definidos, positivos e negativos, o que nem sempre é possível de se obter. 
O paradigma de aprendizado totalmente não-supervisionado baseia-se em alguma medida de similaridade entre os exemplos. Assim, a escolha da métrica desta similaridade é fator crucial. Além disso, dado um conjunto particular de exemplos, o número de classes esperado é indeterminado, o que leva a outras preocupações como a utilização de algum critério de validação para obter o melhor número delas. Também existe o fato de que dados espúrios ou pequenos grupos possam não ser distinguidos como uma classe representativa, se realmente o forem. A rotulação das classes é feita após o término do processo, por algum agente externo, e o principal problema é que esta identificação pode não ser totalmente acurada.

O paradigma do aprendizado por reforço possibilita uma realimentação qualitativa sobre a direção tomada no processo. Alguns autores, dentre eles Haykin (1999), situam-no como uma subdivisão do aprendizado não-supervisionado, pela falta de rótulos explícitos a cada exemplo. Outros porém não consideram desta forma, pois o reforço é uma forma de controle do processo de aprendizado. Esta forma de aprendizado está mais direcionada a aprender qual a seqüência de ações que leva à solução do problema, do que propriamente a construção de classes de objetos.

Aprendizado híbrido Sistemas inteligentes híbridos são produto da combinação de mais de uma abordagem, procurando suplantar as dificuldades de cada uma delas, ou procurando utilizar as vantagens oferecidas por cada uma. Seu objetivo final é obter um sistema com desempenho superior àqueles baseados em abordagens isoladas. A hibridização de sistemas inteligentes tornou-se um campo promissor no desenvolvimento de novas soluções para problemas em inteligência computacional e, recentemente, tornou-se popular por sua habilidade em lidar com as complexidades do mundo real que envolvem incerteza e vaguidade (ver, por exemplo, as quatro edições do recém-lançado "International Journal of Hybrid Intelligent Systems" - IJHIS (GROSSBERG, 2004)).

No trabalho aqui proposto, a combinação dos paradigmas de aprendizado supervisionado e não-supervisionado objetiva:

- explorar a vantagem do aprendizado não-supervisionado em lidar com muitas instâncias, agrupando-as por similaridade, e possibilitar a definição de classes ou conceitos sobre os grupos formados;

- explorar a vantagem do aprendizado supervisionado na utilização de um agente especialista para rotular e identificar os grupos obtidos e definir classes; 
- contornar a incapacidade do aprendizado não-supervisionado de atribuir rótulos significativos aos grupos formados;

- contornar a tarefa dispendiosa de rotular corretamente cada instância (típica em aprendizado supervisionado).

Representação das classes. Classes, em função dos atributos, podem ser representadas de várias maneiras, de acordo com o contexto envolvido:

Regras de inferência: um exemplo é "se $R<20$ e $G<20$ e $B<20$ então a cor é PRETA".

Descrição funcional: um exemplo consiste em classes que são separadas por uma inequação tal como $\omega_{1,2} \lessgtr x^{2}+4 y-\cosh (z)$.

Rotulação direta: através de uma tabela que descreva o atributo do objeto e explicite sua classe (referida freqüentemente como "lookup table" - LUT).

Indireta: no caso em que a representação não é diretamente observável, e a obtenção da classe ocorre somente na interação com o classificador; exemplo: redes neurais artificiais.

Sammut (1994), de forma parecida, descreve três diferentes abordagens para o problema da representação:

Baseada em instâncias: onde as classes são construídas pelo armazenamento de exemplos prototípicos, e não há abstração das mesmas. Aqui se incluem as representações não-funcionais.

Por aproximação de funções: mais relacionadas às noções tradicionais de aproximação e interpolação, onde as classes são representadas por formulações matemáticas. Incluem-se aqui os modelos estatísticos e conexionistas.

Simbólica: descrições abstratas das classes, que trabalham com representações em lógica de primeira ordem e proposicional (como "frames" e redes semânticas).

Portanto, neste trabalho, a construção de um classificador de pixels emprega o paradigma de aprendizado híbrido, explorando as vantagens da parte supervisionada e da parte não-supervisionada. Sendo um aprendizado a partir de instâncias, as classes são representadas pela reunião e rotulação adequada destas instâncias. 
A construção automática de um classificador passa a ser atrativa quando é possível explorar as vantagens desta automação. No entanto, a construção de um classificador de objetos através da cor deve considerar as seguintes características do domínio em questão:

1. uma imagem digitalizada é composta de milhares ou milhões de pixels. Cada pixel tem associado a si a informação da cor, normalmente representada por uma tripla como $[R G B],[Y U V],[H S I]$ ou outra;

2. a distribuição de cores na imagem é desconhecida, pois depende das condições dos objetos na cena (textura, sombras, iluminação, etc.);

3. a relação nome da cor e tripla de dados é vaga.

Assim, é desejável uma forma de obter um classificador que se aprimore sob os paradigmas de aprendizado computacional e possa manipular adequadamente classificações vagas. É importante notar que algumas classes adquirem significado após a análise de uma quantidade razoável de objetos. Individualmente, estes objetos são classificados com algum grau de ambiguidade. Este tipo de problema a ser resolvido - a definição de classes em conjuntos de exemplos vagos - é a preocupação central deste trabalho.

A principal questão neste trabalho é:

como construir automaticamente um classificador que, considerando instâncias individualmente vagas, possa obter classes de conceitos subjetivos, de definição imprecisa?

Relacionadas a ela, algumas outras questões podem ser levantadas:

1. As técnicas de agrupamentos nebulosos são eficientes para identificar o grupo de pixels correspondentes às cores típicas de um objeto em uma imagem, permitindo o seu reconhecimento? A teoria dos conjuntos nebulosos pode ser então uma ferramenta útil neste caso?

2. Os valores de pertinência de cada pixel, obtidos por agrupamentos nebulosos, refletem com precisão o grau de sua representatividade dentro da classe de cores que caracterizam um dado objeto?

3. Podem ser identificadas e tratadas algumas características inerentes ao aprendizado computacional, como a generalização e o excesso de ajuste ( "overfitting")? 
4. Existe algum espaço preferencial de representação de cores para construir o classificador e a detecção ser executada mais eficientemente?

Os paradigmas de aprendizado citados não podem ser aplicados de forma "pura" na construção do classificador com as características propostas se o desejo é aumentar sua eficiência e acurácia. A estratégia híbrida parece uma boa alternativa, evitando-se a sobrecarga de se rotular previamente muitos exemplos, ao mesmo tempo que exemplos não rotulados participam do treinamento.

\subsection{Objetivos deste trabalho}

O objetivo principal deste trabalho consiste em definir um método de aprendizado híbrido para a construção de um classificador nebuloso, baseado em cores de objetos presentes em imagens digitais coloridas. Sua utilidade é reconhecer uma classe específica de cores. Este método será avaliado na construção de um classificador nebuloso para cores de pele humana.

Os objetivos secundários, relacionados à concepção deste modelo híbrido, consistem em:

- simplificar a intervenção do supervisor na definição das classes, rotulando grupos de pixels similares;

- gerar modelos de classes que levem em conta a vaguidade do conceito cor, através de conjuntos nebulosos;

- propiciar a atualização das classes de forma incremental;

- propiciar um modo de classificar instâncias não apresentadas no processo de aprendizado, utilizando algum método de generalização das classes;

- aplicar a metodologia proposta na construção de um modelo de cor da pele humana para o classificador.

No caso em estudo, este trabalho não aborda técnicas morfológicas, nem faz uso delas no processo de detecção. Atributos espaciais, concernentes à posição relativa entre os pixels, não são considerados. O escopo deste trabalho está na construção de uma base de conhecimento para a cor de objetos, utilizando apenas informações de cor e baseado em imagens introduzidas como exemplos. 


\subsection{Proposta: construção de classificador nebuloso por aprendizado computacional.}

Considerando o problema de definir classes de conceitos subjetivos, constituídos de instâncias vagas e as características de cores em imagens digitais, este trabalho propõe a construção automática de um classificador por cores, utilizando a teoria dos conjuntos nebulosos. O classificador examina pixels de várias imagens e, levando em conta sua distribuição de cores, particiona-a em classes. Cada classe recebe um rótulo de acordo com o conhecimento disponibilizado por um agente externo. Para isto, a proposta foi concebida seguindo uma abordagem híbrida para o aprendizado, com a seguinte estrutura:

a) um nível não-supervisionado, onde os exemplos vagos são classificados por algum algoritmo de agrupamento nebuloso. Neste módulo, são definidos grupos nãorotulados com a pertinência de cada instância relativa a cada grupo obtido. Podem ser empregados os algoritmos "fuzzy c-means" (HöPPNER, 1999), "fuzzy learning vector quantization" (KARAYIANNIS; BEZDEK, 1997) ou "self-organizing maps" (KOHONEN, 1990), que possuem a característica de identificar grupos no espaço de cores. Os algoritmos de agrupamento requerem uma métrica de similaridade; dentre as diversas propostas (DIDAY; SIMON, 1976), propõe-se aqui a utilização da distância de Mahalanobis, que permite a detecção de grupos alongados no espaço de atributos;

b) um nível supervisionado, onde os grupos definidos são rotulados por algum especialista e selecionados para compor uma base de conhecimento, agregando convenientemente os valores de pertinência obtidos na etapa anterior e construindo as classes de interesse para o posterior reconhecimento.

O nível de supervisão incluído no processo de construção do modelo aqui proposto busca melhorar sua acurácia. Por outro lado, muitos instantes de intervenção vão diminuindo a característica autônoma de construção do classificador. Por isto, busca-se um balanceamento, maximizando a acurácia e minimizando a intervenção do agente supervisor.

Este classificador constrói uma representação das classes de cores na base de conhecimentos, com a respectiva pertinência dos pixels à classe do objeto de interesse, permitindo:

i) uma maior flexibilidade na modelagem das classes, e também

ii) permite a utilização de um aprendizado incremental. 
Neste aspecto, o classificador está disponível para testes com qualquer número de instâncias de treinamento, e, à medida que este treinamento prossegue, as classes construídas podem ser expandidas ou revisadas. No classificador proposto, a representação das classes se dá com base em instâncias, permitindo a atribuição da pertinência de cada elemento à referida classe. $\mathrm{O}$ aprendizado incremental realiza-se pela atualização das pertinências das instâncias, na retomada do treinamento.

Esta proposta atende aos requisitos do problema: lidar com a vaguidade das instâncias individuais e construir classes de conceitos subjetivos, usando a premissa básica que alguns conceitos adquirem significado após a classificação de um conjunto razoável de exemplos individualmente vagos. Esta proposta também atende aos requisitos do domínio em estudo, no caso, a construção de um classificador para detecção de objetos pela cor. Um pixel individualmente apresenta a propriedade cor, que é classificada de maneira vaga. Um conjunto de tais pixels define, no espaço de atributos (neste caso, o espaço de representação de cores), as cores $A, B, C, \ldots$, modeladas de forma supervisionada via classes de pixels obtidas.

É importante salientar que o método proposto executa a detecção de objetos na cena única e exclusivamente pela cor. Pode ser parte de uma metodologia maior, que complete o reconhecimento através de análises morfológicas do conteúdo da imagem. Este classificador comporta-se como um filtro que reduz o espaço de dados ao selecionar apenas os pixels da cor de interesse, agilizando o processamento morfológico executado a posteriori.

O modelo de construção do classificador aqui proposto pretende explorar, no âmbito do aprendizado computacional:

- como atribuir supervisão, ou não, aos níveis do conhecimento necessários no processo de construção do classificador;

- como ponderar melhor a combinação dos grupos em classes, utilizando o conhecimento sobre o domínio;

- como generalizar adequadamente o modelo aprendido do conceito, para ampla aplicação.

\subsection{Contribuições}

A principal contribuição do trabalho aqui proposto é desenvolver uma metodologia de aprendizado de conceitos subjetivos a partir de instâncias vagas, com o tratamento dado 
pela teoria dos conjuntos nebulosos, para aplicação em tarefas de classificação de objetos pela cor. Neste tipo de aplicação, as instâncias são pixels, de coordenadas bem definidas em algum espaço de cores (p.ex., RGB), e que apresentam um conceito nebuloso: o nome da cor.

A originalidade da proposta está nos seguintes pontos:

1. aprendizado híbrido, combinando o paradigma de aprendizado não-supervisionado com o supervisionado;

2. supervisão no nível das classes, não no nível de instâncias, aliviando o custo de rotulação por um especialista;

3. agregação supervisionada dos grupos para formação das classes, dirigindo a aplicação dos operadores de agregação, através de pesos relativos;

4. generalização automática do conceito aprendido.

Como contribuições secundárias, relata-se:

- a combinação das pertinências das instâncias para o caso de aprendizado incremental, onde a classe aprendida é preservada para os futuros treinamentos, de onde pode haver revisão da mesma. Mantém-se a informação nebulosa na representação das classes, onde a classificação de futuras instâncias é acompanhada de um grau de confiança, dado pela pertinência resultante da agregação realizada na etapa supervisionada;

- a proposta de generalização da base de conhecimento após a etapa de treinamento e antes da etapa de testes e detecção;

- a aplicação da proposta no domínio da visão computacional em uma nova abordagem para modelar a cor da pele, por aprendizado incremental nebuloso.

\subsection{Organização deste trabalho}

O texto subseqüente está organizado em duas partes:

Parte I - Bases conceituais: dedicada a relacionar os conceitos preliminares necessários para a formulação da proposta. No capítulo 2, é apresentado um perfil geral para 
reconhecimento de padrões. No capítulo 3, os fundamentos da teoria dos conjuntos nebulosos, agrupamentos e agregação são fornecidos. No capítulo 4, os paradigmas e estratégias de aprendizado computacional são descritos, com vistas à construção autônoma das classes.

Parte II - Classificador proposto: nesta parte, o modelo é descrito com base nos requisitos do problema, e os resultados experimentais obtidos são mostrados. O capítulo 5 delineia o perfil geral do modelo de construção do classificador, integrando as bases conceituais utilizadas. No capítulo 6, uma arquitetura funcional do modelo é apresentada, detalhando as tarefas realizadas em cada etapa. No capítulo 7 são mostrados os resultados obtidos para o caso específico de classificação de pixels em cores da pele.

O capítulo 8 é dedicado a considerações finais sobre a tese, e a proposta de trabalhos futuros. 


\section{Parte I}

CONCEITOS FUNDAMENTAIS 


\section{RECONHECIMENTO DE PADRÕES: CLASSIFICAÇÃO}

Reconhecimento de padrões é definido de maneiras diferentes, de acordo com a área de estudo. No escopo computacional, Duda, Hart e Stork (2000) caracterizam reconhecimento de padrões como

\footnotetext{
"a área relacionada ao reconhecimento de regularidades significativas em ambientes ruidosos ou complexos, através de máquinas".
}

Uma definição mais pragmática é dada por Bezdek e Pal (1992):

"reconhecimento de padrões é a busca de estruturas em dados".

O reconhecimento de padrões utiliza o processo de classificar objetos por categorias (classes). Um padrão caracteriza uma dada classe, logo, reconhecer um padrão é identificar a classe à qual um dado objeto pertence. De acordo com a aplicação, objetos podem ser imagens, sinais temporais, ou mais geralmente, quaisquer medidas associadas a conceitos do mundo real. O reconhecimento de padrões é uma área de estudo científico de natureza inexata, que admite abordagens diferentes, muitas vezes dependentes do problema. Muitas destas abordagens são complementares, outras são concorrentes, e freqüentemente retornam uma solução aproximada para o problema.

O reconhecimento de padrões até os anos 60 estava mais relacionado às pesquisas da área de estatística, mas, com o crescente aumento da utilização da computação aliada ao desenvolvimento da automação industrial, tornou-o uma das ferramentas essenciais nas aplicações e na pesquisa moderna em engenharia (THEODORIDIS; KOUTROUMBAS, 1999). De forma intensa nos dias atuais, o reconhecimento de padrões é parte integrante dos sistemas inteligentes concebidos para suporte à decisão.

Algumas áreas de aplicação que se utilizam do reconhecimento de padrões, dentre muitas, são: 
- reconhecimento óptico de caracteres - OCR, que permite o isolamento e a identificação de caracteres numéricos, alfanuméricos e até mesmo simbólicos, a partir de imagens registradas principalmente em papel;

- reconhecimento da fala e do locutor: partindo do sinal elétrico coletado por microfones, são identificados padrões de timbre, volume, freqüência e velocidade que caracterizam um locutor, e também os padrões característicos associados a fonemas, que por sua vez permitem o reconhecimento de palavras, no comando de sistemas pela voz;

- diagnóstico auxiliado por computador: informações provenientes de imagens de raios-X, tomografias, ultrassom, eletrocardiogramas, eletroencefalogramas, microscopia, e outros sinais resultantes de exames diversos, geram padrões de doença ou normalidade. Tanto na área médica como na área de materiais, ajudam a identificar estruturas intactas ou alteradas por algum evento físico ou fisiológico;

- identificação pessoal: muitos dados biométricos, como as impressões digitais, as linhas da íris ocular, timbre de voz, expressões faciais e até mesmo o modo de andar das pessoas têm sido estudados e organizados em classes;

- taxonomia biológica, na classificação de seres vivos em divisões hierárquicas: reinos, classes, filos, gênero, espécie;

- visão de máquinas: é uma área de aplicação dos métodos de reconhecimento de padrões por excelência, estendendo a tarefa de processar imagens coletadas em tarefas de análise das cenas. Estas abrangem localização de pessoas, objetos, peças, ferramentas; inspeção industrial; identificação de áreas urbanas, tipos de vegetação, mananciais hídricos por imagens de satélite; navegação autônoma; e várias outras.

\subsection{Modelagem do processo de reconhecimento}

O reconhecimento de padrões, em relação ao tipo de dados tratados e informação extraída, apresenta duas grandes vertentes: a) tratamento numérico e b) tratamento sintático ou estrutural. Este último ainda está em franco desenvolvimento, com abordagens variadas, e sua conceituação básica pode ser vista em Pavlidis (1977) e Fu (1982).

Bezdek e Pal (1992) caracterizam o reconhecimento numérico como um processo que integra quatro fases: 
i) descrição do processo: onde são definidos os objetos de interesse e relações entre eles, quando estas relações puderem ser diretamente observadas;

ii) análise dos atributos: os atributos do objeto, relevantes para o problema em questão, são selecionados e é escolhida a representação mais adequada para eles;

iii) análise de agrupamentos: uma vez escolhidos os atributos dos objetos e sua representação, a análise dos agrupamentos procura identificar similaridades entre os objetos, revelando grupos que contenham valores de atributos comuns entre si. Em muitos domínios de aplicação, a classificação é executada nesta fase através da rotulação dos grupos, porém as classes necessitam ser identificadas e rotuladas por um agente externo;

iv) construção do classificador: é a fase onde as classes são constituídas, e onde são definidas as regras para identificação de qualquer objeto desconhecido, dados os atributos escolhidos na fase $i$.

O desenvolvimento de um modelo de reconhecimento de padrões, em si, pode revelar uma alta dependência entre as quatro fases, ou mesmo prescindir de algumas delas. Em geral, estas fases são operacionalmente detalhadas da seguinte forma:

1. Os dados físicos são escolhidos e identificados como variáveis que possam exprimir relações significativas no modelo.

2. Os dados são coletados por humanos ou sensores. Dados numéricos podem ser valores de atributos ou relações de similaridade (dados relacionais), ou ainda, descrições simbólicas dos valores dos atributos.

3. Busca-se alguma estruturação nos dados, para fundamentar hipóteses que descrevem o processo em análise e relações entre variáveis. Esta estruturação pode ser obtida por agrupamentos ou rotulação prévia (dados de exemplos).

4. As hipóteses são expressas de modo formal por equações, regras e algoritmos que propõem um modelo para o processo em análise. Aspectos teóricos do modelo são discutidos para um aumento da compreensão do processo.

5. O modelo é testado com dados de rótulos conhecidos. O desempenho, estabilidade, eficiência e eficácia são avaliados nesta etapa, e correções propostas, com reajuste das etapas anteriores. 
6. O modelo é incorporado a um sistema através de "hardware" e "software". Com isto, é possível classificar, predizer, estimar e controlar elementos do processo em análise e dos seus subprocessos.

Cada uma das quatro fases do processo de reconhecimento de padrões é comentada a seguir.

\subsubsection{Descrição do processo.}

A primeira consideração, na modelagem de um sistema para reconhecimento de padrões, consiste na representação dos objetos. No tratamento sintático, os objetos são decompostos em relações estruturais entre suas partes, que são representadas por algumas sentenças, gramáticas e autômatos. O tratamento numérico implica na descrição dos objetos em forma de vetores de propriedades, de atributos ou de características. Aqui será escolhida a denominação atributos, que expressa bem o fato de um objeto ser caracterizado pelos respectivos valores das propriedades em consideração.

$\mathrm{Na}$ descrição do processo, tais objetos podem estar rotulados, ou seja, cada vetor classificado em uma descrição previamente conhecida, ou não-rotulados, se apresenta tãosomente a representação numérica. Se os objetos tiverem rótulo prévio, o processo de classificação em padrões é mais imediato. Caso contrário, o agrupamento dos objetos por relações de semelhança possibilita sua classificação posterior.

\subsubsection{Atributos e vetores de atributos.}

Posto que o reconhecimento dos padrões dos objetos requer dados expressos em uma dada representação, então utilizar a representação adequada é importante no processo de

reconhecimento. É, inclusive, uma preocupação anterior ao processo de reconhecimento em si. Esta representação se faz pela escolha dos atributos relevantes dos objetos. Seres humanos escolhem e denominam quais atributos dos objetos serão analisados. A escolha mais comum é a representação numérica dos objetos, que podem ser representados em diferentes métricas, unidades ou escalas. Representações simbólicas também são úteis, requerendo uma linguagem mais apropriada para manipulá-las.

Seja um conjunto de $N$ dados com sua representação $\mathbf{X}=\left\{\mathbf{x}_{1}, \mathbf{x}_{2}, \ldots, \mathbf{x}_{N}\right\}$, onde cada um dos dados $\mathbf{x}_{k}$ do conjunto $\mathbf{X}$ possui $\ell$ atributos. Muitos atributos são unidimensionais: idade, altura, peso, comprimento, intensidade, temperatura, débito, custo, fator de qualidade, mas há outros, como o timbre de um som (p.ex. voz), cores (p.ex. de cabelos, 
da pele, olhos, mar, vegetação), atributos morfológicos de objetos, entre outros, que são melhor descritos por mais de uma variável. Mais ainda, é freqüente ocorrer que um objeto (p.ex. casa) seja modelado através da combinação de vários atributos unidimensionais, gerando um atributo específico multidimensional.

No caso mais geral, cada atributo do $k$-ésimo dado é descrito por um vetor, geralmente representado por uma matriz coluna de $\ell$ componentes (aqui transposta):

$$
\mathbf{x}_{k}=\left[\begin{array}{llll}
x_{k 1} & x_{k 2} & \ldots & x_{k \ell}
\end{array}\right]^{T}
$$

onde cada componente depende da representação do atributo em questão.

Por exemplo, dada uma lista de pessoas com os respectivos atributos, descritos na tabela 2.1, elas podem ser associadas em classes de maneiras diferentes, conforme o atributo em foco. Neste exemplo, cada pessoa apresenta um vetor de atributos, respectivamente, numérico, binário e dois nominais. Por exemplo, para a pessoa $A$ :

$$
\mathbf{x}_{\mathrm{A}}=\left[x_{A 1}=1,54 \quad x_{A 2}=\text { 'falso' } \quad x_{A 3}=\text { 'masculino' } \quad x_{A 4}=\text { 'parda' }^{T}\right.
$$

Tabela 2.1: Exemplo de pessoas e atributos.

\begin{tabular}{ccccc}
\hline Pessoa & Altura $(\mathrm{m})$ & Usa óculos & Sexo & Cor da pele \\
\hline A & 1,54 & falso & masculino & parda \\
B & 1,78 & verdadeiro & masculino & parda \\
C & 1,83 & falso & feminino & parda \\
D & 1,62 & verdadeiro & masculino & parda \\
E & 1,80 & verdadeiro & masculino & parda \\
\hline
\end{tabular}

O escopo das variáveis que representam os atributos é chamado espaço de atributos. No exemplo dado, $x_{1}$ pertence ao conjunto das variáveis reais, $x_{2}$ pertence ao conjunto das variáveis binárias, $x_{3}$ e $x_{4}$ pertencem ao conjunto das variáveis nominais. As variáveis nominais não apresentam necessariamente uma relação de ordem. Outros escopos de valores de atributos são os ordinais e os proporcionais. As variáveis reais e as inteiras são descritas como uniformemente espaçadas (JAIN; MURTY; FLYNN, 1999) e (ANDERBERG, 1973).

A classificação mostrada na tabela 2.2 varia conforme o atributo de interesse. Usando operações entre conjuntos, novas classes podem ser obtidas (GENESERETH; NILSSON, 
1987). Por exemplo,

Altura $($ Classe 2) $\cap$ Usa óculos $($ Classe 2) $\cap$ Sexo $($ Classe 1) $=\{$ pessoa $B ;$ pessoa $D\}$

Tabela 2.2: Uma possível classificação de pessoas, a partir da tabela 2.1

\begin{tabular}{cccc}
\hline Atributo em foco & Classe 1 & Classe 2 & Classe 3 \\
\hline Altura & C, E & B, D & A \\
Usa óculos & A, C & B, D, E & - \\
Sexo & A, B, D, E & C & - \\
\hline
\end{tabular}

A ausência do atributo cor da pele, na classificação da tabela 2.2, pode ser interpretada das seguintes maneiras:

- a cor da pele, sendo a mesma para todos, não oferece nenhuma informação que particione o conjunto universo em classes;

- a cor da pele pode não ser relevante para a análise em questão, é um atributo que não foi incluído no procedimento de classificação.

Pode-se notar ainda na tabela 2.2 dois atributos de classificação vaga, imprecisa:

- a medida da altura: embora sendo uma instância bem definida (usando um sensor com precisão de $1 \mathrm{~mm}$ ), está atribuída a uma das classes, 1 (rotulada alta), 2 (mediana) ou 3 (baixa), que apresentam definição nebulosa (e na tabela 2.2 aparece na classe onde possui maior pertinência);

- a cor da pele: um colorímetro ${ }^{1}$ pode captar uma medida da cor (expressa em proporções de cores primárias) com alguma precisão predeterminada, logo, uma instância bem definida. Mas, a definição de parda é vaga - quais os limites desta classe? Com quais outras classes faz fronteira?

Análise dos atributos. Consiste na exploração e "melhoria" dos dados coletados $\mathbf{x}_{k}$. Diversas operações de pré-processamento podem ser efetuadas para esta melhoria, como alterações de escala, normalização, filtragem, transformações de domínio, suavização e realce, análise de componentes principais (PCA) e várias outras. Existem questões básicas

\footnotetext{
${ }^{1} \mathrm{Um}$ aparelho que mede a radiação luminosa, refletida ou difundida por um objeto. Esta é decomposta em três cores primárias e sua composição analisada, sendo expressa em unidades relativas aos espaços de representação de cores
} 
sobre como estabelecer os vetores de atributos para os objetos analisados no processo de reconhecimento:

- como os atributos são identificados? Como os vetores são gerados? No exemplo dado, foram escolhidos apenas quatro atributos sobre pessoas, dentre muitos possíveis. Na prática, a escolha dos atributos adequados depende fortemente do problema em questão, e ela não é trivial. Então, uma etapa de geração de tais vetores deve ser considerada, antes do processo de classificação em si;

- uma investigação cuidadosa dos atributos disponíveis (incluindo possíveis transformações, como pré-processamento) podem melhorar a eficácia e o desempenho do processo de classificação;

- qual é o melhor número $\ell$ de atributos a ser empregado? Também está relacionado à etapa de geração dos vetores, e também é fortemente dependente do problema. $\mathrm{Na}$ prática, um número de atributos maior do que $\ell$ é gerado, permitindo uma "melhor escolha" dos atributos necessários para o tipo de classificação desejado, gerando alguns outros irrelevantes. Blum e Langley (1997) tratam o problema dos atributos relevantes e discutem algumas abordagens de seleção. Retornando ao exemplo dado na tabela 2.1, três atributos mencionados (altura, usa óculos e sexo) podem ser relevantes para classificar candidatos ao serviço militar, mas não o são (ou são insuficientes) para classificar candidatos a modelos de moda.

\subsubsection{Análise de agrupamentos.}

A finalidade é identificar subgrupos naturais, dividindo o espaço de atributos e agrupando dados $\mathbf{x}_{k}$ com algum grau de similaridade. Esta similaridade é função direta dos atributos selecionados para análise, portanto, uma alteração na estratégia de seleção reflete-se no resultado do agrupamento. Como geralmente não é fornecida nenhuma informação prévia a respeito das estruturas das classes, a divisão em grupos baseia-se em algumas assunções ou critérios, podendo inclusive gerar alguns grupos sem significado ou sem utilidade.

O particionamento do espaço de atributos deve apresentar as seguintes propriedades:

- homogeneidade entre dados do mesmo grupo, isto é, o mais similares possível;

- heterogeneidade entre grupos diferentes, isto é, dados de grupos diferentes com menor similaridade entre si. 
O conceito de similaridade depende fortemente da representação dos atributos e da métrica empregada para medi-la. A métrica mais intuitiva é a distância euclidiana, outras métricas são discutidas em função do domínio e da natureza dos dados (GOWER; LEGENDRE, 1986). Mesmo quando os atributos são representados por valores nominais (ex: vermelho, azul; automóvel, caminhão; belo, feio), valores numéricos podem ser atribuídos através de assunções adicionais, ou até mesmo pela definição de subatributos. Ex.: automóvel tem dois eixos, peso leve; belo se forma for arredondada (atributo "curvatura"), cor dada pela composição percentual das cores primárias; e assim por diante.

Com a teoria dos conjuntos nebulosos ( "fuzzy sets") proposta por Zadeh (1965), um objeto pode ter vários graus de similaridade respectivamente a classes diferentes do mesmo espaço de atributos. Assim, um agrupamento convencional é binário, levando um objeto a pertencer a um determinado grupo, e a não pertencer aos outros. Um agrupamento nebuloso admite fronteiras nebulosas entre os grupos, de modo que eles se sobreponham parcial ou até totalmente. Os grupos nebulosos permitem o tratamento mais adequado de objetos vagos, de classificação incerta, minimizando e até evitando erros de classificação. O capítulo 3 trata dos conjuntos nebulosos com maior profundidade, dado o problema abordado aqui nesta tese.

\subsubsection{Construção do classificador.}

É a parte mais complexa de um modelo de reconhecimento de padrões. Um classificador determina uma partição, convencional ou nebulosa, do espaço de atributos.

A diferença fundamental entre agrupamento e classificação é que, naquele, as classes são rotuladas após a definição dos grupos, enquanto que um classificador (uma vez construído) rotula qualquer dado no espaço inteiro de atributos (BEZDEK; PAL, 1992). É importante ressaltar que o agrupamento revela similaridades entre objetos via atributos. Classificadores são geralmente, mas nem sempre, projetados com dados pré-rotulados, e as funções de partição podem ser explícitas (funções analíticas, regras, tabelas de consulta) ou implícitas (ex. "perceptrons", vizinhos mais próximos). Um exemplo de classificador que não seja projetado com dados pré-rotulados são as regras de inferência em controle nebuloso, dadas por algum especialista humano conhecedor do processo.

Um processo de reconhecimento de padrões está relacionado a uma etapa de classificação. Muitas vezes, ocorre que a construção do classificador não é suficientemente acurada, pois quase sempre é dependente dos objetos disponíveis em um dado espaço de atributos. Assim, um novo objeto pode ser incorretamente classificado, exigindo uma re- 
visão dos parâmetros que descrevem o classificador. Os objetos que possibilitam o ajuste dos parâmetros do classificador são chamados dados de treinamento, representados pelos seus vetores de atributos. Enquanto os dados são representados por vetores de atributos, o classificador representa e armazena o conhecimento através de algoritmos, regras de decisão ou tabelas de consulta.

O processo de buscar a melhor partição do espaço de atributos em classes denomina-se construção do classificador. Formalmente,

"dados os exemplos $\mathbf{x}_{k}$, representados pelos atributos $\mathbf{x}_{k \ell}$, e a classe $\omega_{i}$ associada a cada exemplo, a construção do classificador procura a melhor função de mapeamento $f$, de forma que $\omega_{i}=f\left(\mathbf{x}_{k}\right)$ " (BEZDEK; PAL, 1992).

Pode-se pensar em classificação como uma forma de regressão tal que, nesta, $f$ seja contínua, e na classificação, $f$ é discreta - categorias ou classes (WEISS; INDURKHYA, 1995).

Aqui também existem questões básicas sobre o projeto do classificador, após decidir os atributos julgados relevantes para a tarefa de classificação:

- como construir o classificador? No exemplo mostrado pela fig. 2.1, uma curva de decisão foi criada para particionar o espaço de atributos e permitir a classificação de algum novo objeto que possa surgir. Esta curva é adequada? Realiza bem a tarefa de classificação? Uma linha reta, de parametrização mais simples, poderia ser adotada no lugar? A preocupação aqui refere-se à adoção de um critério ótimo para que o classificador atenda às metas do problema;

- resolvida a questão de modelagem do classificador, como avaliar seu desempenho? Qual sua taxa de erro? Objetos escolhidos sob certos critérios constituem o chamado conjunto de teste, onde a classe de cada objeto é previamente conhecida e o resultado fornecido pelo classificador é comparado com o resultado desejado para cada objeto.

Construção autônoma do classificador. Um modelo de construção autônoma do classificador necessita das teorias de aprendizado computacional. No presente trabalho, a construção do classificador usando as teorias de aprendizado computacional está voltada à organização do conhecimento. Este conhecimento consiste em classificar corretamente instâncias de conceitos vagos, e é adquirido de acordo com as fases envolvidas no reconhecimento de padrões, mais um tratamento adequado da vaguidade intrínseca das instâncias. 
A organização deste conhecimento está na capacidade de um classificador representá-lo e armazená-lo para ser reutilizado.

A classificação é uma tarefa de aprendizado básica e essencial. Conforme Mitchell (1997), o desempenho do classificador deve melhorar com o treinamento. Logo, aprender consiste em classificar corretamente os dados, com desempenho cada vez melhor. Classes obtidas através de dados utilizados como exemplos (ou não) definem os padrões, e o reconhecimento de novos exemplos se dá por algum processo comparativo. Assim, o classificador concebido sob os paradigmas de aprendizado em máquinas irá gerar classes cada vez mais precisas, através de ajustes no modelo. Monard (1997) e colegas compilaram alguns dos métodos de aprendizado computacional, classificando-os como:

a) simbólico: voltado à construção de representações simbólicas de um conceito, através da análise dos exemplos e contra-exemplos. Estas representações são dadas por expressões lógicas, árvores de decisão, regras de produção ou redes semânticas;

b) estatístico: classificadores que operam sob este paradigma têm a assunção que os valores dos atributos seguem uma distribuição normal. Classificadores baseados na teoria de decisão de Bayes se enquadram nesta categoria. Em geral, os vetores de atributos não são independentes, e as classes estão relacionadas entre si;

c) baseado em instâncias: novos dados são classificados utilizando dados similares típicos de cada classe. Além da escolha dos dados típicos, outros elementos deste paradigma são a função de similaridade, que informa o grau de separação das classes, e a função de classificação, que decide a qual classe um dado novo deve pertencer (AHA; KIBLER; ALBERT, 1991). É o mais usado;

d) conexionista: cujo modelo típico é o das redes neurais, que são inspiradas no modelo biológico do sistema nervoso. Sua arquitetura baseia-se em unidades altamente interconectadas. O classificador resultante deste paradigma é construído com uma representação binária ou contínua dos dados, o número correto de unidades de entrada e saída e o ajuste das conexões entre as unidades (HAYKIN, 1999);

e) genético: paradigma derivado do modelo evolucionário de aprendizado. O classificador é formado por elementos que competem para realizar a tarefa de predição. Os elementos com maior taxa de erro ("mais fracos") são descartados, enquanto 
que os mais fortes se reproduzem com algumas variações ("mutações"). A população destes elementos evolui com o tempo ("gerações") até que a solução do problema esteja arbitrariamente próxima da solução ótima (DEJONG, 1988) e (FREITAS; KIRNER, 1992).

O esquema proposto neste trabalho está relacionado com a construção do classificador baseado em instâncias, por isto, este método de aprendizado é discutido com mais detalhes no capítulo 4 .

\subsection{Discriminação entre classes}

Supõe-se agora um número finito de objetos, descritos pelos atributos arbitrários $m$ e $n$, e um gráfico com os valores destes atributos (para cada objeto), mostrado na fig. 2.1. Nesta, uma curva de decisão $b$ executa a função de um classificador, separando o espaço de atributos em duas regiões, correspondentes às duas classes que distinguem os objetos dados.

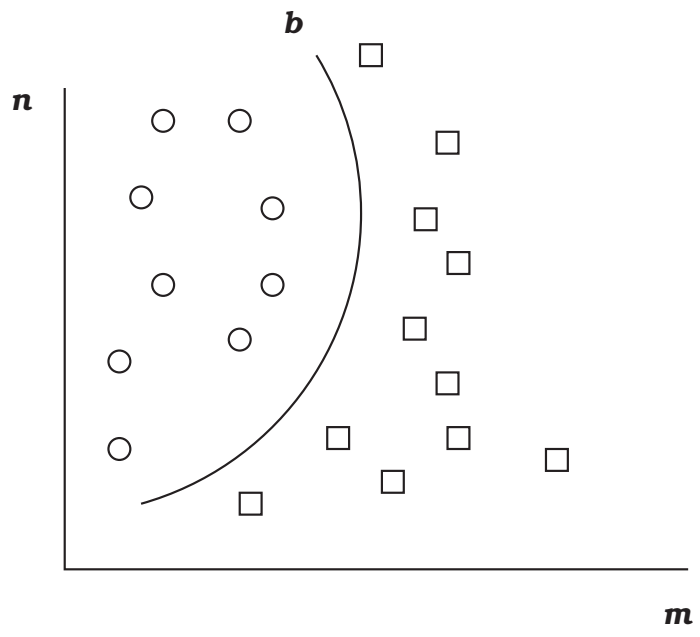

Figura 2.1: Gráfico representando atributos de objetos e uma curva de decisão.

A curva de decisão pode ser representada por alguma descrição funcional, como, por exemplo, $n=\alpha m^{2}+\beta m+\gamma$, onde os parâmetros $\alpha, \beta$ e $\gamma$ são ajustados para a melhor partição do espaço de atributos em duas classes. Outra forma de representação é através de uma tabela de valores que descreva esta fronteira. Esta curva pode ser generalizada em uma hipersuperfície que separa o espaço $n$-dimensional, com $n+1$ parâmetros. Quanto maior o número de classes existentes, mais numerosas e complexas ficam estas superfícies, de sorte que freqüentemente se interceptam. 
Uma vez definido este classificador, qualquer novo objeto será analisado pelos valores de seus atributos. A posição do objeto relativamente às fronteiras de decisão define a classe a que pertence. Assim, no caso de cada objeto pertencer somente a uma classe, define-se a chamada partição "hard" ou convencional.

No entanto, a classificação pode deixar de ser binária, para levar em conta qual o grau de similaridade de um objeto em relação às classes que compõem o universo de atributos. Havendo graus de similaridade diferentes de um objeto em relação a várias classes, a partição é chamada nebulosa ou pseudo-partição (CHI; YAN; PHAM, 1996) e (HöPPNER, 1999).

Define-se a partição do conjunto $\mathbf{X}$ de $N$ dados em $c$ classes $\omega_{1}, \omega_{2}, \ldots, \omega_{c}$ de forma a satisfazer três condições:

$$
\begin{aligned}
& \text { a) } \omega_{i} \neq \emptyset, \quad i=1, \ldots, c \\
& \text { b) } \bigcup_{i=1}^{c} \omega_{i}=\mathbf{X} \\
& \text { c) } \omega_{i} \cap \omega_{j}\left\{\begin{array}{l}
=\emptyset, \quad \text { se classificação binária } \\
\neq \emptyset, \quad \text { se classificação nebulosa }
\end{array} \quad \forall i, j, i \neq j\right.
\end{aligned}
$$

$\mathrm{Na}$ classificação binária, um objeto $\mathbf{x}_{k}$ pertence ou não a uma dada classe $\omega_{i}$. Na classificação nebulosa, o grau de similaridade de $\mathbf{x}_{k} \operatorname{com} \omega_{i}$ é dada por uma função de pertinência $u_{i}$, da forma

$$
u_{i}\left(\mathbf{x}_{k}\right): \mathbf{X} \rightarrow[0,1], i=1, \ldots, c ; k=1, \ldots, N
$$

sujeita aos vínculos

$$
\sum_{i=1}^{c} u_{i}\left(\mathbf{x}_{k}\right)=1
$$

ou seja, a soma das pertinências de um objeto qualquer é 1, em relação aos conjuntos nebulosos que compartilham o espaço de atributos, e

$$
0<\sum_{k=1}^{N} u_{i}\left(\mathbf{x}_{k}\right) \leqslant N .
$$

Cada vetor $\mathbf{x}_{k}$ pertence a mais de uma classe simultaneamente, "com um certo grau $u_{i}$ ". Os valores de pertinência indicam a estrutura do conjunto de dados $\mathbf{X}$, pois dois dados $\mathbf{x}_{1}$ e $\mathbf{x}_{2}$ com pertinências $u_{i}\left(\mathbf{x}_{1}\right) \approx 1$ e $u_{i}\left(\mathbf{x}_{2}\right) \approx 1$, relativos à classe $\omega_{i}$ são considerados muito similares (WINDHAM, 1982). 


\subsection{Conclusão do capítulo}

Foi ressaltado que um modelo de reconhecimento de padrões passa por um estágio de classificação dos objetos. Esta classificação é altamente dependente do problema a ser resolvido, logo, uma fase anterior igualmente importante é a definição dos atributos associados aos objetos.

O trabalho aqui realizado concentra-se na construção do classificador de objetos em imagens digitais, através da cor. O atributo cor é representado por uma tripla de valores, reais ou inteiros, conforme o espaço de representação (RGB, YUV, HSI, ou outro). Portanto, a descrição do processo e a escolha de atributos ficam definidos, de acordo com as fases de reconhecimento de padrões. A análise completa dos atributos permanece em discussão, a decidir se há um espaço de representação de cores mais adequado e que torne a construção do classificador mais direta ou eficiente.

Objetos pertencentes a categorias de definição vaga, mesmo que seus atributos não o sejam, podem ser melhor tratados com a lógica nebulosa. No caso, uma determinada cor não é um atributo nebuloso, pois fica univocamente definida por três valores no espaço de representação. Porém, é nebulosa a classe à qual se associa o nome de uma determinada cor. Dentro deste panorama, a cor, sendo um atributo vago, passa a ter um tratamento formal adequado. A teoria dos conjuntos nebulosos será discutida no próximo capítulo. 


\section{CLASSIFICAÇÃO INCERTA E TEORIA DOS CONJUNTOS NEBULOSOS}

A teoria dos conjuntos nebulosos foi introduzida por Zadeh (1965) como uma nova forma de representar conceitos vagos na comunicação humana. Conceitos como "homens altos", "garotas bonitas", "números muito maiores que 1", "freiar bem antes", "estacionar longe da calçada", "longa duração", definem conceitos imprecisos que não podem ser tratados como conjuntos convencionais. Formalmente, a teoria nebulosa foi concebida como uma generalização da teoria convencional dos conjuntos, fornecendo a instrumentação básica necessária ao estender a definição de operações como pertinência de um elemento, união e intersecção, complemento, continência, leis de DeMorgan, leis distributivas, convexidade e operações algébricas entre conjuntos. Posteriormente, Zadeh ampliou seu trabalho ao propor um modo aproximado, e ainda assim eficaz, de descrever o comportamento de sistemas muito complexos, como os sistemas descritos pelas ciências humanas (ZADEH, 1973). Nele, é enfatizado que as técnicas quantitativas convencionais não são adequadas para lidar com sistemas de complexidade comparável aos humanísticos. Tais sistemas são caracterizados por não serem conhecidos em detalhes, ou por serem modelados empiricamente, ou por terem atributos definidos de maneira vaga.

A modelagem de agentes inteligentes e a construção de classificadores com a teoria dos conjuntos nebulosos permite que regras heurísticas possam capturar as estratégias de decisão relacionadas à ação ou à classificação. Seres humanos conseguem definir estratégias de ação sobre conceitos vagos, utilizando regras condicionais: "se hoje estiver muito frio, usarei uma blusa mais grossa". É evidente que a temperatura do ambiente e a espessura da blusa (ou até o material que a compõe) não estão especificadas nesta regra, mas armazenadas em alguma base de conhecimento humana, cujas "unidades de medida" ainda não são ${ }^{\circ} \mathrm{C}$ ou ${ }^{\circ} \mathrm{F}$, nem tampouco algum múltiplo do milímetro. A modelagem dos conjuntos nebulosos "muito frio" e "blusa mais grossa", usando como domínio as medi- 
das de temperatura, espessura e especificação do material empregado, é que possibilita o transporte das regras heurísticas do senso humano para o domínio da computação.

Incerteza: probabilidade ou vaguidade. A questão de um exemplo apresentar um conceito vago (nebuloso) difere da questão probabilística. Na ilustração clássica do sorteio das bolas, diz-se por exemplo que, em um conjunto de 6 bolas vermelhas e 3 amarelas, há a probabilidade de $1 / 3$ de sair uma bola amarela. No entanto, assim que a bola é sorteada, a probabilidade se dissipa: a bola é (ou não é) amarela. A possibilidade de uma bola ser de cor amarela, considerada individualmente, é uma medida booleana. Probabilidade é um modo de tratar a incerteza proveniente da falta de informação. A probabilidade varia de 0 (incerteza absoluta) a 1 (certeza absoluta) de um evento estar associado a um conceito (por exemplo, uma ocorrência).

A vaguidade, por sua vez, mede quanto uma instância (ou valor numérico) se ajusta com um conceito (ou significado ideal). Ela não se altera com o tempo, sendo uma propriedade intrínseca de um evento ou objeto. A possibilidade refere-se a um evento (ou propriedade de um objeto) poder ser verificado em relação a um conceito ou afirmação. A teoria dos conjuntos nebulosos - "fuzzy sets" - é tratada como uma espécie possibilística de vagueza dos elementos em relação aos conjuntos.

Exemplo ilustrativo dado em Bezdek e Pal (1992): suponha que você esteja no deserto com duas garrafas marcadas como $A$ e $C$. No rótulo da garrafa $A$ lê-se: "a probabilidade desta garrafa conter líquido potável é 0,91". Na garrafa $C$, "o grau de pertinência do conteúdo desta garrafa em relação ao conjunto dos líquidos potáveis é 0,91”. Qual das duas você escolheria para beber? O valor de pertinência significa que o conteúdo de $C$ tem um grau de 0,91 de similaridade com um líquido potável, podendo ser, por exemplo, cerveja ou água tônica. A probabilidade significa que, dentre um conjunto de garrafas observadas, 91 em 100 possui um líquido potável, e as outras 9 em 100 podem conter um líquido mortal. Continuando a idéia de observação, suponha que você examinou os conteúdos de $A$ e $C$, e descobriu conterem ácido clorídrico e água de batata, respectivamente. Após a observação, o valor de pertinência de $C$ permanece, enquanto que a probabilidade da afirmação sobre $A$ cai para zero.

\subsection{Conjuntos nebulosos}

Os conjuntos clássicos contêm elementos que satisfazem propriedades precisas. Por exemplo, o conjunto de números reais entre 9 e 10 é descrito por um conjunto 
$\mathbf{H}=\{x \in \mathbb{R} \mid 9 \leqslant x \leqslant 10\}$, ou, em termos de uma função de pertinência $u_{\mathbf{H}}(x)$ dada por:

$$
u_{\mathbf{H}}(x)= \begin{cases}1 ; & \text { se } 9 \leqslant x \leqslant 10 \\ 0 ; & \text { em outros casos. }\end{cases}
$$

Todo número real $x$ está ou não em $\mathbf{H}$. Pelo fato de que $u_{\mathbf{H}}(x)$ mapeia todos os números reais em uma imagem de dois pontos $\{0,1\}$, os conjuntos convencionais correspondem a uma lógica bivalorada: sim ou não, 0 ou 1, preto ou branco, e assim por diante.

Os conjuntos nebulosos, de outra forma, contêm elementos que apresentam atributos imprecisos, de graduação variável. Por exemplo, "aproximadamente 9,5". A interpretação comum é que o número 9 é mais próximo de 9,5 do que o número 11, isto sugere uma avaliação gradativa da pertinência para o conjunto de números próximos ao 9,5. O grau de pertinência deste número para o conjunto "aproximadamente 9,5" é 1, e decresce simetricamente para números eqüidistantes acima ou abaixo. A função de pertinência ficaria descrita neste caso como uma representação convexa, com máximo em 9,5:

$$
u_{\mathbf{H}}(x)= \begin{cases}1-|x-9,5| ; & \text { se } 8,5 \leqslant x \leqslant 10,5 \\ 0 ; & \text { em outros casos. }\end{cases}
$$

Devido ao conceito de nebulosidade associado ao conjunto "aproximadamente 9,5 ", não há uma função de pertinência única. A questão de decidir quais os valores que tornam esta pertinência nula fica em aberto: se a função deve decair assintoticamente, ou abruptamente a partir de uma distância do ponto 9,5. Logo, é facultado ao agente modelador de tal conjunto decidir o formato da função, baseado nas propriedades necessárias para este conjunto, no contexto da aplicação que está sendo desenvolvida.

\subsubsection{Relações e operações}

Zadeh (1965) definiu as operações básicas sobre conjuntos nebulosos através de relações funcionais entre as respectivas funções de pertinência da seguinte forma:

sejam os conjuntos nebulosos $\mathbf{A}$ e $\mathbf{B}$ definidos pelas suas funções de pertinência $u_{\mathbf{A}}(x)$ e $u_{\mathbf{B}}(x)$. São definidas as seguintes operações e relações:

Igualdade:

$$
\mathbf{A}=\mathbf{B} \Leftrightarrow u_{\mathbf{A}}(x)=u_{\mathbf{B}}(x)
$$


Continência:

$$
\mathbf{A} \subset \mathbf{B} \Leftrightarrow u_{\mathbf{A}}(x) \leqslant u_{\mathbf{B}}(x)
$$

Complemento:

$$
\tilde{\mathbf{A}} \Leftrightarrow u_{\tilde{\mathbf{A}}}(x)=1-u_{\mathbf{A}}(x)
$$

Intersecção:

$$
\mathbf{A} \cap \mathbf{B} \Leftrightarrow u_{\mathbf{A} \cap \mathbf{B}}(x)=\min \left(u_{\mathbf{A}}(x), u_{\mathbf{B}}(x)\right)
$$

União:

$$
\mathbf{A} \cup \mathbf{B} \Leftrightarrow u_{\mathbf{A} \cup \mathbf{B}}(x)=\max \left(u_{\mathbf{A}}(x), u_{\mathbf{B}}(x)\right)
$$

Nota-se que as operações de união e intersecção são ambas associativas e comutativas, isto é, $(\mathbf{A} \diamond \mathbf{B}) \diamond \mathbf{C}=\mathbf{A} \diamond(\mathbf{B} \diamond \mathbf{C})$ e $\mathbf{A} \diamond \mathbf{B}=\mathbf{B} \diamond \mathbf{A}$, onde o operador $\diamond$ representa uma ou outra operação.

Zadeh (1965) definiu também as seguintes operações algébricas:

Produto algébrico:

$$
\mathbf{A B} \Leftrightarrow u_{\mathbf{A B}}(x)=u_{\mathbf{A}}(x) \cdot u_{\mathbf{B}}(x)
$$

Soma algébrica:

$$
\mathbf{A}+\mathbf{B} \Leftrightarrow u_{\mathbf{A}+\mathbf{B}}(x)=u_{\mathbf{A}}(x)+u_{\mathbf{B}}(x)
$$

Deve-se enfatizar que tais operações são executadas sobre o mesmo domínio $\{x \in \mathbb{R}\}$. O domínio que dá suporte às funções de pertinência é denominado universo de discurso. Posteriormente, foram propostas outras maneiras de combinar conjuntos nebulosos sobre o universo de discurso, fornecendo suporte a outras necessidades de modelagem (BLOCH, 1996).

\subsubsection{Modificadores de conjuntos nebulosos.}

Um modificador $h$ ("hedge") pode ser visto como um operador que transforma um conjunto nebuloso $\mathbf{A}(u)$, que representa o significado de $u$, em outro conjunto nebuloso $\mathbf{A}(h u) . u$ tem a função de gerar todas as sentenças lingüísticas possíveis para uma variável lingüística. Antecedem um predicado vago (que rotula um conjunto nebuloso) e continuam originando um predicado vago, mas ampliam ou diminuem sua extensão.

Os operadores de modificação atuam nas funções de pertinência $u$, com alguns deles predefinidos (ZADEH, 1973). 
- Concentração.

$$
\operatorname{CON}(\mathbf{A}(u))=u^{2}
$$

usado para definir o modificador linguístico muito.

- Dilatação.

$$
D I L(\mathbf{A}(u))=u^{1 / 2}
$$

usado para definir o modificador linguístico mais ou menos.

- Intensificação de contraste.

$$
I N T(\mathbf{A}(u))= \begin{cases}2 u^{2} & \text { para } 0 \leqslant u \leqslant 0,5 \\ 1-2(1-u)^{2} & \text { para } 0,5 \leqslant u \leqslant 1\end{cases}
$$

usado para definir o modificador linguístico positivamente.

- $\mathrm{O}$ adjetivo "mais": $u^{5 / 4}$;

- $\mathrm{O}$ adjetivo "menos": $u^{3 / 4}$

Por exemplo, se houver a necessidade de enfatizar o conjunto nebuloso que representa o conceito quente, dado por

$$
u= \begin{cases}0,05 T-2, & \text { para } 40 \leqslant u \leqslant 60 \\ 1, & \text { para } u>60\end{cases}
$$

o conceito muito quente é dado por

$$
u= \begin{cases}(0,05 T-2)^{2}, & \text { para } 40 \leqslant u \leqslant 60 \\ 1, & \text { para } u>60\end{cases}
$$

\subsubsection{Operadores de agregação nebulosa}

Os operadores de agregação (ou combinação) nebulosa podem ser definidos sucintamente como aqueles que combinam conjuntos nebulosos (do mesmo universo de discurso) em um único conjunto nebuloso. Logo, a função de pertinência combinada $u$ é uma função das funções de pertinência $u_{i}$ dos conjuntos envolvidos:

$$
u(x)=\Theta\left(u_{1}(x), u_{2}(x), \ldots, u_{n}(x)\right)
$$


O mapeamento desta função permanece normalizado, isto é, $\Theta:[0,1]^{n} \rightarrow[0,1]$ para $n$ conjuntos nebulosos combinados e deve satisfazer os seguintes axiomas (DOMBI, 1982); (BLOCH, 1996) e (DETYNIECKI, 2001):

Axioma 1: $\Theta(0,0,0, \ldots, 0)=0$ e $\Theta(1,1,1, \ldots, 1)=1$. Limites normalizados.

Axioma 2: $\Theta\left(a_{1}, a_{2}, a_{3}, \ldots, a_{n}\right) \leqslant \Theta\left(b_{1}, b_{2}, b_{3}, \ldots, b_{n}\right)$ se $\left(a_{i}, b_{i}\right)$ forem $t$-uplas tal que $a_{i}, b_{i} \in[0,1]$ e $a_{i} \leqslant b_{i}, \forall i \in \mathbb{N}$.

Axioma 3: $\Theta$ é contínua.

Axioma 4: é desejável que os conjuntos a serem agregados tenham a mesma importância, ou influência.

Os operadores de agregação primordiais intersecção e união, definidos por Zadeh (1965) satisfazem ainda:

Axioma 5: $\Theta$ é idempotente: $\Theta(u, u, u, \ldots, u)=u$. A combinação de valores iguais em vários conjuntos leva a um igual valor na agregação.

Os axiomas 1 e 3 são importantes para se obter funções de pertinência resultantes bem comportadas. O axioma 4 tem sido tradicionalmente empregado, mas considerações sobre domínios específicos podem sugerir a designação de pesos das funções que estão sendo combinadas. Se $\Theta$ também satisfizer os axiomas 2 e 5 , então

$$
\min \left(u_{1}, u_{2}, \ldots, u_{n}\right) \leqslant \Theta\left(u_{1}, u_{2}, \ldots, u_{n}\right) \leqslant \max \left(u_{1}, u_{2}, \ldots, u_{n}\right),
$$

o que leva a concluir que todos os operadores de agregação entre a intersecção e a união nebulosas de Zadeh são idempotentes.

Normas e conormas Na teoria dos conjuntos nebulosos, as normas e conormas triangulares desempenham um papel fundamental, fornecendo modelos gerais para operadores de união e intersecção.

A norma triangular (norma-t) expressa a idéia de conjunção, e está associada às operações de intersecção. Possui as seguintes propriedades (KLIR; YUAN, 1995) e (PEDRYCZ; GOMIDE, 1998):

- comutatividade: $u(\mathbf{x}, \mathbf{y})=u(\mathbf{y}, \mathbf{x})$, 
- associatividade: $u_{1}\left(\mathbf{x}, u_{2}(\mathbf{y}, \mathbf{z})\right)=u_{1}\left(u_{2}(\mathbf{x}, \mathbf{y}), \mathbf{z}\right)$,

- condições de contorno: do axioma 1 anterior, $\Theta(0,0,0, \ldots, 0)=0$ e $\Theta(1,1,1, \ldots, 1)=1$, incluindo $\Theta\left(u_{1}, u_{2}, \ldots, 0, \ldots, u_{N}\right)=0$,

onde $\mathbf{x}, \mathbf{y}, \mathbf{z}$ são vetores de atributos.

Como construção formal, definem-se as conormas-t (também denominadas normas$s)$, que são duais às normas-t e estão associadas aos operadores de disjunção. As mesmas propriedades já descritas também são satisfeitas, com exceção das condições de contorno, que é o axioma 1 incluindo $\Theta\left(u_{1}, u_{2}, \ldots, 1, \ldots, u_{N}\right)=1$.

Utilizando $\tau$ para representar operadores norma-t, e $\sigma$ para operadores norma-s, a dualidade é expressa em termos gerais por:

$$
u_{1} \sigma u_{2}=1-\left(1-u_{1}\right) \tau\left(1-u_{2}\right) \Rightarrow 1-u_{1} \sigma u_{2}=\left(1-u_{1}\right) \tau\left(1-u_{2}\right)
$$

e alternativamente por:

$$
u_{1} \tau u_{2}=1-\left(1-u_{1}\right) \sigma\left(1-u_{2}\right) \Rightarrow 1-u_{1} \tau u_{2}=\left(1-u_{1}\right) \sigma\left(1-u_{2}\right)
$$

que correspondem às leis de De Morgan encontradas em teoria de conjuntos (PEDRYCZ; GOMIDE, 1998).

As normas triangulares têm como limitante superior o operador intersecção de Zadeh (eq. 3.6), enquanto que as conormas apresentam o operador união de Zadeh (eq. 3.7) como limite inferior, de acordo com a eq. 3.14. Se também for considerada a propriedade de idempotência (axioma 5 ), pode-se concluir que a norma-t min $(\cdot)$ e a conorma-t $\max (\cdot)$ são as únicas que satisfazem todas as propriedades enunciadas.

Operadores de agregação gerais Os operadores $\max \left(u_{1}, u_{2}\right)$ e $\min \left(u_{1}, u_{2}\right)$ foram originalmente definidos por (ZADEH, 1965), porém, formas alternativas de combinação de conjuntos nebulosos têm sido propostas (ZIMMERMANN; ZYSNO, 1980); (DOMBI, 1982); (YAGER, 1988) e (DETYNIECKI, 2001).

Em um trabalho sobre operadores de agregação $\Theta\left(u_{1}, u_{2}\right)$, Bloch (1996) classificou-os em função do seu comportamento: a) severo, b) indulgente ou c) cauteloso:

- $\Theta$ é um operador de conjunção se $\Theta\left(u_{1}, u_{2}\right) \leqslant \min \left(u_{1}, u_{2}\right)$, correspondendo a um comportamento severo; 
- $\Theta$ é um operador de disjunção se $\Theta\left(u_{1}, u_{2}\right) \geqslant \max \left(u_{1}, u_{2}\right)$, correspondendo a um comportamento indulgente;

- $\Theta$ tem um comportamento cauteloso quando $u_{1} \leqslant \Theta\left(u_{1}, u_{2}\right) \leqslant u_{2}$ para $u_{1} \leqslant u_{2}$ ou vice-versa permutando-se $u_{1}, u_{2}$. São também denominados operadores compensatórios.

Bloch (1996) também explicitou um ordenamento entre eles, resultando que os operadores de comportamento severo resultam nos menores valores resultantes para $u_{i}$ e os de comportamento indulgente apresentam os maiores, ficando os operadores cautelosos na região intermediária. Estes permitem um comportamento gradativo entre o mínimo e o máximo de Zadeh, por ajustarem-se melhor a várias classes de experimentos. Foram propostos vários operadores compensatórios, por exemplo, os operadores ordenados ponderados por pesos (YAGER, 1988), as integrais nebulosas (SUGENO, 1977) e (Grabisch apud Bloch (1996)), e os de tendência central ou médias (aritmética, geométrica, harmônica, quadrática e mediana). Estes são os mais simples de se propagar para várias variáveis (combinar várias fontes de incerteza $u_{1}, u_{2}, \ldots$ ) da forma incremental, ou seja, as médias são atualizadas de forma mais simples a cada novo valor de pertinência incorporado ao conjunto resultante.

Há operadores baseados em transformações funcionais mais complexas (YAGER, 1988) e (BLOCH, 1996). Os operadores de agregação em geral são caracterizados formalmente pelas seguintes propriedades: condições de contorno e monotonicidade.

Segundo Cox (1994), algumas características devem ser analisadas ao se decidir pelo operador mais apropriado:

1. a seleção do operador compensatório para um modelo particular exige alguma experiência. Geralmente é feita heuristicamente, observando-se os efeitos de sua aplicação no problema abordado;

2. seguindo a Lei da Mínima Complicação (ou Navalha de Ockham), deve-se testar inicialmente os operadores de Zadeh, em seguida, a média, o produto e a soma algébricos, e o produto e a soma limitados, antes de experimentar funções compensatórias mais complicadas (como as funções de Yager (1988));

3. a vantagem dos operadores de Zadeh é serem comutativos, porém, são sensíveis a valores extremos. Isto envolve implicações epistemológicas ao lidar com o significado da composição das variáveis nebulosas, especialmente, conhecimento sobre o domínio onde a aplicação é realizada; 
4. o operador compensatório média satisfaz dois critérios importantes: a) não é tão sensível a valores extremos (mínimo e máximo), b) é comutativo - a ordem de aplicação não importa - desde que seja aplicada de forma funcional, não-consecutiva.

Os operadores de agregação são um dos pontos chaves desta tese. Ao longo do processo de aprendizado, as pertinências $u_{i}\left(\mathbf{x}_{k}\right)$ de uma mesma instância $\mathbf{x}_{k}$, provenientes de cada grupo $i$ com o mesmo rótulo, serão combinadas na classe de cores expressa por este rótulo, em uma pertinência resultante para $\mathbf{x}_{k}$.

\subsubsection{Determinação das funções de pertinência}

A escolha da função de pertinência e o ajuste dos seus parâmetros normalmente dependem da natureza do problema. Pedrycz e Gomide (1998) apresentam uma lista das formas de $u(x)$ mais utilizadas na literatura, sempre de acordo com o conhecimento relacionado ao conjunto nebuloso. Apesar de existirem formas mais utilizadas das funções de pertinência, elas podem falhar ao exprimir a semântica de um modelo em particular (COX, 1994). Por exemplo, as funções triangular e a trapezoidal são muito utilizadas em engenharia de controle, pela sua simplicidade e fácil implementação em "hardware". Porém, as funções de pertinência provenientes de otimização iterativa, como nos algoritmos de agrupamentos nebulosos, apresentam um formato funcional não-analítico. Os conjuntos nebulosos devem refletir os padrões de pertinência relativos ao conceito, ou rótulo a ser definido, e nem sempre funções analíticas padronizadas adaptam-se a esta necessidade. Outros conceitos ainda podem ser descontínuos. Muitos métodos de construção podem produzir funções de pertinência com estas características. Segundo Pedrycz e Gomide (1998), seis classes de métodos experimentais auxiliam na determinação das funções de pertinência:

1. método horizontal de estimação da função de pertinência;

2. método vertical de estimação da função de pertinência;

3. método da comparação par-a-par, de estimação da função de pertinência;

4. método do problema baseado em especificação da função de pertinência;

5. otimização paramétrica para estimação da pertinência;

6. agrupamentos nebulosos para estimação da pertinência. 
Neste trabalho, onde o espaço de atributos é o espaço de representação de cores, a descrição da função de pertinência não é bem representada por uma função analítica. Então, a proposta aqui é estimar a pertinência por agrupamentos nebulosos, que pode ser recalculada a cada avaliação dos dados, resultando num modelo mais preciso de classificação. Além disso, atende aos requisitos de construção automática do classificador, uma vez que a modelagem das funções de pertinência deve estar relacionada à estrutura dos dados no espaço de atributos.

\subsection{Agrupamentos nebulosos}

As técnicas de agrupamento visam essencialmente particionar conjuntos de dados em classes homogêneas, em relação a uma determinada métrica. Os elementos que pertencem a um grupo devem ser os mais semelhantes possíveis entre si, e os que pertencem a grupos diferentes devem apresentar a menor semelhança. É um processo não-supervisionado de classificação de padrões, organizando-os em grupos por um critério de (des)similaridade. Havendo pouca informação preliminar sobre a distribuição dos dados no espaço de atributos, os métodos de agrupamento são particularmente apropriados para explorar as relações entre tais dados e sua estrutura (JAIN; MURTY; FLYNN, 1999).

É importante, neste ponto, ressaltar a relação entre grupo e classe. Dois ou mais grupos formados, em um processo de agrupamento nebuloso ou não, podem se referir à mesma classe. Isto ocorre porque o padrão descrito pela classe pode ser descontínuo no espaço de atributos, em função de como os mesmos foram selecionados, e em função do domínio em consideração. Daí a importância dos operadores de agregação para fornecer consistência ao classificador, ou seja, um modelo de predição eficaz. Um exemplo muito utilizado na discussão das redes neurais tipo "perceptron" é a classificação dada pela tabela-verdade ou-exclusivo, que se for resolvida por agrupamentos, gera quatro grupos (triviais) para duas classes. Portanto, esta seção tratará como grupos a reunião de valores de atributos que estejam próximos entre si, em relação a outros valores. Mais formalmente, Everitt (1980) apresenta algumas definições para "grupo":

1. conjunto de entidades parecidas, e as entidades que estão em grupos diferentes não são parecidas;

2. agrupamento no espaço de testes, de forma que a distância entre quaisquer dois pontos em um grupo é menor que aquela entre um ponto de um grupo e um ponto de outro grupo; 
3. região conectada em um espaço multidimensional, com uma alta densidade de pontos, separada de outras regiões de alta densidade por regiões de baixa densidade.

Nas técnicas de agrupamento binário, as fronteiras entre os grupos são bem definidas, e cada elemento pertence ou não a um dado grupo (KLIR; YUAN, 1995) e (JAIN; MURTY; FLYNN, 1999). Aqui, binário é empregado no sentido de que um dado elemento pertence ou não a um dos grupos. Freqüentemente, a distribuição de dados é tal que esta separação se torna demasiado arbitrária, e as fronteiras não ficam precisamente definidas.

No contexto deste trabalho surgem as técnicas de agrupamento nebuloso. Um determinado ponto pode pertencer a mais de um grupo, com graus de pertinência distintos. Para o processamento de imagens digitais, o tratamento da incerteza que surge da definição dos detalhes (por problemas de sensoriamento, limitações de resolução espacial ou do número de cores) pode ser adequadamente realizado na versão nebulosa da classificação por agrupamento.

\subsubsection{Algoritmos de agrupamento nebuloso.}

Como parte do processo de construção do classificador nebuloso, é importante que cada instância ou dado (no caso, valores da cor de um pixel) esteja relacionado a algumas classes com seus respectivos valores de pertinência. Sendo o número de pixels de uma imagem extremamente grande (da ordem de $10^{5}$ ), é impraticável uma classificação e atribuição dos valores de pertinência por especialistas humanos. Além disso, nas cenas de imagens digitais, os objetos são freqüentemente caracterizados por transições suaves de cor. Pode-se concluir daí que os pixels de um mesmo objeto freqüentemente apresentam cores vizinhas no espaço de representação. Logo, um processo de agrupamento é bastante indicado para revelar a densidade das distribuições dos pixels no espaço de cores, com uma descrição adequada da transição contínua e suave entre classes, ou seja, descrição por conjuntos nebulosos.

Para executar a análise de agrupamentos nebulosos, as seguintes categorias de algoritmos podem ser consideradas:

1. de aprendizado competitivo, inspirados em modelo biológico e atualmente desenvolvidos como uma das espécies de redes neurais artificiais, usando o paradigma "the winner takes all". Nesta categoria, estão os mapas auto-organizáveis de Kohonen (SOM - "self-organizing maps") e os chamados "learning vector quantization" LVQ, com suas versões para classificação nebulosa; 
2. baseados em otimização de função custo, como os algoritmos de decomposição de misturas, os algoritmos possibilísticos e o algoritmo "k-means" ou ISODATA, e sua versão nebulosa, "fuzzy c-means" (FCM). Nos primeiros, a função custo é construída sobre vetores de atributos aleatórios e a atribuição dos grupos segue argumentos probabilísticos (classificação bayesiana). A função custo nos agrupamentos possibilísticos considera quão típico é um vetor em relação a um grupo, desconsiderando a restrição probabilística $\sum_{i=1}^{c} P_{i}\left(\mathbf{x}_{k}\right)=1$, enquanto que, na abordagem nebulosa, são construídas as funções de pertinência no espaço de atributos levando em conta a distribuição dos dados.

A seguir, são descritos os algoritmos mais difundidos da primeira categoria. Na seção seguinte, o algoritmo mais difundido da segunda categoria, o FCM, será descrito com maiores detalhes por ser o algoritmo base utilizado neste trabalho, para a fase de aprendizado não-supervisionado do classificador proposto.

"Self-organizing maps" Os mapas auto-organizáveis de Kohonen utilizam o aprendizado não-supervisionado para ajustar os pesos de uma rede neural, que classifica as instâncias de treinamento (KOHONEN, 1990). Uma rede SOM básica consiste de uma rede bidimensional de neurônios, retangular ou hexagonal, onde cada neurônio está conectado respectivamente a 4 ou 3 outros vizinhos. A cada neurônio é associado um vetor ( "codevector"), e o conjunto é denominado "codebook". Um mapa topográfico é iterativamente organizado, de forma planar, e os pesos associados a cada nó $i$ da rede representam uma média de cada classe obtida. O treinamento da rede começa por uma inicialização aleatória dos vetores do "codebook", e cada instância $\mathbf{x}_{k}(t)$ é apresentada. As instâncias de treinamento $\mathbf{x}_{k}$ são classificadas por estes pesos $\mathbf{W}_{i}=\left\{w_{i k}\right\}$, como centróides. Ao final, as classes mais semelhantes ficam em neurônios mais próximos, resultando numa visualização topológica da classificação. O mecanismo de atualização dos pesos dos $i$ neurônios é competitivo, logo, uma inicialização heurística ajuda a evitar a formação de "neurônios inertes". A representação de uma rede SOM treinada é feita por uma matriz, onde as classes mais similares formam regiões mais claras na rede. Tal forma de representação pode ser interpretada como as pertinências das classes, daí a sugestão de que uma SOM pode ser empregada como etapa de agrupamento. Como aplicação, tanto Wu, Liu e Huang (2000) como Brown, Craw e Lewthwaite (2001) executaram a classificação dos pixels da imagem usando mapas auto-organizáveis (SOM), para identificar a cor da pele. Os mapas auto-organizáveis também dependem fortemente do número de grupos desejado. No caso dos algoritmos de agrupamento, este número é informado a priori, enquanto que, 
na rede SOM, a quantidade de neurônios de saída (também determinados a priori) deve ser maior que o número de grupos a ser obtido.

"Fuzzy learning vector quantization" - FLVQ A quantização de vetores visa representar $M$ vetores de atributos, rotulados ou não, por um conjunto de protótipos $\nu=\left\{\mathbf{v}_{1}, \mathbf{v}_{2}, \ldots, \mathbf{v}_{c}\right\}, c \ll M$, também referido como um "codebook". A arquitetura LVQ é conhecida como uma rede de aprendizado por competição, onde cada nó de entrada representa as componentes dos vetores de dados $\mathbf{x}_{k}$. Existem duas famílias de LVQ: a de aprendizado não-supervisionado (LVQ) e a de aprendizado supervisionado (LVQ1, LVQ2, LVQ3). As relações formais entre os agrupamentos "fuzzy c-means" e FLVQ foram demonstradas por Karayiannis e Bezdek (1997). Após obtidos os protótipos pelo algoritmo FLVQ, as pertinências podem ser calculadas pela equações 3.22, 3.19 e 3.20, utilizadas no algoritmo FCM para agrupamentos alongados.

\subsection{2 "Fuzzy c-means"}

O "fuzzy c-means" - FCM - é o algoritmo de agrupamento nebuloso mais empregado, sendo uma derivação do algoritmo "k-means" (DUDA; HART; STORK, 2000). A medida de similaridade empregada é a distância euclidiana entre dois pontos no espaço de atributos escolhido. Seja $\mathbf{X}=\left\{\mathbf{x}_{1}, \mathbf{x}_{2}, \ldots, \mathbf{x}_{N}\right\}$ um conjunto de $N$ elementos, expressos por um vetor de atributos $\mathbf{x}_{k}$, a ser dividido em $c$ grupos ou classes. Suponha um particionamento inicial aleatório ou uniforme. O algoritmo "fuzzy c-means" baseia-se em uma otimização iterativa. Esta otimização implica na definição de uma função que siga as duas premissas para uma boa partição: similaridade dos dados do grupo e separabilidade entre os grupos. Ou seja, as distâncias $d_{i k}$ entre o centro do grupo $\mathbf{v}_{i}$ e os dados $\mathbf{x}_{k}$ de cada grupo são minimizadas. A distância mais comumente empregada é a euclidiana, embora outras métricas também possam ser usadas (KLIR; YUAN, 1995) e (HöPPNER, 1999). O algoritmo procura minimizar esta distância em relação a todos os pontos do mesmo grupo. A função a ser minimizada é

$$
J(\mathbf{U}, \mathbf{v})=\sum_{i=1}^{c} \sum_{k=1}^{N}\left(u_{i k}\right)^{m} d_{i k}^{2}
$$

onde $u_{i k}=u_{i}\left(\mathbf{x}_{k}\right)$ é uma notação condensada para o valor de pertinência do elemento $k$ no grupo $i, c$ é o número de grupos predeterminado, $N$ é o número de elementos no espaço de atributos e

$$
d_{i k}=\left\|\mathbf{x}_{k}-\mathbf{v}_{i}\right\|_{p}
$$


é uma distância de acordo com uma norma $p$ escolhida, euclidiana $(p=2)$ ou outra qualquer. O expoente $m$ (fator de nebulosidade), expressa o grau de superposição dos grupos, onde $1<m<\infty$. Para $m \rightarrow 1$, a partição resultante é binária, e para $m \rightarrow \infty$, não há partição resultante: todos os elementos pertencem a todos os grupos, com valor de pertinência $1 / c$. Como resultado, $\mathbf{U}=\left\{u_{i k}\right\}$ é o conjunto de partições nebulosas a ser obtido. Esta minimização é feita sob os vínculos das equações 2.4 e 2.5.

Gustafson e Kessel (1979) desenvolveram uma solução para permitir que os grupos do algoritmo FCM possam ser alongados (elipsóides), introduzindo uma métrica corrigida por uma matriz positiva definida, com as covariâncias entre as dimensões do espaço de atributos. Isto pelo fato de que a distância euclidiana empregada constrói apenas grupos hiperesféricos, e a correção proposta permite a detecção de grupos hiperelipsoidais. Esta métrica utiliza a distância de Mahalanobis ${ }^{1}$ dada por

$$
d_{M a h}^{p}\left(\mathbf{v}_{i}, \mathbf{x}_{k}\right)=\left|\mathbf{C}_{i}\right|^{\frac{1}{p}}\left(\mathbf{x}_{k}-\mathbf{v}_{i}\right)^{T} \mathbf{C}_{i}^{-1}\left(\mathbf{x}_{k}-\mathbf{v}_{i}\right)
$$

onde $p$ é a dimensão da métrica utilizada (2, se euclidiana), C é uma matriz de covariância que mostra a correlação entre as componentes de cada dimensão, e permite identificar a direção e o tamanho dos grupos. Esta matriz de covariância, no caso nebuloso, é ponderada pelas pertinências $u_{i k}$, tendo como peso o fator de nebulosidade $m$, e é expressa por

$$
\mathbf{C}_{i}=\frac{\sum_{k=1}^{N} u_{i k}^{m}\left(\mathbf{x}_{k}-\mathbf{v}_{i}\right)\left(\mathbf{x}_{k}-\mathbf{v}_{i}\right)^{T}}{\sum_{k=1}^{N} u_{i k}^{m}}
$$

e $\left(\mathbf{x}_{k}-\mathbf{v}_{i}\right)$ é um vetor com o número de componentes do espaço de atributos.

Esta distância é empregada no processo de agrupamento para atributos cujos valores variam muito entre suas componentes e apresentam grandes variâncias. O algoritmo "fuzzy c-means", com a métrica introduzida por Gustafson e Kessel para detecção de grupos alongados, será citado aqui como algoritmo FCM-GK.

Outro modelo de agrupamento FCM, elaborado por Gath e Geva (FCM-GG), considera os grupos no espaço de atributos como distribuições normais de elementos não correlacionados (GATH; GEVA, 1989). Sua formulação pode ser considerada uma extensão do modelo de Gustafson e Kessel, onde a distância do exemplo $\mathbf{x}_{k}$ ao centróide

\footnotetext{
${ }^{1}$ Prasanta Chadra Mahalanobis (1893-1972) foi um estatístico indiano, mais conhecido por formular a distância que leva seu nome. Realizou trabalhos pioneiros em antropometria e fundou o Instituto Indiano de Estatística, chegando a trabalhar como meteorologista por algum tempo.
} 
$\mathbf{v}_{i}$ agora está relacionada a uma distribuição de probabilidades. Porém, as funções de pertinência decrescem muito mais lentamente a partir dos respectivos centros, de modo que funções vizinhas se sobrepõem bastante, e o algoritmo fica mais propenso a convergir indesejavelmente a um mínimo local. Por isto, costuma-se executar o algoritmo FCMGK (mais robusto) e os centros daí obtidos serem utilizados para inicializar o algoritmo FCM-GG (HöPPNER, 1999).

No algoritmo FCM e suas variantes, para a função $J$ atingir o mínimo (eq. 3.17), as condições necessárias são tais que, derivando-a em relação a $v$ para $u_{i k}$ fixo, e derivando-a em relação a $u_{i k}$ com $v$ fixo, obtêm-se respectivamente:

$$
\mathbf{v}_{i}=\frac{\sum_{k=1}^{N} u_{i k}^{m} x_{k}}{\sum_{k=1}^{N} u_{i k}^{m}} i=1,2, \ldots, c
$$

$\mathrm{e}$

$$
u_{i k}^{(I T+1)}=\frac{\left(1 / d_{i k}^{2}\right)^{\frac{1}{m-1}}}{\sum_{j=1}^{c}\left(1 / d_{j k}^{2}\right)^{\frac{1}{m-1}}} \quad k=1,2, \ldots, N
$$

sendo IT o número de iterações do algoritmo e $d_{j k}$ a distância entre o $j$-ésimo centro e o $k$-ésimo ponto, na iteração $I T$.

É importante ressaltar que os resultados do agrupamento nebuloso dependem do fator de nebulosidade $m$ e do número de grupos $c$ escolhidos. Este é um problema ainda em aberto e totalmente dependente do domínio. Algumas soluções para acelerar o processo de convergência ao melhor número de grupos $c$ foram propostas (COSIC; LONCARIC, 1994); (LIM; LEE, 1990); (PEDRYCZ; WALETZKY, 1998) e (KAYMAK; SETNES, 2002).

O algoritmo FCM apresenta um alto custo computacional: $\mathcal{O}(I T . N . c)$, e é descrito no quadro 1.

Análise das duas categorias de algoritmos. Na categoria dos algoritmos de aprendizado competitivo, o modelo não-supervisionado do algoritmo LVQ pode ser visto como um caso especial do algoritmo SOM, pois cada grupo é representado apenas pelo neurônio vencedor ( "the winner takes all"). Por isto, um dos problemas é que os protótipos, candidatos a representantes das classes, são subutilizados. Outro problema é que o algoritmo LVQ, por ser de treinamento seqüencial, depende fortemente da ordem com que os dados passam pela rede neural, demandando muitas iterações para convergência. Devido à 


\section{Quadro 1 FCM: otimização alternada.}

1. fornecer o número de grupos desejados: $2 \leqslant c \leqslant c_{\text {max }}$;

2. escolher o nível de nebulosidade: $1<m<\infty$;

3. criar uma partição inicial $\mathbf{U}(I T=0$ ) aleatória (ou uniforme, ou baseada em alguma aproximação heurística), com valores dos centros entre $x_{\max }$ e $x_{\min }$;

4. escolher um limite $\epsilon$ para a convergência e uma distância mínima $d_{\text {min }}$ para evitar singularidade na equação 3.22 ;

5. Repita:

- calcular os centros $\mathbf{v}_{i}$ usando a equação 3.21, com a partição inicial dada;

- atualizar as partições $\mathbf{U}(I T)$ calculando novos valores de pertinência para $\mathbf{U}(I T+1)$ como segue:

- para $i=1$ até $c / /$ todos os grupos

- para $k=1$ até $N \quad / /$ todos os pontos

- calcular $d_{i k}$ euclidiana ou outra métrica; // eq. 3.18 ou eqs. 3.19 e 3.20

- se $d_{i k}<d_{\text {min }}$ então $u_{i k}=1 \quad$ (evitando singularidade ou erro de precisão na eq. 3.22); senão atualizar $u_{i k}$ conforme eq. 3.22;

6. até que $\|\mathbf{U}(I T+1)-\mathbf{U}(I T)\|<\epsilon$

onde $\|\mathbf{U}(I T+1)-\mathbf{U}(I T)\|=\sqrt{\sum_{i, k}\left(u_{i k}^{(I T+1)}-u_{i k}^{(I T)}\right)^{2}}$ 
distância euclidiana empregada, o desempenho é baixo para grupos de distribuição nãoesférica. Para minimizar este problema, e reduzir a importância dos dados ruidosos e dos muito distantes, versões nebulosas incorporando valores de pertinência foram propostas (YAIR; ZEGER; GERSHO, 1992); (TSAO; BEZDEK; PAL, 1994); (BEZDEK; PAL, 1995) e (WU; YANG, 2003).

Os algoritmos que minimizam a função custo utilizam técnicas de cálculo diferencial (BEZDEK, 1980); (HöPPNER, 1999) e (DUDA; HART; STORK, 2000), e necessitam da informação do número de grupos desejados como parâmetro inicial. Seu maior problema reside no fato de que podem facilmente convergir em um mínimo local, resultando agrupamentos não otimizados. Porém, não apresentam as desvantagens dos algoritmos de aprendizado competitivo, não importando a ordem de apresentação dos dados, e ainda, utilizando a distância de Mahalanobis, podem detectar grupos alongados no espaço de atributos. O algoritmo "fuzzy c-means" fornece o centróide ("valor médio") de cada classe, semelhantemente aos algoritmos SOM e LVQ, e também fornece a matriz de pertinências $\mathbf{U}=\left\{u_{i k}\right\},(2 \leqslant i \leqslant c, 2 \leqslant k \leqslant N)$, de $N$ dados em $c$ classes.

No escopo deste trabalho, são considerados os agrupamentos "fuzzy c-means", que são uma adaptação do "c-means" ou ISODATA (BEZDEK; PAL, 1992). Outros algoritmos de agrupamento, como aqueles baseados em aprendizado competitivo e adaptados para particionamento nebuloso, como "self-organizing maps" e "fuzzy learning vector quantization”, também podem ser empregados (KARAYIANNIS; BEZDEK, 1997). No entanto, por permitir um melhor controle dos parâmetros no processo de agrupamento (como o fator de nebulosidade), por detectar grupos alongados e assim gerar os conjuntos nebulosos mais adequadamente, e por haver funções de validação que permitem obter o melhor número de classes obtidas de forma mais direta, foi escolhido o algoritmo FCM para realizar o agrupamento no espaço de cores, considerando a distância de Mahalanobis. O objetivo almejado é que os valores de pertinência obtidos possam indicar mais precisamente a densidade da distribuição neste espaço.

Neste trabalho, argumenta-se que o algoritmo FCM-GK executa satisfatoriamente a tarefa de classificar cores com a pertinência relativa ao grupo, de modo que o algoritmo FCM-GG geraria mais sobrecarga no processo de classificação.

\subsubsection{Medidas de desempenho do processo de agrupamento.}

A escolha inicial do número de grupos é um parâmetro essencial para a partição do espaço de atributos. Em um processo (semi)automático de classificação, sistemas nebulosos de 
reconhecimento de padrões devem estar aptos a decidir qual o melhor número de classes a ser adotado, baseados na qualidade do agrupamento resultante. Para verificar isto, algumas medidas de qualidade foram desenvolvidas, também denominadas funções de validação. Höppner (1999) e colaboradores relacionam as mais importantes e, dentre elas, neste trabalho foi escolhida a função de validação $S$, dada pela razão entre compactação e separação (XIE; BENI, 1991), ou seja, a razão entre a distância média dos dados aos seus respectivos centros e a mínima distância entre os centros. Uma boa definição dos grupos minimiza esta função $S$, correspondendo a grupos mais compactos e mais separados. Esta escolha foi motivada pelo fato de que os pixels das imagens coletadas formam nuvens quase contínuas no espaço RGB, havendo um alto grau de contato entre elas. Portanto, uma função que possa indicar qual a melhor separação, em função de quantos grupos existem, é mais apropriada neste caso.

A compactação é definida como a função objetivo $J(\mathbf{U}, \mathbf{v})$ já minimizada e dividida pelo número de elementos do espaço de atributos:

$$
C o m p=\frac{J(\mathbf{U}, \mathbf{v})}{N}=\frac{1}{N} \sum_{i=1}^{c} \sum_{k=1}^{N} u_{i k}^{m} d_{i k}^{2}
$$

e a separação é a menor distância entre os centros dos grupos:

$$
S e p=\min _{i, j}\left\|\mathbf{v}_{i}-\mathbf{v}_{j}\right\| \forall i \neq j
$$

resultando que

$$
S=\frac{C o m p}{S e p}=\frac{J}{N d_{\text {min }}^{2}}
$$

O modo mais direto de empregar a função $S$ para avaliar a qualidade do agrupamento obtido é aplicar o algoritmo "fuzzy c-means" iterativamente, para $c=2$ até $c_{\text {max }}$ e escolher o valor $c^{*}$ que minimize o valor de $S$ :

$$
c^{*}=\arg \min _{c}\left(\min _{\mathbf{U}} S(\mathbf{U}, c)\right)
$$

A função de validação $S$ é utilizada para a escolha da melhor partição realizada pelo algoritmo FCM.

É importante ressaltar que, neste modelo proposto, as posições dos centros dos grupos obtidos não são utilizadas, mas apenas os valores da matriz de pertinência U, que é empregada na classificação dos dados. O cálculo dos centros é feito pela eq. 3.21 não de forma desnecessária, mas porque o método utilizado para minimizar a função $J(\mathbf{U}, \mathbf{v})$ atualiza alternadamente a matriz de pertinências $\mathbf{U}$ e os centros $\mathbf{v}_{i}$. 


\subsubsection{Aplicações do agrupamento nebuloso em processamento de imagens}

Chi, Yan e Pham (1996) realizaram uma simples comparação entre limiarização e agrupamentos nebulosos, ao executar a segmentação de caracteres em documentos. Esta comparação é feita diretamente entre o histograma de níveis de cinza (para a limiarização) e o histograma de níveis de pertinência ao fundo da imagem (após aplicação do algoritmo de agrupamento). Os histogramas apresentam picos e vales em um formato bem semelhante, mas o último apresentou um vale mais profundo e amplo, de forma que a escolha do limiar foi bem menos crítica. Geralmente para imagens monocromáticas, atributos morfológicos devem ser acrescentados para enriquecer a classificação, porém, estes nem sempre podem ser tratados como distribuições. Logo, procedimentos de limiarização não são úteis nestes casos.

As aplicações do algoritmo "fuzzy c-means" encontram melhores resultados em aquisições multiespectrais. Sistemas de imagem por ressonância magnética permitem a medição de alguns parâmetros: o decaimento $T_{1}$ (rede de spins), o decaimento $T_{2}$ (transversal), e a densidade de prótons, que constituem em um conjunto com três atributos, análogos aos valores tricromáticos de imagens coloridas (HALL, 1992). Imagens de satélite, captadas por mais de um canal de freqüência, também podem ser tratadas desta forma (Vannier, 1985 apud Hall (1992)). Por outro lado, Liao, Li e Li (1999), para a detecção de defeitos em soldas por raios-X, aplicaram o método de agrupamentos nebulosos não diretamente sobre os dados da imagem, mas em 25 atributos extraídos da mesma, na construção de um perfil modelo que discriminava as soldas defeituosas. Iyer, Kandel e Schneider (2000) também aplicaram agrupamentos nebulosos em mamografias que são muito borradas devido à baixa definição causada pela dose limitada de radiação aplicada. Novamente, a intensidade dos pixels da imagem foi substituída por 63 atributos (definidos por outros especialistas), e a classificação foi realizada em duas etapas: uma primária, utilizando árvores de decisão (QUINLAN, 1993) para selecionar os atributos mais relevantes, e uma secundária, o próprio método FCM, para separar falsos positivos gerados na etapa primária.

Cosic e Loncaric (1994) executaram a segmentação de imagens de ressonância magnética do cérebro, aplicando a técnica de agrupamentos nebulosos com a métrica introduzida por Gath e Geva (1989). Nesta, a função de distância é baseada na fuzzificação de grandezas estatísticas ( "fuzzy maximum likelihood estimation"). Além disso, foram experimentados três métodos para recalcular a posição dos centros $\mathbf{v}_{i}$ dos grupos obtidos, a cada iteração. Para comparação, o algoritmo básico de agrupamentos nebulosos atualiza 
a posição dos centros por uma média ponderada pelas pertinências (BEZDEK; PAL, 1992).

Guliato (1998) descreve métodos de segmentação utilizando agrupamentos nebulosos, detecção nebulosa de arestas e limiarização nebulosa, e contribui para o desenvolvimento do conceito de conectividade nebulosa, para tirar proveito dos atributos morfológicos e de continuidade. Combina as técnicas de detecção de contornos e crescimento de região por meio de operadores de fusão, que são adaptativos de acordo com a região que está sendo segmentada (BLOCH, 1996). O objetivo é extrair um melhor resultado proveniente desta combinação adequada, do que seria se apenas uma técnica fosse utilizada.

\section{A cor como atributo para agrupamentos. Componentes da cor e espaço de}

cores. Vários espaços de representação de cores são utilizados, dentre eles, notadamente o RGB, o HSI e o YUV. O espaço RGB é bastante utilizado, devido à maioria dos dispositivos de aquisição fornecer as cores dos pixels em triplas $[R G B]$, porém, nesta representação, a informação da crominância (cor e saturação) está misturada com a informação da intensidade. Um objeto de cor constante, mas com variações na iluminação (devido à variação da orientação de suas superfícies, por exemplo) terá seus pixels formando um grupo alongado no espaço RGB, dificultando sua representação em simples limiares. Por outro lado, espaços como o HSI e o YUV apresentam a crominância codificada em duas dimensões (HS ou UV) e a intensidade na outra dimensão (I ou Y). Assim, a princípio, a cor de tal objeto de cor constante poderia ser representada por um prisma reto perpendicular ao plano de crominâncias. Alguns equipamentos de digitalização de imagens fornecem dados diretamente com valores de cor em um destes espaços. Jonker, Caarls e Bokhove (2000) mostram que objetos de cores distintas formam grupos isolados no espaço YUV, e que a segmentação é simplesmente executada com um fatiamento radial do plano UV, isolando os grupos detectados.

Como um exemplo de aplicações diretas de agrupamentos nebulosos em imagens coloridas, Tao e Huang (2000) localizaram as fronteiras entre os grupos no espaço de cores RGB ao longo dos vetores que ligam diretamente os centros dos grupos, pelo cálculo do gradiente nestas direções, considerando os valores de pertinência. Wu, Liu e Huang (2000) executaram a classificação dos pixels da imagem usando mapas auto-organizáveis (SOM), para identificar a cor da pele. Os dados da cor foram representados no espaço HSI. Como o objetivo dos autores era o rastreamento da mão humana em seqüências de vídeo, a rede SOM foi treinada com imagens seqüenciais. Este método produz resultados muito similares às técnicas de classificação por LVQ e "k-means clustering" (a versão booleana do FCM). Os mapas auto-organizáveis realizam o agrupamento dependendo fortemente 
da relação entre o número de grupos desejado e o número de neurônios de saída.

Zhang (2000) e colaboradores classificaram imagens de satélite da costa oeste da Flórida, captadas nos comprimentos de onda 443, 520, 550 e 670 nm, e pré-processadas para eliminar efeitos atmosféricos (ex. nuvens). Seu objetivo era identificar as classes água I, água II, maré vermelha e elementos diluídos (rio verde). Porém, ao invés de ser empregado o algoritmo FCM puro, os autores desenvolveram uma melhoria, o "multistage random sampling FCM" ( $m r F C M)$, cujo resultado, aplicado para cada freqüência de captação, foi processado por um conjunto de regras especializadas e orientadas ao domínio, construídas por uma rede neural tipo "propagação para frente". Embora os autores ressaltem a eficiência computacional do $\operatorname{mFCM}$, o sistema apresenta uma complexidade altamente dependente do domínio, na construção das regras de filtragem para as classes descritas.

Boujemaa (2000) propôs uma generalização do algoritmo FCM na forma competitiva, para automatizar a escolha do número ideal de classes. A função-objetivo a ser minimizada ficou composta do termo FCM original $J_{1}$, mais outro termo $J_{2}$ que funciona como bias, reduzindo a cardinalidade de grupos com baixa representatividade, e cuja tendência é fazer todos os elementos ficarem em um único grupo. O número ótimo de grupos é dado pela minimização global da soma destas duas funções. Porém, o resultado do agrupamento, realizado com as imagens em cores apresentadas, mostra os grupos marcados com cores individuais, e não há nenhuma informação sobre o valor da pertinência dos pixels relativamente aos grupos. Deve-se ressaltar aqui que a interpenetração dos grupos (nebulosidade do processo de agrupamento) necessita ser aferida para tratamentos posteriores, como a segmentação. Ainda, os resultados adicionais (extra-artigo), apresentados em www.rocq.inria.fr/ boujemaa/Partielle2.html, exibem a maioria das imagens com cores bem distintas, de forma que algoritmos de classificação mais simples poderiam realizar a tarefa igualmente bem. Mesmo assim, a inclusão do termo $J_{2}$ resulta no pequeno número de classes obtido.

Uma combinação das técnicas de limiarização e agrupamentos nebulosos foi realizada por Lim e Lee (1990). A partir dos histogramas de cada componente, nos espaços de cores RGB, XYZ, YIQ, UVW e I1I2I3, a segmentação por cores foi executada em duas etapas: a primeira, mais grosseira, pela limiarização dos histogramas das três componentes de cor separadamente, sem a preocupação da escolha de um limiar ótimo, mas uma região de limiar. Encontrados todos os limiares nos histogramas das componentes de cor, uma faixa de valores em torno deles foi determinada como transição. Na segunda etapa, a segmentação fina, considerou-se os pixels com valores pertencentes às faixas de transição 
e aplicado o algoritmo de agrupamentos nebulosos, para atribuir estes pixels ao grupo cujo centróide se aproxima mais dos grupos previamente definidos na limiarização. É interessante notar que: a) o número inicial de classes requerido pelo algoritmo FCM já foi determinado na etapa de limiarização; b) o custo computacional da classificação ficou baixo, pois apenas os pixels pertencentes à região de transição foram processados; c) os problemas de identificar uma classe válida foram contornados pela atribuição dos pixels agrupados por FCM a classes já definidas na limiarização.

Limiarização nebulosa também foi utilizada em um trabalho anterior (BONVENTI JR.; COSTA, 2000b), onde conjuntos nebulosos foram construídos sobre histogramas das três componentes do espaço de cores HSI, e a separação das classes em cada componente realizada de maneira supervisionada. A segmentação da imagem foi executada por regras contidas em FAMs - "fuzzy associative memories", construídas também de forma supervisionada, identificando nominalmente as cores percebidas como combinação adequada dos conjuntos nebulosos de cada componente do espaço HSI.

\subsection{Conclusão do capítulo}

Este capítulo forneceu algumas bases da teoria dos conjuntos nebulosos. É mostrado o tratamento de objetos com atributos definidos, mas com classificação vaga. É importante notar que um processo de reconhecimento de padrões envolve a construção de conceitos (classes) mais complexas, obtidas da agregação de classes mais simples. Se as classes forem vagas (conjuntos nebulosos), a utilização dos operadores de agregação possibilita a construção de novos conjuntos, com o tratamento formal das pertinências de cada instância.

No contexto deste trabalho, a manipulação adequada dos conjuntos nebulosos, em função dos dados utilizados para definir as classes, faz uso importante dos operadores de agregação. A escolha destes operadores também é dependente do problema em particular, permitindo a flexibilização na construção das regras.

Os agrupamentos nebulosos são essenciais para revelar estruturas similares nos atributos e para auxiliar na definição das classes, uma vez que são nebulosas. A predefinição das classes na fase de análise de agrupamentos é um estágio anterior à construção do classificador. Ajustes posteriores no classificador fornecem a realimentação necessária para sintonia do processo de agrupamento. Neste trabalho, foram escolhidos o algoritmo FCMGK para realizar o agrupamento no espaço de cores e a função de validação $S$, onde esta é utilizada para decidir a melhor partição. 


\section{APRENDIZADO COMPUTACIONAL}

Conforme exposto no capítulo introdutório, a construção de classificadores pela cor, objetivo deste trabalho, requer muitas imagens contendo os objetos de interesse, para que sejam caracterizados por seus respectivos conjuntos de cores. Estão envolvidos milhares ou milhões de pixels, sendo recomendável automatizar a construção deste tipo de classificadores.

O aprendizado de máquinas é uma área de estudo importante em Inteligência Artificial. Schalkoff (1990) cita a Inteligência Artificial como "a área de estudo que procura explicar e emular o comportamento inteligente em termos de processos computacionais", e Luger e Stubblefield (1993) definem-na como "o ramo da ciência da computação que se preocupa com a automação do comportamento inteligente". Assim, o enfoque dado é o das percepções e ações dos agentes que interagem e atuam no meio ambiente de forma inteligente, ao invés de se basear no comportamento dos seres humanos. Sob este prisma, não é necessário que uma máquina resolva um problema da mesma maneira que um ser humano o resolveria.

Esta visão define Inteligência Artificial relacionando-a a máquinas que agem racionalmente. O conceito de racionalidade está ligado a um "bom comportamento" dos agentes computacionais envolvidos, e um agente racional é aquele que "faz a coisa certa", isto é, é bem sucedido em suas ações. Russell e Norvig (2003) apresentam uma definição de agente racional:

\footnotetext{
"para cada possível seqüência de percepção, um agente racional deve escolher uma ação que maximize seu desempenho, dada a evidência fornecida pela seqüência de percepção e qualquer conhecimento imbuído que o agente possuir".
}

A seqüência de percepção é também definida como "a história completa de tudo que os 
agentes já perceberam" (RUSSELL; NORVIG, 2003).

O aprendizado computacional estuda como modelar um bom sistema de predição, baseado em dados experimentais anteriores ("experiências passadas"). De acordo com Simon (1983),

"aprendizado denota mudanças no sistema, que são adaptativas no sentido de que elas possibilitam que o sistema faça a mesma tarefa ou tarefas sobre a mesma população, de uma maneira mais eficiente e mais efetiva a cada vez".

Weiss e Kulikowski (1991) definem aprendizado como:

"um sistema de aprendizado é um programa de computador que toma decisões baseado nas experiências acumuladas contidas em casos resolvidos com sucesso".

E ainda, segundo Mitchell (1997),

"um programa de computador aprende com a experiência $E$ em relação a alguma classe de tarefas $T$, se o seu desempenho $P$ nas tarefas de $T$ aumentar com a experiência $E "$.

Uma tarefa $T$ pode ser jogar damas, reconhecer e classificar caracteres manuscritos, guiar um robô móvel usando sensores visuais, e suas respectivas medidas de desempenho podem ser a porcentagem de partidas ganhas em relação ao total, a proporção de letras corretamente classificadas, e a distância percorrida pelo robô sem cometer nenhum erro. Muitas técnicas computacionais de aprendizado em máquinas são provenientes dos esforços dos psicólogos e anatomistas, para desenvolver suas teorias de aprendizado animal e humano.

No capítulo 2, foi enfatizado que um classificador autônomo, ao melhorar seu desempenho interagindo sucessivamente com o ambiente externo, necessita ter incorporado os elementos de aprendizado computacional. Tendo já sido exposto que a descrição do processo de classificação e a representação dos atributos são etapas chaves na construção de classificadores, é interessante relacionar agora as estratégias e os paradigmas de aprendizado. 


\subsection{Estratégia de aprendizado indutivo.}

Carbonell (1989) e Monard (1997) relacionam as estratégias utilizadas por um agente para adquirir conhecimento. Muitas delas funcionam adequadamente com representações simbólicas e lógica de primeira ordem, e outras com tratamento numérico. Há também uma combinação destas estratégias, seja porque os atributos são de natureza híbrida (numérica e simbólica), seja porque o conhecimento é representado e tratado de formas diferentes em níveis diferentes.

Dentre estas estratégias, a mais adequada para a construção de um classificador, utilizando como atributos valores numéricos em algum espaço de representação de cores, é a de utilizar exemplos positivos e negativos, ou seja, pertencentes ou não à classe de interesse. Aprender através de exemplos é um caso particular do aprendizado por indução (LAVRAC; DZEROSKI, 1994).

O aprendizado indutivo pode ser entendido como inferência lógica que obtém conclusões gerais a partir de fatos particulares. Raciocínio do específico para o geral, generalização, descoberta de padrões também descrevem esta estratégia. Ao contrário da inferência dedutiva, que parte de regras gerais para obter uma nova regra, o aprendizado indutivo é baseado em exemplos e a generalização destina-se a ampliar o conhecimento, e constrói descrições de conceitos a partir de premissas lógicas. Em muitos casos, as premissas são obtidas de exemplos. Instâncias são agrupadas em função de atributos relevantes, definindo uma classe que por sua vez induz a um conceito.

No contexto da classificação de cores, é importante frisar aqui a equivalência entre conceito, hipótese e classe. Por exemplo, o conceito de "tomates verdes" está ligado ao conhecimento que tomates mudam de cor quando amadurecem. Logo, se um tomate não está maduro, há uma classe de tons verdes ligada a este conceito.

O aprendizado de conceitos utilizando exemplos é formalizado da seguinte maneira:

"Seja $\mathcal{U}$ o conjunto universo dos objetos (todos que o aprendiz puder encontrar). Não existe, a princípio, limite para a cardinalidade de $\mathcal{U}$. Um conceito $\mathcal{C}$ pode ser formalizado como um subconjunto de objetos em $\mathcal{U}$, ou seja, $\mathcal{C} \subset \mathcal{U}$. Aprender um conceito $\mathcal{C}$ significa reconhecer objetos em $\mathcal{C}$. Uma vez que o conceito $\mathcal{C}$ seja aprendido, para qualquer objeto $x \in \mathcal{U}$, o sistema é capaz de reconhecer se $x \in \mathcal{C}^{\prime \prime}$.

Note que um conceito $\mathcal{C}$ está expresso como o conjunto dos conceitos instanciados $c$ que 
descrevem cada objeto (ou exemplo) individualmente.

Dada a pouca disponibilidade no mundo real de exemplos que possuam rótulos naturais (ou seja, classe explícita nos atributos), a construção de conhecimento por aprendizado computacional muito freqüentemente utiliza a estratégia indutiva. É essencial a utilização adequada de linguagens que descrevam apropriadamente os exemplos e o conceito a ser induzido. O problema de aprender um conceito simples $\mathcal{C}$ a partir de exemplos é formalmente estabelecida a seguir.

Aprendizado indutivo de conceitos. Dados os conjuntos $\mathcal{E}^{+}$de exemplos positivos e $\mathcal{E}^{-}$de exemplos negativos de um conceito $\mathcal{C}$, encontrar uma hipótese $h$, expressa em uma linguagem descritiva $\mathcal{L}$, tal que:

- todos os exemplos positivos $e^{+} \in \mathcal{E}^{+}$são cobertos por $h$ (a hipótese é completa),

- nenhum exemplo negativo $e^{-} \in \mathcal{E}^{-}$é coberto por $h$ (a hipótese é consistente).

Esta definição também é denominada consistência do aprendiz, pois o conceito abrange todos os exemplos, sem cometer nenhum erro de classificação (LAVRAC; DZEROSKI, 1994).

Uma hipótese $h$ é, de forma simples, uma expressão que define se uma instância pertence a um conceito (classe), e é uma aproximação da função $f$ (desconhecida) que mapeia os exemplos de entrada nas classes de saída. Quanto melhor $h$, melhor generaliza $f$, e melhor sua capacidade de predição dos dados ainda não vistos. Podem existir várias hipóteses $h_{i}$ consistentes, uma vez que o número de exemplos é finito. O espaço de hipóteses $\mathcal{H}=\left\{h_{i}\right\}$ é uma família de funções que conseguem ajustar $f$. Um critério de escolha da melhor hipótese é o uso da navalha de Okham: dentre todas as hipóteses possíveis consistentes com os exemplos, escolhe-se a mais simples.

Mesmo considerando que uma função suficientemente complexa (ou uma hipótese formada por muitas premissas) possa ajustar bem os exemplos vindouros, na prática há um compromisso entre a complexidade e a capacidade de generalização da hipótese, por questões práticas na construção e utilização de um classificador. Este é o problema da superespecialização ou excesso de ajuste ("overfitting").

Superespecialização. O fenômeno da superespecialização ocorre quando uma hipótese $h$ cobre todos os exemplos provenientes do conjunto de treinamento e outra hipótese $h$ ' cobre um pouco pior o mesmo conjunto de treinamento, mas apresenta um desempe- 
nho melhor ao cobrir outras instâncias "próximas" que não pertencem ao treinamento. Mitchell (1997) define superespecialização desta forma:

"dado um espaço de hipóteses $\mathcal{H}$, uma hipótese $h \in \mathcal{H}$ superespecializa o conjunto de treinamento se existir alguma hipótese alternativa $h^{\prime} \in \mathcal{H}$ tal que h apresente erro menor que h' ao cobrir o conjunto de treinamento, mas o contrário sobre toda a distribuição de exemplos".

A frase final da definição enfatiza o poder preditivo que uma hipótese necessita ter para a inferência indutiva funcionar com um mínimo de erros. Na prática, observa-se a superespecialização da seguinte maneira: depois que o aprendiz tenha sido suficientemente treinado, um conjunto de teste é submetido para avaliar seu desempenho. Inicialmente, a curva de acertos na classificação das instâncias de teste é crescente, mas chega um ponto em que começa a diminuir. Isto significa que a hipótese $h$ está muito bem ajustada aos detalhes do conjunto de treinamento, está específica demais, e ocorrem erros maiores quando outras instâncias são testadas.

A abordagem mais comum para contornar este problema é a chamada validação cruzada: particiona-se aleatoriamente o conjunto de instâncias em três partes desiguais (tipicamente nas proporções 3:1:1 ou 4:1:1) (PRECHELT, 1994) e (HAYKIN, 1999). A maior proporção é usada para o treinamento propriamente dito, a segunda é usada para validação, ou seja, avaliar a precisão da hipótese construída durante o treinamento, e a terceira é o conjunto de testes, que avalia o desempenho final do treinamento. Assim, evita-se incorporar dados que são ruído na formação da hipótese. O conjunto de validação ajuda a estimar qual o ponto em que o treinamento deve cessar. Os dados de validação são usados como teste da hipótese durante "pausas" no treinamento (isto é, momentos regulares em que a hipótese não é atualizada). O ponto de parada do treinamento é onde a curva do erro para os dados de validação atinge um mínimo; neste estágio, a hipótese generaliza suficientemente bem novos exemplos sem "aprender o ruído" dos exemplos de treinamento. Esta escolha do ponto de parada denomina-se método da parada antecipada. Prechelt (1994) discute em detalhes a escolha de conjuntos de treinamento e validação para redes neurais artificiais, mas sua aplicação pode se estender a modelos de aprendizado supervisionado em geral.

Atualização das hipóteses. À medida que novos exemplos são considerados, há a necessidade de atualizar a hipótese corrente para manter sua consistência e completeza. Esta propriedade adaptativa é altamente desejável em modelos de aprendizado, neste caso, 
na atualização de um classificador. A idéia de atualização, baseada numa descrição em diagramas de conjuntos, é exemplificada por Russell e Norvig (2003) e apresentada na fig. 4.1. Uma hipótese $h$ ajustada aos exemplos existentes é completa e consistente (fig. 4.1a). Na fig. 4.1b, aparece um novo exemplo, cujos atributos permitem a classificação em $h$. A hipótese é generalizada para recuperar sua completeza (fig. 4.1c). Em seguida, um novo exemplo negativo aparece no espaço definido por $h$, mas não é consistente com ela (fig. 4.1d). A hipótese é novamente atualizada para manter sua consistência (fig. 4.1e). Esta última atualização agora é denominada especialização.

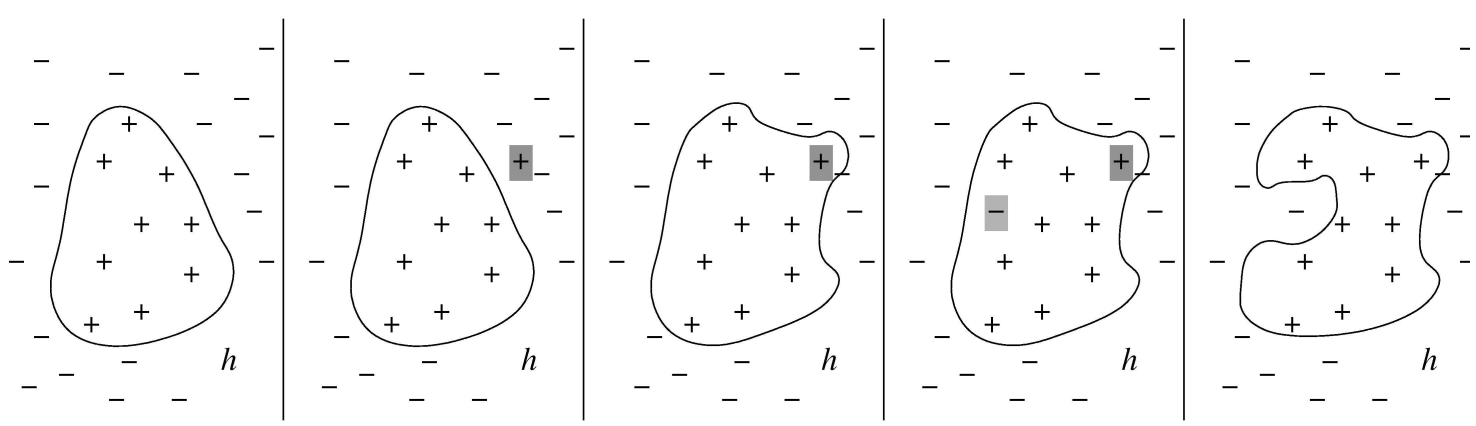

Adaptado de Russell e Norvig (2003).

Figura 4.1: Atualização das hipóteses. a) Consistente. b) Aparece um falso negativo.

c) Generalização. d) Aparece um falso positivo. e) Especialização.

Aprendizado incremental. Conforme a disponibilidade dos exemplos de treinamento, os algoritmos de aprendizado indutivo podem ser classificados em:

1. incremental, onde a hipótese gerada por indução é revisada sempre em resposta a cada novo exemplo apresentado. O conhecimento pode ser atualizado de forma flexível, pois é mais eficiente revisar uma hipótese do que construir uma nova, cada vez que um novo exemplo é observado (UTGOFF, 1989);

2. não-incremental. Todos os exemplos de treinamento devem estar disponíveis. Este tipo de algoritmo é mais indicado para hipóteses com grande possibilidade de serem estáticas, ou quando a hipótese a ser formulada requer um número não muito grande de instâncias.

\subsection{Paradigmas de aprendizado}

Esta seção refere-se aos modelos gerais de interação do classificador com o ambiente, à medida em que evolui. Os paradigmas de aprendizado, também denominados tipos de 
resposta do aprendizado, são discriminados em três casos (HAYKIN, 1999) e (RUSSELL; NORVIG, 2003): supervisionado, não-supervisionado e por reforço.

Enquanto que Russell e Norvig (2003) situam os três casos citados em categorias distintas, Haykin (1999) usa a denominação aprendizado sem professor para englobar o aprendizado não-supervisionado e o aprendizado por reforço, no sentido de que não há exemplos de treinamento rotulados para definir o alcance das classes.

\subsubsection{Supervisionado}

No paradigma supervisionado (ou orientado, ou "com professor"), o classificador aprende uma função de entrada e saída, a partir dos exemplos. Como já mencionado no capítulo 2, a classificação é uma forma discreta de regressão ou ajuste. Uma entidade externa, denominada professor ou supervisor, possui o conhecimento sobre o ambiente e fornece os atributos de cada exemplo e a respectiva classe de saída correta. Normalmente, estes exemplos são rotulados como positivos (ou exemplos propriamente ditos) e negativos (ou contra-exemplos). Este rótulo refere-se ao conceito a ser aprendido. O supervisor supervisiona a resposta do sistema, comparando-a com a resposta desejada, normalmente através de uma função de erro. Os parâmetros de aprendizado do sistema são ajustados de forma a minimizar esta função. O conjunto dos $N$ exemplos entrada-saída é denominado conjunto de treinamento, da forma:

$$
\left\{\left(\mathbf{x}_{i k}, \omega_{i}\right) \mid 1 \leqslant i \leqslant c, 1 \leqslant k \leqslant N\right\}
$$

com a classe $\omega_{i}$ a que cada exemplo pertence sendo previamente informada.

Se forem considerados apenas os exemplos positivos, os limites do conceito a ser construído ficam sempre em aberto, pelo fato de que um novo exemplo apresentado pode gerar uma nova regra, ou modificar algum parâmetro da função de mapeamento no espaço de hipóteses. Os exemplos devem ser escolhidos cuidadosamente, de forma que a construção do conceito seja mais segura. Se algum conhecimento prévio for utilizado, é possível limitar a expansão no espaço de hipóteses (fig. 4.1). Por outro lado, a utilização conjunta de contra-exemplos no treinamento possibilita uma melhor avaliação da consistência do modelo, ajudando a prevenir a superespecialização. 


\subsubsection{Não-supervisionado}

O paradigma não-supervisionado (ou não-orientado, ou "sem professor") é aquele em que os exemplos não são rotulados, e o sistema vai classificando-os de forma natural. Neste caso, os dados de entrada não são amostras de treinamento por não possuírem nenhum rótulo previamente conhecido, nem mesmo se sabe quantas classes podem ser extraídas. Estas classes são produzidas de acordo com alguma medida de similaridade (sob alguma métrica) ou com alguma estrutura inerente aos dados.

Os algoritmos de agrupamentos são essencialmente do tipo não-supervisionado, onde o sistema agrupa automaticamente os dados de entrada, até que estes grupos fiquem estáveis em relação aos dados, por algum processo de avaliação da representação do ambiente (em relação ao conceito ou classes em consideração). Estes algoritmos têm concepções muito diversas na tarefa de revelar a estrutura dos dados. Funções de validação são empregadas para avaliar a separabilidade e compactação dos agrupamentos obtidos (cap. 3).

Alguns trabalhos mais recentes (PEDRYCZ; WALETZKY, 1998); (KAYMAK; SETNES, 2002) e (SANCHES, 2003) procuram introduzir supervisão no processo de agrupamento, para indicar o melhor número de grupos, ou para lidar com o problema de grupos muito desiguais, onde ocorre dos maiores englobarem os menores, se a separação entre eles não for suficiente.

\subsubsection{Aprendizado por reforço}

É o paradigma onde um agente aprende por tentativa e erro, interagindo com um ambiente dinâmico (KAELBLING; LITTMAN; MOORE, 1996). A realimentação não é feita diretamente por cada instância, como no aprendizado supervisionado, mas através de uma forma de recompensa e punição. O agente interage com o ambiente via sensores (estimando o estado corrente) e atuadores (por onde uma ação é escolhida e executada). Analogamente a um sistema de controle de malha fechada, a ação executada muda o estado do ambiente, e esta mudança é comunicada por um sinal de reforço. Um módulo de crítica converte o sinal de reforço recebido do ambiente em um sinal heurístico para a ação (HAYKIN, 1999).

É importante destacar que o aprendizado por reforço difere do aprendizado supervisionado no sentido de que o módulo de crítica desempenha um papel diverso do supervisor, mas também não pode ser considerado rigorosamente um paradigma não-supervisionado. O aprendizado por reforço está ligado à observação seqüencial dos dados do ambiente, com 
o objetivo de maximizar uma função de utilidade acumulada ao longo das ações executadas pelo aprendiz. Este paradigma está mais relacionado com a evolução do aprendizado do que propriamente com a distribuição dos exemplos.

Mesmo com a natureza incremental do modelo de construção do classificador aqui apresentado, o aprendizado por reforço não está sendo empregado neste trabalho, por ser a função "reforço", no caso de classificação por cores, de difícil modelagem na prática.

\subsection{Aprendizado híbrido}

A hibridização dos sistemas inteligentes é um campo promissor nas pesquisas atuais. A concepção de métodos de aprendizado híbrido é conseqüência da combinação e integração de abordagens permitindo estender a gama de problemas a serem solucionados. Tais métodos têm progressivamente mostrado sua capacidade em lidar com problemas complexos do mundo real, envolvendo incerteza, vaguidade e também atributos de representação em espaços com alta dimensionalidade (GROSSBERG, 2004).

Em linhas gerais, abordagens híbridas compreendem o uso simultâneo e integrado de mais de uma técnica inteligente, como os métodos tradicionais baseados em conhecimento simbólico, conjuntos nebulosos, algoritmos genéticos, raciocínio baseado em casos, agentes e sistemas multiagentes. A combinação ou integração destas metodologias pode utilizá-las seqüencial e individualmente, fundi-las umas nas outras ou transformar a representação do conhecimento que é característica de uma delas no formato característico de outra. As metodologias que estão sendo integradas incluem redes neurais, sistemas especialistas, sistemas nebulosos, paradigmas de aprendizado em máquinas, algoritmos de otimização, técnicas de busca, algoritmos evolucionários, sistemas multiagentes, redes bayesianas, raciocínio probabilístico, lógica indutiva, inferência gramatical, para citar algumas delas. As áreas de aplicação são potencialmente vastas, partindo da robótica (visão, navegação, controle e automação), passando por diagnóstico médico e controle de qualidade, mineração de dados, inteligência de negócios, mineração de textos, recuperação de informação, sistemas de apoio à decisão, processamento de linguagem natural, realidade virtual.

Segundo Goonatilake e Khebbal (1995) apud Ludermir (2003), os sistemas inteligentes híbridos apresentam três tipos fundamentais, e esta classificação proposta considera funcionalidade, arquitetura de processamento e necessidades em comunicação. Estes tipos são: 
Tipo I: sistemas com substituição de função. Uma técnica inteligente implementa a função de outra técnica. Não acrescenta funcionalidade ao sistema, apenas procura superar alguma limitação da técnica original ou otimizá-la. Por exemplo, árvores de decisão implementando regras de sistemas nebulosos, as quais são freqüentemente fornecidas por especialistas na aplicação.

Tipo II: sistemas com intercomunicação. Para resolver problemas complexos que possam ser subdivididos em tarefas independentes. Cada módulo responsável por uma tarefa utiliza uma técnica inteligente separadamente. Por exemplo, técnicas de agrupamento classificando instâncias para treinamento de redes neurais.

Tipo III: sistemas polimórficos. Uma técnica é adaptada para realizar tarefas inerentes a outra técnica. Assim, novas funcionalidades podem ser descobertas, expandidas e compreendidas, bem como novas relações entre tais técnicas. Um exemplo é o sistema "neuro-fuzzy".

Dentre alguns trabalhos relativamente recentes em visão, Vatsavai (2002) e colegas combinaram agrupamentos "c-means" com uma árvore de decisão gerada sobre dados geoespaciais. Lai e Tseng (2004) empregaram uma soma de funções densidade de probabilidade gaussianas e algoritmos genéticos para estimativa dos parâmetros de ajuste, na limiarização multiníveis de imagens. Coe (2005) e outros combinaram uma abordagem orientada a objetos com classificação pelo vizinho mais próximo na detecção de superfícies impermeáveis em áreas urbanas. Hewavitharana e Fernando (2002), ao reconhecer caracteres tamil ${ }^{1}$, combinaram técnicas estruturais (análise dos traços) com técnicas estatísticas. Pitiot, Toga e Thompson (2002) e colaboradores realizaram a segmentação de imagens de ressonância magnética combinando gabaritos elásticos com heurística evolucionária.

Conforme exposto anteriormente, no trabalho aqui proposto, a adoção de um esquema híbrido para o treinamento do classificador visa:

- explorar a vantagem do aprendizado não-supervisionado em lidar com muitos pixels, agrupando-os por similaridade de cores, e possibilitar a definição de classes ou conceitos sobre os grupos formados, no caso aqui estudado, cor da pele humana;

- explorar a vantagem do aprendizado supervisionado na utilização de um agente especialista para rotular e identificar os grupos obtidos e definir classes, tal como a cor da pele;

\footnotetext{
${ }^{1}$ Idioma falado em Sri Lanka, Singapura e pequena parte da Índia.
} 
- contornar a incapacidade do aprendizado não-supervisionado de atribuir rótulos significativos aos grupos formados. Uma imagem é particionada em grupos de cores, mas os objetos representados por estas cores são identificados mediante um agente que observa a imagem e estabalece esta relação;

- contornar a tarefa dispendiosa de rotular significativamente cada instância (típica em aprendizado supervisionado). Cada pixel deve ser identificado como sendo ou não cor da pele, e na proposta aqui apresentada, a classificação é nebulosa, implicando no grau de pertinência do pixel ao conjunto cor da pele.

Assim, pode-se considerar que o método aqui proposto é um aprendizado híbrido do tipo II, combinando os paradigmas supervisionado e não-supervisionado e adicionando um procedimento de generalização de classe.

\subsection{Conclusão do capítulo}

Alguns conceitos básicos sobre aprendizado computacional foram apresentados. A idéia principal é que um classificador por cores constrói automaticamente uma hipótese (classe de cores de um objeto) utilizando os paradigmas supervisionado e não-supervisionado. O interesse neste trabalho reside no aprendizado das classes de cores, que se processa com as seguintes características:

- baseado em instâncias;

- de modo incremental;

- sem supervisão em um nível de abstração mais baixo, agrupando pixels pelas cores de acordo com as imagens analisadas;

- com supervisão em um nível superior, onde os grupos obtidos são organizados em classes, e as classes rotuladas;

- com supervisão em mais um nível superior, na combinação ponderada dos grupos em classes.

Este paradigma de supervisão híbrida é fortemente motivado pela necessidade de classificar objetos pela cor, e não classificar as cores somente. Como já exposto, as cores percebidas pelo sistema visual humano são contínuas em um espaço de representação, mas 
os objetos são semanticamente rotulados pela cor. Os valores dos pixels formam grupos nos espaços de cores, e muitos destes grupos podem ser combinados em poucas classes.

O modelo de construção do classificador aqui proposto pretende explorar, no âmbito do aprendizado computacional:

- como atribuir supervisão ou não aos níveis do conhecimento necessários no processo de construção de um classificador de objetos por cores;

- como ponderar melhor a combinação dos grupos em classes, utilizando conhecimento prévio sobre o domínio;

- analisar formas adequadas de generalização da base de hipóteses construída com o treinamento. 
Parte II

PROPOSTA E DETALHAMENTO

DO CLASSIFICADOR POR

CORES 


\section{CONCEPÇÃO DO CLASSIFICADOR}

Este capítulo é dedicado à descrição do método proposto de construção do classificador. São apresentados os pré-requisitos para tal, e as relações entre conjuntos nebulosos, agrupamentos, classificação e aprendizado, enfatizando o tratamento das classes obtidas por agrupamento e a agregação dos conjuntos nebulosos que as definem.

\subsection{Uso da cor para a classificação}

Para classificar objetos por suas cores, deve-se considerar os seguintes quesitos:

1. classificar um conjunto de pixels para definir uma determinada cor como conceito vago, em si, não é útil, pois a sensação de cor é contínua, não limitada apenas pelas freqüências das ondas eletromagnéticas, mas é uma combinação das sensações de três tipos de células da retina. Então, afirmar que "a cor ' $A$ ' abrange todos os pixels dentro de um certo agrupamento no espaço de cores" não é útil se não estiver relacionado a algum objeto ou estrutura da imagem;

2. a classificação pela cor deve considerar que um objeto apresenta variações de cores devido às seguintes características: a) sensibilidade às cores não-uniforme pelo olho humano; b) refletância, absorção e dispersão não-uniformes das cores pelos objetos, em função da freqüência luminosa; c) diferentes curvaturas e orientações da superfície dos objetos, provocando variações na reflexão e, portanto, na cor percebida; d) alterações na cor devido à fonte luminosa, isto é, luz solar direta ou indireta, pôr-do-sol, luz incandescente, luz fluorescente, etc. Portanto, as cores associadas a objetos apresentam variações suaves de intensidade e croma (a cor propriamente dita), a menos que haja alguma superfície do objeto com mudança abrupta de orientação; 
3. a distribuição das cores da imagem forma grupos no espaço de cores, compactos ou não, mas relacionados aos objetos daquela cor presentes na imagem. Portanto, isolar e identificar estes grupos permite a segmentação da imagem em objetos de cores similares;

4. sendo a classificação dos objetos realizada através da cor (no contexto deste trabalho), ela é o atributo utilizado na tarefa de identificação. Muitos objetos são semanticamente relacionados a uma faixa de cores que os caracterizam. Por exemplo: céu, laranja, abóbora, tomate, mar, sol, nuvem, camarão, camisa da seleção brasileira, grama, etc. Afirma-se que tomates maduros são vermelhos, porém, existe uma variação contínua neste vermelho de forma a ocupar uma região característica em qualquer espaço de cores, formando uma nuvem de pontos;

5. o limite da cor vermelha característica dos tomates maduros é nebuloso, logo, parece natural associar o grupo formado por seus pontos coloridos a um conjunto nebuloso, denominado talvez de "vermelho-tomate". Parece natural também que os pontos situados na região mais interior do grupo apresentem pertinência maior ao conjunto "vermelho-tomate". À medida que se aproxima dos limites do grupo, a pertinência deve cair gradativamente;

6. uma imagem apresenta milhares de pontos. Um objeto, caracterizado pela cor, pode aparecer em várias imagens, sob as mais diversas condições, por isto, a cor característica deste objeto pode variar. São necessárias várias imagens para abranger estas variações. Os paradigmas de aprendizado computacional são apropriados para modelar um classificador por cores, utilizando as imagens que contenham os objetos de interesse como treinamento.

Estabelecem-se aqui os fundamentos da classificação de objetos pela cor, consistindo na sustentação dos requisitos para a construção do classificador.

\subsection{Proposta de construção do classificador}

Para construir o classificador, alguns requisitos são de interesse:

i) um conjunto de imagens, contendo o mesmo objeto (ou mesmo grupo de objetos) caracterizado por uma determinada cor típica. Este conjunto deve ser usado como treinamento para o classificador, dentro do paradigma de aprendizado computacional baseado em instâncias; 
ii) como o número de pixels que possuem os diversos valores da cor de interesse é muito grande e os limiares destes valores não são bem definidos, é útil que seja executado o algoritmo de agrupamentos nebulosos, para cada imagem;

iii) algum nível de supervisão pode ser necessário, garantindo uma maior acurácia nas respostas do classificador. Assim, deseja-se que o grupo (ou grupos) de interesse sejam identificados e rotulados;

iv) os grupos de mesmo rótulo, provenientes de cada imagem, devem ser convenientemente combinados num único modelo de classe, uma vez que representam o mesmo objeto de interesse. Levando em conta a pertinência recebida por cada ponto no espaço de cores e a freqüência de ocorrência da cor ${ }^{1}$ no conjunto de treinamento, esta combinação deve ser feita por operadores de agregação nebulosos;

v) a formulação do conceito a ser aprendido pelo classificador deve se dar de forma incremental, isto é, o conceito é gradativamente aperfeiçoado com um maior número de experiências de classificação;

vi) deve-se fornecer ao classificador o poder de generalização, para que o aprendizado do modelo de classe reflita melhor o conceito desejado.

A construção de um classificador que satisfaz tais requisitos é proposta nesta tese; o método para isto segue o diagrama da fig. 5.1. A construção do classificador é concebida em quatro módulos. Cada módulo é independente, com funções bem definidas, sendo descritos a seguir:

1. Módulo de agrupamentos nebulosos. Os atributos escolhidos pelo supervisor são extraídos das imagens de treinamento. Neste trabalho, são as cores dos pixels da imagem. A seguir, o conjunto de pixels é agrupado pela cor de modo nebuloso, obtendo-se a pertinência de cada cor em relação aos grupos obtidos. Imagens são construídas separadamente com os pixels cujas cores apresentam maiores pertinências em cada grupo, aqui denominadas subimagens, para análise do agente supervisor.

2. Módulo de definição de classes. O supervisor analisa as subimagens obtidas de cada imagem de treinamento, rotulando-as e definindo classes. Cada subimagem fica associada a uma classe, com sua respectiva pertinência.

\footnotetext{
${ }^{1}$ freqüência de ocorrência para diferir de freqüência ondulatória da cor.
} 
3. Módulo de agregação. São agregadas as classes de interesse $\omega_{i}^{\prime}, \omega_{i}^{\prime \prime}, \omega_{i}^{\prime \prime \prime}, \ldots$, identificadas no módulo anterior com o mesmo rótulo, existentes em cada imagem de treinamento. Eventualmente, alguns pixels podem pertencer à mesma classe em várias imagens, por causa de sua cor $\mathbf{x}_{k}$. Então, suas pertinências em cada imagem são combinadas por algum operador de agregação nebulosa, definindo a distribuição da classe de interesse $\omega_{i}$.

4. Módulo de generalização. Após o processo de agregação, as classes formam nuvens no espaço de cores. Estas não devem possuir descontinuidades em seu interior, pois espera-se que as cores dos objetos apresentem variações suaves. No entanto, não há garantia que estes valores de cor estiveram presentes nas imagens de treinamento. Este módulo visa preencher o interior das nuvens por algum processo de interpolação, atribuindo valores de pertinência a estes pontos. Desta forma, obtémse a generalização do modelo da classe de modo a refletir instâncias não apresentadas no treinamento.

Estes quatro módulos são detalhados a seguir. 


\section{T R E I N A M E N T O}

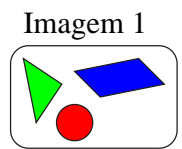

Módulo 1: agrupamentos nebulosos

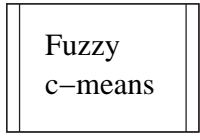

Imagens decompostas em grupos de pixels similares
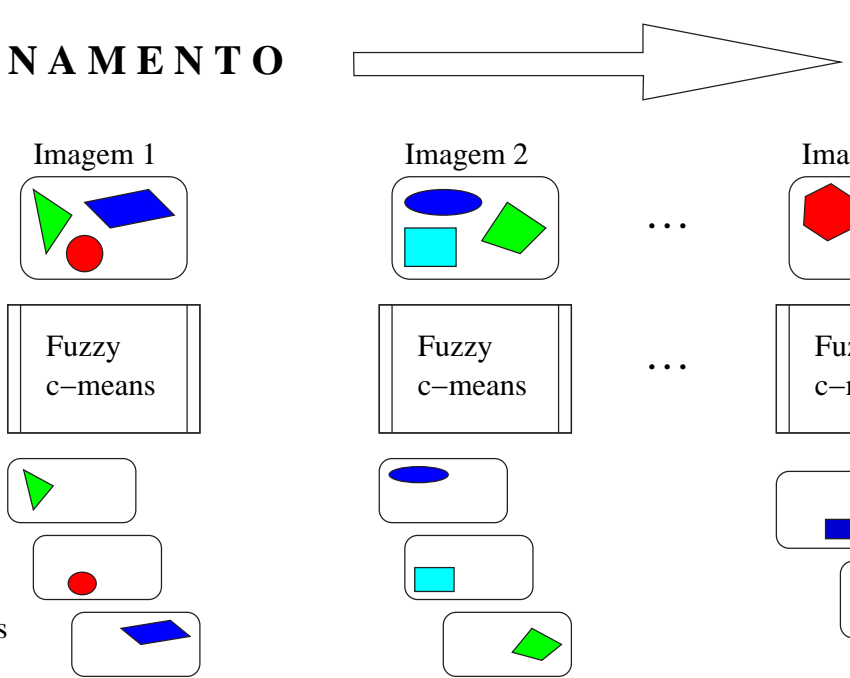

supervisor associa grupos com classes
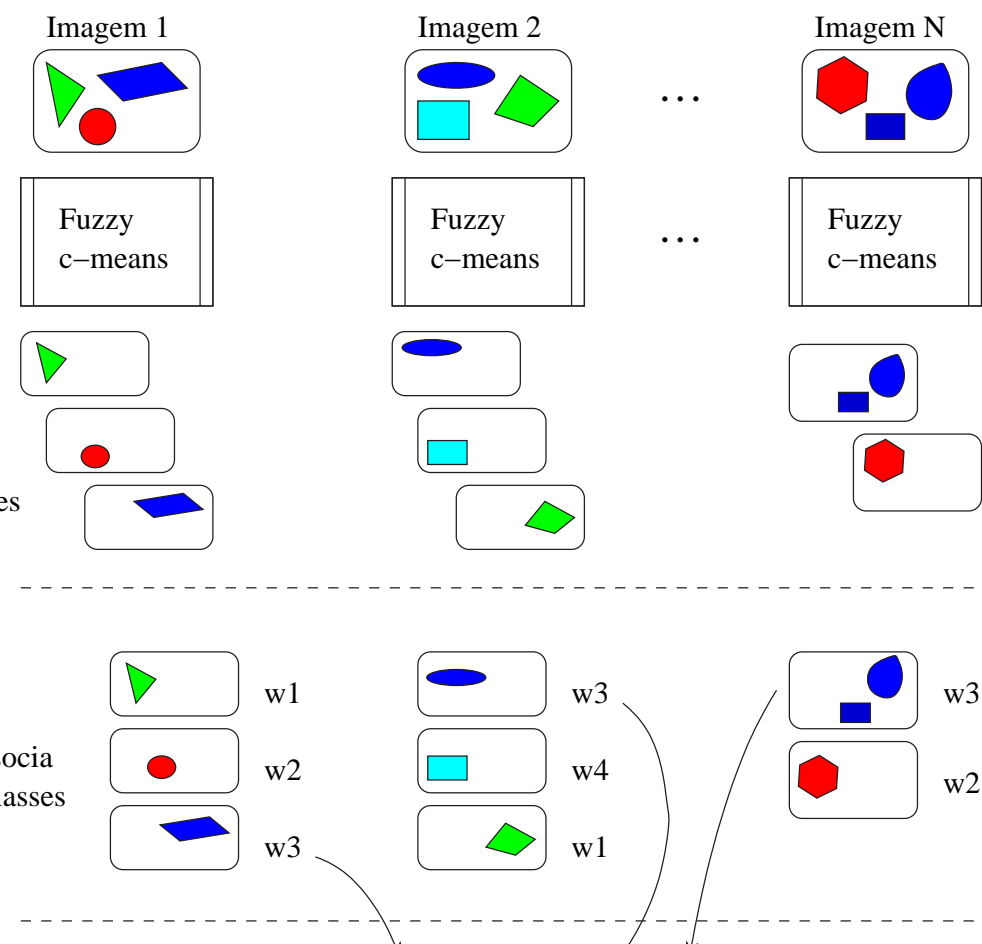
w3

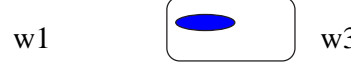
w2
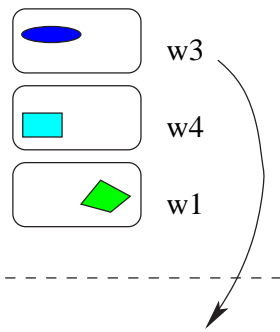

Módulo 3: agregação dos grupos de mesma classe

1
1
1

\section{Módulo 4:}

generalização da classe

$$
\mathrm{u}_{\mathrm{w} 3}^{\star}=\mathrm{G}\left\{\mathrm{u}_{\mathrm{w} 3}\right\}
$$

D E T E C Ç Ã O
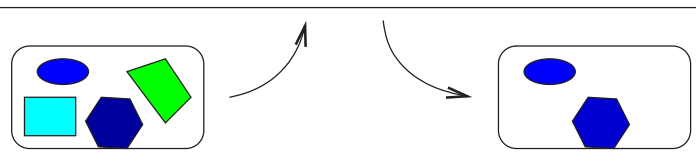

Módulo 1. Agrupamentos nebulosos: revela os grupos formados pelos pontos no espaço de cores, associando-lhes valores de pertinência;

Módulo 2. Definição das classes: um agente supervisor associa os grupos obtidos no módulo 1 a classes, novas ou preexistentes;

Módulo 3. Agregação: combina os grupos atribuídos à mesma classe e calcula a pertinência resultante de cada cor encontrada em comum a estes grupos;

Módulo 4. Generalização: preenche os interstícios nas nuvens de pontos no espaço de cores, para que o classificador considere estes pontos pertencentes à classe dada pela nuvem, com pertinência adequada.

Figura 5.1: Diagrama de blocos da modelagem do classificador. 


\subsubsection{Módulo 1. Agrupamentos nebulosos.}

O objetivo designado para este módulo é revelar estruturas de grupos nos dados analisados, e atribuir um valor de pertinência $u_{i k}$ de cada cor $\mathbf{x}_{k}$ aos grupos obtidos $G_{i}$. O algoritmo escolhido, o FCM-GK, é capaz de detectar grupos alongados, uma vez que a distribuição no espaço de cores de uma dada cor se mostram freqüentemente como elipsóides. Neste módulo, os valores dos atributos das imagens (no caso, pixels com sua tripla de valores da cor), são pseudoparticionados pelo algoritmo FCM-GK de agrupamento nebuloso, devido às seguintes características:

- o agrupamento nebuloso permite, através dos valores de pertinência $u_{i k}$, lidar com a incerteza da classificação dos dados de fronteira, isto é, no limite entre dois ou mais conjuntos nebulosos;

- a matriz de covariância utilizada na distância de Mahalanobis permite a detecção de grupos alongados, em diferentes direções no espaço de atributos (GUSTAFSON; KESSEL, 1979).

Este procedimento é não-supervisionado, como normalmente ocorre com os algoritmos de agrupamento. Devido ao grande número de pixels envolvidos nesta etapa, a supervisão para indicar a classe de cada pixel não se mostra atrativa. Porém, há dois parâmetros do algoritmo FCM-GK que são decididos arbitrariamente:

- o valor do fator de nebulosidade $m$. Segundo Windham (1983), quanto maior $m$, menor a influência dos pontos com menor pertinência $u_{i k}$ na posição dos centróides $v_{i}$ dos grupos, por outro lado, um aumento de $m$ aumenta a influência dos pontos "outliers"". Muitos autores adotam valores entre 1,5 e 2,0 (LIM; LEE, 1990); (WU; YAN; CHALMERS, 1994); (ITO, 1995); (BAUER; BODENHOFER; KLEMENT, 1996); (CHI; YAN; PHAM, 1996); (GULIATO, 1998); (HöPPNER, 1999) e (LIAO; LI; LI, 1999), dependendo do problema e da qualidade dos resultados;

- o número de grupos $c$ no espaço de cores, por imagem. Neste trabalho é empregada a função de validação $S$ de Xie e Beni (eq. 3.25), para obter a melhor relação entre compactação de cada grupo e separação entre grupos.

\footnotetext{
${ }^{2} \mathrm{Um}$ "outlier" é um valor freqüentemente descrito como ruído, mas rigorosamente refere-se a um dado que não corresponde ao fenômeno em estudo, e muitas vezes originado de um erro na etapa de aquisição. Muitos dados experimentais apresentam alguns "outliers", que, uma vez identificados, podem ser descartados.
} 
Os grupos obtidos são conjuntos nebulosos definidos por agrupamento, com a função de pertinência do conjunto $i$ definida pela $i$-ésima linha da matriz $\left\{u_{i k}\right\}$ da eq. 3.22.

Neste trabalho, o emprego dos outros classificadores não-supervisionados no contexto deste método ainda é objeto de investigação futura. Como requisito essencial, estes devem realizar classificação nebulosa, isto é, associar um valor de pertinência de cada instância $\mathbf{x}_{k}$ em relação a cada classe. Mesmo assim, levando-se em conta os objetivos deste módulo, o algoritmo FCM-GK é suficientemente robusto, apresentando resultados bem satisfatórios.

Em linhas gerais, este módulo é de processamento automático. Muitas vezes, pode-se torná-lo mais eficiente se localizar e particionar apenas subquadros na imagem, por exemplo, com a heurística de presselecionar partes da imagem contendo objetos de interesse. Mesmo assim, ainda não há a identificação e rotulação dos grupos formados. Esta decisão é tomada pelo módulo seguinte.

\subsubsection{Módulo 2. Definição de classes.}

Este módulo tem por objetivo rotular os grupos (definidos no módulo anterior) por um agente externo, com conhecimento sobre o domínio. Como o agrupamento realizado pelo módulo anterior é nebuloso, pixels de mesma cor $\mathbf{x}_{k}$ freqüentemente estão presentes em vários grupos, com pertinências variáveis entre 0 e 1 . Então, o grupo $i$ é rotulado pelas cores dos pixels de pertinência mais alta, por exemplo, $u_{i k}>0,5$. Esta rotulação pode ser feita construindo-se subimagens, cada uma contendo os pixels cujas cores apresentam maior pertinência no mesmo grupo. As subimagens geradas no módulo anterior facilitam a associação feita pelo agente externo. É conveniente lembrar que cada grupo obtido no módulo anterior é um conjunto nebuloso, com uma função de pertinência associada.

Neste módulo fica evidenciada a diferença conceitual entre grupo e classe, no contexto de construção do classificador. Os grupos são obtidos por similaridade das cores dos pixels em uma imagem. A classe pode ser formada por grupos disjuntos, ou por grupos de pixels que foram "particionados demais", pois o agrupamento é não-supervisionado. Além disso, grupos diferentes, obtidos de imagens diferentes, podem ser rotulados com o mesmo significado (por exemplo, cor prateada), portanto, constituem a mesma classe.

Um outro nível de supervisão, para aumentar a acurácia do classificador, pode ser incorporado. Consiste em atribuir um grau de relevância na associação do grupo à classe. Por exemplo: em uma imagem é selecionado o grupo de cores $G^{\prime}$ e é associado à classe $\omega_{p}$. Outra imagem contém um grupo $G^{\prime \prime}$ que também é associado à classe $\omega_{p}$. O supervisor 
pode considerar $G^{\prime \prime}$ mais relevante que $G^{\prime}$, e, para facilitar a atribuição, o grau de relevância pode ser descrito lingüisticamente, como "muito", "mais ou menos", "pequeno", e outros. A operacionalização desta relevância é discutida no capítulo seguinte.

É oportuno lembrar aqui que, quanto maior a acurácia requerida para o classificador, maior o grau de intervenção necessária do agente supervisor.

Inclusão dos contraexemplos Os exemplos negativos também precisam ser considerados no processo de treinamento. As cores definidas como não sendo de interesse, ou que recebam algum outro rótulo, deverão ter suas pertinências armazenadas para agregação no módulo seguinte, de forma a serem considerados contraexemplos.

Dependendo da aplicação para a qual o classificador esteja sendo concebido, pode ser mais útil rotular apenas as classes de interesse, ou seja, supondo que o classificador está sendo modelado para reconhecimento de objetos muito específicos, por exemplo, "frutos da cor vermelho escuro". Então, todas os outros grupos podem constituir uma grande classe de contraexemplos, rotulada talvez "objetos que não são frutos da cor vermelho escuro".

Assim, neste tipo de classificador, um pixel de cor $\mathbf{x}_{k}$ é considerado exemplo negativo se apresentar pertinência baixa na classe de interesse e alta em alguma outra classe.

\subsubsection{Módulo 3. Agregação dos grupos nebulosos}

Neste módulo fica a construção propriamente dita do classificador. Aqui, o classificador é modelado pelas agregação dos grupos rotulados com a mesma classe.

Se um pixel $k$ de uma dada cor $\mathbf{x}_{k}^{(n)}$ estiver com pertinência alta na classe de interesse $p$ da imagem $n$, sua pertinência será combinada de uma forma ponderada com as pertinências da mesma cor na mesma classe, provenientes de $N_{T}$ imagens de treinamento anteriores. É realizada uma agregação nebulosa entre a pertinência $u_{p k}^{(n)}$ da cor $k$ da classe $p$, e as pertinências da mesma cor $\mathbf{x}_{k}^{(1)}, \ldots, \mathbf{x}_{k}^{(n)}, \ldots, \mathbf{x}_{k}^{\left(N_{T}\right)}$ já apresentadas em outras imagens de treinamento. $\mathrm{O}$ valor de pertinência final para esta cor é calculado de acordo com o operador de agregação $\Theta$, expresso de uma forma geral por

$$
u_{p k}=\Theta\left(u_{p k}^{(1)}, u_{p k}^{(2)}, \ldots, u_{p k}^{(n)}, \ldots, u_{p k}^{\left(N_{T}\right)}\right)_{\mathbf{x}_{k}} .
$$

Assume-se que o método de agrupamento utilizado em cada conjunto de dados permanece o mesmo e emprega a mesma métrica definida no módulo 1. 
Uma contribuição deste trabalho é a investigação de qual operador nebuloso de agregação atende melhor aos requisitos da construção do classificador, considerando que a estratégia de aprendizado é incremental (permitindo o aumento de desempenho com o treinamento), e baseado em memória (experiências anteriores contendo dados corretamente classificados) (HAYKIN, 1999). Visando preservar as propriedades do aprendizado incremental, foram investigados os efeitos de vários operadores de agregação nebulosa (DOMBI, 1982); (YAGER, 1988); (BLOCH, 1996) e (DETYNIECKI, 2001).

Agregação incremental das funções de pertinência. A questão é: qual tipo de operador de agregação $\Theta$ deve ser aplicado? Deve-se levar em conta o histórico de pertinências da cor $\mathbf{x}_{k}$ e incorporar a informação de novos valores de pertinência, à medida que o treinamento prossegue, com a análise de novas imagens. Considera-se, para a concepção do modelo proposto, que:

- o operador escolhido deve ser comutativo, pois a ordem de apresentação das imagens é aleatória. Logo a ordem de agregação das pertinências da cor $\mathbf{x}_{k}$ não importa e deve levar sempre ao mesmo resultado para a pertinência combinada, dadas as mesmas imagens;

- o operador de agregação não deve ser do tipo severo (cap.3), pois poucas cores de pertinência baixa impõem uma pertinência combinada também baixa, para cor e classe dadas. Conseqüência: cores que aparecem em poucas imagens são superestimadas com pertinência alta para a classe dada;

- o operador escolhido também não deve ser do tipo indulgente, pois a pertinência combinada fica alta. Então, cores que apresentam pertinência alta em uma classe, na maioria das imagens, têm a pertinência facilmente reduzida se apresentarem pertinência baixa em poucas imagens;

- é importante considerar o histórico das pertinências $u_{p k}^{(1)}, u_{p k}^{(2)}, \ldots, u_{p k}^{(n)}, \ldots, u_{p k}^{\left(N_{T}\right)}$ da cor $\mathbf{x}_{k}$ na classe $p$, após $N_{T}$ imagens de treinamento.

Para manter as características do aprendizado incremental, tornando a operação de combinação independente da ordem em que os dados são apresentados, é conveniente empregar o operador média de um modo funcional, isto é, como função de todas as pertinências em conjunto apresentadas pelo mesmo dado no treinamento, como segue:

$$
u_{\text {classe }}\left(\mathbf{x}_{k}\right)=\operatorname{média}\left(u_{1}\left(\mathbf{x}_{k}\right), u_{2}\left(\mathbf{x}_{k}\right), \ldots, u_{N_{T}}\left(\mathbf{x}_{k}\right)\right)
$$


A média é mais robusta às flutuações da pertinência apresentada pelo dado durante o treinamento. Em outras palavras, a memória do treinamento é conservada e a contribuição do novo valor de pertinência é combinada com os valores existentes.

Efeito do operador média. Considerando que a grande maioria das imagens de treinamento apresentadas contenham a classe de interesse, os seguintes casos podem ocorrer:

1. uma cor $\mathbf{x}_{k}$ com pertinência alta na maioria destas imagens, terá uma pertinência combinada também alta. Isto revela que a cor é bem típica na classe considerada;

2. se uma cor estiver presente em poucas imagens com pertinência alta, a pertinência combinada resultará baixa. A cor foi considerada típica ocasionalmente em alguma imagem de treinamento;

3. se uma cor estiver presente em muitas imagens com pertinência baixa, a pertinência combinada resultará baixa. A cor geralmente não é típica da classe considerada;

4. se uma cor estiver presente em poucas imagens com pertinência baixa, a pertinência combinada resultará muito baixa. A cor definitivamente não é típica da classe considerada;

Então, o operador média, aplicado sucessivamente, tem um comportamento severo? Diante dos casos expostos, a análise mais adequada ao comportamento da média sugere que o classificador está sendo modelado como um filtro, reforçando apenas as cores com alto grau de pertinência à classe de interesse.

É importante notar também que o operador média não vai necessariamente expandir a fronteira da classe pele, como a denominação agregação sugere. Por isto, entende-se que a denominação operadores de combinação pode soar mais adequada, no sentido de que a formação supervisionada da classe de interesse é uma combinação de conjuntos nebulosos tal que, em alguns intervalos do universo de discurso (no caso, o espaço de cores), ocorre um reforço e em outros, atenuação, de acordo com os valores das pertinências.

\subsubsection{Módulo 4. Generalização da base de conhecimento}

Este módulo visa estabelecer a completeza do classificador. Considerando-se que o classificador está sendo moldado para reconhecer uma classe específica de cores, por exemplo, 
verde-esmeralda (uma situação típica poderia ser um robô vasculhando uma galeria insalubre à procura de esmeraldas). Após o treinamento do classificador, a agregação e definição desta classe de cores formará uma "nuvem" de contornos difusos no espaço de atributos. Assim, qualquer ponto no interior desta nuvem poderá ser considerado pertencente à classe, esperando-se que, quanto mais interior, maior a pertinência.

Com o classificador de cores construído de acordo com os módulos 1 a 3, é possível realizar testes de detecção em novos conjuntos de treinamento. Mas, ainda resta um problema: ao se executar a detecção (testes), a base de conhecimento restringe-se apenas aos dados de treinamento. Resta incluir no classificador um processo de generalização, ou um módulo para inferir a pertinência de uma "nova" cor.

De acordo com a teoria de aprendizado PAC (VALIANT, 1984) (ver anexo 2), um número muito grande de imagens de treinamento é necessário para preencher todo o interior desta nuvem, definindo bem o seu formato. Porém, algumas considerações sobre o domínio de aplicação podem fornecer uma heurística que otimizam o treinamento. No caso de imagens naturais, a variação de uma cor característica de um objeto na cena é suave, logo, espera-se que estes cores $\mathbf{x}_{k}$ estejam todas em uma vizinhança compacta, formando um grupo - a assunção feita para se empregar algoritmos de agrupamento no módulo 1.

Após um número razoável de imagens utilizadas para moldar tal nuvem, seus contornos ainda poderão ser difusos, mas seu interior talvez seja descontínuo, contendo "buracos" que deveriam estar preenchidos.

Como a abordagem utilizada para a representação de classes é aquela baseada em instâncias, a solução escolhida para este preenchimento foi o algoritmo "fuzzy k-nearest neighbor" (FkNN). A regra nebulosa dos $k$ vizinhos mais próximos ("fuzzy kNN rule") considera os valores de pertinência como função de distância dos $k$ vizinhos mais próximos, e também a pertinência $u_{i j}$ em relação às classes $i$ destes vizinhos $\mathbf{x}_{j}$. Aqui, uma ligeira mudança de notação, em relação à utilizada, para seguir a literatura: classes $i$, pontos $j$, vizinhos $k$. A pertinência final do elemento a ser classificado no espaço de atributos é uma média entre as pertinências dos $k$ vizinhos, ponderada pelas distâncias (de acordo com alguma métrica) que minimizam a função objetivo dada na eq. 3.17. Esta pertinência é 
calculada de uma maneira parecida com o algoritmo FCM-GK, sendo expressa por

$$
u_{i}(\mathbf{x})=\frac{\sum_{j=1}^{k} u_{i j}\left\|\mathbf{x}-\mathbf{x}_{j}\right\|^{\frac{-2}{m-1}}}{\sum_{j=1}^{k}\left\|\mathbf{x}-\mathbf{x}_{j}\right\|^{\frac{-2}{m-1}}}
$$

onde $\mathbf{x}$ é o vetor de atributos a ser classificado com a pertinência $u_{i}$ em relação às classes $\omega_{i}$ dos $\mathbf{x}_{j}$ vizinhos mais próximos, com grau de nebulosidade $m$. Em vez do elemento desconhecido $\mathbf{x}$ ser atribuído à classe da maioria dos $k$ vizinhos, ele passa a compartilhar das classes envolvidas, com a respectiva pertinência $u_{i}$ a cada uma delas.

Para a construção do classificador aqui proposto, em particular, a regra kNN nebulosa foi escolhida pelas seguintes razões:

- "buracos" no interior da nuvem de pontos que representa uma classe terão uma pertinência atribuída conforme a pertinência dos vizinhos;

- próximo à borda, que é difusa, a pertinência será uma composição das pertinências de pontos vizinhos, que mistura cores pertencentes à classe (pertinência alta) e cores de outras classes (pertinência baixa). Esta borda é de transição suave.

Vantagens e desvantagens da regra nebulosa kNN. As vantagens da regra nebulosa kNN são as seguintes:

- permite um cálculo mais preciso da pertinência do dado a ser generalizado, pois agora se trata de uma média ponderada das pertinências da vizinhança. Se a variação da pertinência pela vizinhança for suave, o novo dado será interpolado;

- pode dispensar a tarefa de generalização do sistema (módulo 4), se esta regra for aplicada para classificar instâncias de teste, usando a base de conhecimento obtida no módulo 3. Porém, o procedimento de teste fica bem mais custoso em termos computacionais;

- não importa quão esparsa está a nuvem de dados para um determinado grupo no espaço de atributos, pois a regra busca os $k$ vizinhos mais próximos, e sua distância de busca pode ser controlada, para não expandir a nuvem de modo indesejado;

- classifica apenas os dados da instância de teste, não necessitando explorar o espaço completo. 
Este procedimento apresenta também algumas desvantagens:

- necessita, como parâmetro adicional, um alcance, isto é, uma distância máxima para considerar o tamanho da vizinhança. Isto porque os classificadores do tipo vizinho mais próximo genericamente atribuem a classe mais freqüente dos vizinhos mais próximos, não importando a posição da instância $\mathbf{x}$ a ser classificada;

- apresenta custo computacional alto, pois o número total de vizinhos cresce com o número de camadas vizinhas elevado ao cubo, no caso do espaço de atributos ser discreto. Cada camada neste tipo de vizinhança é uma "casca" cúbica, de arestas dadas por um número ímpar de pontos. Há um problema a ser resolvido experimentalmente: escolher o melhor valor para $k$. Por exemplo, uma vizinhança tridimensional cúbica de uma camada apresenta 26 vizinhos; duas camadas, 142 vizinhos; três camadas, 460 vizinhos; e assim segue. Por exemplo, a expressão geral para vizinhança é

$$
N_{\text {vizinhos }}=\sum_{i=1}^{M_{\text {camadas }}} 2 i\left[4+(2 i+1)^{2}\right]
$$

- se for aplicado como tarefa de generalização do sistema, após a etapa de treinamento, necessita testar todos os pontos do espaço de atributos, pois não se sabe a princípio os limites do grupo provenientes do treinamento. Se um dado testado estiver fora da nuvem correspondente ao grupo, receberá pertinência nula (eq. 5.3), e se estiver no interior da nuvem, terá pertinência dada pela variação de densidade da nuvem. Se estiver na fronteira, sendo ela nebulosa, esta equação pondera a pertinência da vizinhança;

- se for aplicado apenas para classificar os dados de teste, dispensa a etapa de generalização após o treinamento, mas terá que ser aplicado para todos os dados de teste, para a classificação.

Uma boa estratégia de aplicação para a generalização é usar o classificador kNN nebuloso para testar todo o espaço de atributos apenas uma vez e comparando cada cor $\mathbf{x}$ com sua vizinhança nebulosa na base de conhecimentos. Com isto, evita-se classificar toda vez os pixels das imagens de teste.

Um cuidado extra deve ser observado ao se empregar o algoritmo kNN nebuloso (ou mesmo o clássico): são selecionados os $k$ primeiros vizinhos a qualquer distância do ponto 
testado. Como o objetivo aqui é preencher os interstícios da classe no espaço de cores, os $k$ primeiros vizinhos devem ser restritos a uma distância limite do ponto de teste.

Portanto, o melhor conjunto de procedimentos para a construção e utilização da base de conhecimentos consiste em:

- efetuar o treinamento do sistema, (módulos 1, 2 e 3);

- executar a generalização via regra nebulosa $\mathrm{kNN}$, testando todo o espaço de atributos contendo o grupo da classe que se quer obter (módulo 4);

- para cada conjunto de teste, classificar os dados usando a base de conhecimentos já generalizada. Neste caso, esta base fica inalterada, e a detecção é agilizada.

O quadro 2 ilustra o procedimento de utilização do algoritmo kNN nebuloso para generalização do modelo construído por aprendizado.

Quadro 2 Aplicação do algoritmo kNN nebuloso.

1. informar coordenadas $[R G B]_{\text {inicial }}$ e $[R G B]_{\text {final }}$ do espaço de cores, onde será executado o processo de preenchimento dos vizinhos faltantes (com pertinência nula) em uma classe específica;

2. informar $n^{\circ} k$ de vizinhos considerados para ponderação da pertinência;

3. informar a "distância de alcance" $\delta$ para que um ponto seja considerado vizinho; // evita a dilatação da nuvem além desta distância

4. informar o fator de nebulosidade $m$;

5. para $\mathbf{x}=[R G B]_{\text {inicial }}$ até $[R G B]_{\text {final }}$

- para $j=1$ até $k$

- se $\left\|\mathbf{x}-\mathbf{x}_{j}\right\|<\delta \quad / /$ vizinho dentro do alcance considerado então calcular o numerador e o denominador da eq. 5.3;

- armazenar a pertinência $u(\mathbf{x})$;

\subsection{Aspectos do aprendizado computacional}

O método de construção do classificador aqui proposto utiliza uma mescla de paradigmas de aprendizado computacional. Como o agente supervisor considerado é o ser humano, a definição das cores representativas dos objetos em cenas naturais deve corresponder, com boa aproximação, às mesmas cores percebidas pelo sistema visual humano. 
Os paradigmas de aprendizado computacional envolvidos na abordagem híbrida proposta são os seguintes:

Baseado em instâncias. O modelo de classificação de cores é construído unicamente a partir de exemplos e contraexemplos. Os exemplos localizam-se nas classes de interesse, no espaço de atributos, e os contraexemplos recaem em outras classes. Como as bordas das classes de cores (nuvens) são difusas, um número razoável de imagens vai reforçando a definição das mesmas.

Incremental. A disponibilidade dos exemplos que induzem a formação das classes pode ser pequena no início do treinamento do classificador, e assim mesmo ele já pode ser utilizado, executando-se o módulo de generalização. Se o treinamento continuar, com a agregação de novos exemplos às classes preexistentes, a pertinência vai sendo recalculada para cada instância, via operador de agregação na forma incremental.

Supervisionado e não-supervisionado. A abordagem híbrida proposta combina o aprendizado supervisionado com o não-supervisionado. No nível mais baixo, onde a cor de cada pixel dificilmente é rotulada com certeza (e é um trabalho enfadonho), a formação de grupos é não-supervisionada. A rotulação das classes somente toma sentido ao analisar o conjunto de cores de cada classe, no contexto da imagem observada. A supervisão ocorre em identificar quais são as classes iguais em uma seqüência de imagens, facilitando sobremaneira o trabalho do supervisor.

É importante destacar onde a supervisão é decisiva para guiar a modelagem:

- ao iniciar as tarefas do módulo 1, executando-se uma seleção primordial dos pixels. No interior de uma imagem, seleciona-se quadros contendo a maior parte da classe de interesse. Cada quadro será tratado como uma imagem em si. As idéias envolvidas neste procedimento são: $i$ ) descartar previamente uma grande quantidade de pixels que não sejam de interesse, ou ruído; ii) contribuir para que o número de pixels das classes de interesse seja alto em relação a outros pixels da cena, tornando mais robusto o agrupamento nebuloso. É importante diferenciar esta ação, considerada neste contexto como supervisionada, da fase de seleção de atributos, que é integrante do processo de modelagem de um reconhecedor. No contexto aqui descrito, o atributo já foi definido, que é a tripla de valores correspondente à cor do pixel; 
- no módulo 2, na análise e seleção das subimagens geradas. Com os pixels agrupados em cada subimagem, o supervisor define as classes $\omega_{i}$ de cores (geralmente associada a algum objeto da imagem) como união dos grupos $G_{i}$ similares;

- no módulo 3. Agregar as nuvens de pontos, em função da relevância de cada uma delas em relação às classes de interesse. Embora os valores de pertinência sejam um forte indicativo neste sentido, os mesmos são atribuídos na partição das cores considerando-se apenas imagens individuais.

Supervisão no nível das classes. Todo o trabalho do supervisor se concentra em atribuir adequadamente os grupos nebulosos formados às classes semanticamente iguais, ao analisar várias imagens. Esta abordagem permite um aumento da acurácia do classificador, pois um mecanismo de reforço ocorre quando muitas cores (provenientes de várias imagens) apresentam pertinência alta a uma dada classe. Mais ainda, se o classificador for modelado para objetos específicos, a definição da classe de cores típica de tais objetos resulta em uma melhor seleção dos pixels, devido a este mecanismo de reforço.

Muitos trabalhos de segmentação de imagens por classificação de cores são direcionados à formação de partições no espaço de atributos (RGB ou qualquer outro), mas não se preocupam em rotular estas partições como função de objetos reais em cenas naturais. Há poucas exceções, como aqueles que detectam humanos pela cor da pele (YANG; KRIEGMAN; AHUJA, 2002). Por isto, é mais conveniente denominar classificador de objetos pelas cores características, do que apenas classificador de cores.

Devido a estes aspectos, propõe-se aqui investigar formas de agregação dos grupos encontrados no espaço de cores, para modelar classes de maneira mais eficaz, levando em conta sua natureza nebulosa.

\subsection{Conclusão do capítulo}

O método proposto para construir o classificador apresenta uma metodologia para modelar classes no espaço de cores, combinando a natureza vaga da cor específica que caracteriza um objeto em cenas naturais com uma maior acurácia. Assim, apresenta uma solução orientada ao domínio, para classificar objetos caracterizados pela cor.

Aqui também evita-se representar as classes de interesse por alguma composição de funções. Como conseqüência, a definição das classes se dá mais eficazmente, pois modela a nuvem de cores sem estar preso a algum parâmetro geométrico - independe do espaço 
de cores. Isto possibilita a flexibilização da modelagem, pois a forma das classes podem ser revisadas com novos exemplos de treinamento (aprendizado incremental).

Nesta proposta de aprendizado, é dada uma importância especial ao agente supervisor, pois permite a ele utilizar conhecimento prévio sobre o domínio, ao rotular os grupos, associá-los a classes e decidir quais grupos serão agregados em quais classes, com a devida ponderação. Então, é proposta uma solução para o problema de se ter uma classe formada por mais de um grupo. Toda a tarefa de recalcular a pertinência das cores às classes está fora do escopo do supervisor, automatizada na execução do agrupamento nebuloso e na aplicação do operador de agregação.

É importante explorar o enriquecimento proporcionado pela teoria dos conjuntos nebulosos, na manutenção dos valores de pertinência, fornecendo flexibilidade para análise do resultado obtido. O classificador assim modelado não é utilizado simplesmente de maneira binária, mas retorna as classes dos pixels testados com o respectivo valor de pertinência segundo suas cores. Como conseqüência, diferentes métodos de decisão podem ser empregados, levando em conta a aplicação envolvida.

No entanto, o método proposto apresenta um custo computacional alto para o treinamento, em particular:

- na aplicação do algoritmo de agrupamento nebuloso, pois tem como parâmetro inicial o número de classes. O número ótimo de classes $c^{*}$ em que o espaço de atributos é particionado, é dado pelo menor valor da função de validação $S$. Para obter $c^{*}$, o algoritmo FCM-GK necessita ser aplicado para cada valor de $c$, e $S(c)$ obtida;

- na aplicação do algoritmo kNN nebuloso, na generalização da base de conhecimento, sendo que o número de vizinhos visitados está no espaço de atributos, e este número aumenta com o cubo do número de camadas consideradas (distância) em torno do ponto a ser classificado (ver eq. 5.4).

É importante neste ponto mencionar que todo o custo computacional fica concentrado na fase de treinamento, incluindo a generalização efetuada com base nos pontos já classificados.

A classificação dos pontos em conjuntos de teste é feita por simples comparação com a base de conhecimento, cuja representação se dá através de uma "lookup table" (LUT). Nenhum modelo de aproximação de funções (por exemplo, combinação de gaussianas, 
comum na literatura) é adotado aqui, para não restringir a modelagem da base de conhecimento em futuras sessões de treinamento. Nenhum parâmetro funcional necessita ser recalculado, e nenhum reajuste de funções é executado (fato comum em estratégias de aprendizado "batch", não-incrementais).

O aprendizado híbrido e incremental nebuloso proposto apresenta as seguintes características:

1. a modelagem das classes através de conjuntos nebulosos permite lidar melhor com a detecção de falsos positivos;

2. permite uma eventual flexibilização em cada módulo, possibilitando a utilização de algoritmos diversos daqueles aqui propostos;

3. utiliza a representação da base de conhecimento através de LUT. Esta escolha se deu considerando que:

(a) em imagens digitais coloridas, o espaço de representação de cores é discreto. Assim, a LUT fica armazenada de forma indexada;

(b) esta representação é adequada para aprendizado incremental, pois independe de qualquer modelagem analítica e, no caso de imagens coloridas, adequa-se à representação usada para a cor (RGB, YUV, HSI, e outros). Seu formato, densidade e limites podem evoluir ao longo do treinamento;

(c) a classificação é agilizada pela simples busca e comparação com a LUT na fase de testes.

No entanto, o uso da representação das classes por LUT apresenta as seguintes desvantagens:

1. ocupa muito espaço: no espaço de cores RGB, são (255) ${ }^{3}$ posições. Alguns autores, aproveitando-se de que a resolução do olho humano para cores é baixa, preferem quantizar este espaço (GARCIA; TZIRITAS, 1999); (JONES; REHG, 2002);

2. necessita de um procedimento adicional para generalização, interpolando a pertinência entre cores vizinhas, no interior de alguma classe.

3. As etapas de treinamento (módulos 1 a 4) são de alto custo computacional para gerar a LUT com acurácia.

Com base nos aspectos gerais do método proposto, descritos neste capítulo, o próximo capítulo detalha a operacionalização de cada módulo. 


\section{ARQUITETURA DE CONSTRUÇÃO DO CLASSIFICADOR}

Este capítulo dedica-se a apresentar detalhadamente a arquitetura de construção do classificador por cores, e mostrando a estrutura de dados envolvida em cada módulo.

No método proposto para a construção do classificador (ver fig. 5.1), cada módulo está estruturado independentemente, com entradas e saídas definidas. A principal vantagem em se conceber o classificador esquematizado em módulos encapsulados é a sua flexibilidade operacional, permitindo um processamento não estritamente seqüencial entre estes módulos. Durante o treinamento ou retreinamento do classificador, enquanto imagens são particionadas em grupos de cores no módulo 1, o agente supervisor pode analisar as subimagens já geradas (módulo 2) e rotulá-las. Ao mesmo tempo, os pixels das subimagens já indicadas pelo supervisor como classes de interesse podem ser submetidos à agregação no módulo 3. Apesar do agente supervisor intervir bastante no processo de definição das classes, as tarefas mais custosas são realizadas de maneira automática. O tratamento das instâncias individuais $\mathbf{x}_{k}$ (pixels) e respectivas pertinências do pixel às classes $u_{i k}$ é considerado aqui processamento de baixo nível, e a escolha supervisionada dos grupos ocorre em um nível superior (NEWELL, 1982).

Segue-se a descrição funcional dos módulos.

\subsection{Módulo 1: Agrupamentos nebulosos.}

Este módulo opera em "batch", pois o agrupamento se dá de forma não-supervisionada. Não há a identificação e rotulação dos grupos formados. Esta decisão será tomada na etapa seguinte. O quadro 3 detalha o conjunto de ações do módulo 1. O esquema geral de processamento deste módulo está esquematizado na fig. 6.1. Para cada imagem processada, a lista de pixels e suas cores (no espaço de representação escolhido) são extraídas. 
Os dados numéricos assim obtidos são processados pelo algoritmo FCM-GK, produzindo uma matriz $\left\{\mathbf{x}_{k}^{T}, u_{i k}\right\}, 2 \leqslant k \leqslant N, 2 \leqslant i \leqslant c^{*}$, onde $N$ é o número de pixels na imagem e $c^{*}$ é o número de grupos ideal para a partição nebulosa, dado pelo mínimo da função de validação $S(\mathbf{U}, c)$. São geradas subimagens definidas pelos $c^{*}$ grupos formados, compostos pelos pixels com maiores valores de pertinência. O número de grupos obtidos $c^{*}$ depende de cada imagem de treinamento.

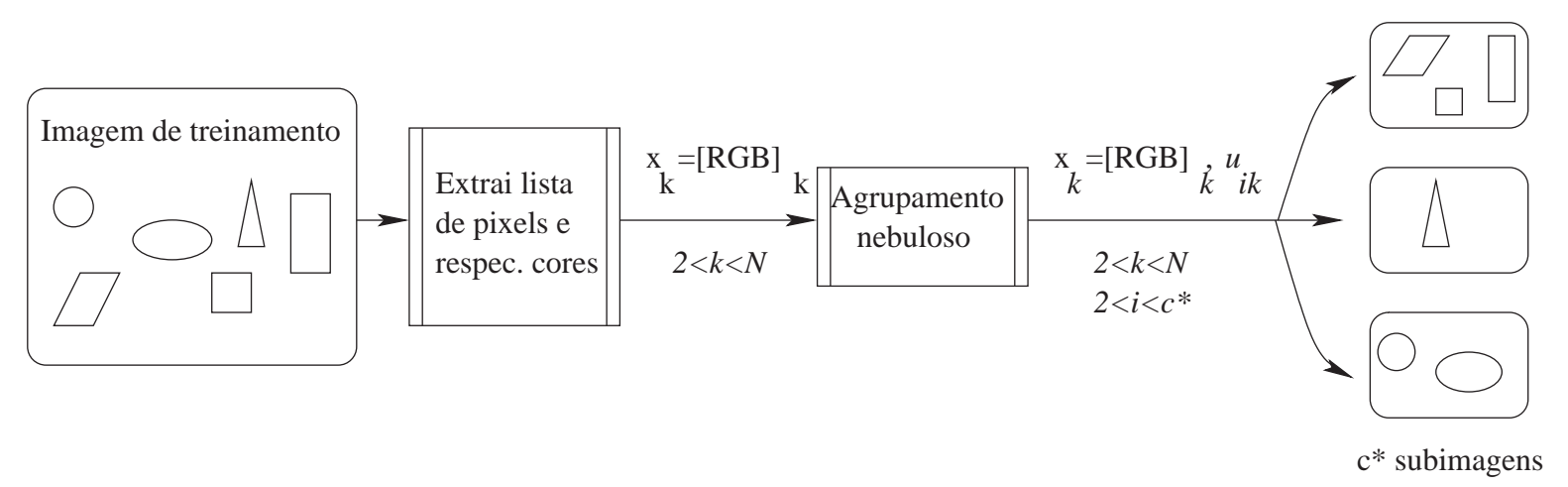

Figura 6.1: Diagrama de blocos do módulo de agrupamentos nebulosos.

\section{Supervisão adicional. Partição grosseira da imagem pelo agente supervisor.}

A fig. 6.2 (original) foi particionada pelo algoritmo FCM-GK, e o melhor número de grupos, quatro, dado pela função de validação $S$ (eqs. 3.25 e 3.26). Observam-se nas figs. 6.2a, $b, c, d$ as subimagens produzidas neste procedimento. Nota-se que alguns objetos, de cores diferentes, foram incluídos no mesmo grupo, como a pele, cabelos e calções pretos em um grupo, e camisa branca e calção azul em outro, produzindo um particionamento insatisfatório.

Uma intervenção adicional pode ser a observação da imagem pelo supervisor e a prévia atribuição do melhor número de grupos $c^{*}$. Como conseqüência, o processamento é agilizado, pois o algoritmo FCM-GK será executado apenas uma vez. Supondo que na fig. 6.2 original sejam definidos sete grupos, correspondentes às principais cores observadas (verde, branco, amarelo, azul, preto, pele, vermelho), aproximadamente em ordem decrescente de quantidade de pixels. O que se observa, em conseqüência, é que o vermelho do emblema não contém um número de pixels significativo para formar um grupo isolado, e o azul foi agrupado juntamente com o preto (figs. 6.3a, b, c, d, e, f, g). Como a escolha de sete grupos é imposta no agrupamento, as cores da grama foram divididas em dois grupos (número grande de pixels) e surgiu um outro grupo (fig. 6.3f). Como o comportamento do algoritmo FCM-GK se dá de acordo com a distribuição do espaço de cores, foram obtidas subimagens que não foram separadas pelas sete cores propostas, mas 


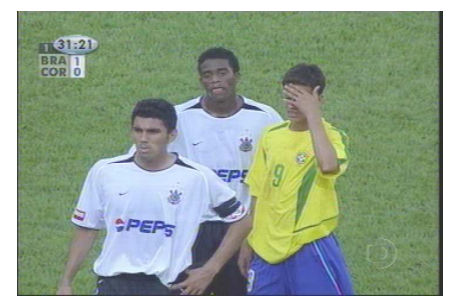

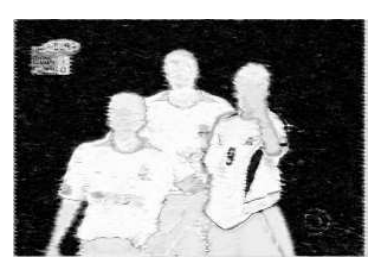

a

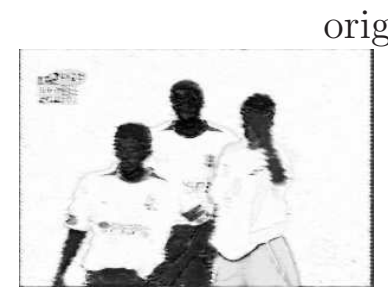

$\mathrm{b}$

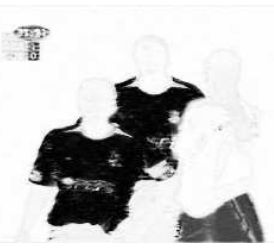

c

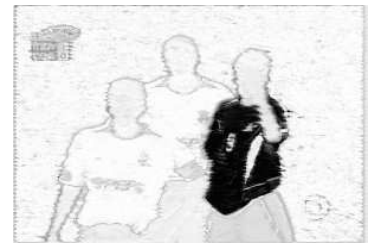

d

Em cima, a imagem original em cores. Embaixo, cada subimagem a...d representa um grupo de pixels com cores agrupadas por similaridade, em escala monocromática. Preto indica pertinência máxima ao grupo associado à subimagem, e branco, pertinência nula.

Figura 6.2: Imagem original e subimagens obtidas para $c^{*}=4(a, b, c$ e $d)$.

pela minimização da função objetivo $J(\mathbf{U}, \mathbf{v})$ (eq. 3.17). Mesmo assim, foram obtidos resultados melhores do que na fig. 6.2, considerando-se que a classe de interesse seja a cor da pele ou a camisa amarela.

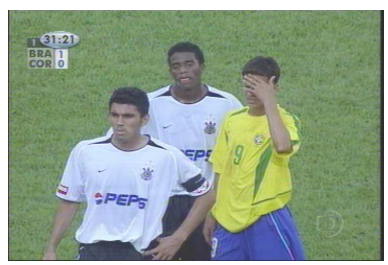

original

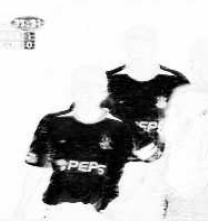

d

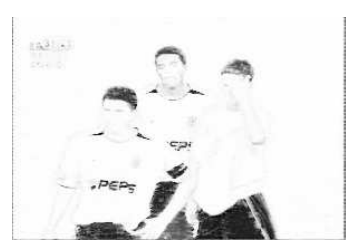

a

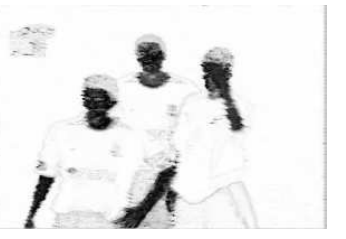

$\mathrm{e}$

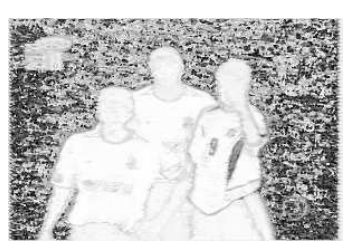

$\mathrm{b}$

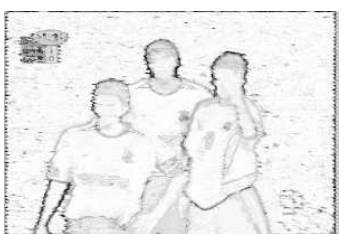

$\mathrm{f}$

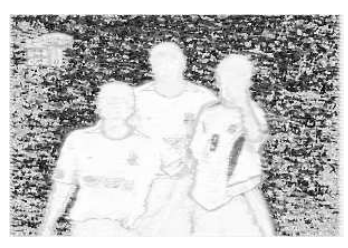

C

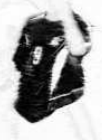

g

Particionamento visual $c^{*}=7$. A intensidade de cada pixel é proporcional à pertinência.

Figura 6.3: Imagem original e subimagens obtidas $(a, b, c, d, e, f$ e $g)$.

Muitas vezes, pode-se tornar esta intervenção heuristicamente mais eficiente localizando apenas subconjuntos do total, onde haja concentração das instâncias positivas (por exemplo, selecionando partes da imagem contendo objetos de interesse). Supondo que os pixels de interesse sejam de cor da pele, um recorte digital pode ser efetuado pelo 
supervisor. Neste caso, recorta-se porções onde os pixels cor da pele estejam em maioria, conforme as figs. 6.4a, $b, c, d$, e, e ainda, informar o número de grupos $c^{*}$ desejado, melhorando o desempenho geral do módulo. Esta intervenção extra não foi necessária nos estudos de caso apresentados adiante, porém ajuda a melhorar a separação do grupo da cor de interesse em cenas muito complexas.

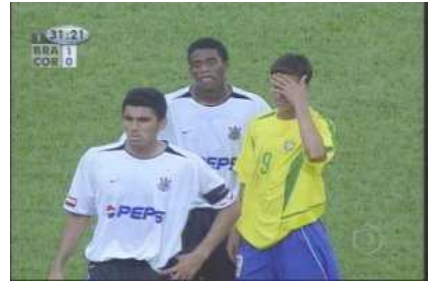

original

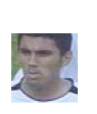

a

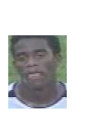

$\mathrm{b}$

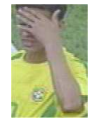

C

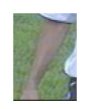

d

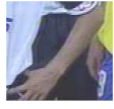

$\mathrm{e}$

Figura 6.4: Imagem original e recortes definidos pelo supervisor, com a cor da pele sendo a classe de interesse.

\subsection{Módulo 2. Definição das classes}

Este módulo é totalmente supervisionado, consistindo na análise das $c^{*}$ subimagens construídas no módulo anterior. Um agente supervisor (por exemplo, operador humano), analisa os grupos obtidos no conjunto de imagens de treinamento, identifica classes de interesse e rotula estes grupos com a denominação destas classes.

É útil lembrar a diferença conceitual entre grupo e classe. Uma classe pode abranger mais de uma subimagem, uma vez que aquela pode ser definida por grupos disjuntos. Ou seja, na execução do módulo 1, pode ocorrer mais de um grupo com o mesmo rótulo, de acordo com o conhecimento sobre o domínio fornecido pelo agente supervisor.

Este módulo é composto das seguintes tarefas:

1. Rotulação dos grupos. O supervisor analisa as $c_{n}^{*}$ subimagens de cada imagem $n$ dentro do conjunto de $N_{T}$ imagens de treinamento, e rotula os grupos $G_{n i}$ (onde $i \leqslant c_{n}^{*}, n \leqslant N_{T}$ ) representados em cada subimagem. Por exemplo, se a imagem $n$ contiver frutos vermelhos, haverá uma ou mais subimagens com os pixels que compõem estes frutos, outras subimagens contendo folhas e caules, e outras subimagens contendo outros objetos caracterizados por outras cores.

2. Definição das classes. O supervisor analisa os $G_{n i}$ grupos rotulados e verifica quais grupos constituem a mesma classe $\omega_{i}$. Sendo $\Omega=\left\{\omega_{i}\right\}$ o conjunto das classes 
Quadro 3 Detalhamento das tarefas do módulo 1.

Para cada uma das $N_{T}$ imagens de treinamento:

- Opcional: seleção prévia dos exemplos por meio de interação com o supervisor. Se viável, selecionar janelas na imagem, onde facilmente se possa obter pixels da classe de interesse como maioria.

\section{- Agrupamento não-supervisionado:}

1. descrição dos pixels com suas cores $\mathbf{x}_{k}$ em algum espaço de representação de cores;

2. para $c=2$ até $c_{\max }\left(c_{\max }\right.$ arbitrário, de acordo com o domínio):

(a) aplicação do algoritmo FCM-GK. Inicialização de parâmetros:

i. $\mathrm{n}^{\mathrm{O}}$ de grupos $=c$;

ii. fator de nebulosidade $m$;

iii. critério de parada $\epsilon$;

iv. centróides $\mathbf{v}_{i}^{(0)}, 2 \leqslant i \leqslant c$, na iteração 0 . Como imagens naturais apresentam cores menos saturadas, a heurística para iniciar os centróides $\mathbf{v}_{i}^{(0)}$ é alocá-los ao longo do eixo de cinzas do espaço de cores;

(b) obter a matriz de pertinências $\mathbf{U}_{(c \times N)}=\left\{u_{i k}\right\}$ após a convergência do algoritmo FCM-GK, associada aos pixels $\mathbf{X}_{(N)}=\left\{\mathbf{x}_{k}\right\}$;

3. escolher como o número ideal de grupos $c^{*}$ aquele que minimiza a função de validação $S$;

4. do $n^{\circ}$ de grupos ideal $c^{*}$, armazenar os dados e as respectivas pertinências, em relação a cada grupo: $\left\{\mathbf{x}_{k},\left\{u_{i k}\right\}\right\}, 2 \leqslant k \leqslant N, 2 \leqslant i \leqslant c^{*}$;

5. construir $c^{*}$ subimagens (uma para cada grupo), contendo apenas os pixels com pertinência $\left\{u_{k}\right\}_{i}$ acima de algum valor de pertinência limite $u_{\text {lim }}$, em relação ao $i$-ésimo grupo dado, $2 \leqslant i \leqslant c^{*}$. Esta pertinência limite depende da aplicação, e define o grau de aceitação das instâncias nos $c^{*}$ grupos de interesse. Se não houver algum indicativo para o valor ideal, pode-se adotar $u_{\text {lim }}=0,5$.

Ao final, são obtidas $N_{T}$ matrizes de pertinência $\mathbf{U}_{n}=\left\{u_{i k}\right\}_{n}$ onde $1 \leqslant n \leqslant N_{T}$, $2 \leqslant i \leqslant c^{*}(n), 2 \leqslant k \leqslant N$. 
identificadas e $\Gamma=\left\{G_{i}\right\}$ o conjunto dos grupos que as compõem, a $i$-ésima classe é formada por $\omega_{i}=\bigcup_{n} G_{i}$, e, por haver cores iguais provenientes de vários grupos, $\left|\omega_{i}\right| \leqslant \sum_{n}\left|G_{n i}\right|$.

3. Seleção das classes de interesse. Agora o agente supervisor seleciona subimagens com pixels da $p$-ésima classe de interesse $\left(\omega_{p} \in \Gamma\right)$. Os pixels selecionados de cores $\mathbf{x}_{k}$ e suas respectivas pertinências $u_{p k}$ compõem a classe $\omega_{p}$.

Esta seqüência de tarefas é organizada no algoritmo descrito no quadro 4.

Quadro 4 Detalhamento das tarefas do módulo 2.

- Para cada uma das $N_{T}$ imagens de treinamento:

- para cada uma das $c_{n}^{*}$ subimagens construídas:

* rotular o grupo $G_{i}$ de pixels da $i$-ésima subimagem;

* se este grupo corresponde a uma classe $\omega_{i}$ já existente, então rotular este grupo $G_{i}$ com a denominação da classe $\omega_{i}$, senão associar este grupo a uma nova classe $\omega_{i++}$, com um novo rótulo.

- Considerar as $\omega_{p}$ classes de interesse.

Deste módulo resultam as classes $\omega_{p}$ de interesse, contendo a matriz de pertinências $\left\{u_{p k}\right\}$ associadas às $p$ classes de cores $\mathbf{x}_{k}$.

O esquema geral de processamento deste módulo está esquematizado na fig. 6.5.

Relevância do grupo na classe. Conforme proposto no capítulo anterior, grupos de pixels de imagens diferentes, e rotulados com a mesma classe, podem representar contribuições diferentes na constituição da mesma. Esta contribuição é expressa por um grau de relevância, visando alterar a pertinência (limitando no máximo a 1) dos pixels, aumentando-a nos grupos mais relevantes e diminuindo-a nos menos relevantes. Esta idéia pode ser formalizada assim:

"a subimagem formada pelos pixels de maior pertinência em $G_{i}$ é rotulada com a classe $\omega_{p}$ com relevância $r_{i p} "$;

sendo $r_{i p}$ proposta de duas maneiras:

1. por um modificador nebuloso ("hedge") como "muito", "mais ou menos", "pequeno", e outros; 
2. por pesos, que são multiplicadores $w_{i}$ atuando nas funções de pertinência $u_{i}$, escolhidos arbitrariamente de acordo com a relevância do grupo em relação à classe.

A aplicação do grau de relevância pode ser efetivada de uma primeira maneira conforme descrito em 3.1.2, ou de uma segunda maneira pela associação dos pesos $w_{i}$ a "escalas linguísticas" dadas como exemplo por:

a) pouco relevante: $w_{i}=0,2$;

b) menos relevante: $w_{i}=0,5$;

c) mais relevante: $w_{i}=0,7$;

d) totalmente relevante: $w_{i}=1,0$.

Os valores de $w_{i}$ são atribuidos arbitrariamente.

As pertinências do grupo $G_{i}$ são recalculadas do primeiro modo por

$$
u_{G}^{\prime}=f\left(u_{G}\right),
$$

onde $f($.$) é um modificador nebuloso, ou do segundo modo por$

$$
u_{G}^{\prime}=w_{i} u_{G}
$$

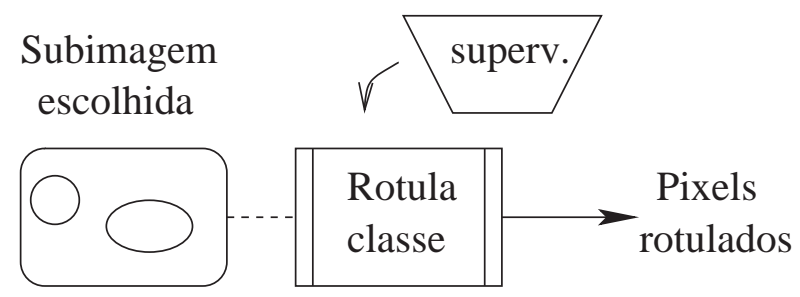

Figura 6.5: Diagrama de blocos do módulo de definição das classes.

\subsection{Módulo 3. Agregação.}

Este módulo agrega os pixels rotulados com a mesma classe, provenientes das imagens de treinamento. Dados os grupos $G_{i}$ obtidos das imagens, rotulados com as classes $\omega_{p}$, contendo os pixels $\mathbf{x}_{k}$ e respectivas pertinências aos grupos $u_{i k}$, a agregação será feita sobre 
os grupos de mesmo rótulo, tais que $G_{i} \subset \omega_{p}$. Como o número de grupos freqüentemente é maior que o número de classes, a agregação implica em calcular a pertinência resultante da inclusão de mais de um grupo na mesma classe.

Para manter as características do aprendizado incremental, tornando a operação de agregação independente da ordem em que os pixels são apresentados, é conveniente empregar o operador média de um modo funcional, isto é, como função de todas as pertinências em conjunto apresentadas pelo mesmo pixel no treinamento, como segue:

$$
u_{p}\left(\mathbf{x}_{k}\right)=\operatorname{media}\left(u_{1}\left(\mathbf{x}_{k}\right), u_{2}\left(\mathbf{x}_{k}\right), \ldots, u_{i}\left(\mathbf{x}_{k}\right), \ldots, u_{N_{T}}\left(\mathbf{x}_{k}\right)\right) .
$$

Esta forma de calcular a média (descrita na eq. 6.3), mostra que é mais robusta às flutuações da pertinência apresentada pelo pixel durante o treinamento. Em outras palavras, a memória do treinamento é conservada e a contribuição do novo valor de pertinência é combinada com os valores existentes.

Ainda, um problema adicional foi solucionado. Se a média fica mais robusta e mais fiel às características do treinamento, deve-se armazenar todos os valores de pertinência apresentados por um dado na base de conhecimento do classificador? Observa-se que a simples média entre a pertinência armazenada $u_{\text {agreg }}\left(\mathbf{x}_{k}\right)$ e a pertinência $u_{i}\left(\mathbf{x}_{k}\right)$ que está sendo incorporada é tendenciosa, pois, após $N$ conjuntos de treinamento, a média aritmética cumulativa se torna

$$
u_{\text {agreg }}\left(\mathbf{x}_{k}\right)=\frac{\frac{\frac{u_{1}+u_{2}}{2}+u_{3}}{2}+\ldots}{2}+\ldots
$$

O cálculo correto da média aritmética das pertinências de um dado $\mathbf{x}_{k}$ é

$$
\overline{u_{n, k}}=\frac{1}{n} \sum_{i=1}^{n} u_{i, k}=u_{\text {agreg }}\left(\mathbf{x}_{k}\right)
$$

sendo necessário guardar todo o histórico de pertinências $u_{i}\left(\mathbf{x}_{k}\right)$ para este dado. Quando um novo conjunto de dados é apresentado, a média das pertinências de um dado se torna

$$
\overline{u_{n+1, k}}=\frac{1}{n+1} \sum_{i=1}^{n+1} u_{i, k} .
$$

É fácil notar que (omitindo-se o índice $k$ ):

$$
n \cdot \overline{u_{n}}=\sum_{i=1}^{n} u_{i} \quad \text { e } \quad(n+1) \cdot \overline{u_{n+1}}=\sum_{i=1}^{n+1} u_{i}=u_{n+1}+n \cdot \overline{u_{n}}
$$


de modo que a média, ao ser apresentado o dado pela $(n+1)$-ésima vez é atualizada por

$$
\overline{u_{n+1}}=\frac{u_{n+1}+n \cdot \overline{u_{n}}}{n+1}
$$

Isto implica que é suficiente armazenar o número de vezes em que o dado $\mathbf{x}_{k}$ foi classificado no grupo e a pertinência média $\overline{u_{n}}$ até o momento da nova inclusão $u_{n+1}$, na base de conhecimento. Em termos práticos, um deslocamento para menos no índice na eq. 6.8 , tal que

$$
\overline{u_{n}}=\frac{u_{n}+(n-1) \cdot \overline{u_{n-1}}}{n}
$$

facilita o cálculo em termos computacionais pois, quando o dado é incluído pela primeira vez, $n=1$ e $u_{1}$ torna-se o único valor de pertinência obtido.

Outras médias, além da aritmética, também produzem resultados úteis para este modelo. De forma análoga, obtém-se para o modelo incremental de combinação aqui proposto, a média geométrica como

$$
\overline{u_{n}}=\left[u_{n}\left(\overline{u_{n-1}}\right)^{n-1}\right]^{\frac{1}{n}}
$$

Para a média harmônica, o mesmo tratamento resulta:

$$
\overline{u_{n}}=\frac{n \cdot u_{n} \cdot \overline{u_{n-1}}}{(n-1) u_{n}+\overline{u_{n-1}}}
$$

e a média quadrática fica:

$$
\overline{u_{n}}=\left[\frac{1}{n}\left(u_{n}^{2}+(n-1) \cdot{\overline{u_{n-1}}}^{2}\right)\right]^{\frac{1}{2}} .
$$

O índice $n$ que aparece nas equações acima representa o número de operações de agregação realizadas sobre um pixel $\mathbf{x}_{k}$ no grupo $G_{i}$.

Com isto, um dado que foi classificado com pertinência alta em poucos destes conjuntos de treinamento tem sua pertinência atenuada, em comparação com um dado que apareceu na grande maioria deles, com pertinência menor, conforme discutido no cap. anterior.

Poder-se-ia estender este raciocínio a outras medidas de tendência central, como a mediana. Porém, o cálculo desta, na prática, é por posto, isto é, exige um reordenamento dos valores de pertinência sempre que um novo valor é incluído. Isto implica em armazenar todos os valores de pertinência já apresentados, gerando um excessivo consumo de memória, além da sobrecarga no processamento ao executar uma rotina de ordenação. 
A incorporação dos dados de treinamento segue a estratégia descrita no quadro 5.

Quadro 5 Tarefas do módulo 3.

1. Para todos os pixels dos grupos $i$, das $N_{T}$ imagens, que correspondem à mesma classe $\omega_{p}$ com respectivas pertinências $u_{i k}$;

- realizar uma combinação que pondere todos eles, com um operador de agregação nebuloso da forma

$$
u_{p k}=\Theta\left(u_{i k}^{(1)}, u_{i k}^{(2)}, \ldots, u_{i k}^{(n)}, \ldots, u_{i k}^{\left(N_{T r}\right)}\right)_{\mathbf{x}_{k}}
$$

Assume-se que o método de agrupamento utilizado em cada conjunto de dados permanece o mesmo e que a mesma métrica seja empregada (módulo 1).

\section{Operadores de combinação ao se considerar também contra-exemplos Da-}

das as instâncias pertencentes às classes não selecionadas $\left(x_{k} \notin \omega_{p}\right)$ e suas pertinências $\left(u_{q k}\right)_{\neg \omega_{p}} \mid 1 \leq q \leq c^{\prime}$, onde $c^{\prime}$ é o número das classes não selecionadas, observa-se a seguinte situação:

- um exemplo $\mathbf{x}_{k}$ pode ter pertinência $u_{p k}$ em relação às $p$ classes de interesse, mas, por conseqüência da seleção feita no módulo 2 , tem pertinência $u_{q k}$ maior em relação às classes que não são de interesse;

- combina-se os pixels das classes $\omega_{q}$ da mesma forma que nas classes $\omega_{p}$, pela eq. 6.13

- se $u_{q k}>u_{p k}, \forall(q, p)$, então a cor é mais pertinente a uma classe que não é de interesse, $\operatorname{logo} \mathbf{x}_{k}$ é um exemplo negativo.

Esta solução simples é devida à restrição existente no algoritmo FCM-GK, isto é, $\sum_{i=1}^{c} u_{i k}=1$, que significa, a grosso modo, que um pixel $k$ apresenta pertinência alta em relação a um grupo, ela fica menor em relação aos outros grupos. Com isto, pode-se lidar com a pertinência de um exemplo $\mathbf{x}_{k}$ nas $\omega_{q}$ classes não selecionadas, classificando-o como negativo. Como já mencionado, os exemplos negativos auxiliam na robustez do treinamento.

O esquema geral de processamento deste módulo está esquematizado na fig. 6.6. 
Grupos de interesse

das imagens de treinamento

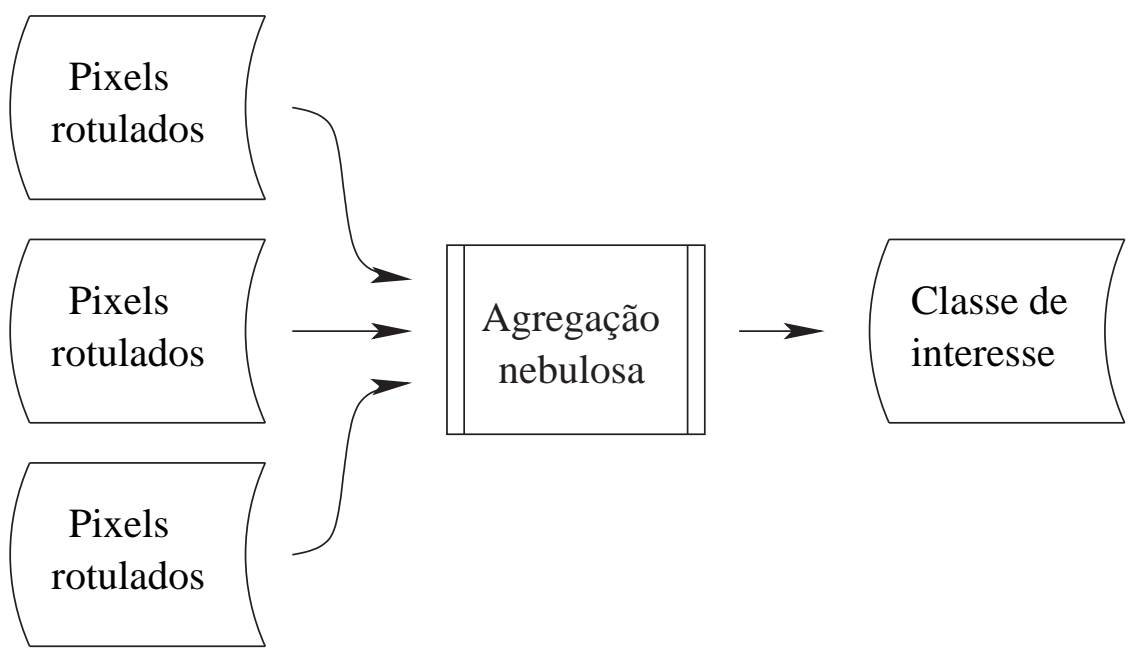

Figura 6.6: Diagrama de blocos do módulo de agregação.

\section{Quadro 6 Regra nebulosa kNN para generalização do modelo.}

- Dados: $x$ (vetor de atributos), $k$ (número de vizinhos a considerar), $d$ (uma medida de distância, p.ex. euclidiana ou de Mahalanobis).

- Considerar os $k$ vizinhos mais próximos já armazenados e que estejam a uma distância menor que $d$, independentemente da classe a que pertençam. Se nesta distância inferior a $d$ houver um número de vizinhos $k^{\prime}<k$, considerar somente estes.

- Destes $k$ 'vizinhos, identificar suas classes $c_{i}$ e respectivas pertinências $u_{i j}$ com $i=1,2, \ldots, c$ e $j=1,2, \ldots, k$ '. Resulta que $\sum_{i} u_{i j}=1 \forall x_{j}$, se as pertinências forem normalizadas, como as obtidas pelo algoritmo FCM-GK.

- Calcular a pertinência de $x$ de acordo com a eq. 5.3.

\subsection{Módulo 4. Generalização.}

Conforme exposto no capítulo antecedente, a alternativa escolhida para resolver o problema da pertinência de pontos faltantes na nuvem que corresponde a uma classe é a regra kNN nebulosa. Esta regra não atribui a classe da maioria dos vizinhos, mas executa um cálculo ponderado das pertinências da vizinhança.

Em vez do elemento desconhecido $\mathbf{x}$ ser atribuído à classe da maioria dos $k$ vizinhos, ele passa a compartilhar das classes envolvidas, com a respectiva pertinência $u_{i}$ a cada uma delas. O procedimento empregado é mostrado no quadro 6. 
A regra nebulosa kNN atuaria como um classificador para os dados não encontrados na base de conhecimento, mesmo que não tenham sido atingidos pelo preenchimento de regiões $3 \mathrm{D}$ acima descritos.

De acordo com a eq 5.3, um novo pixel $\mathbf{x}$ é classificado com a pertinência $u_{i}$ em relação à classe $i$. Se este valor de pertinência for acima de $u_{\text {lim }}$, o pixel é incluído no grupo $i$, e seus atributos $\left(x, u \geqslant u_{l i m}\right)$ incorporados à base de conhecimento.

O procedimento para generalização usando esta regra baseia-se na exploração de todo o espaço de atributos, contendo as informações da base de conhecimento. Este procedimento é aplicado apenas uma vez, ao final do treinamento, para "interpolar" a nuvem da base de conhecimento. A generalização proposta é executada da forma descrita no quadro 7 .

Quadro 7 Generalização da base de conhecimento pela regra kNN.

1. explorar todo o espaço de atributos que contém a base de conhecimentos para a classe em destaque, considerando os valores de pertinência;

2. escolher a distância máxima para considerar um pixel como vizinho;

3. para cada conjunto de atributos $\left\{x_{k}, u_{i k}\right\}$

- se $u(x)=0 \quad / /$ dado não foi incluído na base de conhecimento então aplicar a regra nebulosa kNN (quadro 6).

O esquema geral de processamento deste módulo está esquematizado na fig. 6.7

Classes: nuvens no

espaço de cores

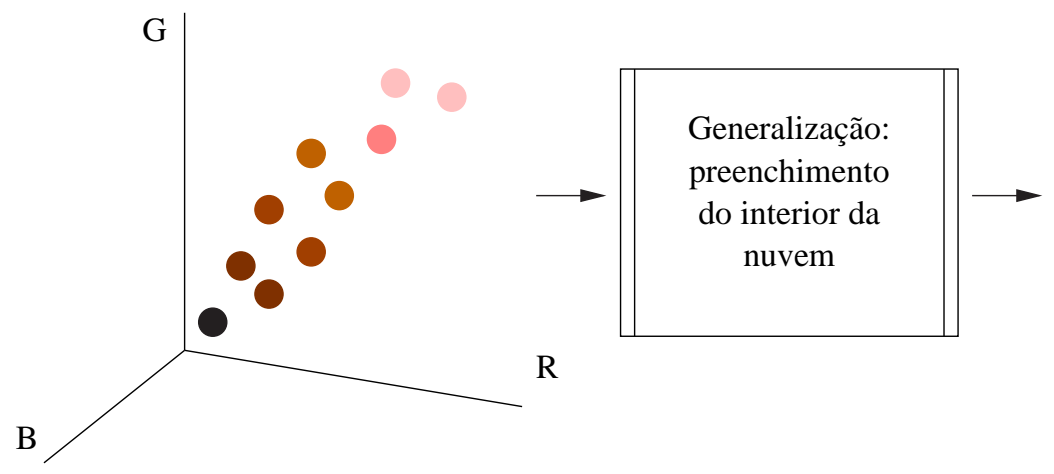

Classe generalizada

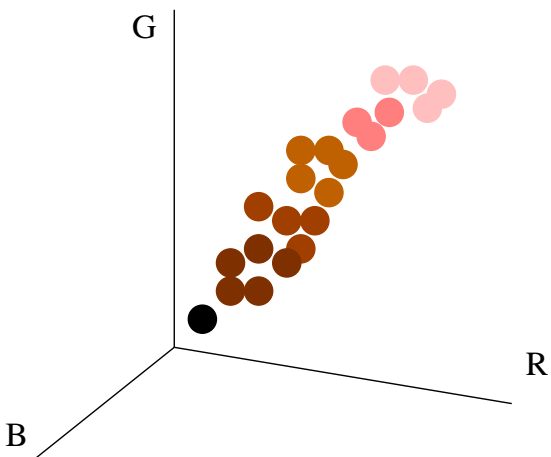

Figura 6.7: Diagrama de blocos do módulo de generalização. 


\subsection{Conclusão do capítulo}

Explorando o perfil do modelo de construção do classificador, relatado no capítulo anterior, este capítulo apresentou detalhes de implementação dos algoritmos envolvidos.

O custo computacional do processo todo é evidenciado principalmente na aplicação dos algoritmos de agrupamento e de generalização. Entretanto, toda a tarefa de recalcular a pertinência dos pixels às classes fica fora do escopo do supervisor, automatizada na execução do agrupamento nebuloso e na aplicação do operador de agregação.

O próximo capítulo é dedicado a apresentar alguns resultados obtidos na modelagem do classificador de objetos pela cor. 


\section{ESTUDO DE CASOS EM MODELAGEM DA COR DA PELE}

Uma aplicação que motiva a investigação do problema de classificar exemplos vagos é a detecção de seres humanos (ou partes) através da cor da pele. Este é um atributo onde as cores individuais dos pixels variam muito. Mas o conceito cor da pele tem significado bem definido, formando uma classe no espaço de cores de limites e densidade incerta, sendo portanto adequada para tratamento por conjuntos nebulosos.

A detecção automática de seres humanos em imagens tem se tornado um requisito importante no desenvolvimento de sistemas de controle de acesso, resgate ou em sistemas que indexam informação baseada em conteúdo, como o "Distributed AudioVisual Archives Network" - DiVAN (1997). Em muitos ambientes de visão artificial, o ser humano passa a constituir parte da cena, onde deve ser distinguido por razões de segurança, por exemplo. Os exemplos mais numerosos estão em detecção de faces, onde, nas imagens em cores, utilizam como característica principal o modelo de cor de pele, em conjunto com atributos morfológicos (YANG; KRIEGMAN; AHUJA, 2002). Outro domínio de aplicação é a filtragem de imagens impróprias de pessoas nuas (FORSYTH; FLECK, 1996) e que não utiliza a morfologia de faces. Ainda, resultados obtidos nesta área podem ser eficientemente aproveitados em realidade virtual, entretenimento, interação homem-máquina, e outras. Como um exemplo deste domínio de aplicação, o rastreamento da mão do operador possibilita a reprodução de todos os seus movimentos em um ambiente virtual, sem a necessidade de luvas especiais para guiar o sistema de rastreamento (WU; LIU; HUANG, 2000).

A detecção de seres humanos em imagens (completos ou em partes) ou faces concentrase no tratamento de dois tipos de atributos: morfológicos e cores. Em sua grande maioria, os atributos morfológicos têm sido utilizados para detecção de faces. Esta tarefa emprega atributos como posicionamento dos olhos, boca e nariz, biometria, orientação da cabeça 
em relação à câmera, existência de artefatos oclusivos (barba, óculos, chapéus e adereços) (WU; CHEN; YACHIDA, 1999); (HSU; ABDEL-MOTTALEB; JAIN, 2002) e (YANG; KRIEGMAN; AHUJA, 2002). O emprego de atributos morfológicos para detecção de mãos e corpos humanos, em geral, é dificultado pela grande variedade de posições em que podem ser encontrados. Ainda, técnicas deste tipo foram desenvolvidas tanto para imagens em tons de cinza como em cores (YANG; KRIEGMAN; AHUJA, 2002). Já o emprego de cores, para detecção de seres humanos ou partes, tem sido usado como uma tarefa preliminar, pois o processamento da cor, em imagens individuais, é geralmente de baixo custo computacional. Seu objetivo principal é localizar as regiões candidatas a serem identificadas como humanos ou partes e eliminar o resto da imagem, reduzindo o número de pixels a serem analisados. Como o vestuário apresenta cores variadas, a referência relativamente estável em termos de cores é a pele (e em alguns casos específicos, a cor dos cabelos) (WANG; SUNG, 1999).

O domínio de cor da pele foi escolhido como um caso neste trabalho por fornecer um conceito semanticamente bem definido. Porém, a definição em termos de representação digital de cores é complexa, devido à variação das características de pele em relação à geografia, variação entre povos, e das condições de iluminação. Neste sentido, o termo cor da pele passa a ter definição vaga e imprecisa, indicando ser bem apropriado o uso de lógica nebulosa para a sua modelagem. A detecção da pele é um processo complexo, com alto grau de incerteza e sujeito a fatores extrínsecos. Em vista disto, o tratamento nebuloso da informação parece ser mais adequado.

\subsection{Propriedades ópticas da pele humana}

O termo cor da pele é um conceito subjetivo, do ponto de vista da interpretação humana. A representação da cor da pele, em tese, deve ser semelhante à percebida pelo sistema de visão humano. A cor da pele é diferenciada pela exposição à radiação ultravioleta e inclui fatores de transmissão genética. As variações encontradas em diversos povos são relacionadas à evolução e reprodução (BECHELLI; CURBAN, 1963). A cor da pele é determinada pelas características de filtragem da luz em camadas: a melanina (marrom) na epiderme, o caroteno (laranja) na derme e camada subcutânea, e a hemoglobina nos capilares da derme (vermelha se oxigenada e púrpura-azulada caso contrário). A epiderme é composta de células opticamente inativas (não fluorescentes), que aumentam a difusão da luz refletida. Em geral, apresenta maior refletância nos maiores comprimentos de onda (ANGELOPOULOU; MOLANA; DANIILIDIS, 2001). Cálculos colorimétricos efetuados so- 
bre algum dos espectros de refletância da pele permitem reproduzir a cor média percebida pelo sistema visual humano (STöRRING; ANDERSEN; GRANUM, 2000).

\subsection{Pesquisa relacionada à detecção de pele em ima- gens coloridas.}

Devido à enorme extensão de trabalhos que propõem classificação de cores, empregando técnicas e espaços de cores variados, restringe-se aqui à apresentação de métodos conceitualmente próximos à abordagem proposta neste trabalho.

1. Regras de inferência. Peer, Kovac e Solina (2003) construíram classificadores que modelam os limites da cor da pele através de regras explícitas. Gomez e Morales (2002) produziram regras por árvores de decisão, evitando regras mais complexas para prevenir o excesso de ajuste ("overfitting").

2. Modelos paramétricos. As fronteiras das instâncias que representam a cor da pele são obtidas de forma analítica, isto é, através de funções que procurem modelar o formato destas fronteiras, em relação ao espaço de cores considerado para representação. Os parâmetros de ajuste de tais funções são estimados por métodos numéricos diversos.

Gaussiana simples e composição de gaussianas. Gaussianas únicas foram utilizadas por Yang, Lu e Waibel (1998), Saber e Tekalp (1998) e Hsu, Abdel-Mottaleb e Jain (2002) para modelar a cor da pele. Uma modelagem mais sofisticada para melhorar o ajuste da complexidade da distribuição foi utilizada por Jones e Rehg (2002), pela composição de gaussianas. Seu modelo está esquematizado na fig. 7.1.

Fronteira elíptica Lee e Yoo (2002) ajustaram uma elipse no grupo de pixels cor da pele sobre a base de dados obtida por Jones e Rehg (2002). Analisando-se o conjunto de pixels cor da pele coletados por Schumeyer e Barner (1998), Zarit, Super e Quek (1999), Jones e Rehg (2002) e Martinkauppi (2002), conclui-se que a aproximação por uma única elipse não se ajusta bem com as fronteiras da classe.

3. Modelagem não-paramétrica A idéia principal é estimar a distribuição da cor da pele sem modelos funcionais explícitos, cujo resultado é muitas vezes denominado "skin 


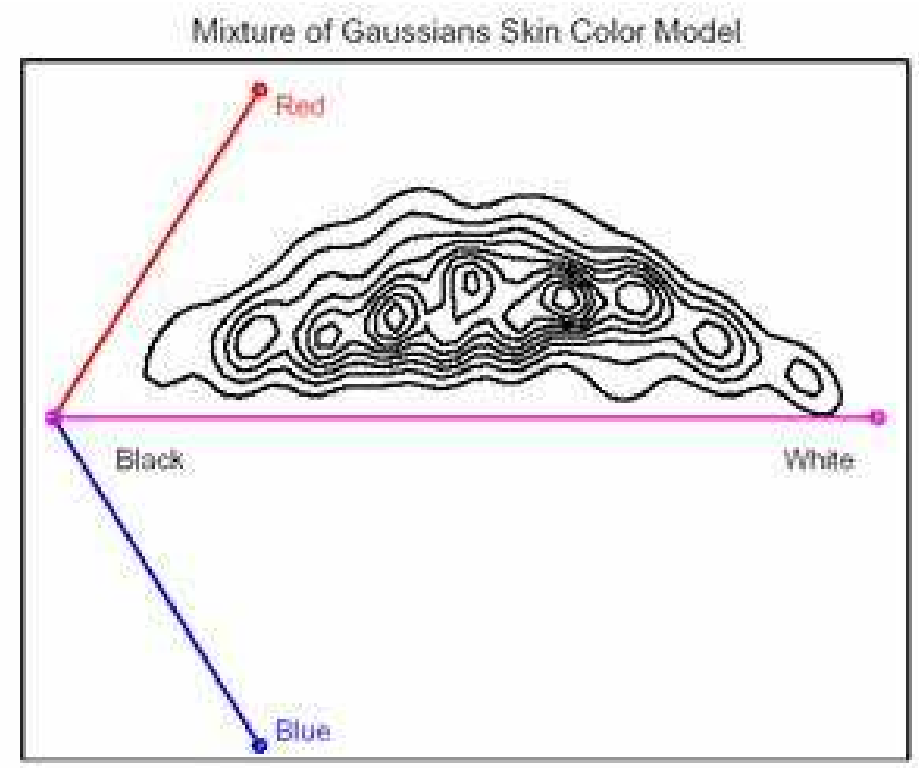

Extraído de Jones e Rehg (2002).

Figura 7.1: Curvas de nível da mistura de gaussianas que modelam a distribuição da cor da pele no espaço RGB.

probability map - SPM" (GOMEZ; MORALES, 2002).

Classificador de Bayes Usando a regra de Bayes, a probabilidade de se obter um pixel cor da pele é

$$
p(\text { pele } \mid \text { cor })=\frac{p(\text { cor } \mid \text { pele }) \cdot p(\text { pele })}{p(\text { cor } \mid \text { pele }) \cdot p(\text { pele })+p(\text { cor } \mid \neg \text { pele }) \cdot p(\neg \text { pele })},
$$

onde $p$ (cor $\mid$ pele) e $p($ cor $\mid \neg$ pele $)$ podem ser obtidas diretamente de histogramas. Probabilidades a priori $p($ pele) e $p(\neg$ pele) são obtidas por amostragem das instâncias de treinamento. O cálculo completo da eq. 7.1 é simplificado se apenas interessa calcular a proporção $p$ (pele $\mid$ cor $) / p(\neg$ pele $\mid$ cor $)$, a qual é comparada com um valor limiar de decisão (ZARIT; SUPER; QUEK, 1999).

"Self-organizing maps" (SOMs). Uma das redes neurais mais usadas para classificação não-supervisionada. Brown, Craw e Lewthwaite (2001) treinaram duas SOMs, uma com instâncias positivas e negativas (pele e não-pele) e a outra apenas com exemplos positivos (pele). Vários espaços de cores foram utilizados, sem haver diferenças significativas nos resultados. Embora seu desempenho nos testes tenha sido inferior ao modelo de Jones e Rehg (2002), os autores argumentam que este método consome menos recursos e apresenta respostas muito rápidas se implementadas em hardware. 
LUT normalizada. O espaço de cores é quantizado em bins (bits de cor), cada um representando uma faixa de cores, e acumulando sobre si a quantidade de pixels com cores dentro desta faixa. Esta abordagem geralmente é utilizada para análise de histogramas (JONES; REHG, 2002) e (ZARIT; SUPER; QUEK, 1999).

4. Métodos híbridos. Uma combinação das técnicas de limiarização e agrupamentos nebulosos foi realizada por Lim e Lee (1990). A partir dos histogramas de cada componente, nos espaços de cores RGB, XYZ, YIQ, UVW e I1I2I3, a segmentação por cores foi executada em duas etapas: a primeira, mais grosseira, pela limiarização dos histogramas das três componentes de cor separadamente, sem a preocupação da escolha de um limiar ótimo, mas uma região de limiar. Faixas de valores em torno dos limiares foram consideradas de transição. Na segunda etapa, a segmentação fina, considerou-se os pixels das faixas de transição e aplicado o algoritmo de agrupamentos nebulosos, para atribuí-los ao grupo cujo centróide se aproxima mais dos grupos previamente definidos na limiarização. É interessante notar que: a) o número inicial de classes requerido pelo algoritmo FCM já foi determinado na etapa de limiarização; b) o custo computacional da classificação ficou baixo, pois apenas os pixels pertencentes à região de transição foram processados; c) os problemas de identificar uma classe válida foram contornados pela atribuição dos pixels agrupados por FCM a classes já definidas na limiarização.

Mais recentemente, Zheng, Daoudi e Jedynak (2004) e colaboradores construíram um modelo de cor da pele conjugando um modelo de máxima entropia com uma aproximação para as árvores de Bethe, obtendo resultados muito bons na detecção, utilizando a base de dados de Jones e Rehg (2002).

Considerações. Conclui-se que a modelagem não paramétrica é independente do formato da distribuição da cor da pele e do espaço de cores, o que favorece a elaboração de um modelo de aprendizado incremental. Os modelos paramétricos já explorados na literatura são pouco flexíveis ao aprendizado incremental. Por exemplo, a composição de gaussianas de Jones e Rehg (2002) ou elipsóides, seguindo um modelo de agrupamento nebuloso. Um modelo incremental deveria alterar os parâmetros das elipses 3D ou gaussianas para incluir ou excluir as novas instâncias aprendidas no treinamento. O problema se complica mais se for necessário alterar o número de elipses 3D ou gaussianas a cada novo treinamento, reajustando todos os parâmetros das funções preexistentes no modelo. Além do mais, estes modelos paramétricos são fortemente dependentes do espaço de cores adotado, voltando à questão "qual o melhor espaço de cores para ajustar tais funções?" 
Observando os trabalhos citados, os pixels rotulados como cor-da-pele formam agrupamentos alongados e compactos, distribuindo-se em torno da diagonal principal $(0,0,0)$ a $(255,255,255)$ do espaço RGB. Isto significa que as cores apresentadas denotam baixa saturação, isto é, estão próximas dos tons acinzentados (fig. 7.2a,b). Estes grupos assim formados não possibilitam uma descrição matemática precisa, qualquer que seja o espaço de cores escolhido. Logo, algum processo de identificação através de alguma função ajustada é acompanhado de erros, principalmente se o pixel apresentar uma cor próxima à borda da distribuição.

\subsubsection{Representação da classe "cor da pele" nos espaços de co- res.}

De acordo com o espaço de cores utilizado, algumas observações podem ser feitas. No espaço HSV, os valores de saturação são quase todos ocupados pela distribuição cor de pele, portanto, a componente saturação não é um bom discriminante. Martinkauppi (2002) apresentam a distribuição de cor da pele sob diferentes espaços de cores YCbCr, 111213, logcroma, proporções G/R, B/R e B/G, P1P2, Y.E.S., rgb modificado, NCC $r b$ e $g b$, YIQ, YUV, Yuv, e ab modificado, utilizando câmeras diferentes, tipo 1CCD web câmeras (fabricantes Alaris, Nogatech and Winnov) e uma tipo 3CCD câmera (Sony). Em geral, observa-se que a nuvem de pontos cor da pele nestes espaços é compacta, alongada e ligeiramente curva (fig. 7.2). Conclui-se que não é suficientemente simétrica para ser descrita por uma distribuição simples monofuncional, e que, em espaços que separam a intensidade da cromaticidade, a região ocupada no plano de cromaticidades é dependente da intensidade.

Um resultado recente e bastante incisivo diz respeito à escolha do melhor espaço de cores para detecção de pele (SHIN; CHANG; TSAP, 2002). Utilizando imagens de bancos de dados de faces e, através de medidas como a separabilidade entre grupos pele e não-pele, e análise de histogramas, os autores concluíram que: a) as representações 2D e 3D levaram ao mesmo resultado, b) a melhora na separação é mínima na transformação entre espaços de cores, c) a eliminação da componente intensidade não melhora significativamente a precisão na detecção da pele.

Como conclusão geral, os melhores espaços são o YCbCr e o RGB em termos de separabilidade, e mais ainda, o espaço RGB ocupou sempre a primeira ou segunda posição nas listas de cinco das oito medidas de desempenho. Ou seja, a maioria das transformações de espaços de cores não auxiliaram na detecção da pele. Conclui-se que um esforço compu- 

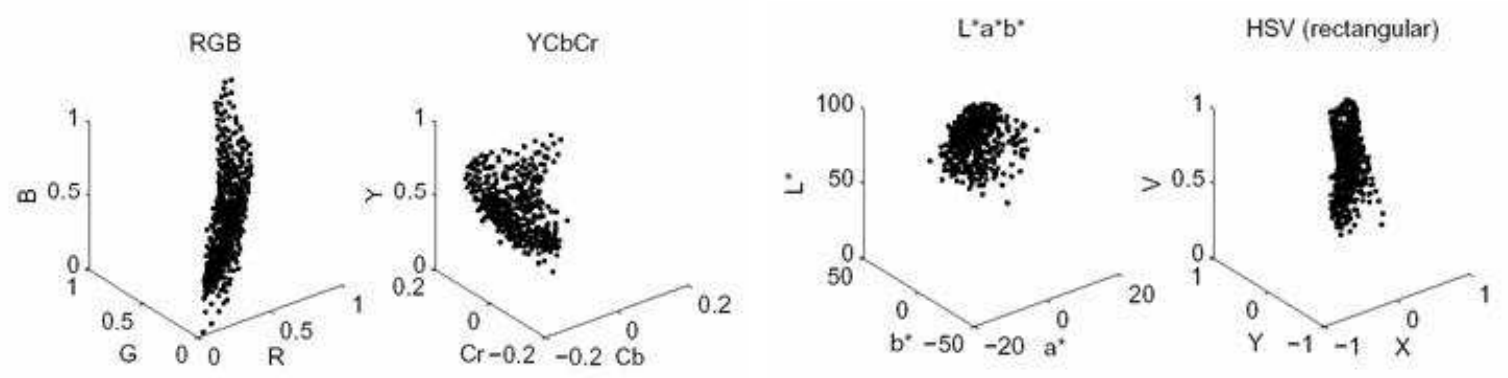

(a) Extraído de Schumeyer e Barner (1998)
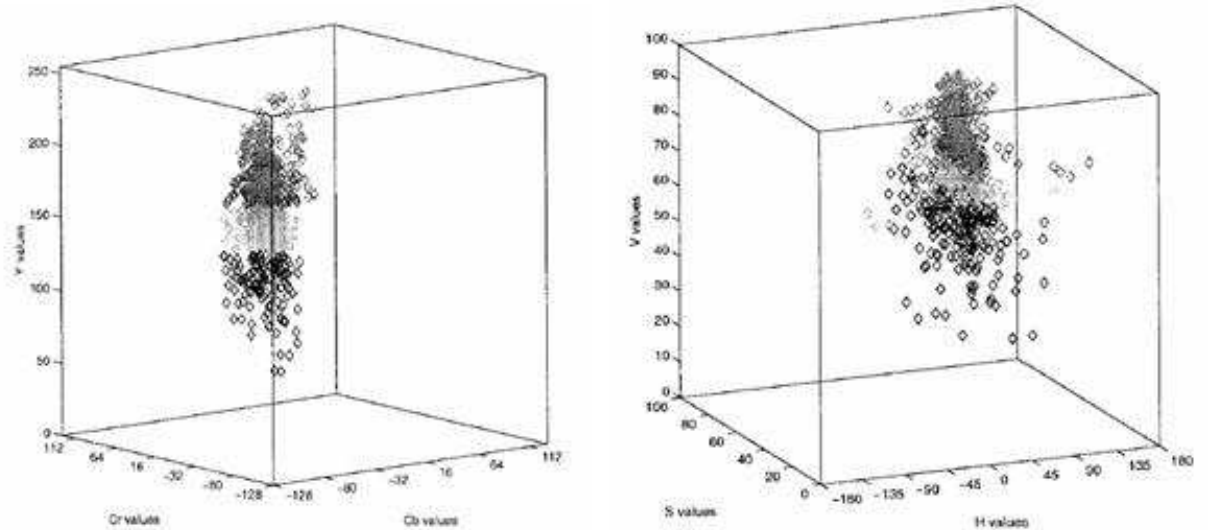

(b) Extraído de Garcia e Tziritas (1999)
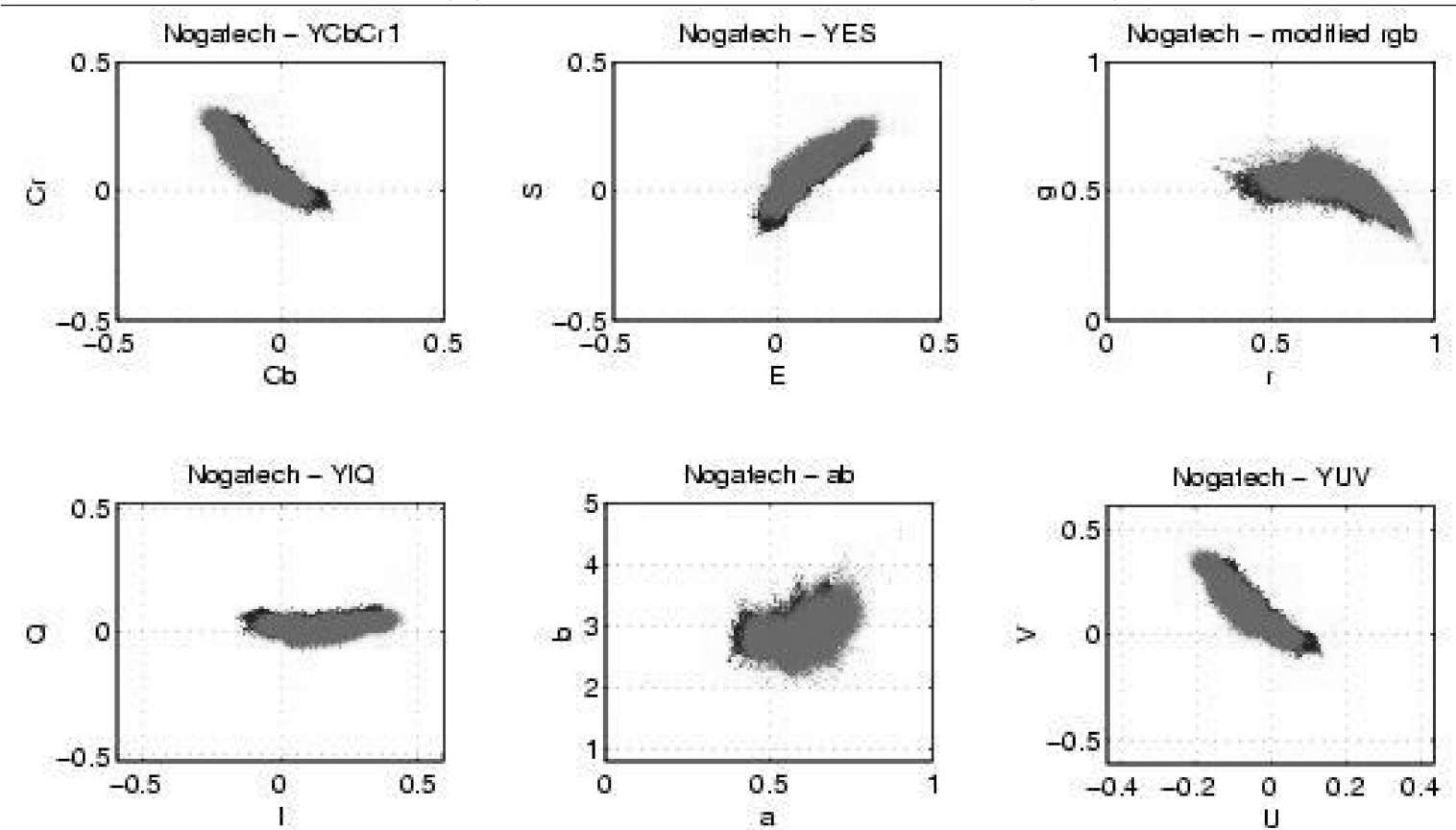

(c) Extraído de Martinkauppi (2002)

Figura 7.2: Distribuição de amostras de cor de pele nos espaços de cores. (a) RGB, YCbCr, L*a*b* e HSV; (b) espaços YCbCr e HSV; (c) projeções nos planos cromáticos de diferentes espaços de cores. 
tacional extra para a transformação do espaço RGB para outro qualquer é desnecessário, devido à variedade de tons de pele observados nestas bases de dados, e não melhora a acurácia na separação. Por outro lado, comparações entre espaços de cor podem não ser absolutas em geral, mas dependentes de qual modelo de cor de pele está sendo construído (TERRILLON, 2000) e (LEE; YOO, 2002). Métodos não-paramétricos, empregando SOM ou LUT, p.ex., são praticamente independentes da escolha do espaço de cores.

O problema de mapear a cor da pele consiste em identificar uma distribuição contínua, irregular (matematicamente complexa) e de fronteira difusa. Espaços de cores baseados em propriedades visuais humanas (YUV, UCS e outros) são úteis para caracterizar diferenças percebidas entre cores. A cor da pele captada, seja pela visão humana, ou por algum dispositivo fotossensível, depende fortemente da iluminação, de modo que não há vantagem adicional em se utilizar um espaço de cor que separe a componente de intensidade das componentes cromáticas, de acordo com os resultados de Shin, Chang e Tsap (2002). Em outros domínios, tal argumento se reforça (SIMÕES; COSTA, 2000). Portanto, a construção de uma LUT durante o treinamento se torna a abordagem mais apropriada, sendo escolhida para este trabalho.

Agrupamento dos pixels cor da pele. Geralmente, no algoritmo FCM-GK, os grupos pequenos são influenciados pelos dados das bordas dos grupos maiores vizinhos, deslocando ligeiramente os centros dos grupos das posições consideradas "intuitivas". Outro problema comum a este algoritmo é sua convergência estacionar em um mínimo local da função objetivo $J(\mathbf{U}, \mathbf{v})$. Dependendo da distribuição dos dados, a execução do FCM-GK deve se repetir algumas vezes para obter o melhor agrupamento (HöPPNER, 1999). Na detecção de cor da pele, estes problemas não se evidenciaram, pelo fato de: o espaço de cores ser discreto e limitado; não haver correlação com a posição dos pixels na imagem e as posições dos centros serem irrelevantes para este método.

\subsection{Avaliação do classificador}

Em linhas gerais, um classificador é projetado para gerar saídas booleanas, probabilísticas, nebulosas ou nominais, sempre da mesma maneira durante as etapas de treinamento, validação e testes. Classificadores projetados para saídas booleanas $\{0,1\}$ muitas vezes produzem valores contínuos no intervalo $[0,1]$ (como as redes neurais), sendo necessário o estabelecimento de um valor limiar para forçar a classificação como positiva ou negativa. Se as saídas são de natureza probabilística, expressam sua posição dentro da distribuição 
de probabilidades construída durante o treinamento, ou seja, como são distribuídas as instâncias positivas e negativas no treinamento. Saídas nebulosas, porém, expressam a instância individualmente como composição parcial das classes envolvidas, independentemente das outras instâncias de treinamento. Por fim, saídas nominais indicam a classe da instância de maneira puramente booleana, sem expressar um "grau de afinidade" entre a instância e a classe. Estas considerações visam estabelecer uma consistência na avaliação do classificador, ao contabilizar suas saídas e respectivas naturezas.

Na avaliação de um classificador é comumente utilizada a matriz de confusão (SWETS, 1988). Esta é construída para mostrar a proporção de acertos na atribuição de classes às instâncias, pelo classificador, na fase de testes. A taxa de acertos é medida em função de um gabarito, que provê a informação sobre qual classe a instância verdadeiramente pertence. Este gabarito pode ser gerado de diversas maneiras, em função da existência de um mecanismo de avaliação, que realize a atribuição verdadeira de forma confiável e eficaz. A escolha e utilização deste mecanismo depende principalmente do domínio a que pertence as instâncias que estão sendo classificadas.

\section{Matriz de confusão clássica}

A denominação clássica refere-se a instâncias classificadas de maneira booleana em uma ou outra classe, ou seja, pertencem a uma e somente uma classe. A construção da matriz de confusão clássica segue basicamente o esquema da tabela 7.1, onde:

- a é o número de instâncias que o classificador atribuiu corretamente como negativas;

- $b$ é o número de instâncias que o classificador atribuiu incorretamente como positivas;

- $c$ é o número de instâncias que o classificador atribuiu incorretamente como negativas;

- $d$ é o número de instâncias que o classificador atribuiu corretamente como positivas;

Note que a matriz de confusão assim definida corresponde a uma classificação booleana em que a instância pertence a uma classe ou a outra. No caso em que há várias classes, as instâncias podem ser correta ou incorretamente classificadas em relação a qualquer classe. Neste caso, a matriz de confusão toma a forma da tabela 7.2. Os elementos $n_{i i}$ da diagonal principal são as previsões corretas do classificador. 
Tabela 7.1: Matriz de confusão para duas classes

\begin{tabular}{ccc}
\hline \multirow{3}{*}{$\begin{array}{c}\text { Número de instâncias } \\
\text { Reais (gabarito) }\end{array}$} & Previstas (classificador) \\
\cline { 2 - 3 } & Negativas & Positivas \\
\hline Negativas & $a$ & $b$ \\
\hline Positivas & $c$ & $d$ \\
\hline
\end{tabular}

Tabela 7.2: Matriz de confusão para várias classes

\begin{tabular}{ccccc}
\hline \multirow{2}{*}{ Neais (gabarito) } & \multicolumn{4}{c}{ Previstas (classificador) } \\
\cline { 2 - 5 } & Classe 1 & Classe 2 & $\ldots$ & Classe N \\
\hline Classe 1 & $n_{11}$ & $n_{12}$ & $\ldots$ & $n_{1 N}$ \\
Classe 2 & $n_{21}$ & $n_{22}$ & $\ldots$ & $n_{2 N}$ \\
$\vdots$ & $\ldots$ & & & $\vdots$ \\
Classe N & $n_{N 1}$ & $n_{N 2}$ & $\ldots$ & $n_{N N}$ \\
\hline
\end{tabular}

Como os elementos da matriz de confusão referem-se a contagens de instâncias, e os conjuntos de teste podem sofrer alterações em seu tamanho, medidas normalizadas do desempenho são desejáveis. Entre as várias existentes, são definidas:

$$
\begin{aligned}
& T P=d /(c+d) \text { taxa de verdadeiros positivos, } \\
& F P=b /(a+b) \text { taxa de falsos positivos, } \\
& T N=a /(a+b) \text { taxa de verdadeiros negativos, e } \\
& F N=c /(c+d) \quad \text { taxa de falsos negativos. }
\end{aligned}
$$

\section{Matriz de confusão nebulosa}

Gómez (2002) e colegas propuseram uma forma de construir matrizes de confusão nebulosa, levando em conta que qualquer instância é classificada com diferentes graus de pertinência nas classes envolvidas. Para isto, utilizaram o conceito de conjunção entre as classes real e prevista e os operadores nebulosos associados (ZADEH, 1965). Neste caso, a contagem simples das instâncias nesta ou noutra classe perdem o significado, e os conceitos 
de verdadeiros ou falsos negativos e positivos são dados pelas seguintes expressões:

$$
\begin{aligned}
& T P=\sum_{k=1}^{n} \min \left(u_{\text {real }}\left(\mathbf{x}_{\omega k}\right), u_{\text {prevista }}\left(\mathbf{x}_{\omega k}\right)\right) \\
& T N=\sum_{k=1}^{n} \min \left(1-u_{\text {real }}\left(\mathbf{x}_{\omega k}\right), 1-u_{\text {prevista }}\left(\mathbf{x}_{\omega k}\right)\right) \\
& F P=\sum_{k=1}^{n} \min \left(1-u_{\text {real }}\left(\mathbf{x}_{\omega k}\right), u_{\text {prevista }}\left(\mathbf{x}_{\omega k}\right)\right) \\
& F N=\sum_{k=1}^{n} \min \left(u_{\text {real }}\left(\mathbf{x}_{\omega k}\right), 1-u_{\text {prevista }}\left(\mathbf{x}_{\omega k}\right)\right)
\end{aligned}
$$

onde $\omega$ corresponde à classe de interesse na detecção (no caso, cor da pele) e $n$ é o número de instâncias testadas. $u_{\text {real }}$ corresponde à pertinência "verdadeira" do pixel em relação à cor da pele e $u_{\text {prevista }}$ corresponde à pertinência dada pelo classificador. A figura 7.3 ilustra estes conceitos.
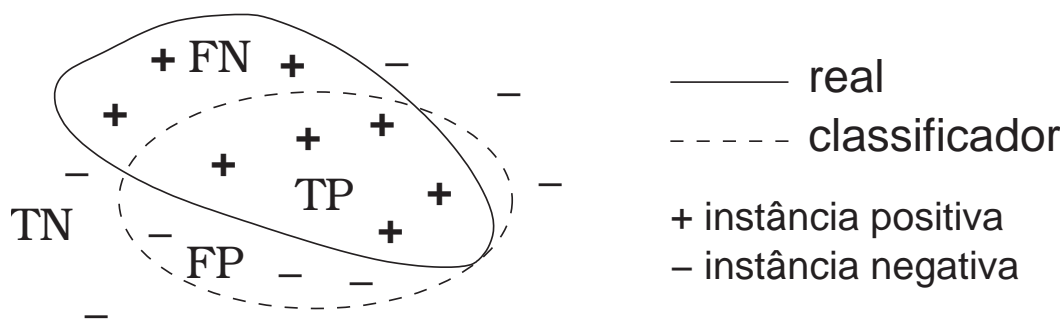

Figura 7.3: Conjuntos que definem a matriz de confusão nebulosa.

\section{Gráfico ROC}

O "gráfico ROC" é outra forma de avaliação de classificadores (SWETS, 1988). Consiste em mostrar a taxa de falsos positivos no eixo $x$ e a taxa de verdadeiros positivos no eixo y. O termo "ROC" provém de "Receiver Operating Characteristic" devido a estudos na década de 50 sobre sinais de rádio contaminados com ruído. Nos últimos anos, os gráficos ROC têm sido intensamente utilizados em diagnóstico médico, em tomada de decisões, incluindo a proposta de metodologias de análise - por exemplo, ver os artigos de revisão de Hanley (1989) e de Henderson (1993).

Em muitos classificadores construídos com parâmetros ajustáveis, o gráfico ROC é utilizado para sintonizar sua eficácia em função de tais parâmetros. Assim, o gráfico é construído pela variação dos parâmetros, produzindo pontos experimentais que, interpolados, geram a curva ROC. No gráfico, o ponto mais próximo da classificação perfeita representa o melhor ajuste, e na prática, como a detecção dos verdadeiros e falsos positivos 
são complementares (eqs. 7.2), a curva interpolada toma o aspecto geral da figura 7.4a, onde o ponto $(0,1)$ corresponde ao classificador perfeito, que atribui corretamente todas as instâncias positivas e negativas. As curvas ROC são também apresentadas em termos de especificidade como função da sensibilidade, estas definidas por

$$
\text { sens }=\frac{T P}{T P+F N} \quad \text { e } \quad \text { espec }=\frac{T N}{T N+F P},
$$

e um exemplo típico desta outra forma de apresentação está ilustrado na figura 7.4b. Neste caso, o classificador perfeito está no ponto $(1,1)$. É útil notar que $T P+F N$ fornece o número de valores positivos reais e que $T N+F P$ o número de reais negativos.

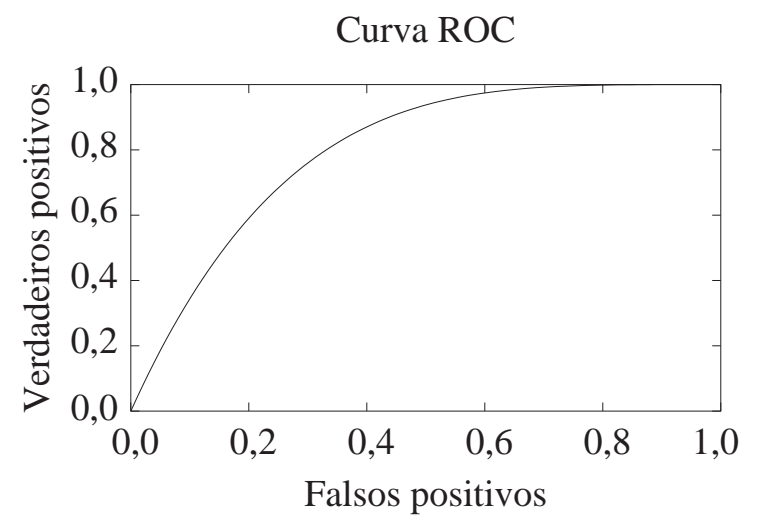

(a)

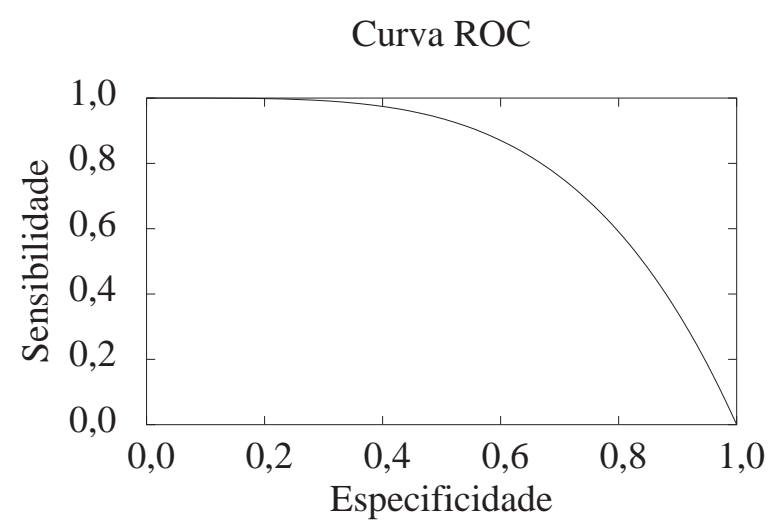

(b)

Figura 7.4: Curvas ROC típicas para classificadores paramétricos.

\section{Características do gráfico ROC}

- Os pontos do gráfico são independentes da distribuição das instâncias na classe e dos pesos dos erros.

- O gráfico ROC engloba toda a informação contida na matriz de confusão, pois $F N=1-T P$ e $T N=1-F P$.

- É uma maneira de examinar visualmente a relação entre as instâncias correta e incorretamente classificadas.

A análise do gráfico ROC para obter o ponto no qual o classificador é mais eficaz consiste na distância euclidiana daquele ponto até o ponto do classificador perfeito. Se a curva empregar os eixos $F P \times T P$, o classificador perfeito está no ponto $(0,1)$ e a distância é calculada por

$$
D C P=\sqrt{(F P)^{2}+(1-T P)^{2}},
$$


onde DCP significa "distância ao classificador perfeito". No caso do gráfico ROC utilizar eixos espec $\times$ sens, o classificador perfeito situa-se no ponto $(1,1)$, e a distância euclidiana torna-se

$$
D C P=\sqrt{(1-\text { sens })^{2}+(1-\text { espec })^{2}} .
$$

\section{Construção do gráfico ROC para classificação nebulosa de pi- xels}

As equações 7.3 apresentam como resultados valores não-inteiros, devido ao operador min ser empregado em valores de pertinência, e não-normalizados, pois são somas sobre todos os pixels da imagem. A utilização do gráfico ROC na versão da figura $7.4 \mathrm{~b}$ se torna mais adequada para a classificação nebulosa de pixels, pois as equações 7.4 normalizam os resultados, devido ao fato de não serem obtidas contagens de pixels, mas a soma de pertinências de todos eles.

Em classificação nebulosa, muitos autores (ver, por exemplo, Chi, Yan e Pham (1996) e Tizhoosh (1998)) procuram estabelecer um valor limiar para a pertinência para definir uma instância como positiva. Naturalmente este valor seria $u_{l i m} \geqslant 0,5$, mas operadores de agregação podem causar um deslocamento no limiar ótimo.

Neste trabalho, foram propostos dois métodos para avaliação do classificador de cores sobre um conjunto de imagens de teste. O primeiro, aqui denominado avaliação nebulosa utiliza as equações 7.3 e 7.4. O gráfico ROC é gerado como função paramétrica do número de imagens empregadas na fase de treinamento. Com estes, foram calculados os valores da sensibilidade e especificidade (eqs. 7.4), que normalizam a taxa de detecções corretas e falsas. Neste caso, a matriz de confusão propriamente dita não é construída, pois os valores obtidos das equações 7.3 não são contagens, mas os índices de acertos e erros do classificador.

O segundo método, denominado avaliação clássica, utiliza a matriz de confusão clássica e as equações 7.2. Sendo que consiste em contagens de acertos e erros do classificador, é necessário estabelecer um valor de pertinência limite $u_{l i m}$. Valores de pertinência $u\left(\mathbf{x}_{k}\right) \geqslant u_{\text {lim }}$ atribuem ao pixel $\mathbf{x}_{k}$ detecção positiva, e negativa caso contrário. Neste caso, é útil também adotar $u_{l i m}$ como o parâmetro a ser utilizado na construção do gráfico ROC para determinar qual o limiar que maximiza a eficiência do classificador. 


\subsubsection{Geração dos gabaritos de pele humana para avaliação do classificador}

As imagens de referência (ou gabaritos, aqui denominados imagens $\mathcal{R}$ ) para o teste do classificador são formadas por pixels de cor da pele, extraídos de cenas contendo seres humanos (imagens de teste $\mathcal{T}$ ). A seleção "manual" de cada pixel ${ }^{1}$ é muito dispendiosa em tempo, por isto, o método seguinte foi aqui idealizado para gerar imagens de referência com valor de pertinência associado a cada pixel:

1. escolhida uma imagem contendo seres humanos com trechos de pele exposta, produzse uma referência inicial usando a técnica de crescimento de regiões através do atributo "cor". Pixels-semente são escolhidos pelo agente supervisor em regiões contendo pele. Esta técnica busca conectar pixels vizinhos com a mesma cor, mas devido às suas variações, foi configurada uma faixa de \pm 10 em cada coordenada $[R G B]$, em relação à cor do pixel-semente. Para cobrir toda a área da imagem relativa à pele, vários pixels-semente são selecionados (poucas dezenas), o que ainda é muito mais viável operacionalmente do que rotular milhares de pixels cor da pele tipicamente contidos em uma imagem. Ainda assim, a utilização do crescimento de regiões não é livre de erros. Se, por exemplo, for diminuída a faixa de variação da cor do pixel-semente, para melhorar a precisão, mais pixels-semente devem ser selecionados. Porém, há a desvantagem da formação de "cubic blobs" no espaço de cores no espaço RGB, ou seja, são sempre selecionados os pixels em uma vizinhança cúbica de tamanho $\pm i$, sendo $i$ o número de pixels vizinhos ao pixel-semente;

- a imagem de referência é gerada através da detecção de todos os pixels na imagem original que apresentam as cores da pele conectada por crescimento de regiões;

2. outra imagem de referência é produzida a partir da imagem inicial escolhida como teste, da seguinte maneira. Aplica-se o algoritmo FCM com a distância de Mahalanobis da mesma forma que no módulo 1, separando-se os pixels classificados como pele e respectivas pertinências. Este procedimento também apresenta erros na seleção, com a vantagem de a pertinência expressar o quão "cor da pele" é cada pixel, e fornece o grau de acurácia na seleção;

3. para reunir as vantagens de ambos os procedimentos anteriores, foi construída uma imagem de referência final $\mathcal{R}$, utilizando a imagem produzida no primeiro procedi-

\footnotetext{
${ }^{1}$ Classificação supervisionada dos pixels que pertencem à pele humana na imagem.
} 
mento como máscara da imagem produzida no segundo procedimento. A intersecção assim resultante melhora a acurácia na construção da referência, devido à seleção de pixels cor da pele por dois métodos, fornecendo uma "referência nebulosa". Ainda, os pixels selecionados juntos em uma região cúbica pela limiarização não ficam com a mesma pertinência.

Naturalmente, como o atributo utilizado para a detecção é apenas a cor, vários objetos de cores similares à da pele podem ser detectados também. As imagens de referência $\mathcal{R}_{i}$ devem ser preparadas levando este fato em conta. Um exemplo de imagem de referência como conjunção de crescimento de regiões e FCM está esboçado nas figuras 7.5a-d.

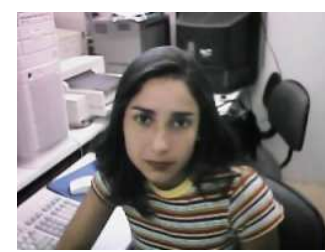

a

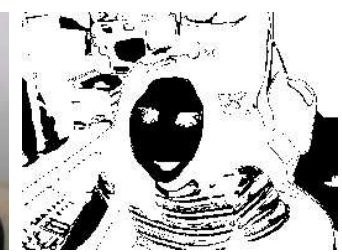

$\mathrm{b}$

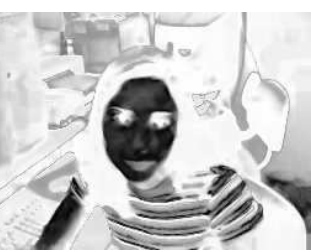

$\mathrm{C}$

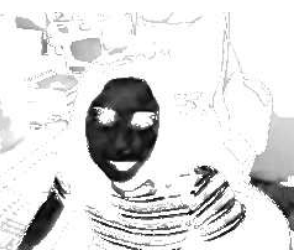

d

Figura 7.5: Formação da figura de referência: a) original, b) crescimento de regiões, c) FCM, d) conjunção das figs. b) e c).

\section{Detecção de cor da pele em imagens de teste e construção da matriz de confusão}

$\mathrm{O}$ conjunto selecionado de imagens de teste $\left\{\mathcal{T}_{1}, \mathcal{T}_{2}, \ldots, \mathcal{T}_{\text {Nteste }}\right\}$ é submetido ao classificador, gerando novas imagens $\left\{\mathcal{D}_{1}, \mathcal{D}_{2}, \ldots, \mathcal{D}_{\text {Nteste }}\right\}$ da seguinte maneira: cada pixel da imagem de teste é lido e extraída sua cor $[R G B]$. Esta cor é consultada na LUT gerada para o classificador. Se encontrada, é lida sua pertinência $u_{p k}$, senão, sua pertinência fica nula. Em seguida, o valor da pertinência é transformado em uma intensidade de cinza $I$ usando a seguinte equação

$$
I_{p k}=255\left(1-u_{p k}\right)
$$

e esta intensidade é associada ao pixel para representar a imagem $\mathcal{D}_{i}$, de tal forma que pixels pretos referem-se à pertinência 1,0 e brancos à pertinência zero. Assim, os pixels $x_{p k}$ cor da pele são detectados com suas respectivas pertinências $u_{p k}$. A partir disto, pode-se gerar imagens $T P, F P, T N$ e $F N$, derivadas da conjunção das imagens $\mathcal{R}_{i}$ e $\mathcal{D}_{i}$, utilizando-se as equações 7.3 e 7.7 .

A seguir, dois estudos de casos são apresentados, com os resultados adquiridos pelo classificador proposto para detecção de pele humana pela cor. 


\subsection{Caso 1: banco de imagens de faces.}

Oitenta imagens de faces, selecionadas do banco de imagens Purdue AR University (MARTINEZ; BENAVENTE, 1998), foram utilizadas como treinamento do classificador. Cada imagem possui de 40 mil a 70 mil pixels, onde cerca de $30 \%$ deles corresponde à cor da pele. Estas imagens foram produzidas em ambientes bem controlados, com fundo e iluminação praticamente constantes. As poses foram frontais, a partir do busto, com vestimentas variadas. Os tons de pele encontrados variam desde rosado até moreno escuro. Foram selecionadas para teste 40 outras imagens do mesmo banco.

\subsubsection{Parâmetros experimentais}

Módulo 1. Agrupamento. No processo de treinamento do classificador, os parâmetros utilizados para os testes preliminares foram:

- $N_{T}=80$ imagens de treinamento.

Na execução do algoritmo FCM-GK:

- $c_{\min }=3$. O banco de imagens utilizado apresenta um fundo branco que ocupa cerca de metade da imagem. Com isto, algoritmo FCM produz a melhor partição nebulosa para $c=2$ (fundo e resto mais escuro da imagem), o que não é um resultado útil.

- $c_{\max }=7$. Para o domínio escolhido, até sete grupos de cores.

- Matriz $\left\{u_{i k}\right\}$ de pertinências dos pixels por grupo inicializada aleatoriamente.

- Posições iniciais $\mathbf{v}_{i}^{(0)}$ dos centros dos grupos distribuídas uniformemente no espaço RGB, em torno da diagonal principal (eixo acromático). Esta é uma escolha heurística, devido às imagens de cenas naturais apresentarem cores não muito saturadas. Como conseqüência, a maioria das cores ficam próximas do eixo acromático (cinzas), como pode ser observado na fig. 7.2. No espaço RGB, este eixo corresponde à diagonal principal do cubo, que vai de $(0,0,0)$ a $(255,255,255)$. Como exemplo, para número total de grupos $c=4$, a inicialização dos centros se torna de acordo com a tabela 7.3.

- Fator de nebulosidade empregado: $m=1,5$. Determina o grau de superposição dos grupos na partição nebulosa. Totalmente arbitrário, e valores acima de 2,0 começam a "espalhar" muito as funções de pertinência. 
- Critério de parada: número máximo de iterações $=300$ ou erro de convergência da matriz de pertinência $\epsilon=0,001$.

Seguem-se a avaliação da função de validação $S$ (eq. 3.25), a obtenção do melhor número de grupos (eq. 3.26) e a construção das subimagens com os pixels de cada grupo.

Tabela 7.3: Exemplo de inicialização heurística dos centros de quatro grupos no espaço de cores RGB, onde cada componente $\{x \mid 0 \leqslant x \leqslant 255\}$.

\begin{tabular}{c|ccc} 
grupo & $\mathrm{R}$ & $\mathrm{G}$ & $\mathrm{B}$ \\
\hline 1 & 32 & 32 & 32 \\
2 & 96 & 96 & 96 \\
3 & 160 & 160 & 160 \\
4 & 224 & 224 & 224 \\
\hline
\end{tabular}

Módulo 2. Definição de classes. Não há parâmetros a serem inicializados, pois o supervisor seleciona as subimagens que reúnem os pixels da classe de interesse.

Módulo 3. Agregação. Nestes experimentos, foi feita a agregação direta de todos os grupos de pixels rotulados com a mesma classe, com o operador média (eq. 6.9), sem a utilização de qualquer fator de relevância.

Experimentos preliminares haviam mostrado que a utilização de um fator de relevância não alterou perceptivelmente a qualidade da detecção, pela análise do gráfico ROC. Por exemplo, em uma imagem como a da fig. 7.6, dois grupos são identificados como pele, onde um deles pode ter maior relevância (valores de pertinência com peso maior).

Módulo 4. Generalização. Este módulo foi idealizado para interpolar os pontos faltantes após o treinamento, no modelo de cor da pele no espaço de cores. Propõese aqui testar todo o espaço de cores após o treinamento e, nos pontos onde não há vizinhos pertencentes à classe cor da pele, a pertinência continua nula. Um ponto de teste com pertinência não-nula é proveniente do treinamento, e deve ser ignorado pelo algoritmo, mantendo sua pertinência. Se um ponto de teste apresenta pertinência nula, esta é recalculada em função de sua vizinhança. Se a vizinhança tiver pertinência nula (pontos fora da classe), a pertinência do ponto testado continuará nula.

Para executar a generalização, foi utilizado o parâmetro: $k=10$ (dez vizinhos) no 
algoritmo kNN nebuloso, e a distância de alcance escolhida no espaço RGB foi de \pm 2 unidades em torno do ponto testado (ver quadro 6).

\subsubsection{Resultados do módulo 1}

Utilizando-se os parâmetros definidos na seção 7.4.1, o número de grupos $c^{*}$ ótimo para particionar a imagem mostrada na fig. 7.6 (original), é dado pelo menor valor da função de validação $S$. Os valores de $S$ são mostrados na tabela 7.4, e as subimagens correspondentes ao melhor particionamento (cinco grupos) estão nas figs. 7.6a-e. Na fig. 7.6 embaixo, mostra-se a distribuição de cores no espaço RGB, projetada em três planos deste, onde os quadradinhos situam os centróides dos grupos obtidos. Os quadradinhos na parte alaranjada da distribuição correspondem aos grupos de pixels cor da pele, representados nas subimagens $a$ e $c$ da fig. 7.6.

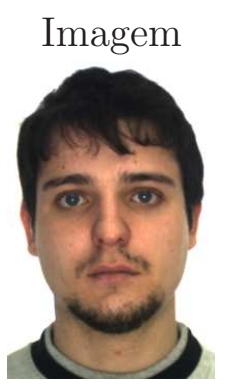

(original)

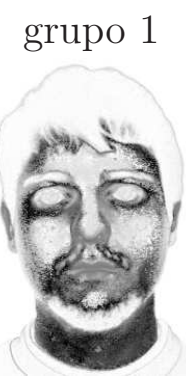

(a)

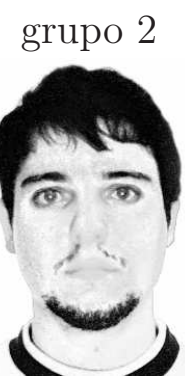

(b)

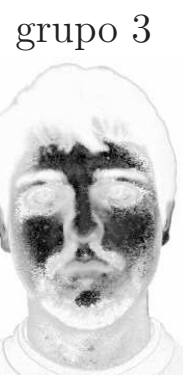

(c)

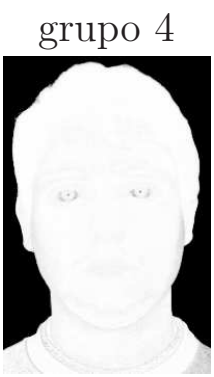

(d)

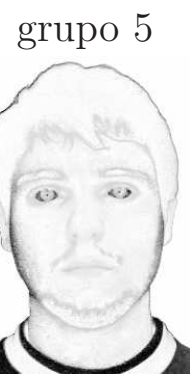

(e)

Grupos apresentados em imagens monocromáticas, com pontos pretos indicando pertinência ao grupo, e branco, pertinência nula.

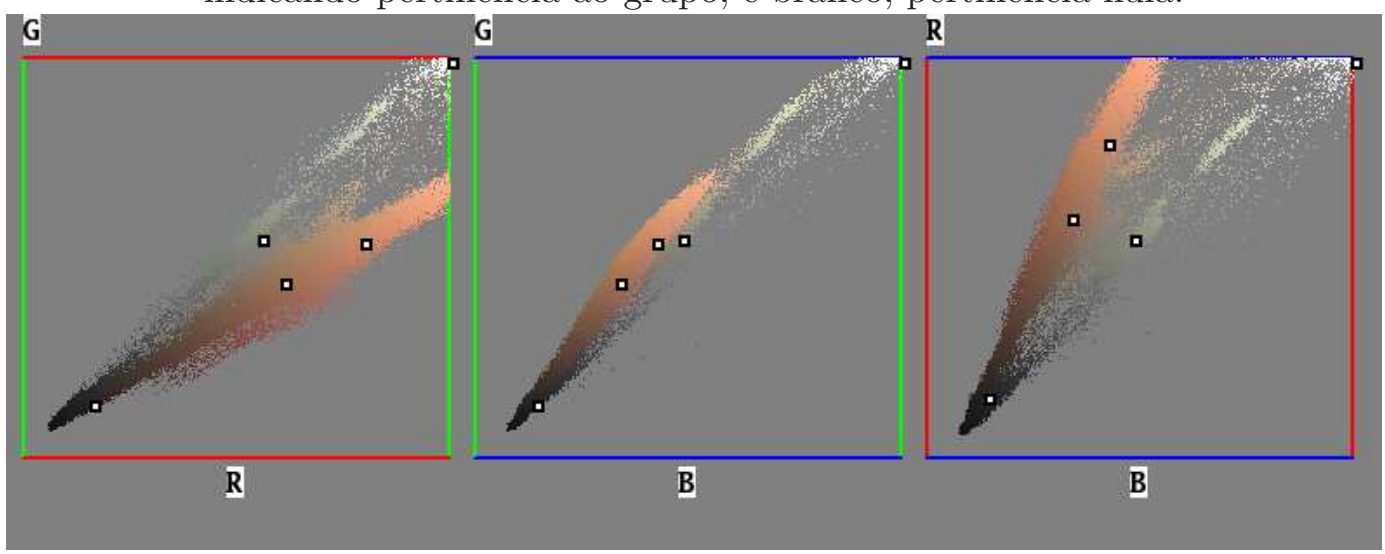

Figura 7.6: Superior: exemplo de imagem colorida utilizada no treinamento do classificador, e subimagens construídas por grupo de pixels. Inferior: distribuições das cores nas projeções laterais do cubo RGB, com marcas indicando os centros dos grupos. 
Tabela 7.4: Número de grupos dados pelo algoritmo FCM-GK e respectiva função de validação $S$, aplicados à fig. 7.6.

\begin{tabular}{lcccc}
\hline Número de grupos $c$ & 3 & 4 & 5 & 6 \\
\hline Função de validação $S$ & 0,262 & 0,136 & 0,085 & 0,202 \\
\hline
\end{tabular}

\subsubsection{Resultados do módulo 2}

São apresentadas as subimagens como as das figs. 7.6a-e, e o usuário seleciona visualmente aquelas que contém os pixels de cor da pele (figs. 7.6a e 7.6c). Uma imagem pode apresentar mais de uma subimagem correspondente à cor da pele, que devem ser selecionados, pois são igualmente rotulados como cor da pele. Este fato é conseqüência do algoritmo FCM-GK executar o agrupamento de forma não-supervisionada, e a rotulação dos grupos cabe ao supervisor.

Vale ressaltar que esta tarefa de rotular grupos, associando-os a classes (conceitos), é muito mais simples do que rotular cada pixel como pertencente ou não à classe cor da pele no treinamento, como é usualmente feito utilizando aprendizado supervisionado; aqui, nesta abordagem híbrida, a supervisão se dá no nível dos grupos.

\subsubsection{Resultados do módulo 3}

Após a seleção dos grupos das imagens de treinamento, a agregação dos grupos de pixels na classe cor da pele, apresenta as distribuições vistas na fig. 7.7. Foi realizada a aplicação do operador de agregação "média aritmética", segundo a equação 6.9.

Pode-se observar, na fig. 7.7, que a distribuição de pertinência da classe de pixels decai suavemente nas suas bordas, evidenciando a transição nebulosa. Este formato é explicado pelo valor utilizado do fator de nebulosidade $m$ do algoritmo FCM-GK.

\subsubsection{Resultados do módulo 4 .}

A figura 7.8 mostra um exemplo de detecção de cor da pele em uma imagem de teste, antes e após o procedimento de generalização feito pelo módulo 4. A intensidade dos pixels está proporcional à pertinência na classe, variando de branco $\left(u_{p k}=0,0\right)$ a preto $\left(u_{p k}=1,0\right)$. Na imagem central desta figura, observa-se uma detecção esparsa de pixels cor-da-pele. Para preencher melhor estes interstícios, seriam necessárias mais imagens de 

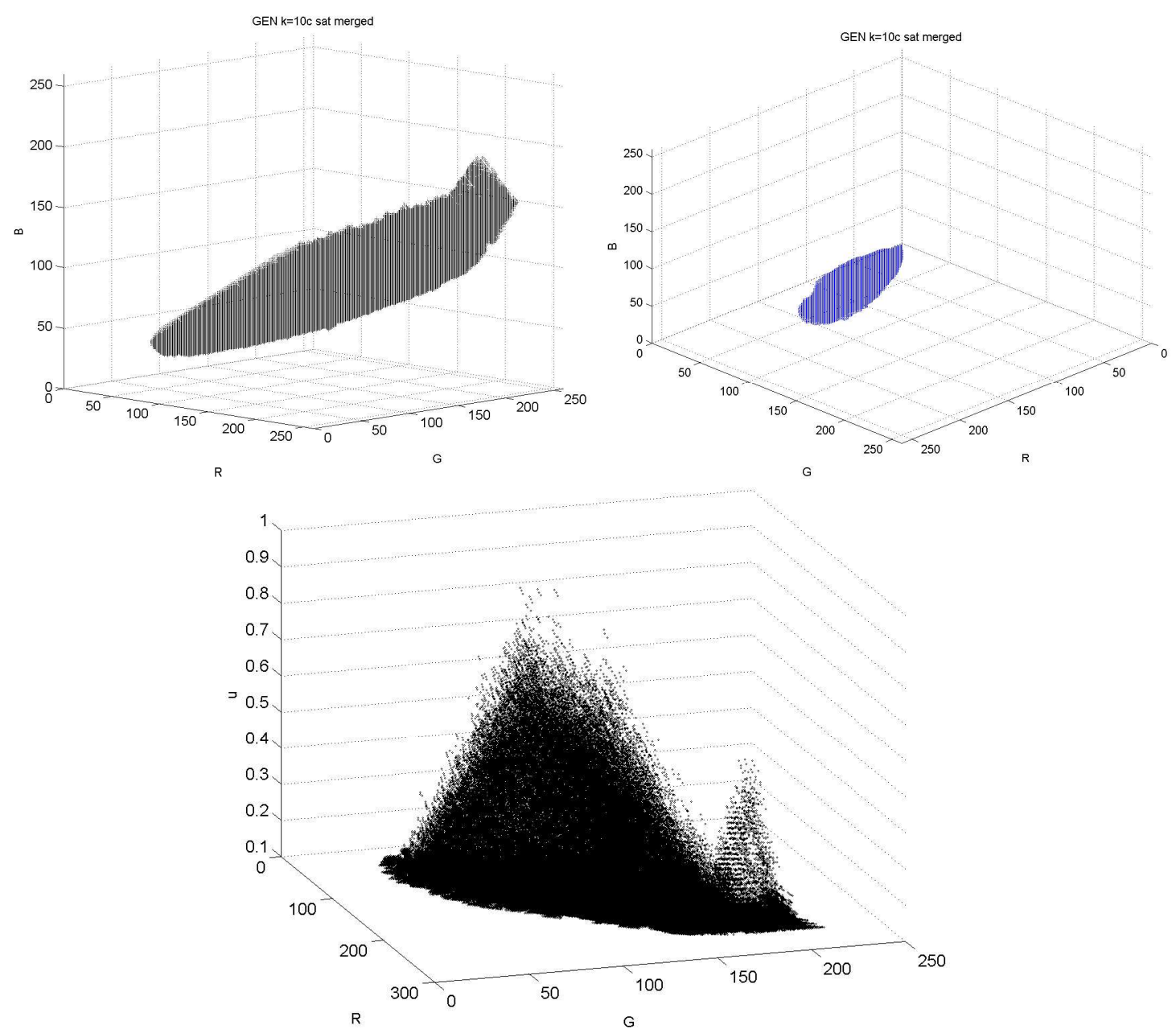

Figura 7.7: Distribuição dos pontos cor da pele, após apresentação das imagens de treinamento. Em cima, duas visões da classe formada no espaço RGB. Embaixo, projeção no plano RG do espaço de cores (horizontal). No eixo vertical, os valores de pertinência após o treinamento.

treinamento (quanto? ${ }^{2}$ ), caso não fosse aplicada a técnica de generalização. No entanto, observa-se a grande contribuição deste procedimento na imagem da direita, especialmente na boa separação de classes entre os pixels da parte inferior do pescoço e a gola da camisa.

A fig. 7.9 mostra a classe cor da pele no espaço RGB seccionada na coordenada $R=140$, antes e após a generalização, demonstrando seu efeito. Este plano em $R=140$ foi escolhido apenas para fins de ilustração. A dilatação observada na classe deve-se à contribuição das pertinências dos pixels vizinhos em todas as direções (incluindo os planos $R=138,139,141$ e 142). Os valores de pertinência não estão representados nesta figura, porém decrescem em direção às bordas.

\footnotetext{
${ }^{2}$ A resposta está na aplicação do modelo PAC, com o cálculo da probabilidade conjunta de haver pixels de treinamento exatamente nestas posições.
} 

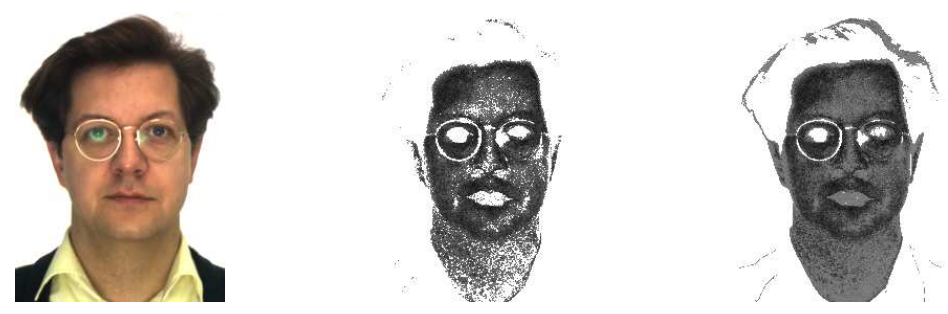

Figura 7.8: Esquerda: imagem original, ao centro: cor da pele detectada antes do procedimento de generalização e à direita, após a generalização.
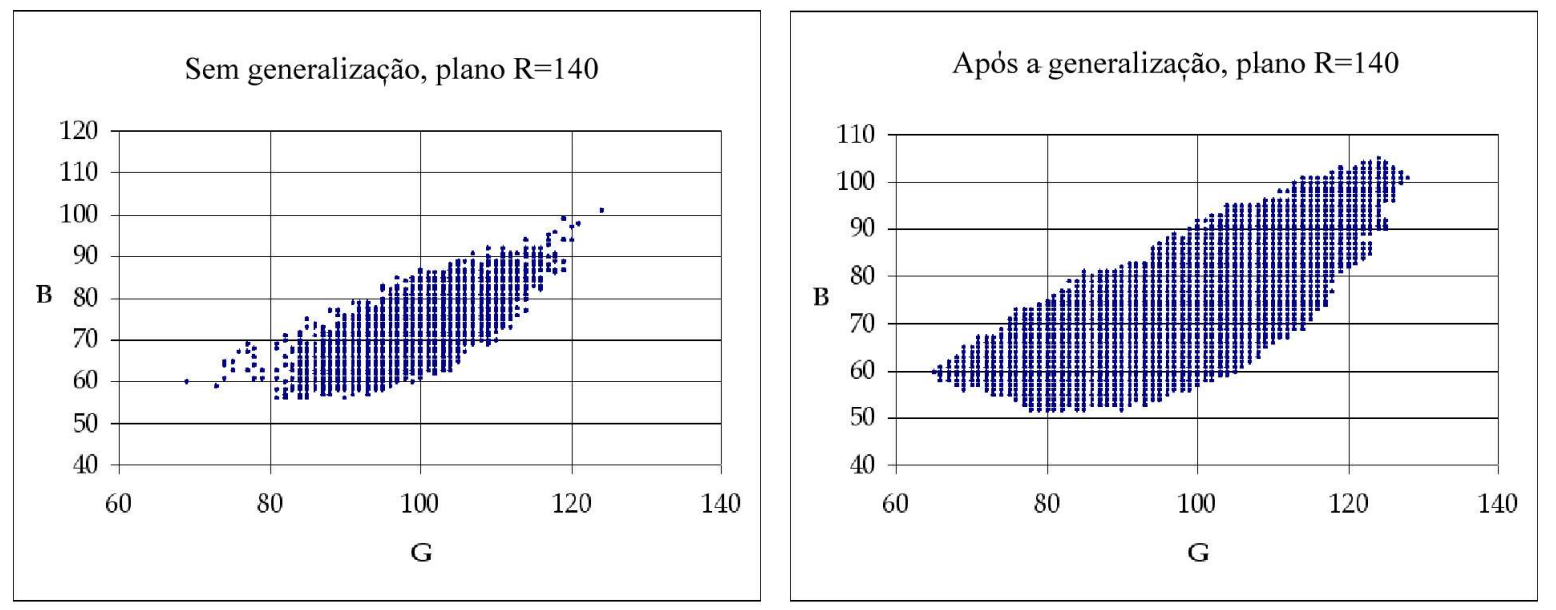

Figura 7.9: Pixels da classe cor da pele no plano GB, secção $R=140$ do espaço RGB. À esquerda, antes da generalização e à direita, após a mesma.

\subsubsection{Teste do modelo e detecção da cor da pele}

Sendo o modelo de aprendizado incremental, o treinamento pode ser interrompido a qualquer momento e pode-se classificar pixels de outras imagens com o conhecimento até então armazenado. Partes do corpo humano podem ser identificadas pela cor da pele, através dos valores de pertinência dos pixels à classe cor da pele, armazenada na base de conhecimento.

\section{Teste utilizando as imagens restantes do banco $A R$ Face $D B$}

Conforme o procedimento explanado na seção 7.3.1, a fig. 7.10 mostra exemplos de imagens de teste provenientes do banco de faces $A R$ Face $D B$, e a detecção de pele usando o modelo de classe cor da pele após um treinamento com 80 imagens do mesmo banco, e com o procedimento de generalização executado. A intensidade dos pixels mostrados é proporcional às suas pertinências.

Nas figuras 7.11a-d, os gráficos ROC mostram o desempenho do classificador sobre 40 imagens restantes da AR Face DB, empregadas como teste. Na fig. 7.11a, os pontos repre- 


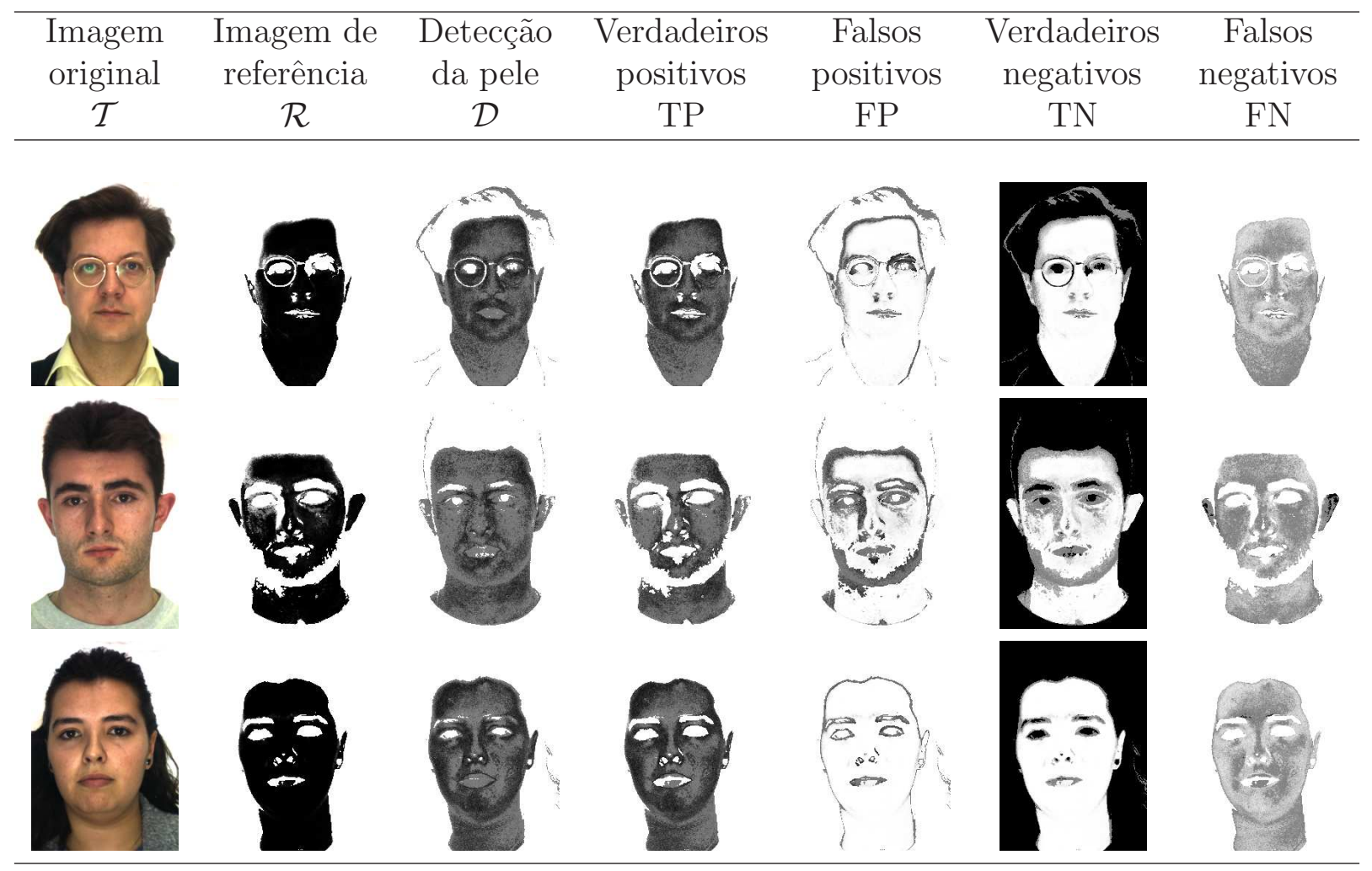

Figura 7.10: Algumas imagens de teste e detecção de pele resultantes.

sentados por "quadrados" representam a avaliação do classificador com o procedimento de generalização executado. Os "losangos" representam o desempenho do classificador sem o mesmo procedimento, mostrando que o módulo de generalização melhora a qualidade da detecção. Sem generalização, é mostrada a melhoria da detecção com o aumento do número de imagens de treinamento (de 10 a 80), mas a generalização melhora a detecção mesmo que poucas imagens tenham sido usadas no treinamento (visto que os quadrados estão agrupados).

A fig. 7.11b apresenta o mesmo tipo de gráfico na abordagem clássica, onde um ponto na imagem é considerado cor da pele se $u \geqslant u_{l i m}$. Observou-se a variação da sensibilidade e da especificidade em função do valor de $u_{l i m}$. Foram utilizadas as mesmas imagens de treinamento para esta avaliação. Pode-se inferir as mesmas conclusões que no caso da fig. 7.11a, porém o desempenho melhorou, observado pelo aumento da sensibilidade do classificador (eixo vertical). No entanto, convém lembrar que o cálculo clássico é booleano, de modo que se pode considerar $u_{\text {prevista }}=1$ na eq. 7.3. Os "círculos" e as "cruzes" praticamente coincidem para $u_{\text {lim }}=0,6$ e 0,7 .

As figuras 7.11c e 7.11d esclarecem um pouco melhor o comportamento da detecção em função de $u_{\text {lim }}$. A sensibilidade é praticamente constante na faixa $0,01 \leqslant u_{l i m} \leqslant 0,5$, 
decaindo rapidamente para valores superiores. O melhor valor para $u_{l i m}$ é aproximadamente 0,5 , pois a escolha de valores menores implica em considerar cores de pertinência muito baixa à classe cor da pele, isto é, com uma relação "fraca" com a classe. Com o procedimento de generalização (fig. $7.11 \mathrm{~d}$ ), valores $u_{\text {lim }} \geqslant 0,4$ mostram o mesmo desempenho na detecção para quantidades variáveis de imagens de treinamento. 


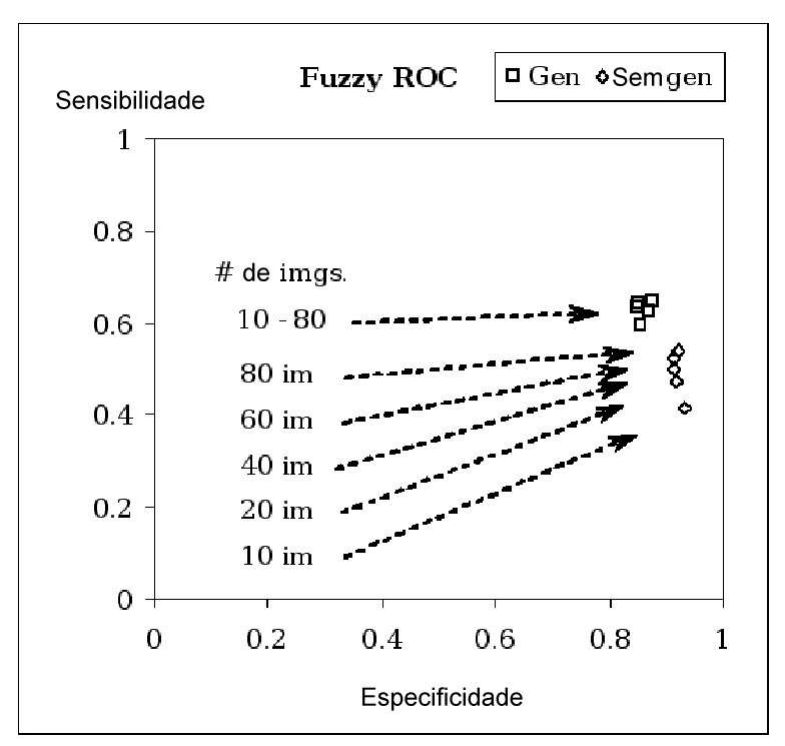

(a)

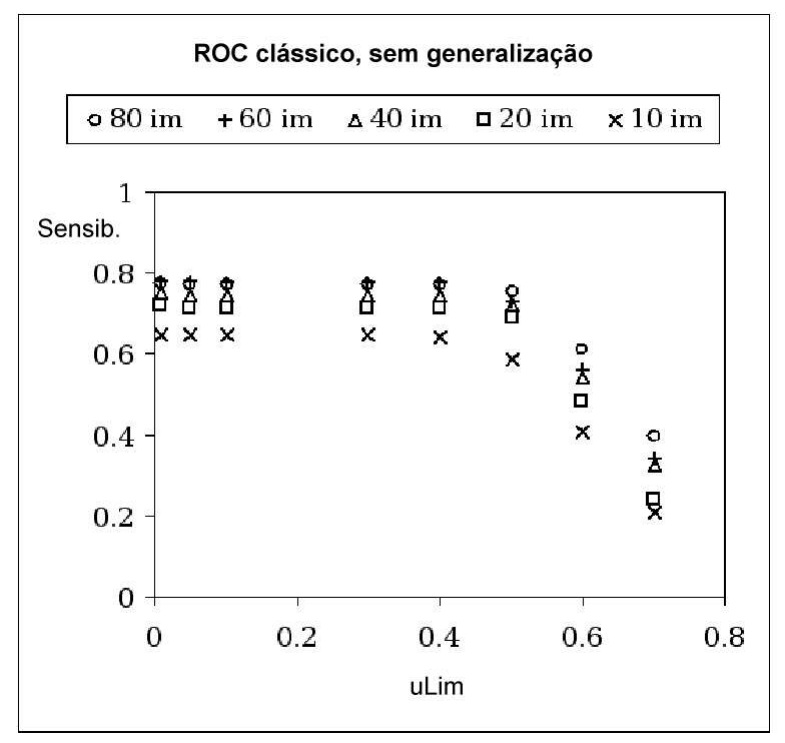

(c)

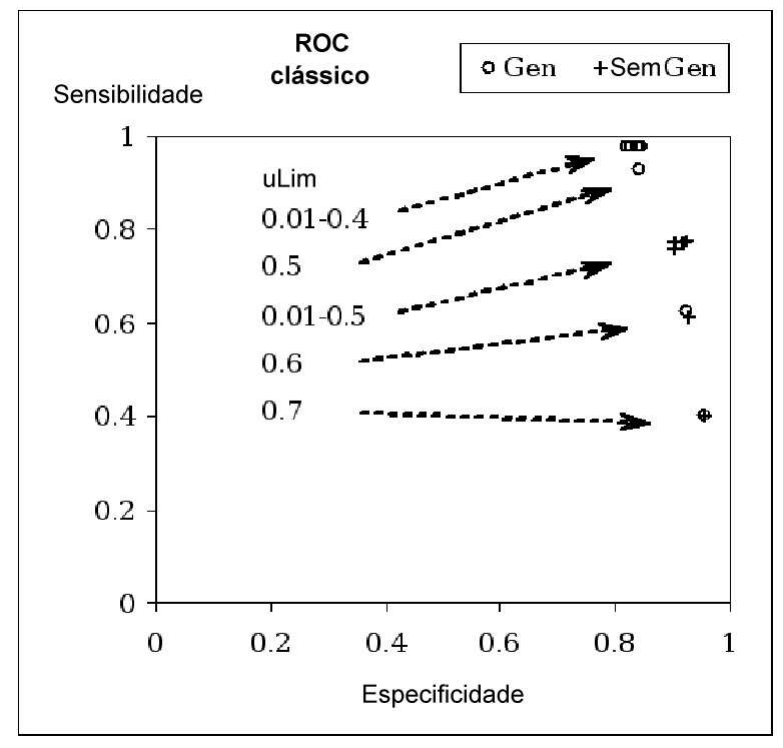

(b)

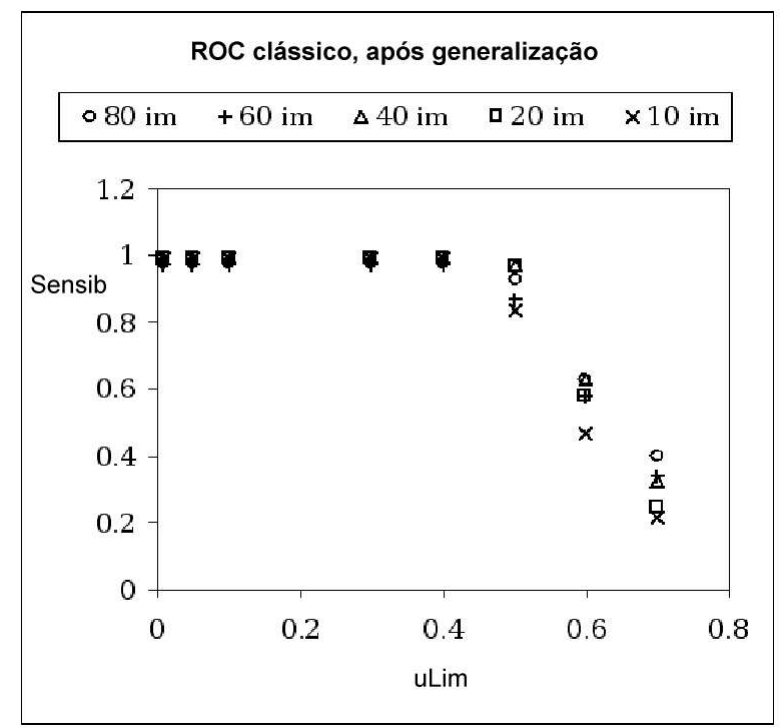

(d)

(a) Gráfico ROC nebuloso parametrizado pelo número de imagens de treinamento, antes e após o procedimento de generalização (módulo 4).

(b) Gráfico ROC clássico mostrando a relação com $u_{\text {lim }}$.

(c) Sensibilidade do classificador como função de $u_{l i m}$, antes da generalização.

(d) Sensibilidade do classificador como função de $u_{l i m}$, após a generalização.

Figura 7.11: Gráficos ROC: (a) nebuloso parametrizado por $N_{T}$; (b) clássico parametrizado por $u_{l i m}$; (c) e (d), sensibilidade no ROC clássico como função de $u_{l i m}$. 


\section{Teste utilizando outras imagens}

Para avaliar o classificador construído com o banco de faces $A R$ Face DB, 20 imagens foram obtidas aleatoriamente da Internet e de revistas, e submetidas à detecção. A fig. 7.12 mostra um exemplo destas imagens e resultados. À exceção das originais, a intensidade dos pixels das demais imagens são linearmente proporcionais ao valor de pertinência à classe cor da pele. A "detecção global" refere-se a todas as cores de pele reconhecidas pelo classificador, na imagem completa.

Na imagem (a) desta figura, o fundo marrom foi corretamente classificado como nãopele (pixels verdadeiros-negativos). Nas imagens $(b)$ e $(c)$, há muitos pixels cor da pele que não estão na pessoa representada, motivando a análise do desempenho da classificação de duas maneiras: uma, considerando todos os pixels da imagem (filas superiores das colunas $b$ e $c$ ), e outra, considerando os locais onde há somente pele humana (filas inferiores "somente pele"). Estas filas inferiores tiveram suas imagens de referência produzidas a partir das referências que estão respectivamente acima de cada uma, porém, eliminando-se manualmente todos os pixels cor da pele que não sejam efetivamente pele. Em particular, a imagem $b$ apresenta muitos pixels cor da pele no plano de fundo. Esta análise em paralelo, considerando apenas os pixels que sejam realmente pele, visa avaliar o classificador de forma "mais justa". No entanto, cabe aqui lembrar que o atributo analisado é apenas a cor, sem levar em conta a posição da imagem e conectividade entre pixels.

O desempenho do classificador para este conjunto de 20 imagens está na tabela 7.5, que apresenta uma análise nebulosa pela equação 7.3 e outra clássica pela equação 7.2 , esta parametrizada por $u_{l i m}$. Cada valor representa a média das 20 imagens, e os respectivos desvios padrões. As colunas "DCP" mostram a distância ao classificador perfeito, dado por $(1,1)$. Semelhantemente ao teste utilizando as mesmas imagens do banco $A R$ Face $D B$, a avaliação clássica mostra um melhor desempenho para $u_{l i m}=0,5$. Acima deste valor, a sensibilidade diminui fortemente. É importante notar que a mudança no valor de $u_{l i m}$ provoca efeitos bem diversos na detecção para todas as 20 imagens de teste, fato que se reflete na oscilação dos desvios padrões na coluna "detecção global". Isto pode ser justificado pela natureza das imagens, provenientes de cenas naturais sem controle dos objetos presentes. Assim, pixels classificados como "positivos" para um valor limiar de pertinência passam a ser "negativos", aparecendo em quantidades diferentes nas diversas imagens de teste. A avaliação nebulosa parece corresponder mais fielmente à observação da figura 7.12, em relação aos verdadeiros e falsos negativos e positivos. 
Original Referência Pele Verdadeiros Falsos Verdadeiros Falsos detectada positivos positivos negativos negativos

a)
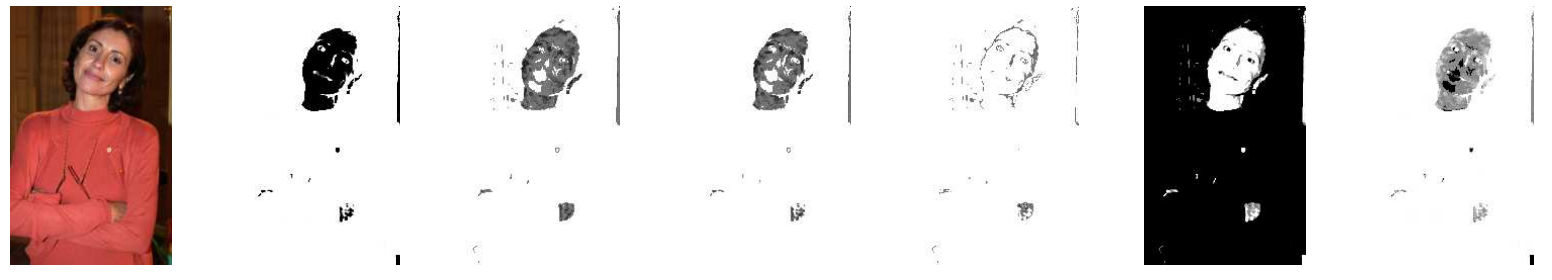

b)
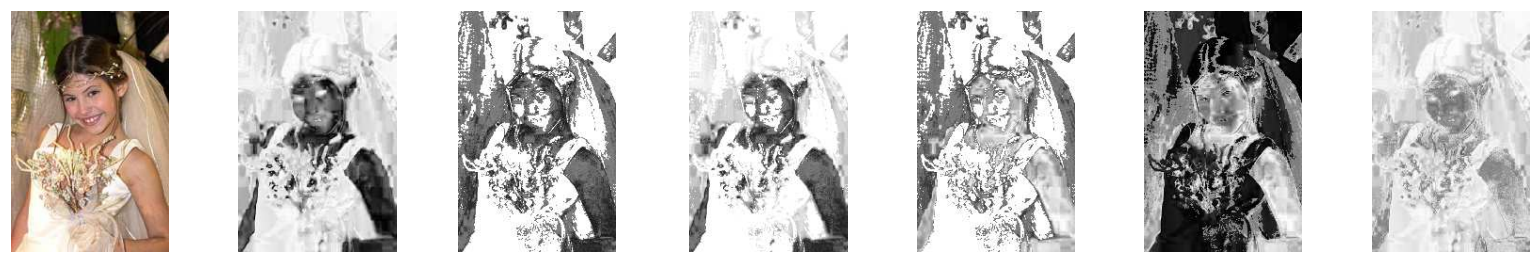

somente pele:
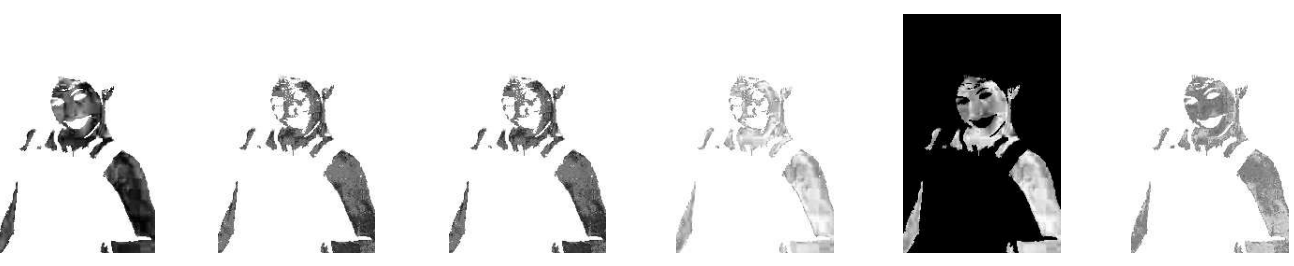

c)
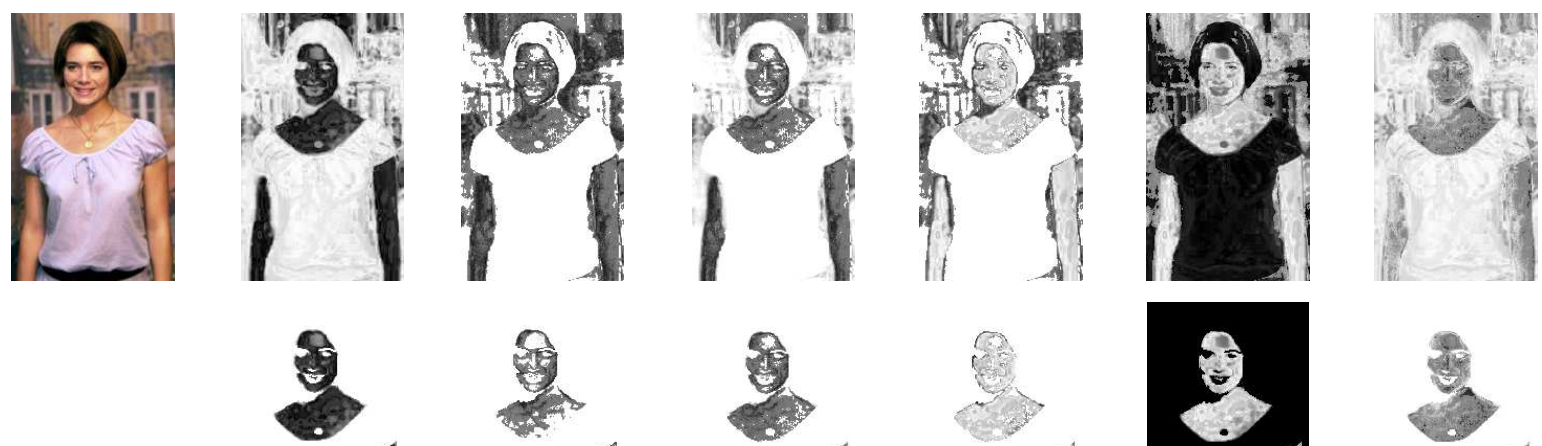

somente pele:
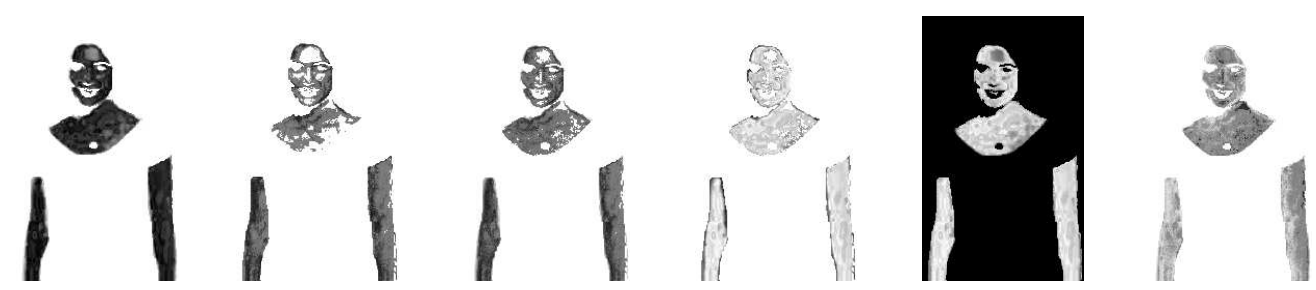

Figura 7.12: Exemplo de imagens retiradas da Internet e de revistas, e resultados na detecção de pele. 
Tabela 7.5: Avaliações nebulosa e clássica do desempenho nas 20 imagens da Internet e revistas, com valores médios de especificidade e sensibilidade e respectivos desvios padrões.

\begin{tabular}{c|ccc|cccc}
\hline & \multicolumn{4}{|c}{ Detecção global } & \multicolumn{3}{c}{ Detecção somente pele } \\
& Especificidade & Sensibilidade & DCP & Especificidade & Sensibilidade & DCP \\
\hline & & & Nebulosa \\
& $0,83 \pm 0,14$ & $0,52 \pm 0,02$ & 0,51 & $0,96 \pm 0,01$ & $0,59 \pm 0,00$ & 0,42 \\
\hline$u_{\text {lim }}$ & \multicolumn{5}{c}{ Clássica } \\
0,1 & $0,86 \pm 0,11$ & $0,75 \pm 0,13$ & 0,29 & $1,00 \pm 0,01$ & $0,91 \pm 0,01$ & 0,09 \\
0,3 & $0,78 \pm 0,18$ & $0,91 \pm 0,01$ & 0,24 & $0,99 \pm 0,01$ & $0,90 \pm 0,01$ & 0,10 \\
0,4 & $0,77 \pm 0,19$ & $0,92 \pm 0,02$ & 0,24 & $0,99 \pm 0,01$ & $0,91 \pm 0,01$ & 0,09 \\
0,5 & $0,79 \pm 0,17$ & $0,91 \pm 0,04$ & 0,23 & $0,99 \pm 0,01$ & $0,93 \pm 0,04$ & 0,07 \\
0,6 & $0,91 \pm 0,08$ & $0,50 \pm 0,19$ & 0,51 & $0,99 \pm 0,01$ & $0,47 \pm 0,04$ & 0,53 \\
0,7 & $0,94 \pm 0,06$ & $0,32 \pm 0,20$ & 0,68 & $0,99 \pm 0,01$ & $0,33 \pm 0,10$ & 0,67 \\
\hline
\end{tabular}

\subsection{Caso 2: imagens humanas em ambientes variados}

Foram utilizadas 58 imagens de faces para aplicação do método, disponibilizadas na Internet (GARCIA, 2002), das quais 46 foram escolhidas para treinamento e 12 para testes. Este conjunto inicial de imagens foi escolhido pelo fato de aparentemente ser obtido com a mesma câmera fotográfica (não descrita pelos autores). As condições de iluminação foram variadas, desde luz artificial (a grande maioria) até luz solar indireta. Também se apresentam diversas condições de fundo da cena, incluindo a presença de outras pessoas.

Cada imagem apresentou cerca de 60000 pixels, variando de 7000 a 20000 cores diferentes (valores RGB). Os pixels classificados pelo supervisor como cor da pele, obtidos pelo algoritmo FCM-GK em cada imagem, foram da ordem de 8000. Na base de conhecimento ficaram inclusas aproximadamente 20000 cores diferentes das 46 imagens, rotulados com pertinência não nula para o conjunto cor da pele.

\subsubsection{Parâmetros experimentais}

No processo de treinamento do classificador, os parâmetros utilizados para os testes foram:

- $N_{T}=46$ imagens de treinamento.

Na execução do algoritmo FCM-GK:

- $c_{\max }=9$. Para o domínio escolhido, até nove grupos de cores.

- Matriz $\left\{u_{i k}\right\}$ de pertinências dos pixels por grupo inicializada aleatoriamente. 
- Posições iniciais $\mathbf{v}_{i}^{(0)}$ dos centros dos grupos distribuídas uniformemente no espaço RGB, em torno da diagonal principal (eixo acromático).

- Fator de nebulosidade empregado: $m=1,5$.

- Critério de parada: número máximo de iterações $=300$ ou erro de convergência da matriz de pertinência menor que $\epsilon=0,001$.

Com exceção do número de imagens de treinamento e do número máximo de grupos $c_{\text {max }}$, os demais parâmetros foram semelhantes àqueles usados no caso 1.

\subsubsection{Resultados do módulo 1}

Utilizando-se os parâmetros definidos na seção 7.5.1, o número de grupos $c^{*}$ ótimo para particionar a imagem mostrada na fig. 7.13a é dado pelo menor valor da função de validação $S$. Os valores de $S$ são mostrados na tabela 7.6, e as subimagens correspondentes ao melhor particionamento (três grupos) estão na fig. 7.13b-d. Na fig. 7.13 embaixo, a distribuição de cores no espaço RGB, projetada em três planos deste. Nota-se que o grupo de pixels azuis aparece mais destacado. As imagens $b, c$ e $d$ da fig. 7.13 estão reproduzidas em tons de cinza, onde a cor preta representa pertinência 1 do pixel em relação ao grupo que constitui cada imagem, e a cor branca, pertinência 0. Os tons cinzas representam valores proporcionais na escala $[0,1]$.

Tabela 7.6: Número de grupos dados pelo algoritmo FCM-GK e respectiva função de validação $S$, aplicados à fig. 7.13a.

\begin{tabular}{c|c|c|c|c|c|c|c|c} 
Número de grupos $c$ & 2 & 3 & 4 & 5 & 6 & 7 & 8 & 9 \\
\hline Função de validação $S$ & 0,357 & 0,195 & 0,290 & 0,397 & 0,335 & 0,301 & 0,267 & 0,384
\end{tabular}

\subsubsection{Resultados do módulo 2}

São apresentadas as subimagens (p.ex., fig. 7.13b, c e d) e o usuário seleciona visualmente aquela que contém os pixels de cor da pele. Uma imagem pode apresentar mais de uma subimagem correspondente à cor da pele, logo, para cada imagem de treinamento, pode haver mais de uma seleção. O módulo 2 consiste em uma escolha atenta de todas as subimagens onde se encontram pixels cor da pele, conforme ilustra a fig. 7.14. Nesta figura, 
as subimagens também foram construídas com intensidade proporcional à pertinência na classe cor da pele. Os pixels bem escuros apresentam pertinências próximas a 1.

Nota-se nas duas primeiras imagens da fig. 7.14 que há dois grupos de pixels cor da pele provenientes da mesma imagem. Ambos devem ser selecionados no módulo 2, pois são igualmente rotulados como "cor da pele". Este fato é conseqüência do algoritmo FCM-GK executar o agrupamento de forma não-supervisionada, e a rotulação dos grupos cabe ao usuário supervisor. 


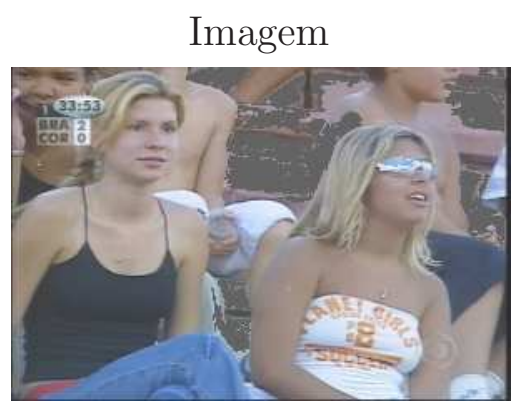

(a)

grupo 2

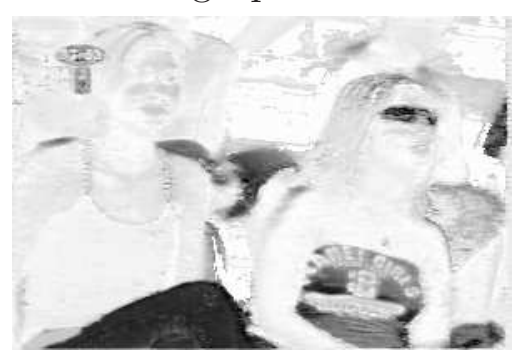

(c)

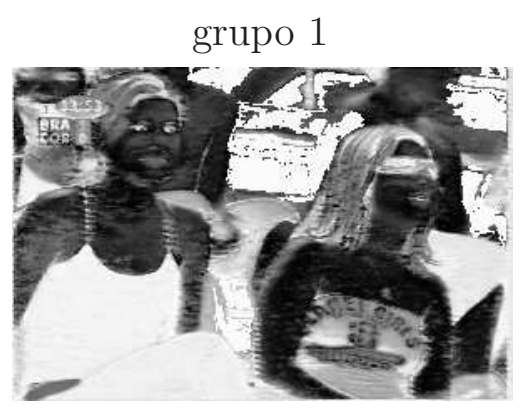

(b)

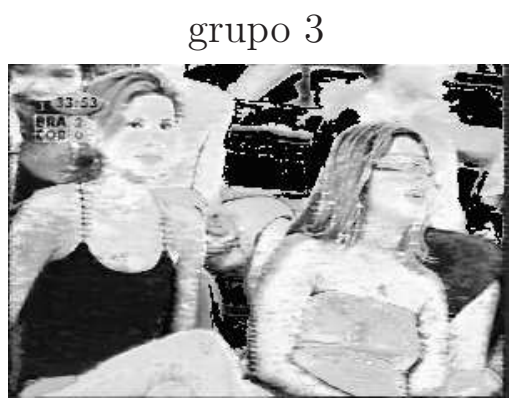

(d)

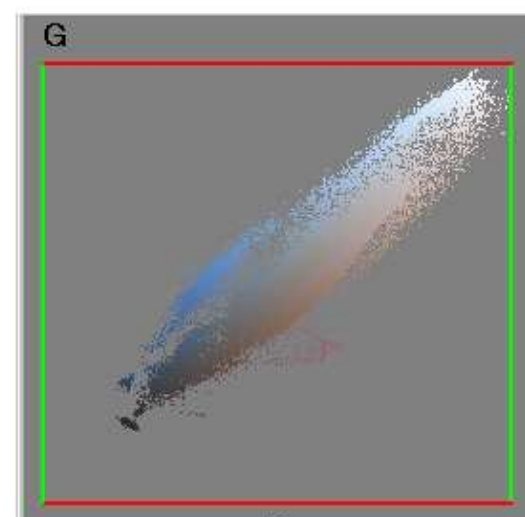

$\mathrm{R}$
G

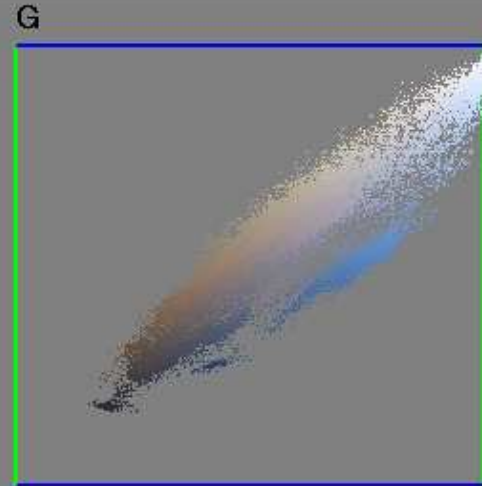

B
$\mathrm{R}$

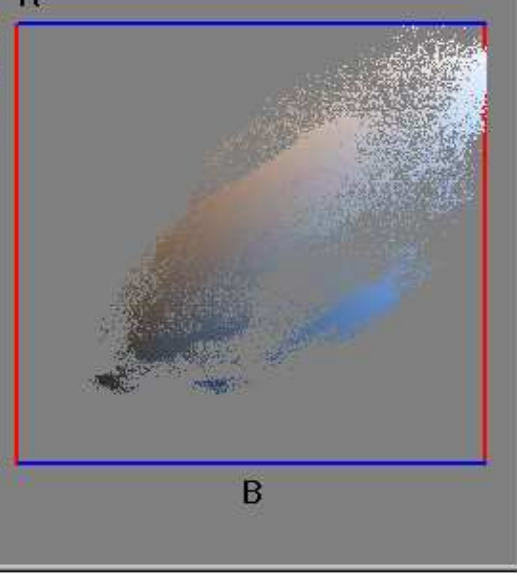

Figura 7.13: Em cima e centro: (a) exemplo de imagem colorida utilizada no treinamento e (b-d) subimagens construídas por grupo de pixels. Embaixo: distribuições das cores nas projeções laterais do cubo RGB. 


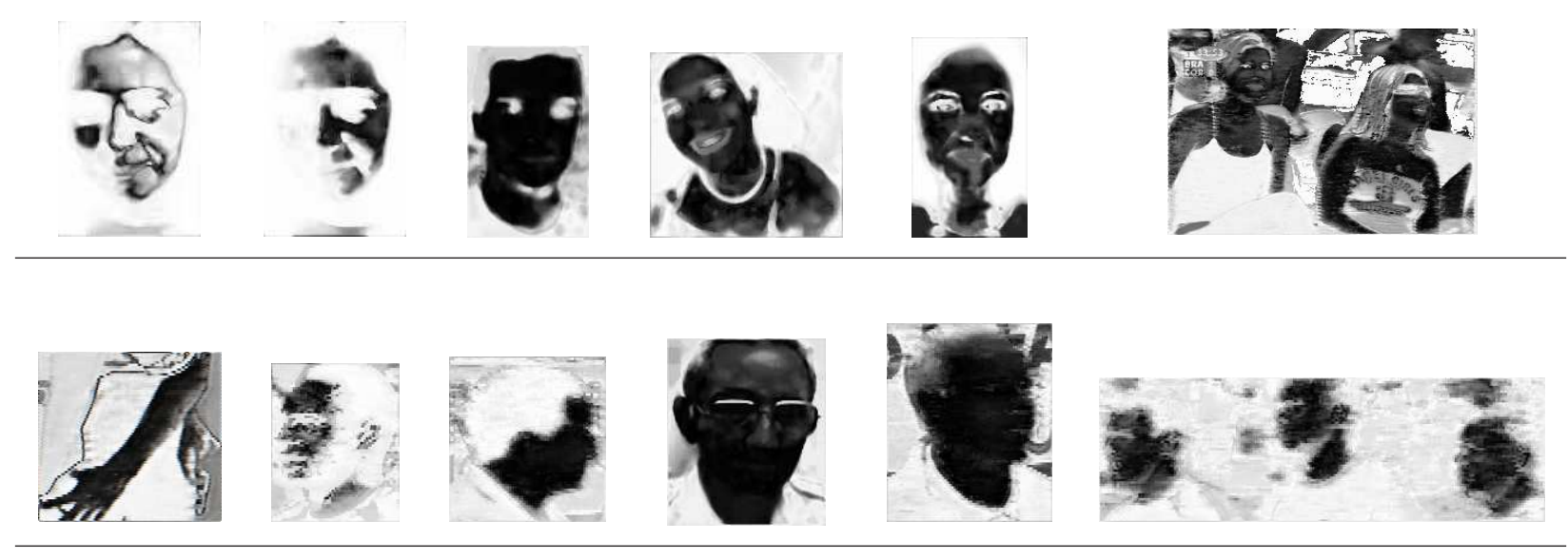

Figura 7.14: Exemplo de seleções de subimagens com pixels cor da pele, construídas no módulo 1.

\subsubsection{Resultados do módulo 3}

Após submeter as 46 imagens de treinamento, a agregação dos grupos de pixels na classe cor da pele apresenta a distribuição vista na fig. 7.15a. Foi realizada a aplicação direta do operador de agregação "média aritmética", segundo a equação 6.9, para a formação da classe durante o treinamento.

\subsubsection{Resultados do módulo 4 .}

As figuras 7.15a e 7.15b mostram a classe cor da pele no espaço RGB antes e após a generalização. A dilatação observada na classe deve-se à contribuição das pertinências dos pixels vizinhos em todas as direções. Na fig. 7.15c observa-se a distribuição das pertinências da classe sobre a projeção RG do espaço RGB.

A figura 7.16 mostra um exemplo de detecção de cor da pele em uma imagem de teste do conjunto de Garcia (2002), antes e após o procedimento de generalização pelo módulo 4. A intensidade dos pixels está proporcional à pertinência na classe. 


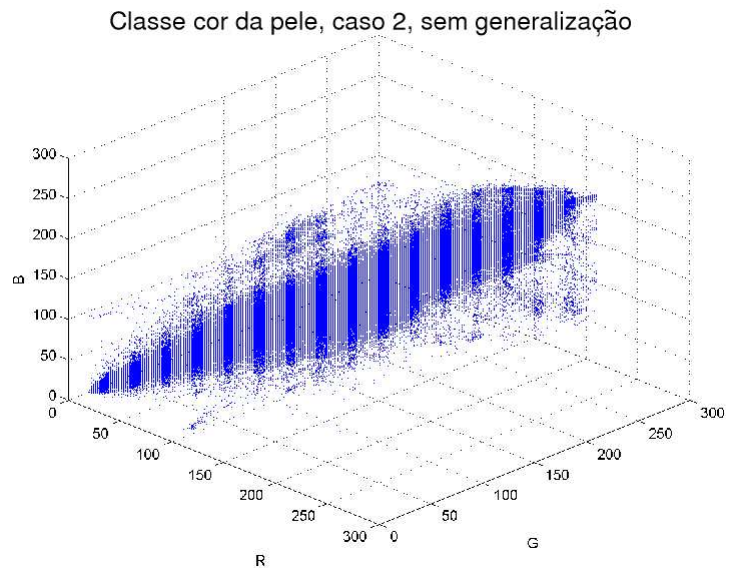

(a)

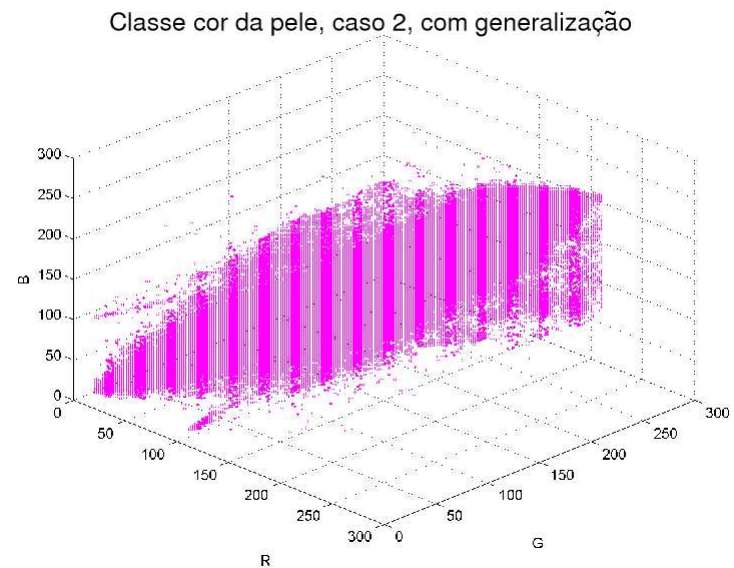

(b)

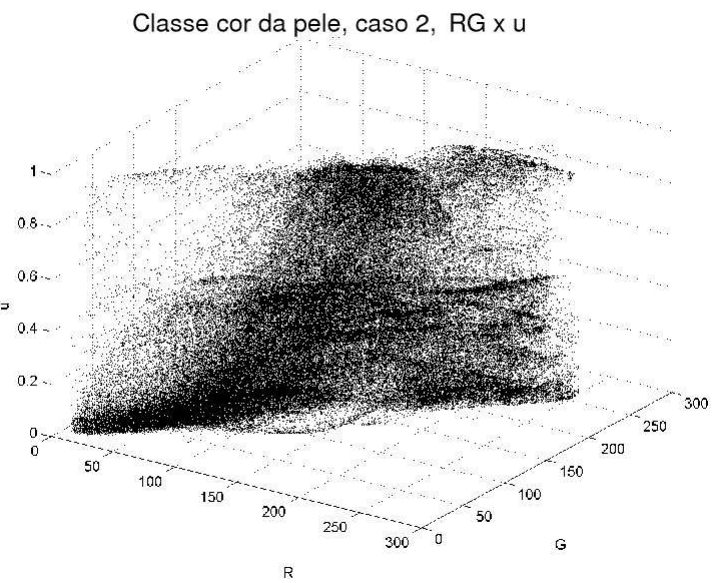

(c)

Figura 7.15: Distribuição dos pontos cor da pele, após apresentação das imagens de treinamento. Em (a), antes do procedimento de generalização, em (b), após o mesmo, e em (c), a distribuição de pertinências projetando-se a classe no plano RG.
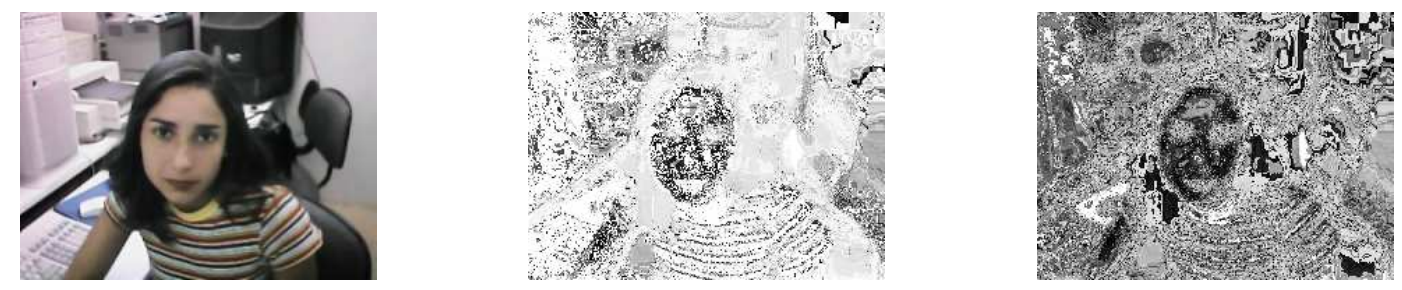

Figura 7.16: Esquerda: imagem original, ao centro: cor da pele detectada antes do procedimento de generalização e à direita, após a generalização.

\subsubsection{Teste do modelo e detecção da cor da pele}

Para avaliar o modelo de pele construído com o conjunto de imagens de Garcia (2002), 12 imagens de teste foram separadas. O processo de avaliação seguiu os mesmos critérios do caso 1. A exemplo da seção 7.4.6, onde imagens provenientes de cenas naturais foram 
testadas, procedeu-se à avaliação das imagens completas (contendo todos os elementos da cena) e das mesmas imagens, cujas referências $\mathcal{R}$ contêm apenas as regiões onde há de fato pele humana $\mathcal{R}_{\text {pele }}$.

\section{Detecção nas imagens completas}

Algumas das imagens testadas e respectivos resultados podem ser observados na fig. 7.17. Nesta, são mostradas as imagens de referência produzidas de acordo com a seção 7.3.1, e a comparação com o resultado da detecção pelo classificador.

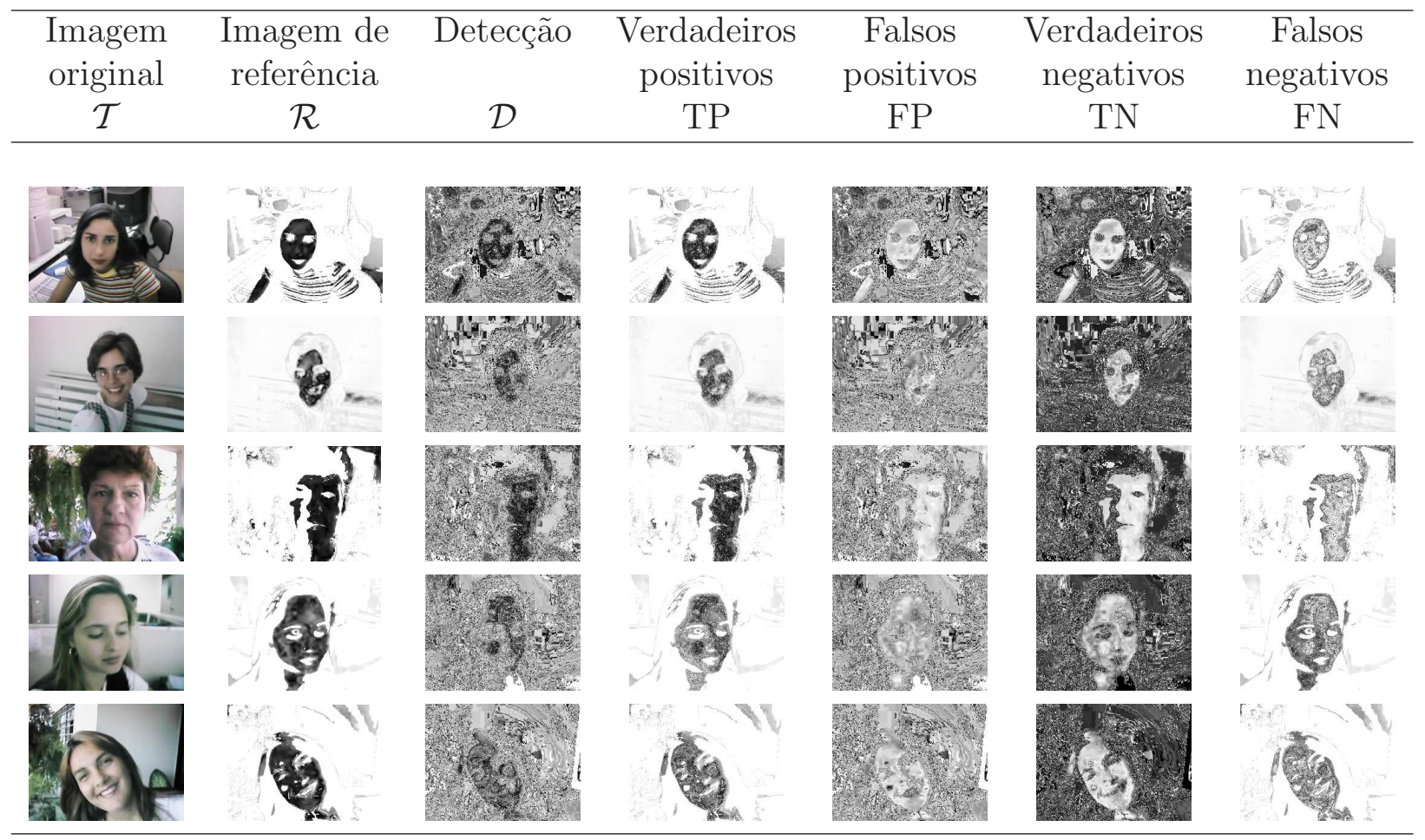

Figura 7.17: Algumas imagens de teste do caso 2 e detecção de pele resultante.

Em relação à detecção de pixel cor da pele, algumas características podem ser observadas na figura 7.17 :

1. na coluna de detecção, há muitos pontos detectados como pele fora da pessoa representada, mas os pontos de maior pertinência se concentram onde é de fato pele humana;

2. na coluna de falsos positivos, esta grande quantidade apresenta pertinência baixa e há poucos deles na região onde está a pele; 
3. o número de falsos negativos na região onde há pele é menor do que verdadeiros positivos, e também apresentam pertinência menor em relação a estes.

\section{Detecção usando como referência as regiões contendo apenas pele humana}

Devido à natureza não controlada das imagens do caso 2, onde muitos objetos na cena apresentam cores próximas à da pele, novas imagens de referência $\mathcal{R}_{\text {pele }}$ foram construídas sobre as imagens de teste. Estas imagens $\mathcal{R}_{\text {pele }}$ são subconjuntos das imagens de referência da fig. 7.17, removendo-se tais objetos e deixando apenas as regiões com pele humana, com respectivas pertinências.

Os resultados da detecção para as imagens "somente pele" aparecem na figura 7.18. Da mesma maneira que na detecção da imagem completa, observa-se que: a) os pontos de maior pertinência se concentram onde é de fato pele humana; b) na coluna de falsos positivos, esta grande quantidade apresenta pertinência baixa; c) o número de falsos negativos na região onde há pele é menor do que verdadeiros positivos, apresentando pertinência menor em relação a estes.

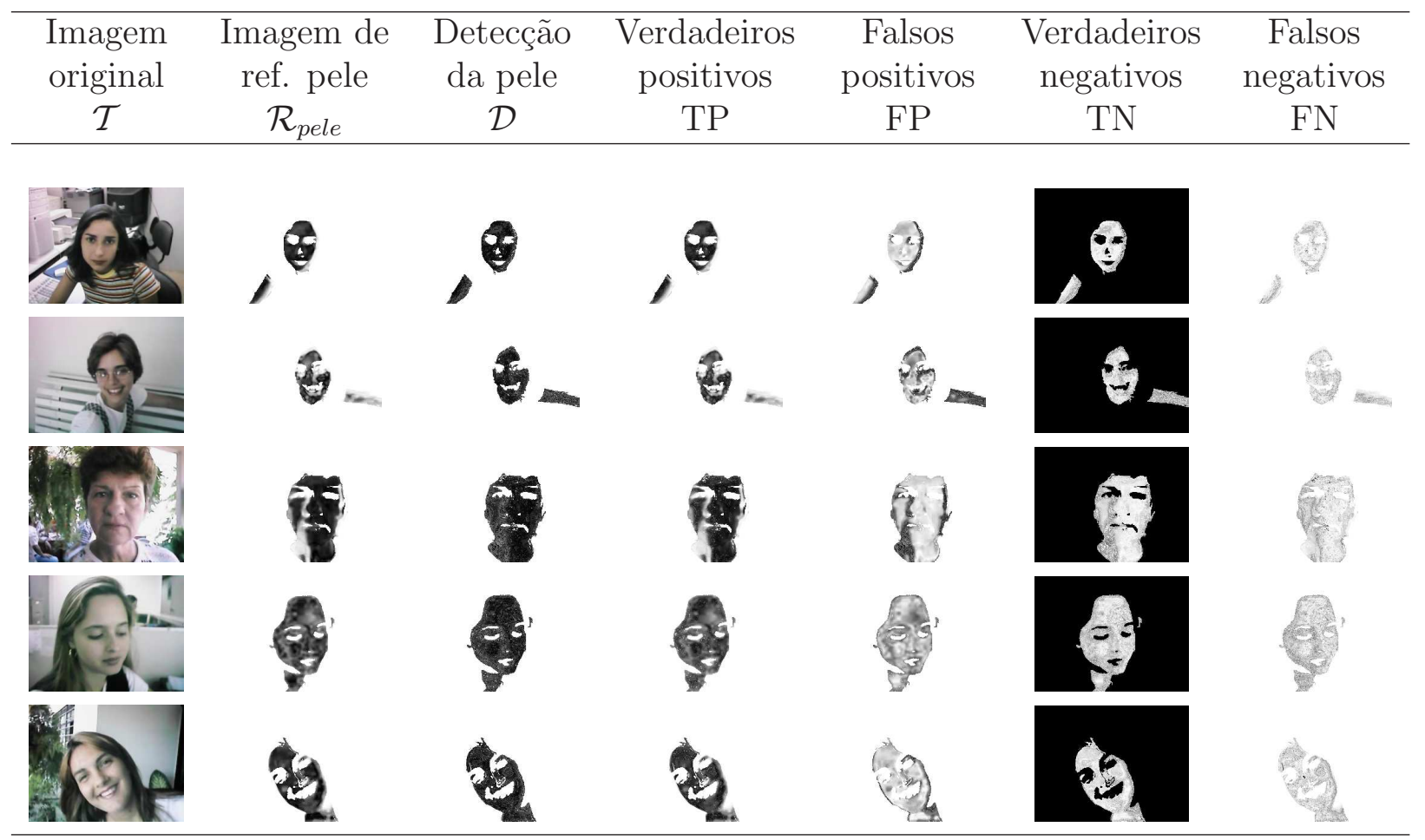

Figura 7.18: Algumas imagens de teste do caso 2 com referência apenas para a pele, e detecção resultante. 


\section{Desempenho do classificador no caso 2}

As equações 7.3 fornecem uma medida mais acurada da qualidade da detecção, em relação à inspeção visual. Neste caso 2, para os testes em imagens completas e imagens "somente pele", a tabela 7.7 mostra os resultados da detecção nas abordagens nebulosa e clássica. Observa-se que, no caso "somente pele", a melhor detecção (menor DCP) ocorre para $u_{l i m}=0,1$. Considerando-se que o operador de agregação provocou um decréscimo global nas pertinências finais da classe, da mesma forma que no caso 1, o motivo de um resultado melhor para pertinências muito baixas decorre da forma com que as imagens de referência foram produzidas, minimizando a possibilidade de detectar falsos positivos.

Na abordagem nebulosa, os valores de especificidade e sensibilidade são mais coerentes com a observação das figuras 7.17 e 7.18. A abordagem clássica mostra qual valor de $u_{\text {lim }}$ torna a detecção mais eficaz. É importante lembrar que este valor depende fortemente do resultado do operador de agregação, no módulo 3.

Tabela 7.7: Avaliações nebulosa e clássica do desempenho nas 12 imagens de teste do caso 2, com valores médios de especificidade e sensibilidade e respectivos desvios padrões.

\begin{tabular}{c|ccc|ccc}
\hline & \multicolumn{3}{|c|}{ Detecção global } & \multicolumn{3}{c}{ Detecção somente pele } \\
& Especificidade & Sensibilidade & DCP & Especificidade & Sensibilidade & DCP \\
\hline & $0,55 \pm 0,06$ & $0,61 \pm 0,03$ & 0,58 & $0,78 \pm 0,04$ & $0,94 \pm 0,02$ & 0,22 \\
\hline$u_{\text {lim }}$ & 0,550 Clássica \\
0,1 & $0,991 \pm 0,004$ & $0,04 \pm 0,02$ & 0,95 & $0,993 \pm 0,002$ & $0,991 \pm 0,006$ & 0,01 \\
0,2 & $0,90 \pm 0,03$ & $0,29 \pm 0,04$ & 0,72 & $0,994 \pm 0,002$ & $0,98 \pm 0,01$ & 0,02 \\
0,3 & $0,82 \pm 0,07$ & $0,48 \pm 0,05$ & 0,55 & $0,994 \pm 0,002$ & $0,97 \pm 0,01$ & 0,02 \\
0,4 & $0,73 \pm 0,10$ & $0,63 \pm 0,06$ & 0,46 & $0,994 \pm 0,002$ & $0,97 \pm 0,01$ & 0,03 \\
0,5 & $0,60 \pm 0,11$ & $0,73 \pm 0,05$ & 0,48 & $0,989 \pm 0,004$ & $0,96 \pm 0,01$ & 0,04 \\
0,6 & $0,50 \pm 0,12$ & $0,81 \pm 0,03$ & 0,53 & $0,96 \pm 0,01$ & $0,95 \pm 0,01$ & 0,05 \\
0,7 & $0,41 \pm 0,11$ & $0,86 \pm 0,03$ & 0,60 & $0,91 \pm 0,05$ & $0,95 \pm 0,02$ & 0,10 \\
\hline
\end{tabular}

\subsection{Análise dos resultados e conclusão do capítulo.}

Nos resultados apresentados para a detecção de pele (tabelas 7.5 e 7.7), observa-se que o melhor desempenho do classificador está nos valores de $u_{l i m} \approx 0,5$. O operador de agregação provocou um decréscimo global nas pertinências finais de muitos pontos da classe, após o treinamento, devido à sua natureza de extrair o valor médio. Uma normalização nos valores de pertinência seria desejável, porém, já existem dezenas de pontos com pertinência próxima de 1,0. Estes aspectos podem ser observados nas figuras 7.7 
e 7.15c. Uma dada cor $\mathbf{x}_{k}$ somente apresentaria pertinência 1,0 se estivesse presente todas as imagens de treinamento. É importante lembrar que cerca de 20 a 30\% da imagem são pixels cor da pele, logo, o restante (não-pele) apresenta pertinência muito menor que 0,1 (a grande maioria, próxima de zero).

Apesar do custo computacional dos algoritmos de classificação do módulo 1, a separação dos grupos de pele em todas as imagens de treinamento foi bastante acurada. Há um ângulo em que a luz incidente é bastante refletida, formando uma mancha brilhante na imagem da pele. Este reflexo é caracterizado pela forte intensidade e por possuir cor bem próxima da cor da fonte luminosa. O algoritmo FCM-GK separou este reflexo dos pixels da pele, atribuindo pertinência diferente, conforme se observa na subimagem que está bem no centro da fila inferior da fig. 7.14 (uma mancha clara no alto da testa). Esta subimagem corresponde à imagem original C4 no Anexo 2.

Sobre os resultados do algoritmo FCM-GK, observando-se ainda a fig. 7.14, nota-se um número alto de pixels com pertinência baixa, indicando maior pertinência a outros grupos do que a cor da pele. Se o fator de nebulosidade $m$ aumentar excessivamente, a separação dos grupos ficará mais confusa, pois a pertinência de cada cor $\mathbf{x}_{k}$ crescerá em relação a todos os outros grupos, dificultando a classificação dos pixels cor-da-pele.

É importante salientar que este esquema de construção do classificador tem por finalidade executar o processo de reconhecimento única e exclusivamente pela cor. Este pode ser parte de um sistema maior, que complete o reconhecimento através de análises espaciais e morfológicas. Seu comportamento é de um filtro que reduz o espaço de dados ao selecionar apenas os pixels cor da pele, agilizando o processamento espacial executado a posteriori.

Nas diversas imagens de treinamento, há muitos pontos incluídos como cor-da-pele, que foram agrupados como tal no módulo 1, mas não estavam necessariamente localizados em pessoas. Considera-se este evento como casual, uma vez que a classificação se dá apenas pela cor. Estes pixels assim classificados podem receber um valor de pertinência alto, mas, à medida que novas imagens de treinamento são acrescentadas na base de conhecimento, esta pertinência é minimizada pela agregação no módulo 3 (eq. 6.9). A probabilidade de tais pixels serem classificados como pele vai diminuindo.

Ruídos e pixels de outros objetos cor-da-pele podem apresentar altos valores de pertinência, afetando consideravelmente a posição dos centros dos grupos, os quais podem varia significativamente de uma imagem para outra. Porém, neste trabalho, a posição dos centros é irrelevante, ainda que se possa calculá-los em cada subimagem de interesse. 
Essencialmente, o treinamento foi realizado com um número muito baixo de imagens, no caso, dezenas, comparados com a literatura sobre detecção de pele por cores (ZARIT; SUPER; QUEK, 1999); (TERRILLON, 2000); (BROWN; CRAW; LEWTHWAITE, 2001); (MARTINKAUPPI, 2002); (HSU; ABDEL-MOTTALEB; JAIN, 2002); (SHIN; CHANG; TSAP, 2002); (JONES; REHG, 2002); (ZHENG; DAOUDI; JEDYNAK, 2004), que utilizaram um número da ordem de centenas ou milhares.

Alguns autores mostraram o desempenho da detecção de cor da pele usando o conceito de matriz de confusão, e outros se limitaram a apresentar o resultado através de marcação em imagens dos pixels localizados na posição da pele. Jones e Rehg (2002) construíram gráficos ROC utilizando como parâmetro um limiar de separação pele - não-pele pelo teorema de Bayes, resultando $85 \%$ de verdadeiros positivos e $10 \%$ de falsos positivos, a partir de milhares de imagens da Internet. Zheng, Daoudi e Jedynak (2004) e colegas, utilizando a mesma base de dados, obtiveram o mesmo resultado. Zarit, Super e Quek (1999) testaram a detecção em cinco espaços de representação de cores, relatando cerca de $80 \%$ de detecção positiva, com cerca de $(5 \pm 1) \%$ de falsos positivos e $(20 \pm 5) \%$ de falsos negativos, usando LUT para modelar a classe. Ainda, executaram a detecção com regras bayesianas, chegando a $90 \%$ de verdadeiros positivos e $20 \%$ de falsos negativos. Brown, Craw e Lewthwaite (2001), através de uma rede SOM hexagonal, obtiveram até 94\% de detecção positiva, porém sem relatar a proporção de detecções falsas. Nesta, foram utilizadas quase 400 imagens, em um total de quase 3 milhões de pixels usados como treinamento. Sigal, Sclaroff e Athitsos (2004) construíram um gráfico ROC a partir de cerca de um bilhão de pixels coletados por Jones e Rehg (2002). Entre os resultados obtidos, o melhor limiar de separação da classe "pele" foi de $85 \%$ para verdadeiros e $25 \%$ para falsos positivos. Kruppa, Bauer e Schiele (2002) utilizaram gráficos precision-recall ${ }^{3}$ em seus experimentos, obtendo $80 \%$ e $80 \%$ respectivamente para faces com fundos de cena variados e $(75 \%, 75 \%)$ para cenas semelhantes à fig. 7.12. Em muitos trabalhos, a detecção da pele humana foi uma das etapas para detecção de faces, e cuidados devem ser tomados para distingüir os dois tipos de detecção (MARTINKAUPPI, 2002); (LEE; YOO, 2002); (SHIN; CHANG; TSAP, 2002) e (YANG; KRIEGMAN; AHUJA, 2002). Outros autores utilizaram outras ferramentas para homogeneizar a região de pele detectada, como filtromediana (CAMPOS; BLOCH; CESAR JR., 2001) e quantização de cores (JONES; REHG, 2002) nas imagens de treinamento.

Considerando-se o número pequeno de imagens de treinamento utilizadas, compare-se estes valores com os deste trabalho, aqui apresentado em pares de valores (espec, sens):

\footnotetext{
${ }^{3}$ precision $=\frac{T P}{T P+F P} ;$ recall $=T P$
} 
$(65 \%, 88 \%)$ na abordagem nebulosa da detecção "AR Face DB" no caso 1;

$(77 \%, 90 \%)$ na abordagem clássica da detecção "AR Face DB" no caso 1;

$(83 \%, 52 \%)$ na abordagem nebulosa da detecção global de imagens de revista e Internet no caso 1 ;

$(96 \%, 59 \%)$ na abordagem nebulosa da detecção "somente pele" de imagens de revista e Internet no caso 1;

$(79 \%, 91 \%)$ na abordagem clássica da detecção global de imagens de revista e Internet no caso 1 , para $u_{l i m}=0,5$;

$(99 \%, 93 \%)$ na abordagem clássica da detecção "somente pele" de imagens de revista e Internet no caso 1 , para $u_{\text {lim }}=0,5$;

$(55 \%, 61 \%)$ na abordagem nebulosa da detecção global de imagens no caso 2;

$(78 \%, 94 \%)$ na abordagem nebulosa da deteç̧ão "somente pele" de imagens no caso 2;

$(73 \%, 63 \%)$ na abordagem clássica da detecção global de imagens no caso 2, para $u_{\text {lim }}=0,4$;

$(99,3 \%, 99,1 \%)$ na abordagem clássica da detecção "somente pele" de imagens no caso 2 , para $u_{l i m}=0,1$;

Neste trabalho, objetiva-se atingir um número máximo de verdadeiros-positivos, todos eles num máximo valor possível de pertinência. Como efeito colateral, aumenta-se o número de falsos-positivos. Porém, a abordagem efetuada neste trabalho também possibilita, como já comentado, que estes falsos-positivos obtenham um valor menor de pertinência à classe cor-de-pele. Assim, algoritmos de agregação espacial poderão segmentar partes correspondentes à cor-de-pele nas imagens, com grande facilidade, através da busca por pixels com altos valores de pertinência, numa dada região.

Neste trabalho, em particular, não houve a preocupação de executar o treinamento com um número enorme de imagens (várias centenas) de acordo com o encontrado na literatura, pelos seguintes motivos:

- de acordo com a teoria do aprendizado PAC e o observado na figura 7.3, a qualidade da detecção melhora com o aumento no número de imagens de treinamento. Pretende-se aqui mostrar que a idealização do procedimento de generalização, viabiliza o emprego do classificador com poucas dezenas de imagens de treinamento; 
- em conseqüência, o emprego de uma enorme quantidade de imagens de treinamento não evidenciaria as vantagens do esquema de construção do classificador proposto nesta tese. 


\section{CONSIDERAÇÕES FINAIS E PROPOSTAS FUTURAS}

O presente trabalho objetivou a modelagem de classes nebulosas, aqui exemplificada na cor da pele, através de aprendizado híbrido, combinando aprendizado supervisionado e não-supervisionado. Esta abordagem permite o aprendizado incremental do modelo de classes, no caso, a cor da pele, permitindo preservar a informação adquirida na retomada do treinamento. A abordagem híbrida forneceu uma ponte entre a classificação em baixo nível (agrupamentos) e alto nível (atribuição de classes), onde a supervisão atuou apenas neste último nível. Com isto, atingiu-se o objetivo de balancear a carga de trabalho entre supervisão e automação.

O supervisor atua no nível da associação grupos para classes, e o trabalho de rotulação individual das instâncias, de alto custo para ser realizado pelo agente supervisor, ficou automatizado, permitindo uma grande agilidade no processo de treinamento do classificador, apesar do alto custo computacional envolvido nos módulos 1, 3 e 4 . O papel do supervisor ficou definido na seleção dos grupos, via subimagens, atribuindo-as às classes de interesse. Apresentou-se, também, uma proposta para atribuir relevância aos grupos selecionados para a mesma classe (seção 6.2). O experimento realizado para detecção da cor da pele, entretanto, mostrou que, neste domínio de aplicação, o resultado da detecção foi pouco modificado pela atribuição de fatores de relevância aos grupos, provavelmente porque pixels dados como pouco relevantes em uma imagem de treinamento foram considerados mais relevantes em outra, de forma que seu efeito foi imperceptível na agregação final.

Os resultados obtidos foram significativos, na aplicação estudada, em função do baixo número de imagens de treinamento utilizadas. Com a inclusão das imagens da Internet e de revistas para testes do modelo obtido no caso 1, e treinamento do classificador com imagens em ambientes não-controlados no caso 2, ressalta-se que:

1. as imagens foram obtidas em diversas condições de iluminação e em cenas naturais 
contendo muitos elementos estranhos ao objeto de interesse (nos estudos de caso, a pele humana);

2. foram utilizadas relativamente poucas imagens na etapa de treinamento, para as condições ambientais em que o experimento foi realizado;

3. buscou-se um modelo de cor da pele, válido para um grande número de imagens com diferentes condições de captura.

Nota-se nas figs. 7.7 e $7.15 \mathrm{c}$ como a classe cor da pele apresenta pertinências altas nas regiões internas, e como estas vão decaindo de forma suave nas bordas, demonstrando a transição suave da classe para as classes vizinhas (as quais, não sendo de interesse, não foram representadas). A modelagem da cor da pele é um problema difícil, e a despeito da grande quantidade de estudos existentes, ainda tem sido objeto de muitas investigações.

Em relação ao desenvolvimento da metodologia aqui proposta, as questões levantadas no capítulo introdutório podem ser respondidas da seguinte maneira:

1. As técnicas de agrupamentos nebulosos são eficientes para identificar o grupo de pixels correspondentes às cores típicas de um objeto em uma imagem, permitindo o seu reconhecimento? A teoria dos conjuntos nebulosos pode ser então uma ferramenta útil neste caso?

O agrupamento nebuloso realiza eficientemente a partição em grupos, como se pode observar nas figuras 7.6 e 7.13 , sendo a rotulação deles e a atribuição das classes realizada pelo supervisor. A teoria de conjuntos nebulosos permite a composição adequada dos grupos em classes, operando sobre os valores de pertinência de um pixel em cada grupo.

2. Os valores de pertinência de cada pixel, obtidos por agrupamentos nebulosos, refletem o grau de sua representatividade dentro da classe de cores que caracterizam um dado objeto?

Observou-se, através dos experimentos, que a resposta é afirmativa. Os valores de pertinência permitem uma interpretação adequada da incerteza contida na definição das classes, mensurando o grau de confiança na atribuição delas a cada pixel.

3. Podem ser identificadas e tratadas algumas características inerentes ao aprendizado computacional, como a generalização ou excesso de especialização (overfitting)? Os módulos de agregação e generalização foram concebidos para tratar desta questão. Embora o termo "agregação" possa denotar um crescimento constante da classe de 
interesse, o operador "média" foi justamente escolhido devido a suas características "conservativas" (BLOCH, 1996). O módulo de generalização pode causar uma ligeira dilatação nos limites da classe, porém, considera-se isto como um "efeito de bordas", onde a pertinência decai rapidamente.

4. Existe algum espaço preferencial de representação de cores para construir o classificador e a detecção ser executada mais eficientemente?

Embora o trabalho de Shin, Chang e Tsap (2002) responda negativamente a esta questão, este problema ainda está em aberto. Ao se adotar uma representação não paramétrica das classes de cores, há flexibilidade suficiente no modelo para que o espaço de cores escolhido seja irrelevante. Porém, um cuidado adicional deve ser tomado se houver supervisão humana diretamente sobre as classes formadas, onde provavelmente um espaço de representação que separe as componentes intensidade e crominância facilite a supervisão.

Experimentos anteriores indicaram que esta metodologia tem sido promissora, sendo inicialmente realizada com imagens em ambientes controlados (caso 1) e posteriormente estendida a imagens em ambientes mais gerais, como no caso 2 (BONVENTI JR.; COSTA, 2003).

Conforme foi abordado na seção 7.2, os modelos não-paramétricos são independentes dos espaços de representação de cores e permitem uma revisão do modelo de classe. Uma representação por uma LUT permite a incorporação de um número qualquer de instâncias na classe, facilitando o desenvolvimento de um aprendizado incremental, porém, necessita de um procedimento de generalização adicional. A representação paramétrica, onde funções são ajustadas para "encapsular" a classe, dispensaria o procedimento de generalização, bastando uma boa descrição da fronteira de decisão, mas dificultaria a implementação do aprendizado incremental. Além disso, há a questão do domínio de aplicação: por exemplo, um classificador paramétrico desenvolvido para detectar o grau de maturação de frutas pela cor pode ser mais eficaz em um espaço de cores, do que outro classificador projetado para discriminar flores.

\subsection{Sumário das contribuições}

É oportuno rever, neste ponto, quais as contribuições trazidas por este trabalho. Em primeiro lugar, está o desenvolvimento de uma metodologia de aprendizado de instâncias cuja classificação é vaga. O domínio escolhido foi as cores em imagens digitais, as quais 
definem objetos ou partes destes, uma vez que a cor é um atributo importante na segmentação de imagens. Os valores deste atributo, representados em um espaço de cores, variam suavemente quando os pixels pertencem ao mesmo objeto, e mais abruptamente quando se passa para outro objeto na cena. Mesmo quando o espaço é discreto, como o RGB, há $(255)^{3}$ possíveis valores, e as classes de cores que definem os objetos são tratadas neste trabalho pela teoria dos conjuntos nebulosos.

Outro aspecto neste método de aprendizado é a utilização de um esquema híbrido de aprendizado, motivado pelo fato de haver milhões de instâncias (valores de cor) a serem classificadas. A parte não-supervisionada agrupa estas instâncias por proximidade destes valores, e a parte supervisionada estabelece as classes existentes, muitas vezes agregando mais de um grupo semanticamente equivalente. Com isto, a rotulação individual das instâncias, muito custosa, passa a ser a rotulação de grupos de instâncias similares.

Uma propriedade abordada neste método de aprendizado é a possibilidade de continuar o treinamento para o aperfeiçoamento das classes obtidas, sem perder o esforço anteriormente empregado. Os operadores de agregação foram escolhidos não somente para fornecer uma combinação adequada das classes, mas também para revisar as classes existentes através da análise de novos grupos de instâncias, ou até incorporar novas classes obtidas com a continuidade do treinamento.

Outra contribuição importante foi a proposta de um método de generalização que possibilite a análise de instâncias não existentes na fase de treinamento. Aqui, a inovação está na inclusão deste procedimento ainda na fase de treinamento, e não na fase de detecção. Assim, melhora-se a completeza das classes formadas e agiliza-se o processo de detecção, por simples comparação com a base de conhecimento. Ainda, melhora o desempenho do classificador na detecção, por gerar bons resultados com um número relativamente pequeno de instâncias de treinamento.

Finalmente, o estudo de caso proposto gera um modelo de classe de cor da pele humana de maneira nebulosa. A cor da pele é um conceito bem definido, mas as cores dos pixels constituintes apresentam variações de tal forma que um grau de pertinência (ou de certeza) pode ser atribuído do pixel à classe.

\subsection{Propostas futuras}

Este trabalho possibilita novas investigações relacionadas ao método de aprendizado proposto. Para continuar nesta linha de investigação, alguns aspectos podem ser melhor 
explorados:

1. empregar esta metodologia considerando outros atributos, não apenas a cor, mas características da vizinhança, como conectividade. Mesmo sem acrescentar novos atributos (relacionados à vizinhança), o exame das subimagens pelo supervisor permite associar classes diferentes a grupos de pixels espacialmente isolados;

2. explorar a supervisão na agregação dos grupos para formar as classes. Verificar se tal procedimento potencializa o efeito dos exemplos positivos e negativos, permitindo uma definição mais acurada das classes (mesmo sendo nebulosas), e verificar a melhor forma de definir esta acurácia. Realizar esta exploração em outro domínio de aplicação onde a cor seja um atributo importante, uma vez que no problema de detecção de pele humana, tal potencialização não foi claramente percebida;

3. verificar se há valores mais adequados para o fator de nebulosidade $m$ utilizado no módulo de agrupamento, e se ele pode ser caracterizado em função do domínio de aplicação. Investigar um indicador adequado para o desempenho do classificador em função de $m$;

4. verificar a viabilidade de se empregar estratégias, como a validação cruzada, para estimar o melhor ponto de parada no treinamento. Foi mostrado que o procedimento de generalização melhora a detecção, mas pode-se investigar o quanto o treinamento sem generalização deveria continuar para o classificador atingir o mesmo desempenho daquele atingido com a interrupção do treinamento e aplicação do procedimento de generalização;

5. utilizar outros métodos de classificação nebulosa não-supervisionada, além do FCM, para o módulo 1, analisando a eficácia e o custo de processamento;

6. investigar o emprego de outros paradigmas de aprendizado, como, por exemplo, a supervisão fraca. Segundo Kuncheva (2001), a literatura recente sobre a combinação de classificadores tem mostrado a preferência de promover alterações no conjunto de exemplos durante o treinamento, com o objetivo de criar um "ensemble" de classificadores com desempenho combinado melhor que o individual. Esta diversidade implica que os classificadores isolados cometem erros consideráveis sobre dados diferentes. Uma questão geral ainda não muito explorada é a utilização de classificadores nebulosos nos paradigmas de supervisão fraca, medindo a qualidade da classificação sob alterações do conjunto de treinamento. Outro ponto a ser analisado é se a taxa de predições corretas do classificador nebuloso pode caracterizá-lo como aprendiz 
fraco, nos moldes do modelo PAC. De maneira geral, a utilização de "ensembles" de classificadores implica na alteração da arquitetura para a construção do modelo de aprendizado.

Assim, este trabalho procurou demonstrar a viabilidade de se unir a teoria de conjuntos nebulosos e paradigmas de aprendizado na modelagem de classes vagas, formada por instâncias de valores definidos no espaço de atributos, levando-se em consideração o domínio de aplicação. 


\section{ANEXO 1. TEORIA DO APRENDIZADO COMPUTACIONAL}

O desempenho de um classificador é dado pela sua taxa de erro. Se um número muito grande de exemplos de treinamento estiver disponível, então a taxa de erro tenderá à taxa de erro verdadeira. O número de exemplos geralmente é pequeno, desta forma, uma questão importante é:

"quantos exemplos são necessários para que a taxa de erro se torne efetivamente a taxa de erro verdadeira?"

Para respondê-la, considera-se em termos gerais a seguinte idéia: após processar um pequeno número de exemplos, observa-se que, qualquer hipótese muito errada com alta probabilidade, fará predições incorretas. Assim, para qualquer hipótese consistente com um número suficientemente grande de exemplos de treinamento, é pouco provável que ela esteja muito errada. Esta hipótese deve ser provavelmente e aproximadamente correta (PAC - "probably and approximately correct").

É importante que a hipótese seja aproximadamente correta também no conjunto de teste, e não apenas no conjunto de treinamento. Nesta teoria, assume-se que tanto o conjunto de treinamento quanto o conjunto de teste são tomados aleatoriamente do mesmo conjunto de exemplos, usando a mesma distribuição de probabilidade fixa $\mathcal{D}$. Esta teoria geral de aprendizado possibilita responder à seguinte questão:

"quantos exemplos de treinamento são necessários para que a hipótese $h$ encontrada pelo algoritmo de aprendizado seja PAC?"

Dados:

- $\mathbf{X}=\left\{\mathbf{x}_{1}, \mathbf{x}_{2}, \mathbf{x}_{3}, \ldots\right\}$ o conjunto de todos os possíveis exemplos (pode ser finito); 
- $\mathcal{D}$ a distribuição da qual os exemplos são retirados;

- $\mathcal{H}=\left\{h_{1}, h_{2}, h_{3}, \ldots\right\}$ o conjunto das possíveis hipóteses (também pode ser finito);

- $m$ o número de exemplos necessário para o treinamento.

Assumindo que a função verdadeira $f_{v} \in \mathcal{H}$, em um exemplo $\mathbf{x}_{i} \in \mathbf{X}$ da hipótese $h$ em relação a $f_{v}$, dada a distribuição $\mathcal{D}$, o erro pode ser definido como a probabilidade de $h$ ser diferente de $f_{v}$ no exemplo $\mathbf{x}_{i}$ :

$$
\operatorname{erro}(h)=P\left(h \neq f_{v}\right)
$$

A hipótese $h$ é denominada aproximadamente correta se o erro $(h) \leqslant \epsilon$, onde $\epsilon$ é uma constante suficientemente pequena. Após o algoritmo ter visto $m$ exemplos, todas as hipóteses consistentes serão, com alta probabilidade, aproximadamente corretas. $f_{v}$ está dentro dos limites de $\epsilon$.

Uma hipótese $h^{\prime}$ é ruim se o erro $\left(h^{\prime}\right)>\epsilon$, ou seja, está fora dos limites aproximadamente corretos. A probabilidade de $h^{\prime}$ cobrir algum exemplo $x_{i}$ é $P\left(h^{\prime}\right) \leqslant 1-\epsilon$, e de cobrir $m$ exemplos é $P\left(h^{\prime}\right) \leqslant(1-\epsilon)^{m}$.

Porém, para o conjunto de hipóteses ruins $\mathcal{H}^{\prime}$ conter hipóteses consistentes, pelo menos uma delas $h \in \mathcal{H}^{\prime}$ precisa ser consistente. A probabilidade de que isto aconteça está limitada pela soma das probabilidades individuais

$$
P\left(h \in \mathcal{H}^{\prime}\right) \leqslant\left|\mathcal{H}^{\prime}\right|(1-\epsilon)^{m} \leqslant|\mathcal{H}|(1-\epsilon)^{m}<\delta
$$

onde $\delta$ é um limitante para esta probabilidade. Aplicando-se o logaritmo na última desigualdade: $\ln |\mathcal{H}|+m \cdot \ln (1-\epsilon) \leqslant \ln (\delta)$ e com a inequação $(1-\epsilon) \leqslant e^{-\epsilon}$ obtém-se

$$
m \geqslant \frac{1}{\epsilon}\left(\ln \frac{1}{\delta}+\ln |\mathcal{H}|\right)
$$

Esta inequação mostra que, se um algoritmo de aprendizado computacional tiver uma hipótese consistente com este número de exemplos $m$, então essa hipótese terá erro máximo de $\epsilon$ com probabilidade mínima de $1-\delta$. $\epsilon$ é denominado parâmetro de erro e $\delta$ é parâmetro de confiança.

Em princípio, o modelo de aprendizado PAC somente leva em conta os exemplos e sua classificação. Ele não possui informação referente ao esquema de representação que está sendo utilizado pelo algoritmo. Por fim, deve-se ressaltar que esta é uma análise de pior caso. Para todas as possíveis distribuições resultantes de um conjunto de amostras, 
ela garante que os resultados de classificação serão corretos com uma pequena margem de erro. Mesmo para classificadores simples, os resultados indicam que um grande número de casos é necessário para garantir o desempenho (MITCHELL, 1997), (BATISTA, 1997).

\section{Tamanho do conjunto de treinamento para imagens digitais}

Uma vez que o modelo de aprendizado requer muitas imagens contendo pixels da classe de interesse para o treinamento, seria muito desejável um cálculo aproximado da quantidade necessária. Para uma estratégia de aprendizado que não possa definir diretamente quão suficiente treinado o sistema esteja, o problema a ser resolvido é: determinar o número de exemplos de treinamento necessário para que o sistema classifique pixels, com alta probabilidade $(1-\delta)$ de erro $\epsilon$ pequeno.

O conjunto de instâncias possíveis $\mathbf{X}$ é o conjunto de regiões contendo as cores de interesse. Supondo que é utilizado o espaço de representação RGB (discreto), cada componente da cor ( $R, G$ ou $B$, constituída por 8 bits) pode assumir os valores de 0 a 255, possibilitando $\sim 16$ milhões de cores diferentes. Cada instância é formada por $N$ pixels. Assim, o conjunto possível de instâncias passa a ser algo da ordem de $N^{256^{3}}$, ou seja, a combinação de $n$ pixels, cada um deles apresentando alguma das 16 milhões de cores.

Utilizando como exemplo a construção da classe "cor da pele humana", qual o número de imagens necessário para cobrir o espaço de hipóteses relativo a esta classe, com 95\% de probabilidade $(\delta=0,05)$ que o erro para esta cobertura seja inferior a $10 \%(\epsilon=0,1)$ ?

Usando as fórmulas do aprendizado PAC (VALIANT, 1984) e (MITCHELL, 1997),

$$
m \geqslant \frac{1}{0,1}\left(256^{3} \ln (N)+\ln \frac{1}{0,05}\right)=16 \times 10^{7} \ln (N)+30
$$

e utilizando imagens de faces para o treinamento, onde pixels cor da pele podem ocupar de 30 a $50 \%$ da área, então imagens do tamanho próximo a 256 por 256 pixels serão suficientes. Temos $n \sim 30000$ pixels cor da pele, obtendo $m \approx 16 \times 10^{8}$ imagens de treinamento! Se for realizada a detecção de pessoas pela cor da pele, onde elas são mostradas em corpo inteiro, e mais de uma pessoa, uma resolução espacial maior das imagens pode ser necessária (em torno de 1000 por 1000 pixels). Daí, obtém-se $n \sim 10^{6}$, resultando em $m \approx 2 \times 10^{9}$ imagens de treinamento!

O espaço de hipóteses é muito grande para aplicação do modelo de aprendizado PAC. A alternativa para reduzir o número de exemplos necessários é adicionar algum conheci- 
mento prévio no sistema de aprendizado. Neste caso, as fórmulas básicas do aprendizado PAC perdem sua validade estimativa. Uma vez que o cálculo do tamanho do conjunto de treinamento é baseado em combinações de instâncias possíveis, parece ser mais conveniente armazenar as instâncias consideradas positivas, com respectivo valor de pertinência. 


\section{ANEXO 2. IMAGENS DE TREINAMENTO DO CLASSIFICADOR}

Este anexo contém uma amostra das imagens utilizadas para treinamento nos dois estudos de caso, possibilitando-se alguma análise visual.

Caso 1. Imagens de faces.

Na fig. 1, são mostradas algumas imagens utilizadas no treinamento do caso 1 (MARTINEZ; BENAVENTE, 1998).

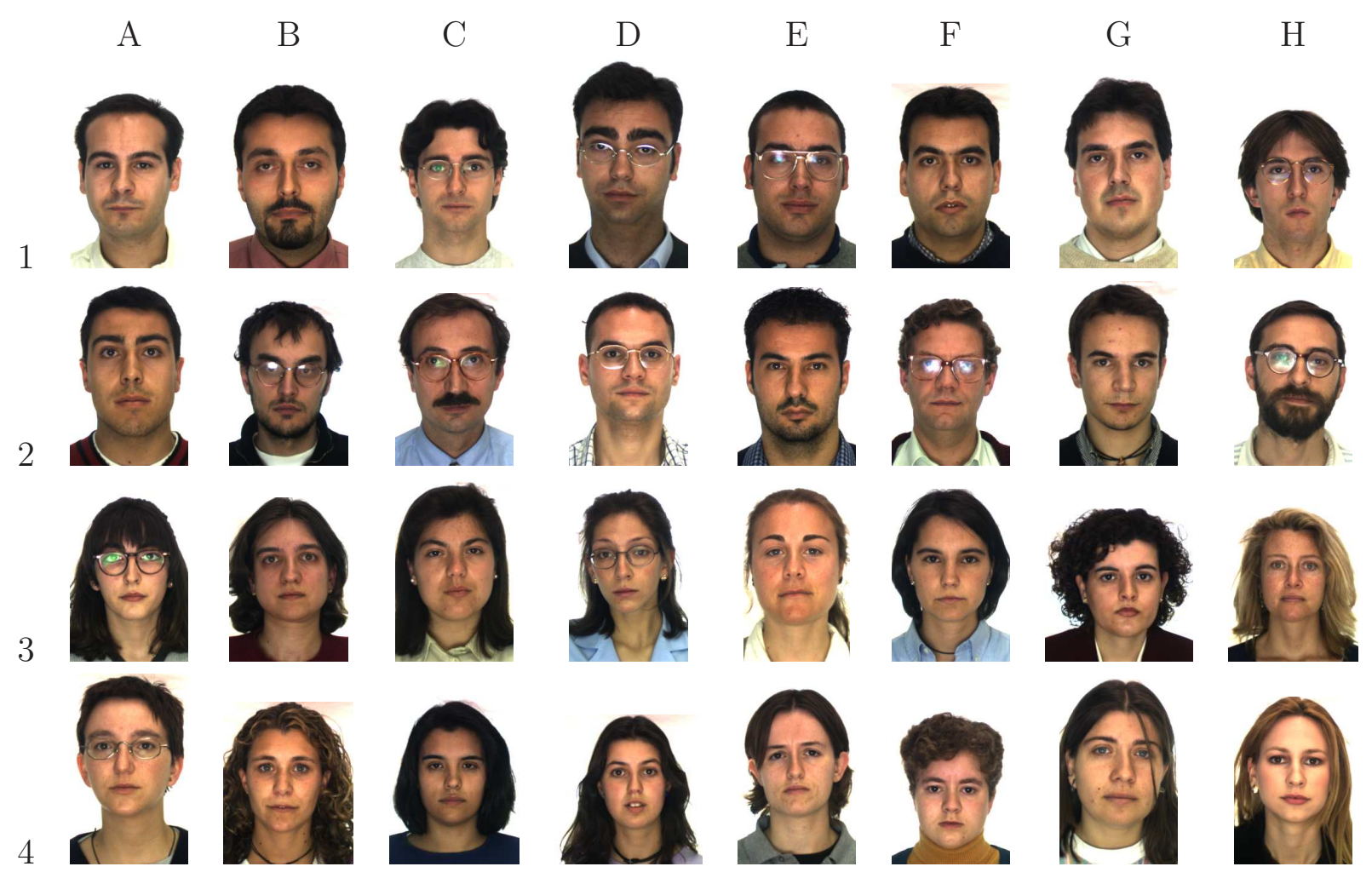

Figura 1: Algumas imagens de treinamento do caso 1. 


\section{Caso 2. Imagens humanas em ambientes variados.}

Na figura 2, são apresentadas algumas das imagens coletadas por Garcia (2002) e colegas.

1

2

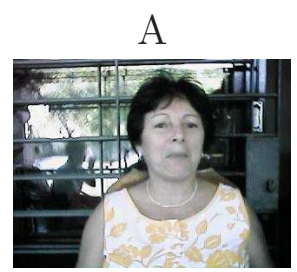

3
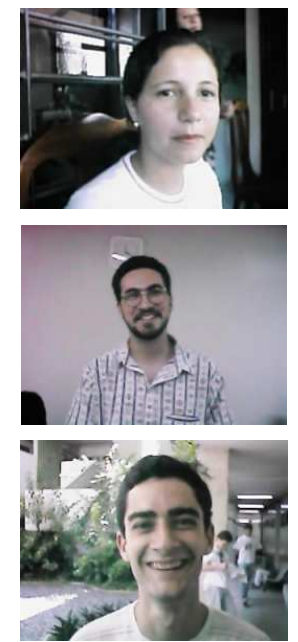

4

5

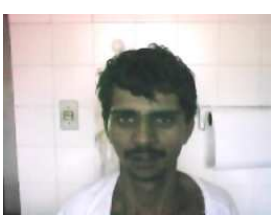

6

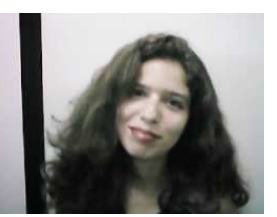

B
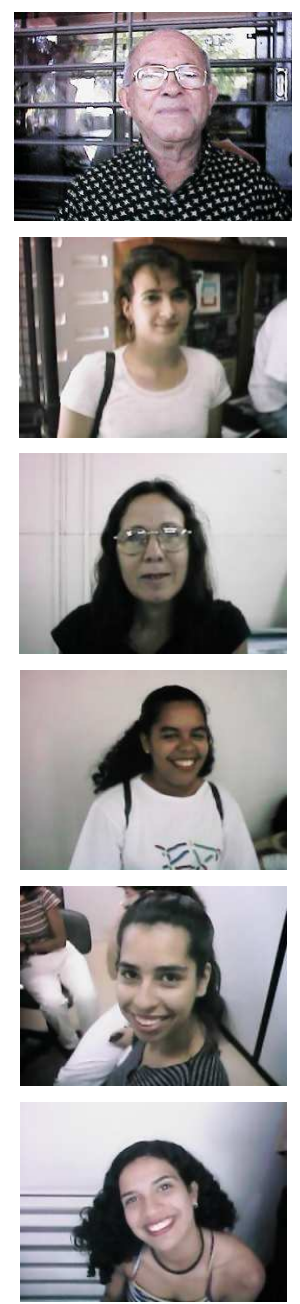

C
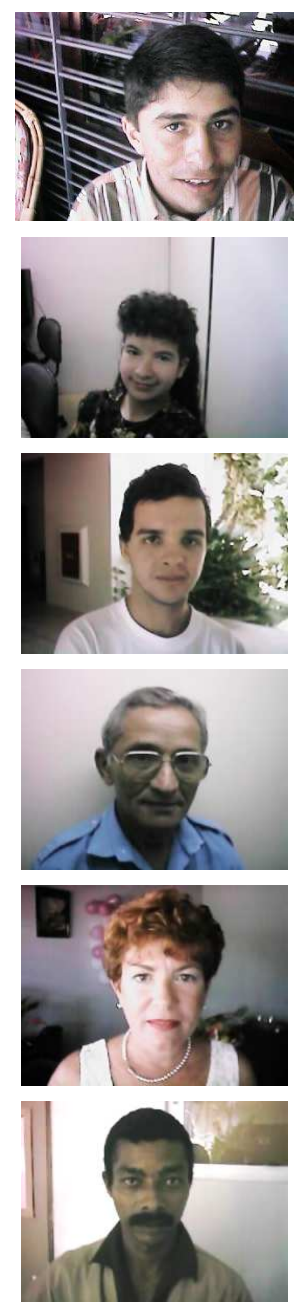

$\mathrm{D}$
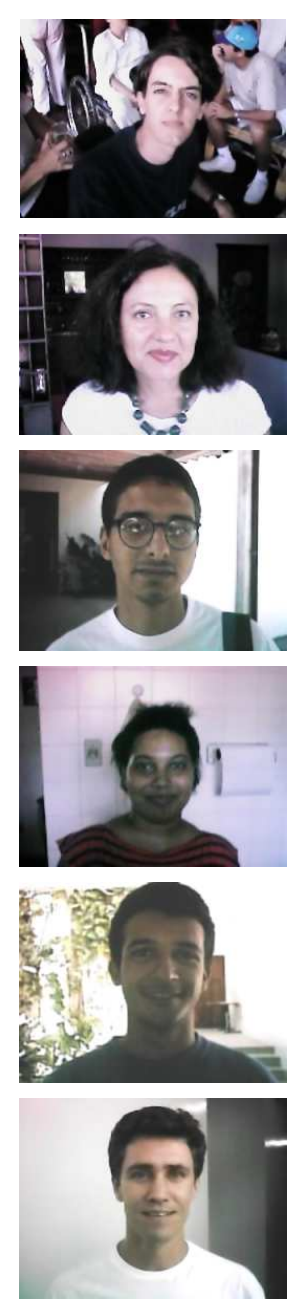

Figura 2: Algumas das imagens de treinamento do caso 2. 


\section{Referências Bibliográficas}

AHA, D. W.; KIBLER, D.; ALBERT, M. K. Instance-based learning algorithms. Machine Learning, v. 6, n. 1, p. 37-66, 1991.

ANDERBERG, M. R. Cluster analysis for applications. New York: Academic Press, 1973.

ANGELOPOULOU, E.; MOLANA, R.; DANIILIDIS, K. Multispectral skin color modeling. In: PRESS, I. C. S. (Ed.). IEEE conference on Computer Vision and Pattern Recognition (CVPR) 2001. [S.l.: s.n.], 2001. p. 635-642.

BATISTA, G. E. A. P. Um ambiente de avaliação de algoritmos de aprendizado de máquina utilizando exemplos. Dissertação (Mestrado) — Instituto de Ciências Matemáticas de São Carlos, Universidade de São Paulo, 1997. Orient. Dra. Maria Carolina Monard.

BAUER, P.; BODENHOFER, U.; KLEMENT, E. P. A fuzzy method for pixel classification and its application to print inspection. In: Proceedings of IPMU'96. Granada, Spain: [s.n.], 1996. III.

BECHELli, L. M.; CURBAN, G. V. Compêndio de Dermatologia. São Paulo SP Brasil: Atheneu Editora, 1963.

BEZDEK, J. C. A convergence theorem for the fuzzy isodata clustering algorithms. IEEE Transactions on Pattern Analysis and Machine Intelligence, v. 2, p. 1-8, 1980.

BEZDEK, J. C.; PAL, N. R. Two soft relatives of learning vector quantization. Neural Networks, n. 8, p. 729-743, 1995.

BEZDEK, J. C.; PAL, S. K. Fuzzy models for pattern recognition. New York: IEEE Press, 1992.

BLOCH, I. Information combination operators for data fusion: a comparative review with classification. IEEE Trans on Systems, Man and Cybernetics - part A: Systems and Humans, v. 26, n. 1, jan 1996.

BLUM, A. L.; LANGLEY, P. Selection of relevant features and examples in machine learning. Artificial Intelligence, n. 97, p. 245-271, 1997.

BONVENTI JR., W.; COSTA, A. H. R. Classificação de pixels de imagens coloridas digitais por lógica nebulosa. In: RIBEIRO, C. H. C.; SAKUDE, M. T. S. (Ed.). III Workshop de Computação Workcomp'2000. São José dos Campos SP Brasil, 2000. p. 67-72. 
BONVENTI JR., W.; COSTA, A. H. R. Comparação entre métodos de definição de conjuntos nebulosos de cores para classificação de pixels. In: N. BARROS R. M. Cesar Jr., F. G. C.; COSTA, A. H. R. (Ed.). International Joint Conference IBERAMIA'2000 and SBIA'2000, Workshop Proceedings, I WAICV - Workshop on Artificial Intelligence and Computer Vision. Atibaia SP Brasil, 2000. p. 105-110.

BONVENTI JR., W.; COSTA, A. H. R. Sistema semiautomático de detecção de pele por agrupamento nebuloso. In: SBAI. Simpósio Brasileiro de Automação Inteligente VI SBAI. Bauru SP Brasil, 2003. p. 567-572.

BOUJEMAA, N. Generalized competitive clustering for image segmentation. In: 19th International Meeting of the North American Fuzzy Information Processing Society NAFIPS 2000. Atlanta USA: [s.n.], 2000. v. 1.

BROWN, D.; CRAW, I.; LEWTHWAITE, J. A som based approach to skin detection with application in real time systems. In: Proc. of the british machine vision conference. Manchester UK: [s.n.], 2001. I.

BRUCE, J.; BALCH, T.; VELOSO, M. Fast and inexpensive color image segmentation for interactive robots. 2000.

CAMPOS, T. E. d.; BLOCH, I.; CESAR JR., R. M. Feature selection based on fuzzy distances between clusters: First results on simulated data. Lecture Notes in Computer Science, v. 2013, p. 186+, 2001. Disponível em: $<$ citeseer.nj.nec.com/campos01feature.html>.

CARBONELL, J. G. Introduction: Paradigms for machine learning. In: CARBONELL, J. (Ed.). Machine Learning: Paradigms and Methods. London: MIT Press, 1989. p. 1-9.

CHEN, J.-L.; KUNDU, A. Unsupervised texture segmentation using multichannel decomposition and hidden markov models. IEEE Trans. on Image Processing, v. 4, n. 5, p. 603-620, 1995.

CHI, Z.; YAN, H.; PHAM, T. Fuzzy algorithms: with application to image processing and pattern recognition. In: Advances in Fuzzy Systems - Application and Theory. Singapore: World Scientific Publ. Co. Pte. Ltd., 1996. v. 10.

COE, S. et al. A hybrid approach to detecting impervious surface at multiple scales. In: Proceedings of the ISPRS WG VII/1 Human Settlements and Impact Analysis 3rd International Symposium Remote Sensing and Data Fusion Over Urban Areas (URBAN 2005) and 5th International Symposium Remote Sensing of Urban Areas (URS 2005). Tempe, AZ, USA: [s.n.], 2005. v. 1, n. 1.

COSIC, D.; LONCARIC, S. New methods for cluster selection in unsupervised fuzzy clustering. Automatika, v. 37, p. 133-137, 1994.

COX, E. The fuzzy systems handbook. Cambridge MA USA: Academic Press, 1994.

DAS, M.; MANMATHA, R.; RISEMAN, E. M. Indexing flowers by color names using domain knowledge-driven segmentation. In: Proceedings of the 4th IEEE Workshop on Applications of Computer Vision (WACV'98). Princeton NJ: IEEE Press, 1998. p. 94-99. 
DEJONG, K. Learning with genetic algorithms: an overview. Machine Learning, v. 3, p. 121-138, 1988.

DETYNIECKI, M. Numerical aggregation operators: State of the art. In: International Summer School on Aggregation Operators and their Applications. Asturias Spain: [s.n.], 2001. Invited.

DIDAY, E.; SIMON, J. J. Clustering analysis. In: . Digital Pattern Recognition.

Heidelberg Secaucus, NJ, USA: Springer-Verlag, 1976. p. 47-94.

DIVAN. DiVAN - Distributed AudioVisual Archives Network. jan 1997.

Http://divan.intranet.gr/ Acesso em jan 2003. Html.

DOMBI, J. A general class of fuzzy operators, the De Morgan class of fuzzy operators. Fuzzy Sets and Systems, v. 8, p. 149-163, 1982.

DUDA, R. O.; HART, P. E.; STORK, D. G. Pattern Classification. 2nd. ed. New York: John Wiley \& Sons, 2000.

EVERITT, B. Cluster Analysis. New York, USA: Academic Press, 1980.

FORSYTH, D. A.; FLECK, M. M. Identifying nude pictures. In: IEEE Workshop on the Applications of Computer Vision. Sarasota, Florida: [s.n.], 1996. p. 103-108.

FREITAS, A. A.; KIRNER, C. Introdução a algoritmos genéticos. In: UNIVERSIDADE FEDERAL DE SÃO CARLOS. Anais do I Workshop sobre Redes Neurais. São Carlos SP, 1992. p. 71-88.

FU, K. S. Syntactic Pattern Recognition with Applications. Englewood Cliffs, New Jersey: Prentice-Hall, 1982.

GARCIA, B. et al. Banco de dados de cor de pele humana. 2002. Http://www.cin.ufpe.br/ if291/galeria/pele/welcome.html.

GARCIA, C.; TZIRITAS, G. Face detection using quantized skin color regions merging and wavelet packet analysis. IEEE Trans on Multimedia, v. 1, n. 3, sep 1999.

GATH, L.; GEVA, A. Unsupervised optimal fuzzy clustering. IEEE Transactions on Pattern Analysis and Machine Intelligence, v. 11, p. 773-781, 1989.

GENESERETH, M. R.; NILSSON, N. J. Logical foundations of artificial intelligence. Palo Alto CA USA: Morgan Kaufmann Publishers Inc., 1987. ISBN 0-934613-31-1.

GOMEZ, G.; MORALES, E. Automatic feature construction and a simple rule induction algorithm for skin detection. In: Proc. of the ICML workshop on machine learning in computer vision. Sydney AU: [s.n.], 2002. p. 31-38.

GóMEZ, J. et al. Complete expression trees for evolving fuzzy classifiers systems with genetic algorithms and application to network intrusion detection. In: . New Orleans, LA, USA: Proceedings of NAFIPS-FLINT Joint Conference, 2002. p. 469-474.

GONZALEZ, R. C.; WOODS, R. E. Digital image processing. Massachusetts: Addison-Wesley Publishing Co., 1992. 
GOWER, J. C.; LEGENDRE, P. Metric and euclidean properties of dissimilarity coefficients. J. of Classification, v. 3, p. 5-48, 1986.

GROSSBERG, S. Foreword. International Journal of Hybrid Intelligent Systems, v. 1, n. 1, p. i, Jan. 2004.

GULIATO, D. Combinação de algoritmos de segmentação de imagens por operadores de agregação. Tese (Doutorado) - Escola Politécnica da Universidade de São Paulo, Departamento de Engenharia Eletrônica, São Paulo SP Brasil, 1998.

GUSTAFSON, D. E.; KESSEL, W. C. Fuzzy clustering with a fuzzy covariance matrix. In: Proc IEEE CDC. San Diego CA: [s.n.], 1979. p. 761-766.

HALL, L. O. et al. A comparison of neural network and fuzzy clustering techniques in segmenting magnetic resonance images of the brain. IEEE Trans Neural Networks, v. 3, n. 5, p. 672-682, sep 1992.

HANEK, R. et al. Fast image-based object localization in natural scenes. In: IEEE/RSJ International Conference on Intelligent Robots and Systems (IROS) 2002. Lausanne Suisse: [s.n.], 2002. p. 116-122.

HANLEY, J. Receiver operating characteristic ROC methodology: The state of the art. Critical Reviews in Diagnostic Imaging, v. 29, p. 307-335, 1989.

HAYKIN, S. Neural networks, a comprehensive foundation. 2 ed. New Jersey: Prentice-Hall, 1999.

HENDERSON, A. Assessing test accuracy and its clinical consequences: a primer for receiver operating characteristic curve analysis. [Review]. Annals of Clinical Biochemistry, n. 30, p. 521-539, 1993.

HEWAVITHARANA, S.; FERNANDO, H. C. A two stage classification approach to tamil handwriting recognition. In: INFITT (Ed.). TAMIL INTERNET 2002 CONFERENCE. Foster City, California, USA, 2002.

HöPPNER, F. et al. Fuzzy cluster analysis: methods for classification, data analysis and image recognition. Chichester, England: John Wiley \& Sons Ltd., 1999.

HSU, R.-L.; ABDEL-MOTTALEB, M.; JAIN, A. K. Face detection in color images. IEEE Transactions on Pattern Analysis and Machine Intelligence, v. 24, n. 5, p. 696-706, may 2002.

ITO, N. et al. Fuzzy logic based non-parametric color image segmentation with optional block processing. In: ACM 23rd Annual Conference on Computer Science. Nashville TN USA: [s.n.], 1995. p. 119-126.

IYER, N. S.; KANDEL, A.; SCHNEIDER, M. Feature-based fuzzy classification for interpretation of mammograms. Fuzzy Sets and Systems, v. 114, p. 271-280, 2000.

JAIN, A. K.; MURTY, M. N.; FLYNN, P. J. Data clustering: a review. ACM Computing Surveys, v. 31, n. 3, sep 1999.

JONES, M. J.; REHG, J. M. Statistical color models with application to skin detection. International Journal of Computer Vision, v. 46, n. 1, p. 81-96, Jan 2002. 
JONKER, P.; CAARLS, J.; BOKHOVE, W. Fast and Accurate Robot Vision for Vision based Motion. 2000. Citeseer.

KAELBLING, L. P.; LITTMAN, M. L.; MOORE, A. M. Reinforcement learning: a survey. J. of Artificial Intelligence Research, v. 4, p. 237-285, may 1996.

KARAYIANNIS, N. B.; BEZDEK, J. C. An integrated approach to fuzzy learning vector quantization and fuzzy c-means clustering. IEEE Trans on Fuzzy Systems, v. 5, n. 4, p. 622-628, nov 1997.

KAYMAK, U.; SETNES, M. Fuzzy clustering with volume prototypes and adaptive cluster merging. IEEE Trans on Fuzzy Systems, v. 10, n. 6, p. 705-712, dec 2002.

KIM, H. Y.; CIPARRONE, F. A. M.; ANDRADE, M. T. C. d. Technique for constructing gray-scale morphological operators using fuzzy expert system. Electronics Letters, v. 33, n. 22 , p. 1859-1861, oct 1997.

KLIR, G. J.; YUAN, B. Fuzzy sets and fuzzy logic. New Jersey USA: Prentice Hall, 1995.

KOHONEN, T. The self-organizing map. Proceedings of IEEE, v. 78, n. 9, p. 1464-1480, 1990.

KRUPPA, H.; BAUER, M. A.; SCHIELE, B. Skin patch detection in real-world images. In: 2449, S. L. (Ed.). Annual Symposium for Pattern Recognition of the DAGM. Mustererkennung: [s.n.], 2002. p. 109-116.

KUNCHEVA, L. I. Combining classifiers: soft computing solutions. In: Pattern Recognition: from classical to modern approaches. Singapore: World Scientific Publishing Co., 2001. cap. 15, p. 427-451.

LAI, C.-C.; TSENG, D.-C. A hybrid approach using gaussian smoothing and genetic algorithm for multilevel thresholding. International Journal of Hybrid Intelligent Systems, v. 1, n. 3, p. 143-152, july 2004.

LAVRAC, N.; DZEROSKI, S. Inductive logic programming: techniques and applications. New York USA: Ellis Horwood, 1994.

LEE, J. Y.; YOO, S. I. An elliptical boundary model for skin color detection. In: Proceedings of the 2002 International Conference on Imaging Science, Systems and Technology. Las Vegas USA: [s.n.], 2002.

LIAO, T. W.; LI, D.-M.; LI, Y.-M. Detection of welding flaws from radiographic images with fuzzy clustering methods. Fuzzy Sets and Systems, v. 108, p. 145-158, 1999.

LIM, Y. W.; LEE, S. U. On the color image segmentation algorithm based on the thresholding and the fuzzy c-means techniques. Pattern Recognition, v. 23, n. 9, p. 935-952, 1990.

LUDERMIR, T. B. et al. Sistemas inteligentes híbridos. In: Sistemas Inteligentes: Fundamentos e Aplicações. Tamboré, Barueri, SP: Ed. Manole, 2003. cap. 10, p. 249-254.

LUGER, G. F.; STUBBLEFIELD, W. A. Artificial Intelligence: structures and strategies for complex problem solving. Redwood City CA USA: Benjamim Cummings Publishing Co. Inc., 1993. 
MARTINEZ, A. M.; BENAVENTE, R. The AR Face Database CVC Technical Report 24. West Lafayette IN USA, 1998.

MARTINKAUPPI, B. Face colour under varying illumination - analysis and applications. Tese (Doutorado) - Department of Electrical and Information Engineering, Univ. of Oulu, Oulu, Finland, 2002.

MITCHELL, T. M. Machine Learning. New York USA: McGraw-Hill, 1997.

MONARD, M. C. et al. Uma introdução ao aprendizado simbólico de máquina por exemplos. out 1997. Http://labic.icmc.sc.usp.br/didatico/PostScript/ML.html. Acesso em 19 ago 2003.

NEWELL, A. The knowledge level. Artificial Intelligence, v. 18, p. 87-127, 1982.

NOORDAM, J. C. et al. High-speed potato grading and quality inspection based on a color vision system. In: TOBIN, K. W. (Ed.). Proceedings of SPIE. Bellingham WA USA, 2000. (Machine Vision Applications in Industrial Inspection VIII, v. 3966), p. 206-217.

PAL, S. K.; ROSENFELD, A. Image enhancement and thresholding by optimization of fuzzy compactness. Pattern Recognition Letters, v. 7, p. 77-86, 1988.

PAPAMARKOS, N. Color reduction using local features and a SOFM neural network. Intl. J. of Imaging Systems and Technology, v. 10, n. 5, p. 404-409, 1999.

PAVLIDIS, T. Structural Pattern Recognition. New York: Springer Verlag, 1977.

PEDRYCZ, W.; GOMIDE, F. An introduction to fuzzy sets: analysis and design. Cambridge MA USA: The MIT Press, 1998.

PEDRYCZ, W.; WALETZKY, J. Fuzzy clustering with partial supervision. IEEE Trans. on Systems, Man, and Cybernetics, v. 27, n. 5, p. 787-795, 1998.

PEER, P.; KOVAC, J.; SOLINA, F. Human skin colour clustering for face detection. Submitted to EUROCON 2003 - Intl. Conf. on Computer as a Tool. 2003. Disponível em: <http://www.princeton.edu/ aabdalla/ele579/Human>.

PITIOT, A.; TOGA, A.; THOMPSON, P. Adaptive elastic segmentation of brain MRI via shape model guided evolutionary programming. IEEE Trans. on Medical Imaging, v. 21, n. 8, p. 910-923, aug 2002.

PRECHELT, L. A set of neural network benchmark problems and benchmarking rules. Germany, sep 1994.

PRESS, S. J. Bayesian Statistics: Principles, Models, and Applications. New York: John Wiley \& Sons, 1989.

QUINLAN, J. R. C4.5: Programs for machine learning. San Mateo CA USA: Morgan Kaufmann, 1993.

RUSSELL, S. J.; NORVIG, P. Artificial Intelligence: a modern approach. 2nd ed. New Jersey USA: Pearson Education, Inc., 2003. 
SABER, E.; TEKALP, A. M. Frontal-view detection and facial feature extraction using color, shape and symmetry based cost functions. Pattern Recognition Letters, v. 19, n. 8, p. 669-680, 1998.

SALLES, E. O. T.; LING, L. L. Uma aplicação de sistemas nebulosos em processamento de imagens. In: $3^{\circ}$ Simpósio Brasileiro de Automação Inteligente, Anais. Vitória ES Brasil: [s.n.], 1997. p. 88-93.

SAMMUT, C. Knowledge representation. In: MICHIE, D.; SPIEGELHALTER, D.; TAYLOR, C. (Ed.). Machine Learning, Neural and Statistical Classification. [S.l.: s.n.], 1994. cap. 12, p. 228-245.

SANCHES, M. K. Aprendizado de máquina semi-supervisionado: proposta de um algoritmo para rotular exemplos a partir de poucos exemplos rotulados. Dissertação (Mestrado) - Instituto de Ciências Matemáticas e Computação da USP - São Carlos, ago 2003.

SCHALKOFF, R. J. Artificial intelligence: an engineering approach. New York: McGraw-Hill, 1990. (ISBN 0-07-055084-0).

SCHUMEYER, R. P.; BARNER, K. E. Color-based classifier for region identification in video. In: VCIP '98 - Visual Communications and Imaging Processing - Proceedings of SPIE. San Jose CA: [s.n.], 1998. v. 3309, n. 1, p. 189-200.

SHIN, M. C.; CHANG, K. I.; TSAP, L. V. Does colorspace transformation make any difference on skin detection? In: IEEE Workshop on Applications of Computer Vision. Orlando FL USA: [s.n.], 2002.

SIGAL, L.; SCLAROFF, S.; ATHITSOS, V. Skin color-based video segmentation under time-varying illumination. IEEE Transactions on Pattern Analysis and Machine Intelligence, v. 26, n. 7, p. 862-877, Jul. 2004.

SIMÕES, A. S.; COSTA, A. H. R. Classificação de imagens por redes neurais utilizando a representação HSV. In: MONARD, M. C.; SICHMAN, J. S. (Ed.). IBERAMIA-SBIA 2000 open discussion track Brazilian Conference on Artificial Intelligence. Atibaia SP Brasil: [s.n.], 2000. p. 314-323.

SIMON, H. A. Search and reasoning in problem solving. Artificial Intelligence, v. 1, n. 21, p. 7-30, 1983.

STöRRING, M.; ANDERSEN, H. J.; GRANUM, E. Estimation of the illuminant colour from human skin colour. In: 4th International Conference on Automatic Face and Gesture Recognition. Grenoble France: [s.n.], 2000. p. 64-69.

SUGENO, M. Fuzzy measures and fuzzy integrals - a survey. In: M. M. GUPTA, G. N. S.; GAINES, B. R. (Ed.). Fuzzy Automata and Decision Processes. Amsterdan, Netherlands: North-Holland Publishing Company, 1977. p. 89-102.

SWETS, J. A. Measuring the accuracy of diagnostic systems. Science, v. 240, p. 1285-1293, 1988.

TAO, H.; HUANG, T. S. Color image edge detection using cluster analysis. Urbana-Champaign, IL USA, jan 2000. 
TERRILLON, J.-C. et al. Comparative performance of different skin chrominance models and chrominance spaces for the automatic detection of human faces in color images. In: IEEE COMPUTER SOCIETY. Proceedings of 4 th IEEE international conference on face and gesture recognition. Washington DC, 2000. p. 54-63.

THEODORIDIS, S.; KOUTROUMBAS, K. Pattern recognition. San Diego CA USA: Academic Press, 1999.

TIZHOOSH, H. R. Fuzzy image processing: potentials and state of art. In: 5th Intl. Conf. On Soft Computing. Iizuka Japan: [s.n.], 1998. p. 321-324.

TIZHOOSH, H. R.; KRELL, G.; MICHAELIS, B. On fuzzy image enhancement of megavoltage images in radiation therapy. In: 6th IEEE International Conference on Fuzzy Systems. Barcelona España: [s.n.], 1997.

TSAO, E. C. K.; BEZDEK, J. C.; PAL, N. R. Fuzzy Kohonen clustering networks. Pattern Recognition, n. 27, p. 757-764, 1994.

UTGOFF, P. E. Incremental induction of decision trees. Machine Learning, v. 4, p. 161-186, 1989.

VALIANT, L. G. A theory of the learnable. Communications of the ACM, v. 27, p. 1134-1142, 1984.

VATSAVAI, R. R. et al. An efficient hybrid classication system for mining multi-spectral remote sensing imagery guided by spatial databases. In: IEEE (Ed.). Second Pattern recognition in Remote Sensing. Niagara Falls, Canada, 2002.

VEZHNEVETS, V.; SAZONOV, V.; ANDREEVA, A. A survey on pixel-based skin color detection techniques. In: Proceedings of Graphicon-2003. Moscow, Russia: [s.n.], 2003. p. 85-92.

WANG, J.-G.; SUNG, E. Frontal-view face detection and facial feature extraction using color and morphological operations. Pattern Recognition, v. 20, n. 10, p. 1053-1068, 1999.

WEISS, S. M.; INDURKHYA, N. Rule-based machine learning methods for functional prediction. J. of Artificial Intelligence Research, v. 3, p. 383-403, 1995. Http://www.cs.cmu.edu/afs/cs/project/jair/pub/volume3/weiss95a.ps.Z. Acesso em dez.2001.

WEISS, S. M.; KULIKOWSKI, C. A. Computer systems that learn: classification and prediction methods from statistics, neural nets, machine learning and expert systems. CA USA: Morgan Kaufmann Publishers, 1991.

WINDHAM, M. P. Cluster validity for the fuzzy c-means clustering algorithm. IEEE Trans. on PAMI, v. 4, n. 4, p. 357-363, 1982.

WINDHAM, M. P. Geometrical fuzzy clustering algorithms. Fuzzy Sets and Systems, v. 10, p. 271-279, 1983.

WU, H.; CHEN, Q.; YACHIDA, M. Face detection from color images using a fuzzy pattern matching method. IEEE Transactions on Pattern Analysis and Machine Intelligence, v. 21, n. 6, p. 557-563, jun 1999. 
WU, J.; YAN, H.; CHALMERS, A. Color image segmentation using fuzzy clustering and supervised learning. J. Electronic Imaging, v. 3, p. 397-403, 1994.

WU, K. L.; YANG, M. S. A fuzzy-soft learning vector quantization. Neurocomputing, n. 55, p. 681-697, 2003.

WU, Y.; LIU, Q.; HUANG, T. S. An adaptive self-organizing color segmentation algorithm with application to robust real-time human hand localization. In: Proc. Asian Conf. on Computer Vision. Taiwan: [s.n.], 2000.

WYSZECKI, G.; STILES, W. S. Color science: concepts and methods, quantitative data and formulae. 2nd. ed. New York USA: John Wiley and Sons, 1982.

XIE, X. L.; BENI, G. A validity measure for fuzzy clustering. IEEE Transactions on Pattern Analysis and Machine Intelligence, v. 13, p. 841-847, 1991.

YAGER, R. On ordered weighted averaging aggregation operations in multicriteria decision making. IEEE Trans on Systems, Man and Cybernetics, v. 18, p. 183-190, 1988.

YAIR, E.; ZEGER, K.; GERSHO, A. Competitive learning and soft competition for vector quantization design. IEEE Transactions on Signal Processing, n. 40, p. 294-309, 1992.

YANG, J.; LU, W.; WAIBEL, A. Skin-color modeling and adaptation. In: Proc of ACCV'98. Hong-Kong: [s.n.], 1998. II, n. 1, p. 687-694.

YANG, M.-H.; KRIEGMAN, D. J.; AHUJA, N. Detecting faces in images: a survey. IEEE Transactions on Pattern Analysis and Machine Intelligence, v. 24, n. 1, p. 34-58, jan 2002.

ZADEH, L. A. Fuzzy sets. Information Control, v. 8, p. 338-353, 1965.

ZADEH, L. A. Outline of a new approach to the analysis of complex systems and decision processes. IEEE Trans on Systems, Man and Cybernetics, SMC-3, n. 1, p. 28-44, 1973.

ZARIT, B. D.; SUPER, B. J.; QUEK, F. K. H. Comparison of five color models in skin pixel classification. In: ICCV'99 Intl. workshop on recognition, analysis and tracking of faces and gestures in real-time systems. Corfu, Greece: [s.n.], 1999. p. 58-63.

ZHANG, M. et al. Knowledge-guided classification of coastal zone color images off the west Florida shelf. Intl Journal of Pattern Recognition and Artificial Intelligence, v. 14, n. 8 , p. $987-1007,2000$.

ZHENG, H.; DAOUDI, M.; JEDYNAK, B. Blocking adult images based on statistical skin detection. Electronic Letters on Computer Vision and Image Analysis, v. 4, n. 2, p. $1-14,2004$.

ZIMMERMANN, H.; ZYSNO, P. Latent connectives in human decision making. Fuzzy Sets and Systems, v. 4, p. 37-51, 1980. 